\title{
Atrial flutter / atrial fibrillation : long term follow-up of cryoablation with new pathophysiologic insights
}

Citation for published version (APA):

Moreira, W. (2007). Atrial flutter / atrial fibrillation : long term follow-up of cryoablation with new pathophysiologic insights. [Doctoral Thesis, Maastricht University]. Datawyse / Universitaire Pers Maastricht. https://doi.org/10.26481/dis.20071206wm

Document status and date:

Published: 01/01/2007

DOI:

10.26481/dis.20071206wm

Document Version:

Publisher's PDF, also known as Version of record

\section{Please check the document version of this publication:}

- A submitted manuscript is the version of the article upon submission and before peer-review. There can be important differences between the submitted version and the official published version of record.

People interested in the research are advised to contact the author for the final version of the publication, or visit the DOI to the publisher's website.

- The final author version and the galley proof are versions of the publication after peer review.

- The final published version features the final layout of the paper including the volume, issue and page numbers.

Link to publication

\footnotetext{
General rights rights.

- You may freely distribute the URL identifying the publication in the public portal. please follow below link for the End User Agreement:

www.umlib.nl/taverne-license

Take down policy

If you believe that this document breaches copyright please contact us at:

repository@maastrichtuniversity.nl

providing details and we will investigate your claim.
}

Copyright and moral rights for the publications made accessible in the public portal are retained by the authors and/or other copyright owners and it is a condition of accessing publications that users recognise and abide by the legal requirements associated with these

- Users may download and print one copy of any publication from the public portal for the purpose of private study or research.

- You may not further distribute the material or use it for any profit-making activity or commercial gain

If the publication is distributed under the terms of Article $25 \mathrm{fa}$ of the Dutch Copyright Act, indicated by the "Taverne" license above, 


\section{Atrial Flutter/Atrial Fibrillation: \\ Long term follow-up of cryoablation with new pathophysiologic insights}


(C) Copyright Wendel Moreira, MD, Maastricht 2007 Printed by Datawyse / Universitaire Pers Maastricht

Cover and back by Vincent van Gogh, Starry Night, 1889.

Financial support for the realization of this thesis from Saint Jude Medical and Cryocor is greatfullly aknowledged.

Further financial support from Medtronic, RESCAR, Biosense Webster and Boston Scientific is also much appreciated. 


\section{Atrial Flutter/Atrial Fibrillation: Long term follow-up of cryoablation with new pathophysiologic insights}

\section{PROEFSCHRIFT}

ter verkrijging van de graad van doctor aan de Universiteit Maastricht, op gezag van de Rector Magnificus

Prof. mr. G.P.M.F. Mols, volgens het besluit van het College van Decanen, in het openbaar te verdedigen, op donderdag 6 december 2007 om 10.00 uur

$$
\text { door }
$$

Wendel Moreira

geboren op 28 maart 1975 te Goiânia, Goiás, Brazil

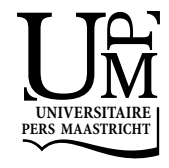




\section{Promotor}

Prof. dr. M.J.A.P. Daemen

\section{Copromotores}

Dr. LM. Rodriguez

Dr. C.C.M.M. Timmermans

\section{Beoordelingscommissie}

Prof. dr. A.P.M. Gorgels (voorzitter)

Prof. dr. R.N.W. Hauer, Universiteit Utrecht

Prof. dr. J.A. Lopez, Baylor College of Medicine, St. Luke's Episcopal Hospital, Texas Heart Institute, Houston, TX, U.S.A.

Prof. dr. J.G. Maessen

Prof. dr. R.J. Myerburg, University of Miami School of Medicine, Miami, FL, U.S.A. 
"Omni autem, cui multum datum est, multum quaeretur ab eo; et cui commendaverunt multum, plus petent ab eo."

"Much will be required of the person entrusted with much, and still more will be demanded of the person entrusted with more."

Luke, 12:48

Para minha família, motivo e razão da minha contínua existência. 


\section{Contents}

\section{Chapter I}

Introduction 9

\section{Chapter II}

Long Term Follow-up after Cavotricuspid Isthmus Cryoablation for the Treatment of Common Atrial Flutter in 180 Patients

Chapter III

Long-term Follow-up after Cryothermic Ostial Pulmonary

Vein Isolation in Paroxysmal Atrial Fibrillation

Chapter IV

Recurrence Patterns of Atrial Fibrillation after Pulmonary

Vein Cryoisolation

Chapter V

Can Common Type Atrial Flutter be a Sign of an Arrhythmogenic Substrate in Paroxysmal Atrial Fibrillation? Clinical and Ablative Consequences in Patients with Coexistent PAF/AFL

Chapter VI

The Importance of a Refractory Period Gradient $\geq 100 \mathrm{msec}$

Between Pulmonary Veins and Adjacent Left Atrium in Identifying the Culprit Pulmonary Vein

Chapter VII

Atrial tachycardia originating from the pulmonary vein: importance of the stimulation sites.

Chapter VIII

Feasibility of Cryoablation for Atrial Fibrillation Using a Non-contact Mapping System

Chapter IX

General Discussion and Future Perspectives

Chapter X

Summary 
Chapter XI

Samenvatting

Chapter XII

Resumen

Chapter XIII

Resumo

Curriculum Vitae

173

Publications

177 



\title{
CHAPTER I
}

\author{
Introduction
}


The first description of atrial fibrillation (AF) dates from 1696 BC when the emperor and physician Huang Ti Nei Ching Su Wen noted that an irregular pulse was related to imminent death (The Yellow Emperor's Classic of Internal Medicine). The discovery of the properties of digitalis leaf (Digitalis purpurea) in 1785 by William Withering led to the first documented therapeutic intervention for atrial fibrillation (rate control). ${ }^{1,2}$ Amiodarone was initially developed in 1961 in Belgium as a treatment for angina but soon it was found that this drug could suppress arrhythmias. Thus the first real antiarrhytmic drug was born. In 1963 Lown recommended cardioversion (rhythm control). ${ }^{3}$ But it was not until 1987, when a group from Washington University in Saint Louis, USA (Cox and colleagues) started to perform a surgical intervention for atrial fibrillation, that the concept about the possibility of permanently curing this arrhythmia began. 4,5

The birth of interventional electrophysiology came in the early 80's when Scheinman et al. first described catheter ablation of the AV junction to treat patients with drug refractory atrial fibrillation. ${ }^{6}$ Since then, percutaneous therapies for arrhythmias became a fast developing field. It was a matter of time before the electrophysiologist could offer a treatment for the most common arrhythmia (atrial fibrillation). And indeed, after the landmark finding by Haissaguerre et $\mathrm{al}^{7}$ (about the importance of the PVs as triggers for AF) a new era in the treatment of the most common arrhythmia began.

Catheter ablation of atrial fibrillation has been one of the major developments in the cardiology field in the past years. A recent survey showed an increase from 18 cases in 1995 to more than 5000 cases in 2002. ${ }^{8}$ Outcomes of the procedures (either focal pulmonary vein isolation for the elimination of triggers or left atrium modification of the arrhythmogenic substrate) are similar or even better than of most antiarrhythmic agents with long term success rates ranging from 60 up to $85 \% .^{9-11}$ And along with the progress of ablative techniques, the variety of patients submitted to this procedure has also increased. From young drug refractory lone atrial fibrillation patients, the spectrum has expanded to patients with chronic atrial fibrillation refractory to therapy, atrial fibrillation and congestive heart failure, and even as first line therapy reported in some cases. ${ }^{12-14}$

Those advances in the treatment of atrial fibrillation brought new knowledge in the pathophysiology of other supraventricular arrhythmias (e.g: iatrogenic form of atrial flutter has been described). ${ }^{15-17}$ The frequent association of cavotricuspid isthmus dependent atrial flutter with atrial fibrillation was shown ${ }^{18,19}$, leading to significant changes in anticoagulation guidelines (in summary, patients with atrial flutter should be anticoagulated as if they had atrial fibrillation). ${ }^{20}$ Ablative therapies started to include "prophylactic" cavotricuspid isthmus ablation in patients submitted to AF ablation. ${ }^{21}$ Atrial flutter has more and more become a definite spectrum of atrial fibrillation.

Three approaches to the catheter ablation of AF are commonly used nowadays: ostial PVI, LACA (left atrial circumferential ablation) and LACA with 
additional roof and mitral isthmus line (with or without cavotricuspid isthmus ablation). ${ }^{22-27}$ Figure. Their differences and particular indications are a matter of controversy. 28,29 But some major complications resulting from those procedure where thought to be inherent of radiofrequency energy, thus opening the door for the development of other energy sources (e.g: laser, high frequency ultrasound, microwaves, cryothermy, etc). ${ }^{30-39}$ The advantages and disadvantages of those will be described in the thesis - Chapter IX).

All those available options strengthen even more the old aphorism "every patient needs to be treated individually" and the challenge to offer the procedure that suits better with each type of AF remains. The current progress in ablative therapies for atrial fibrillation is such that soon, due to the vast difference in the prevalence of this arrhythmia when compared to other arrhythmias, ${ }^{20,40}$ one could speculate that atrial fibrillation ablation will become the most common procedure performed by the electrophysiologist.

Figure.

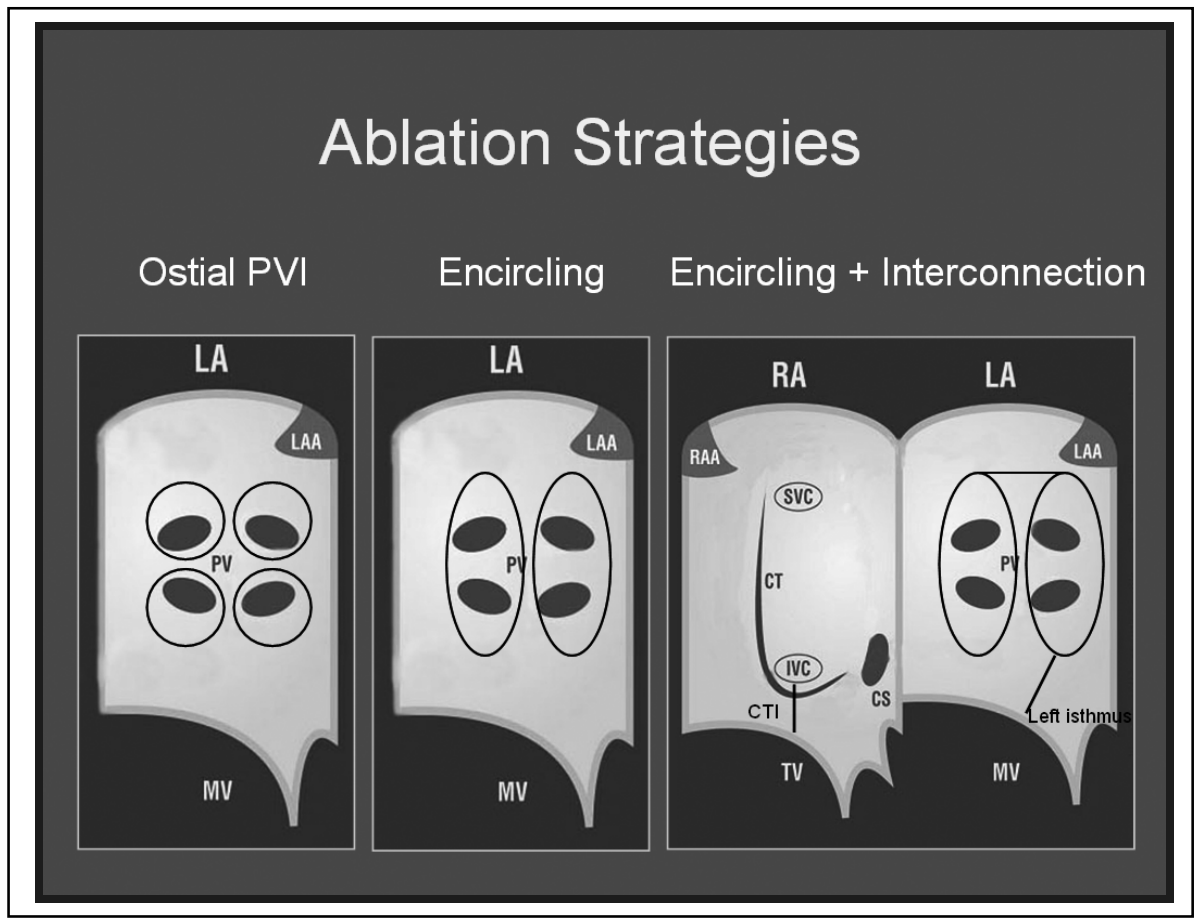

(Courtesy of Dr Luz-Maria Rodriguez) 


\section{Aim of the thesis}

Radiofrequency ablation of the cavotricuspid isthmus for the treatment of common type atrial flutter is now a class I indication in the most recent published guidelines. ${ }^{20}$ But, despite being performed routinely, long term data on the follow-up of patients submitted to this procedure (regardless of the energy source) is rare. Natale and colleagues reported a prospective, randomized study compared chronic oral antiarrhythmic therapy (in 61 patients with AFL) to RF ablation. ${ }^{41}$ After a mean follow-up of $21 \pm 11$ months, only $36 \%$ of patients treated with drugs compared to $80 \%$ of those treated with catheter ablation remained in sinus rhythm. The CRAAFT trial presented the results in $32 \mathrm{pa}-$ tients with AFL submitted to either cryo or RF ablation of the CTI.42 They report an $84 \%$ success rate after a follow-up of 14 months. In Chapter II we reported the long term follow-up (from 12 to 60 months (mean of $27 \pm 17$ months)) of a large number of patients submitted to cavotricuspid isthmus ablation using cryotherapy.

As we described previously, AF is a disease having different stages. Patients presenting early in the disease tend to have triggers as the main cause of their paroxysmal atrial fibrillation. In Chapter III we evaluated the long term follow-up of patients with paroxysmal AF and no or minimal structural heart disease submitted to segmental pulmonary vein cryoisolation.

Up to now no systematic study has been performed as to incidence and type of recurrences following percutaneous ablation of atrial fibrillation. Immediate recurrence of atrial fibrillation after percutaneous ablative therapy has been described and its significance is a matter of debate. ${ }^{43-45}$ It commonly leads to concerns by patients regarding the success of their procedure and may also result in unnecessary interventions. At the same time, recent literature has shown a poor correlation of patients' symptoms with their rhythm after AF ablation. ${ }^{46-48}$ In Chapter IV we evaluated with an objective method (daily transtelephonic telemetry) the characteristics and patterns of AF recurrences after pulmonary vein cryoisolation.

Most of the literature relating atrial flutter and atrial fibrillation comes from the era before the advent of percutaneous treatment of AF. In Chapter $\mathbf{V}$ we evaluated the effect of pulmonary vein cryoisolation not only on atrial fibrillation but also on common type atrial flutter.

Very distinct electrophysiological properties of PVs in patients with AF compared to controls subjects have been described by Jais and collegues. ${ }^{49}$ Shorter refractory periods and decremental properties were seen in patients with AF. However, almost one third of the cohort had a history of exposure to amiodarone. And the former has been shown to significantly alter the refractory periods of the PVs. ${ }^{50}$ In Chapter VI we evaluated the electrophysiologic properties of different PVs (within the same patients) and their adjacent tissue 
in a population with PAF (and not exposed to amiodarone) referred for PV cryoisolation.

In Chapter VII we describe an interesting case with some important observations on the location of pacing and its relation to the inducibility of pulmonary vein tachycardia.

In a worldwide survey done by Cappato and colleagues the navigation system chosen by the great majority of centers was CARTOTM which limits the ablative procedure to radiofrequency (RF) energy. ${ }^{8}$ The same study also showed a big discrepancy regarding the source of power used. Of the data available for 4918 patients: 4127 received radiofrequency current ablation, 220 cryotherapy, 115 ultrasound, 94 laser and 93 other forms of energy. In Chapter VIII we reported the feasibility of using a different source of energy (cryothermy) along a navigation system $\left(\mathrm{NavX}^{\mathrm{TM}}\right)$.

The last Chapter (Chapter IX) gives a general discussion about atrial fibrillation and atrial flutter with some new proposed ideas based partially in our thesis. Also we try to speculate on how some future changes might influence the treatment and prevention of those arrhythmias. 


\section{References}

1. Fuster V, Ryden LE, Asinger RW, Cannom DS, Crijns HJ, Frye RL, Halperin JL, Kay GN, Klein WW, Levy S, McNamara RL, Prystowsky EN, Wann LS, Wyse DG. ACC/AHA/ESC guidelines for the management of patients with atrial fibrillation. A report of the American College of Cardiology/American Heart Association Task Force on Practice Guidelines and the European Society of Cardiology Committee for Practice Guidelines and Policy Conferences (Committee to develop guidelines for the management of patients with atrial fibrillation) developed in collaboration with the North American Society of Pacing and Electrophysiology. Eur Heart J 2001;22:1852-1923.

2. Moss AJ. History of atrial fibrillation. Ann Noninvasive Electrocardiol 2003;8:90-91.

3. Lown B, Perlroth MG, Kaidbey S, Abet T, Harken DE. "Cardioversion" of atrial fibrillation. A report on the treatment of 65 episodes in 50 patients. N Engl J Med 1963;269:325-331.

4. Cox JL, Schuessler RB, Cain ME, Corr PB, Stone CM, D'Agostino HJ, Jr., Harada A, Chang BC, Smith PK, Boineau JP. Surgery for atrial fibrillation. Semin Thorac Cardiovasc Surg 1989;1:67-73.

5. Flegel KM. From Delirium Cordis to Atrial Fibrillation: Historical Development of a Disease Concept. Ann Intern Med 1995;122:867-873.

6. Sheinman MM, Gonzalez R, Thomas A, Ullyot D, Bharati S, Lev M. Reentry confined to the atrioventricular node: electrophysiologic and anatomic findings. Am J Cardiol 1982;49:1814-1818.

7. Haissaguerre M, Jais P, Shah DC, Takahashi A, Hocini M, Quiniou G, Garrigue S, Le MA, Le MP, Clementy J. Spontaneous initiation of atrial fibrillation by ectopic beats originating in the pulmonary veins. N Engl J Med 1998;339:659-666.

8. Cappato R, Calkins H, Chen SA, Davies W, Iesaka Y, Kalman J, Kim YH, Klein G, Packer $\mathrm{D}$, Skanes A. Worldwide survey on the methods, efficacy, and safety of catheter ablation for human atrial fibrillation. Circulation 2005;111:1100-1105.

9. John RM, Michaud G. Atrial fibrillation: nonpharmacologic therapies coming of age. Chest 2004;125:1977-1979.

10. Todd DM, Skanes AC, Guiraudon G, Guiraudon C, Krahn AD, Yee R, Klein GJ. Role of the posterior left atrium and pulmonary veins in human lone atrial fibrillation: electrophysiological and pathological data from patients undergoing atrial fibrillation surgery. Circulation 2003;108:3108-3114.

11. Tse HF, Reek S, Timmermans C, Lee KL, Geller JC, Rodriguez LM, Ghaye B, Ayers GM, Crijns HJ, Klein HU, Lau CP. Pulmonary vein isolation using transvenous catheter cryoablation for treatment of atrial fibrillation without risk of pulmonary vein stenosis. J Am Coll Cardiol 2003;42:752-758.

12. Hocini M, Sanders P, Jais P, Hsu LF, Takahashi Y, Rotter M, Clementy J, Haissaguerre M. Techniques for curative treatment of atrial fibrillation. J Cardiovasc Electrophysiol 2004:15:1467-1471.

13. Wiesfeld AC, Tan ES, van Veldhuisen DJ, Crijns HJ, Van G, I. Radiofrequency ablation of atrial fibrillation. Int J Cardiol 2004;93:231-237.

14. Hsu LF, Jais P, Sanders P, Garrigue S, Hocini M, Sacher F, Takahashi Y, Rotter M, Pasquie JL, Scavee C, Bordachar P, Clementy J, Haissaguerre M. Catheter ablation for atrial fibrillation in congestive heart failure. N Engl J Med 2004;351:2373-2383.

15. Oral H, Knight BP, Morady F. Left atrial flutter after segmental ostial radiofrequency catheter ablation for pulmonary vein isolation. Pacing Clin Electrophysiol 2003;26:1417-1419.

16. Villacastin J, Perez-Castellano N, Moreno J, Gonzalez R. Left atrial flutter after radiofrequency catheter ablation of focal atrial fibrillation. J Cardiovasc Electrophysiol 2003;14:417421. 
17. Duru F, Hindricks G, Kottkamp H. Atypical left atrial flutter after intraoperative radiofrequency ablation of chronic atrial fibrillation: successful ablation using three-dimensional electroanatomic mapping. J Cardiovasc Electrophysiol 2001;12:602-605.

18. Calo L, Lamberti F, Loricchio ML, De RE, Bianconi L, Pandozi C, Santini M. Atrial flutter and atrial fibrillation: which relationship? New insights into the electrophysiological mechanisms and catheter ablation treatment. Ital Heart J 2005;6:368-373.

19. Delise P, Sitta N, Coro L, Marras E, Sciarra L, Bocchino M, Berton G. Common atrial flutter and atrial fibrillation are not always two stages of the same disease. A long-term follow-up study in patients with atrial flutter treated with cavo-tricuspid isthmus ablation. J Cardiovasc Med (Hagerstown ) 2006;7:800-805.

20. Blomstrom-Lundqvist C, Scheinman MM, Aliot EM, Alpert JS, Calkins H, Camm AJ, Campbell WB, Haines DE, Kuck KH, Lerman BB, Miller DD, Shaeffer CW, Jr., Stevenson WG, Tomaselli GF, Antman EM, Smith SC, Jr., Alpert JS, Faxon DP, Fuster V, Gibbons RJ, Gregoratos G, Hiratzka LF, Hunt SA, Jacobs AK, Russell RO, Jr., Priori SG, Blanc JJ, Budaj A, Burgos EF, Cowie M, Deckers JW, Garcia MA, Klein WW, Lekakis J, Lindahl B, Mazzotta G, Morais JC, Oto A, Smiseth O, Trappe HJ. ACC/AHA/ESC guidelines for the management of patients with supraventricular arrhythmias--executive summary: a report of the American College of Cardiology/American Heart Association Task Force on Practice Guidelines and the European Society of Cardiology Committee for Practice Guidelines (Writing Committee to Develop Guidelines for the Management of Patients With Supraventricular Arrhythmias). Circulation 2003;108:1871-1909.

21. Wazni O, Marrouche NF, Martin DO, Gillinov AM, Saliba W, Saad E, Klein A, Bhargava M, Bash D, Schweikert R, Erciyes D, bdul-Karim A, Brachman J, Gunther J, Pisano E, Potenza D, Fanelli R, Natale A. Randomized study comparing combined pulmonary vein-left atrial junction disconnection and cavotricuspid isthmus ablation versus pulmonary vein-left atrial junction disconnection alone in patients presenting with typical atrial flutter and atrial fibrillation. Circulation 2003;108:2479-2483.

22. Aupperle H, Doll N, Walther T, Kornherr P, Ullmann C, Schoon HA, Mohr FW. Ablation of atrial fibrillation and esophageal injury: effects of energy source and ablation technique. J Thorac Cardiovasc Surg 2005;130:1549-1554.

23. Lewalter T, Burkhardt D, Bielik H, Schrickel J, Yang A, Shlevkov N, Schimpf R, Schwab JO, Luderitz B. Circumferential pulmonary vein mapping and ablation in focal atrial fibrillation: single catheter technique. J Interv Card Electrophysiol 2002;7:165-170.

24. Ouyang F, Bansch D, Ernst S, Schaumann A, Hachiya H, Chen M, Chun J, Falk P, Khanedani A, Antz M, Kuck KH. Complete isolation of left atrium surrounding the pulmonary veins: new insights from the double-Lasso technique in paroxysmal atrial fibrillation. Circulation 2004;110:2090-2096.

25. Schwartzman D, Bazaz R, Nosbisch J. Catheter ablation to suppress atrial fibrillation: evolution of technique at a single center. J Interv Card Electrophysiol 2003;9:295-300.

26. Haissaguerre M, Hocini M, Sanders P, Sacher F, Rotter M, Takahashi Y, Rostock T, Hsu LF, Bordachar P, Reuter S, Roudaut R, Clementy J, Jais P. Catheter ablation of long-lasting persistent atrial fibrillation: clinical outcome and mechanisms of subsequent arrhythmias. J Cardiovasc Electrophysiol 2005;16:1138-1147.

27. Pappone C, Santinelli V. Atrial fibrillation ablation: state of the art. Am J Cardiol 2005;96:59L-64L.

28. Feld GK. Catheter ablation of atrial fibrillation: what is the best technique for achieving a high cure rate with acceptable risk? J Am Coll Cardiol 2004;43:2054-2056.

29. de SJ. Curative treatment of atrial fibrillation: which is the best technique? Rev Port Cardiol 2003;22:1311-1314.

30. Cummings JE, Schweikert R, Saliba W, Hao S, Martin DO, Marrouche NF, Burkhardt JD, Kilicaslan F, Verma A, Beheiry S, Belden W, Natale A. Left atrial flutter following pulmonary vein antrum isolation with radiofrequency energy: linear lesions or repeat isolation. J Cardiovasc Electrophysiol 2005;16:293-297. 
31. Friedman PL. Catheter cryoablation of cardiac arrhythmias. Curr Opin Cardiol 2005;20:4854.

32. Hummel JD. Cryoablation of atrial fibrillation: getting warmer? J Cardiovasc Electrophysiol 2005;16:1309-1310.

33. Khairy P, Chauvet P, Lehmann J, Lambert J, Macle L, Tanguay JF, Sirois MG, Santoianni D, Dubuc M. Lower incidence of thrombus formation with cryoenergy versus radiofrequency catheter ablation. Circulation 2003;107:2045-2050.

34. Lustgarten DL, Keane D, Ruskin J. Cryothermal ablation: mechanism of tissue injury and current experience in the treatment of tachyarrhythmias. Prog Cardiovasc Dis 1999;41:481498.

35. Rodriguez LM, Timmermans C. Transvenous cryoablation of cardiac arrhythmias. Technol Cancer Res Treat 2004;3:515-524.

36. Skanes AC, Klein G, Krahn A, Yee R. Cryoablation: potentials and pitfalls. J Cardiovasc Electrophysiol 2004;15:S28-S34.

37. Tuzcu V, Gonzalez MB, Schranz D. Cryoablation: better catheter stability compared to RF ablation. Anadolu Kardiyol Derg 2006;6:182-184.

38. Yiu KH, Lau CP, Lee KL, Tse HF. Emerging energy sources for catheter ablation of atrial fibrillation. J Cardiovasc Electrophysiol 2006;17 Suppl 3:S56-S61.

39. Skanes AC, Jones DL, Teefy P, Guiraudon C, Yee R, Krahn AD, Klein GJ. Safety and feasibility of cryothermal ablation within the mid- and distal coronary sinus. J Cardiovasc Electrophysiol 2004;15:1319-1323.

40. Fuster V, Ryden LE, Cannom DS, Crijns HJ, Curtis AB, Ellenbogen KA, Halperin JL, Le Heuzey JY, Kay GN, Lowe JE, Olsson SB, Prystowsky EN, Tamargo JL, Wann S, Smith SC, Jr., Jacobs AK, Adams CD, Anderson JL, Antman EM, Halperin JL, Hunt SA, Nishimura R, Ornato JP, Page RL, Riegel B, Priori SG, Blanc JJ, Budaj A, Camm AJ, Dean V, Deckers JW, Despres C, Dickstein K, Lekakis J, McGregor K, Metra M, Morais J, Osterspey A, Tamargo JL, Zamorano JL. ACC/AHA/ESC 2006 Guidelines for the Management of Patients with Atrial Fibrillation: a report of the American College of Cardiology/American Heart Association Task Force on Practice Guidelines and the European Society of Cardiology Committee for Practice Guidelines (Writing Committee to Revise the 2001 Guidelines for the Management of Patients With Atrial Fibrillation): developed in collaboration with the European Heart Rhythm Association and the Heart Rhythm Society. Circulation 2006;114:e257-e354.

41. Natale A, Newby KH, Pisano E, Leonelli F, Fanelli R, Potenza D, Beheiry S, Tomassoni G. Prospective randomized comparison of antiarrhythmic therapy versus first-line radiofrequency ablation in patients with atrial flutter. J Am Coll Cardiol 2000;35:1898-1904.

42. Collins NJ, Barlow M, Varghese P, Leitch J. Cryoablation versus Radiofrequency Ablation in the treatment of Atrial Flutter trial (CRAAFT). J Interv Card Electrophysiol 2006;16:1-5.

43. Kobza R, Hindricks G, Tanner H, Schirdewahn P, Dorszewski A, Piorkowski C, Gerds-Li JH, Kottkamp H. Late recurrent arrhythmias after ablation of atrial fibrillation: incidence, mechanisms, and treatment. Heart Rhythm 2004;1:676-683.

44. Lee SH, Tai CT, Hsieh MH, Tsai CF, Lin YK, Tsao HM, Yu WC, Huang JL, Ueng KC, Cheng JJ, Ding YA, Chen SA. Predictors of early and late recurrence of atrial fibrillation after catheter ablation of paroxysmal atrial fibrillation. J Interv Card Electrophysiol 2004;10:221-226.

45. Oral H, Knight BP, Ozaydin M, Tada H, Chugh A, Hassan S, Scharf C, Lai SW, Greenstein R, Pelosi F, Jr., Strickberger SA, Morady F. Clinical significance of early recurrences of atrial fibrillation after pulmonary vein isolation. J Am Coll Cardiol 2002;40:100-104.

46. Senatore G, Stabile G, Bertaglia E, Donnici G, De SA, Zoppo F, Turco P, Pascotto P, Fazzari M. Role of transtelephonic electrocardiographic monitoring in detecting short-term arrhythmia recurrences after radiofrequency ablation in patients with atrial fibrillation. J Am Coll Cardiol 2005;45:873-876. 
47. Hindricks G, Piorkowski C, Tanner H, Kobza R, Gerds-Li JH, Carbucicchio C, Kottkamp $\mathrm{H}$. Perception of atrial fibrillation before and after radiofrequency catheter ablation: relevance of asymptomatic arrhythmia recurrence. Circulation 2005;112:307-313.

48. Vasamreddy CR, Dalal D, Dong J, Cheng A, Spragg D, Lamiy SZ, Meininger G, Henrikson CA, Marine JE, Berger R, Calkins H. Symptomatic and asymptomatic atrial fibrillation in patients undergoing radiofrequency catheter ablation. J Cardiovasc Electrophysiol 2006;17:134-139.

49. Jais P, Hocini M, MacLe L, Choi KJ, Deisenhofer I, Weerasooriya R, Shah DC, Garrigue S, Raybaud F, Scavee C, Le MP, Clementy J, Haissaguerre M. Distinctive electrophysiological properties of pulmonary veins in patients with atrial fibrillation. Circulation 2002;106:24792485.

50. Rostock THOM, Servatius HELG, Risius TIM, Ventura RODO, Weiss CHRI, Meinertz THOM, Willems STEP. Impact of Amiodarone on Electrophysiologic Properties of Pulmonary Veins in Patients with Paroxysmal Atrial Fibrillation. Journal of Cardiovascular Electrophysiology 2005;16:39-44. 



\section{CHAPTER II}

\section{Long Term Follow-up after Cavotricuspid Isthmus Cryoablation for the Treatment of Common Atrial Flutter in 180 Patients}

Wendel Moreira, MD, Carl Timmermans, MD, PhD, Hein J. J. Wellens, MD, PhD,* Yuka Mizusawa, MD, David Perez, MD, Suzanne Philippens, RN and Luz-Maria Rodriguez, MD, PhD

From the Department of Cardiology, Academic Hospital Maastricht and *Cardiovascular Research Institute Maastricht (CARIM)

Maastricht, the Netherlands

Abstract presented at the European Society of Cardiology Congress, Vienna, Austria, September 2007.

(Eur Heart J, 2007).

Manuscript accepted for publication in the Journal of Interventional Cardiac Electrophysiology. 


\section{Abstract}

Objectives: Recent literature has shown that common type atrial flutter (AFL) can recur late after cavotricuspid isthmus (CTI) catheter ablation using radiofrequency energy $(\mathrm{RF})$. We report the long term outcome of a large group of patients undergoing CTI ablation using cryothermy for AFL in a single center.

Methods: Patients with AFL referred for CTI ablation were recruited prospectively from July 2001 to July 2006. Cryoablation was performed using a deflectable, 10.5 F, $6.5 \mathrm{~mm}$ tip catheter. CTI block was reassessed $30 \mathrm{~min}$ after the last application during isoproterenol infusion. Recurrences were evaluated by Holter monitoring every clinic visit $(1 / 3 / 6 / 9$ and 12 months after the procedure and yearly thereafter) or if symptoms developed.

Results: The 180 enrolled patients had the following characteristics: 39 women $(22 \%)$, mean age 58 years, no structural heart disease in 86 patients $(48 \%)$, mean left atrium diameter $44 \pm 7 \mathrm{~mm}$ and mean left ventricular ejection fraction $57 \pm 7 \%$. The average number of applications per patient was 7 (3 to 20) with a mean temperature and duration of $-88{ }^{\circ} \mathrm{C}$ and 3 minutes respectively. Acute success was achieved in 95\% (171) of the patients. There were no complications. After a mean follow-up of $27 \pm 17$ (from 12 to 60) months, the chronic success rate was $91 \%$. The majority of the recurrences occurred within the first year post ablation. One hundred and twenty three patients had a history of atrial fibrillation (AF) prior to CTI ablation and $85(69 \%)$ of those remained having AF after cryoablation. In 20 of 57 (35\%) patients without a history of AF prior to CTI ablation, AF occurred during follow-up.

Conclusions: This prospective study showed a 91\% chronic success rate (range 12 to 60 months) for cryoablation of the CTI in patients with common type AFL and ratified the frequent association of AF with AFL. 


\section{Introduction}

Ablation of the cavotricuspid isthmus (CTI) for the treatment of atrial flutter (AFL) has become standard practice. Most of the procedures are performed using radiofrequency energy (RF). ${ }^{1-5}$ High chronic success rates are described but the majority of the data comes from a relatively short term follow-up. ${ }^{1-13} \mathrm{~A}$ recent study by Chinitz et al ${ }^{14}$ reported some interesting data regarding the long term follow-up of 80 patients with common type AFL who underwent CTI ablation using RF. They found a 12.5\% (10 patients) recurrence rate at an average of 21 months after the procedure with most patients having a recurrence after the first year post ablation.

Our prior experience using cryothermy in a limited number of patients ${ }^{15}$ also showed that AFL may recur one year after CTI cryoablation.

The purpose of this study was to evaluate the long term outcome of CTI cryoablation in a large patient population with common type AFL in a single center.

\section{Methods}

One hundred and eighty patients with symptomatic common type AFL referred for CTI ablation were enrolled prospectively from July 2001 to July 2006 in our institution. Signed written consent, approved by the local ethics committee, was obtained from all participants.

Before CTI cryoablation, anticoagulation with warfarin aiming a therapeutic international normalized ratio of 2 to 3 was kept for at least three weeks. Antiarrhythmic drugs were not discontinued before ablation.

\section{Electrophysiologic Study and Ablation}

A detailed description of our CTI cryoablation protocol (including the baseline electrophysiologic study, number and duration of an application ...) has been already published. ${ }^{15}$ We therefore focused our study on the clinical aspects and long term follow-up of patients with AFL who were submitted to CTI cryoablation. But briefly, our cryoablation protocol is as follows: we use the CryoCor $^{\mathrm{TM}}$ system (CryoCor, Inc., San Diego, California) whose primary refrigerant is $\mathrm{N}_{2} \mathrm{O}$ operating in an open loop fashion that is precooled by a secondary refrigerant (AZ-20) operating in a closed loop circuit. Precooling occurs in a heat exchanger located at the catheter/console interconnect where the secondary mixture extracts heat from the primary gas. The primary refrigerant produces cryoablation via Joule-Thompson expansion of gas through a capillary tube at 
the distal end of the catheter. Catheter tip temperature and system pressure measurements are made throughout the ablation to ensure consistent catheter tip performance. ${ }^{15-19}$

Under local anesthesia and via the femoral route, a decapolar catheter is positioned in the distal coronary sinus (for evaluation of left atrial activation), a duodecapolar catheter (2-mm interelectrode spacing, Halo catheter, Biosense Webster, Baldwin Park, California) for mapping the right atrial lateral wall and a quadripolar catheter in the His bundle area. A deflectable, 10.5 F, $6.5 \mathrm{~mm}$ tip cryoablation catheter (CryoCor Inc., San Diego, California) is inserted into the right atrium through a 12F, 65-cm-long sheath (DAIG, St. Jude Medical Inc., St. Paul, Minnesota).

All patients were studied in the fasting state without sedation. Those presenting in $\mathrm{AF}$ while on the catheterization table were converted to sinus rhythm by internal or external cardioversion.

During the procedure intravenous heparin was given as a $100-\mathrm{IU} / \mathrm{kg}$ bolus dose after the venous sheaths were inserted. The 12 lead ECG and intracardiac electrograms were recorded and stored by the BARD Labsystem PRO.

Entrainment to confirm the isthmus dependence of the AFL circuit was performed in every patient in whom AFL could be induced, according to previously published techniques.,210,15,16,20,21 If AF developed during stimulation or we were unable, even under isoproterenol infusion, to induce AFL, CTI ablation was performed in sinus rhythm. Linear lesions were created by use of a point-by-point technique with gradual pullback of the cryocatheter in a ventricular atrial fashion. The first application was delivered at the ventricular insertion of the isthmus. In patients in whom ablation of the posterior isthmus proved insufficient, an attempt was made to ablate the septal isthmus (4 patients).

Acute success was defined as bidirectional isthmus conduction block, 30 minutes after the last application without and with isoproterenol infusion (1 to $3 \mathrm{mcg} / \mathrm{min}) .^{22}$

\section{Post Ablation Management}

All patients were monitored in hospital for $24 \mathrm{~h}$ and oral anticoagulation was started the day of ablation. Antiarrhythmic drugs (AAD) were stopped after the procedure in patients without a history of AF; in those with AF/AFL the same AAD were continued.

All patients had anticoagulation for at least 1 month. Subsequently, the need for chronic anticoagulation was assessed by the amount of recurrences of AFL/AF and the presence of risk factors for thromboembolic events.

All patients had a 24 hours Holter recording at discharge and during each clinic visit (1 month, 3, 6, 9, 12 months and yearly thereafter) or earlier if they had symptoms. 
Due to the logistics of the Maastricht area - and also the presence of a dedicated research nurse (S. P.) who was available to address patients' concerns and questions at any time - we were able to follow every patient on an individual basis.

\section{Statistical analysis}

Continuous variables are presented as mean $\pm \mathrm{SD}$, where appropriate. In cases of a nongaussian distribution, medians and quartiles are given. Categorical variables are expressed as numbers and percentages of patients.

Statistical analysis was performed using the Student t-test for unpaired data. All values were considered significant at $P<0.05$.

\section{Results}

Of the 180 enrolled patients, 39 patients (22\%) were women with a mean age of 58 (from 18 to 80 ) years. More than half of the patients (92 patients, 52\%) had structural heart disease: arterial hypertension: 57 patients, coronary artery disease: 22 patients, valvular heart disease: 13 patients, congenital heart disease: 11 patients, idiopathic cardiomyopathy: 18 patients. Counterclockwise AFL was documented in 91\% (164) of the patients and clockwise AFL in 9\% (16 patients).

The mean left atrial diameter and the mean left ventricular ejection fraction were $44 \pm 7 \mathrm{~mm}$ and $57 \pm 7 \%$, respectively. A prior history of AF was present in $123(69 \%)$ of the patients. The clinical characteristics of the patients, related to the presence or absence of AF before ablation, are described in Table 1. Note that AF during follow-up is significantly higher in the group with a prior history of this arrhythmia.

Total fluoroscopic - mean of $30 \pm 18$ minutes (range, 12 to 152 minutes) and procedure times - mean of $2.6 \pm 1.1$ hours (range, 1 to 6.5 hours) - have decreased throughout our study with the variation in those values being attributed mainly to the learning curve of this new technology. For the whole group, an average of 7 (3 to 20) applications per patient were delivered with a mean temperature and duration of $-88^{\circ} \mathrm{C}$ and 3 minutes, respectively.

The acute success rate for cryoablation of the CTI was 95\% (171 patients). There were no complications. Of the 9 patients in whom bidirectional CTI block was not achieved, 3 underwent a successful reablation. The other $6 \mathrm{pa}-$ tients had much improvement of their symptoms (despite an incomplete line) and preferred not to have another procedure.

After a mean follow-up of $27 \pm 17$ (range from 12 to 60 ) months, recurrences of symptomatic AFL occurred in 15 patients (9\%) resulting in a 91\% 
chronic success rate. Those recurrences occurred in 6 patients within the first 3 months post ablation, in 4 patients from 3 to 6 months post ablation, in 4 patients from 6 to 9 months post ablation and in one patient at 14 months post ablation (Figure 1). Ten of those 15 patients underwent a second successful cryoablation of the CTI. The other 5 had not only reablation of the isthmus but also pulmonary vein cryoisolation (PVI) for AF during the second procedure.

Despite the success as far as AFL was concerned, AF was still present in 85 patients $(69 \%)$ with a prior history of this arrhythmia. Those patients were treated by AAD (69 patients, 81\%), PVI (14 patients, 16\%) or AV nodal ablation with pacemaker implantation (2 patients, $3 \%$ ). New episodes of AF developed in $20(35 \%)$ of those 57 patients without documented AF prior to CTI cryoablation and were all controlled by AAD.

\section{Discussion}

\section{Main Findings}

Our current study showed a 91\% chronic success rate of CTI cryoablation in a large population (180 patients) with AFL followed for a long period of time (1 to 5 years, mean of 27 months).

According to the most recent ACC/AHA/ESC guidelines for the management of supraventricular arrhythmias CTI ablation is the only therapy with a class I indication for the long term management of AFL. ${ }^{2}$ The majority of those ablations are done using RF energy.

Concerning the follow-up length of those procedures, most of the literature available reports on a relatively short period, the majority of them being less than two years. However Chinitz et al ${ }^{14}$ published a study of 80 patients with AFL submitted to CTI ablation using RF that had up to 6 years follow-up. Interestingly, they found a $12.5 \%$ recurrence of AFL that occurred on an average of 21 months post ablation, ratifying the need of data with a longer followup.

It is important to keep in mind though, that arrhythmias after ablation do not always correlate with symptoms ${ }^{23,24}$ and one could question if those patients with such a late recurrence had those episodes much earlier than what is reported. That might be one reason why our results, where most of our recurrences happened within one year, are discrepant with those from their study. The intrinsic characteristics of our hospital, our clinical follow-up and the population of Maastricht could be responsible for our ability to find those recurrences earlier.

Regarding cryothermy as energy source, a 9 months follow-up study in 39 patients undergoing CTI cryoablation with a different system was reported..$^{25}$ They achieved a chronic success rate of $100 \%$ in the cryoablated group, despite 
documenting reconduction through the isthmus in $31 \%$ of patients during a 3 month follow-up electrophysiologic study. The CRAAFT trial presented the results in 32 patients with AFL submitted to either cryo- or RF ablation of the CTI. ${ }^{26}$ They report an $84 \%$ success rate after a follow-up of 14 months. Those two small studies, with a relatively short follow-up, reported similar success rates with RF and cryothermy for AFL ablation. The results from our study which included a significant larger patient population (180) with a longer follow-up ( 1 to 5 years, mean of 27 months) - reinforces the effectiveness of cryothermy for the treatment of AFL, being the outcomes comparable to those reported in the literature using RF (where most outcome data also comes from non invasive follow-up). 1,4-7,11,12,27,28 Therefore, cryothermy can be considered as an efficient energy source for the treatment of common type AFL.

\section{The relation of $A F$ with $A F L$}

The close relation between AF and AFL is well described. . $^{1,-14,21,29-39}$ Our data showed a high prevalence of AF (123 out of 180 patients, $69 \%$ ) in patients with predominant AFL referred for CTI ablation. A recent study by Ellis and colleagues ${ }^{40}$ strengthened even more this association. They followed 363 patients with lone AFL who underwent CTI RF ablation - during a mean follow-up of 39 months - and were able to report an $82 \%$ incidence of drug refractory AF in their patient population.

The new development of AF in our patient population without a prior history of AF preceding AFL ablation may be a sign of an already present electrical and morphological change in the right and left atria. If in addition, a functional or anatomical line of block between the two venae cavae (or elsewhere) occurs, atypical AFL(s) may develop either in the right (because the CTI is already ablated) or in the left atrium.11,14,21,31,32 37-39

\section{Study Limitations}

Our recurrence data rely mostly on the subjective assessment by the patient, like the great majority of RF data. ${ }^{14,6-8,12}$ Only an objective measurement (such as a repeat electrophysiological study with documented bidirectional block) will determine the long lasting effect of CTI ablation for the treatment of common type AFL. 


\section{Conclusions}

In this prospectively studied large population of patients with common type AFL, cryoablation of the CTI has a $91 \%$ chronic success rate during long term follow-up (range 1 to 5 years, mean of 27 months). These results are similar to those obtained with RF, validating cryothermy as an efficient alternative energy source. We also were able to ratify the frequent association of AF with AFL. 
Figure 1. Percentage of patients (171 successfully ablated) free of common type atrial flutter over time.

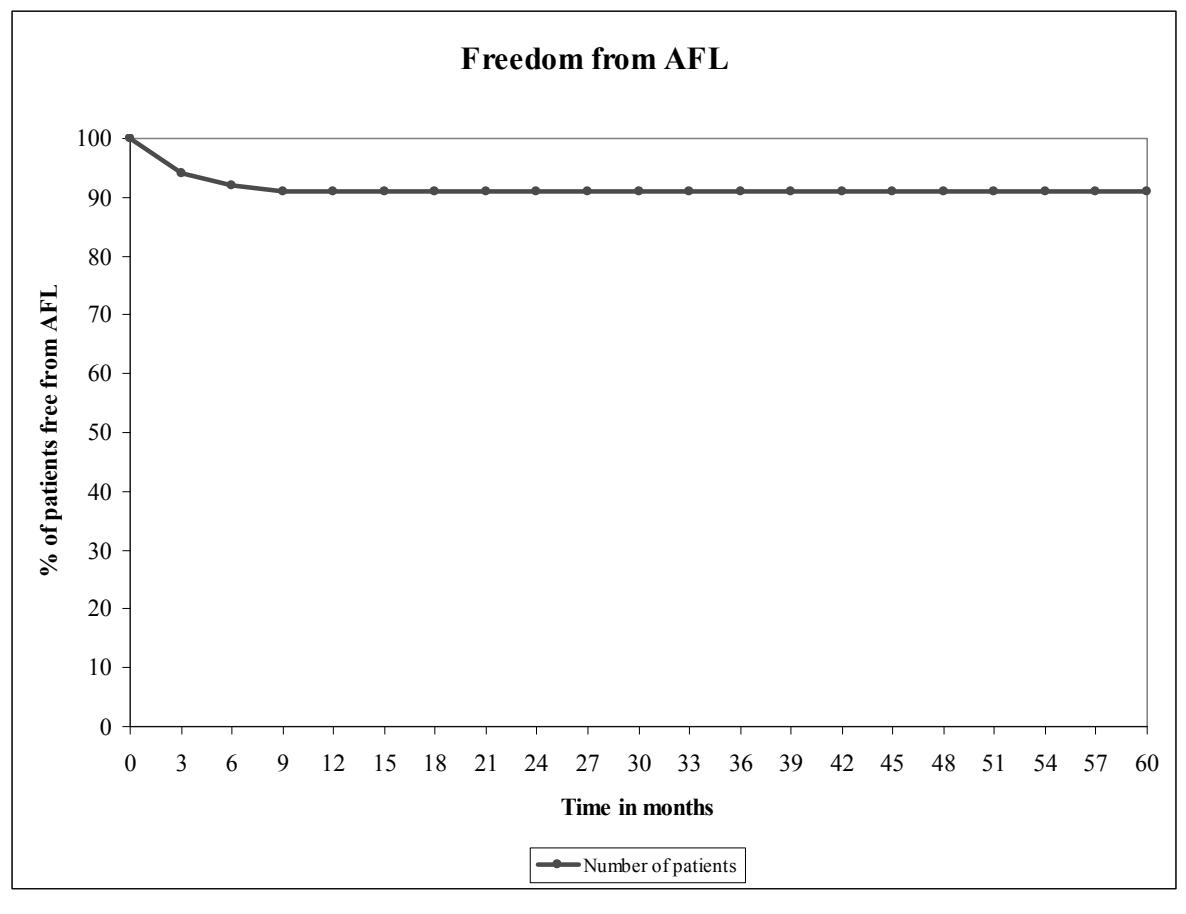

\begin{tabular}{|c|c|c|c|c|c|c|c|c|c|c|c|c|c|}
\hline $\begin{array}{l}\text { Follow- } \\
\text { up in } \\
\text { months }\end{array}$ & 0 & 3 & 6 & 9 & 12 & 18 & 24 & 30 & 36 & 42 & 48 & 54 & 60 \\
\hline Events & 9 & 6 & 4 & 4 & 1 & 0 & 0 & 0 & 0 & 0 & 0 & 0 & 0 \\
\hline $\begin{array}{l}\text { Number } \\
\text { of pa- } \\
\text { tients at } \\
\text { risk }\end{array}$ & 180 & 171 & 165 & 161 & 157 & 156 & 134 & 112 & 92 & 72 & 57 & 42 & 28 \\
\hline
\end{tabular}

Legend: After a mean follow-up of $27 \pm 17$ months, 91\% (156 patients) did not have recurrences of atrial flutter. 


\section{References}

1. Anne W, Willems R, Adriaenssens B, Adams J, Ector H, Heidbuchel H. Long-term symptomatic benefit after radiofrequency catheter ablation for atrial flutter despite a high incidence of post-procedural atrial fibrillation. Acta Cardiol 2006;61:75-82.

2. Blomstrom-Lundqvist C, Scheinman MM, Aliot EM, Alpert JS, Calkins H, Camm AJ, Campbell WB, Haines DE, Kuck KH, Lerman BB, Miller DD, Shaeffer CW, Jr., Stevenson WG, Tomaselli GF, Antman EM, Smith SC, Jr., Alpert JS, Faxon DP, Fuster V, Gibbons RJ, Gregoratos G, Hiratzka LF, Hunt SA, Jacobs AK, Russell RO, Jr., Priori SG, Blanc JJ, Budaj A, Burgos EF, Cowie M, Deckers JW, Garcia MA, Klein WW, Lekakis J, Lindahl B, Mazzotta G, Morais JC, Oto A, Smiseth O, Trappe HJ. ACC/AHA/ESC guidelines for the management of patients with supraventricular arrhythmias--executive summary: a report of the American College of Cardiology/American Heart Association Task Force on Practice Guidelines and the European Society of Cardiology Committee for Practice Guidelines (Writing Committee to Develop Guidelines for the Management of Patients With Supraventricular Arrhythmias). Circulation 2003;108:1871-1909.

3. Marrouche NF, Schweikert R, Saliba W, Pavia SV, Martin DO, Dresing T, Cole C, Balaban K, Saad E, Perez-Lugones A, Bash D, Tchou P, Natale A. Use of different catheter ablation technologies for treatment of typical atrial flutter: acute results and long-term follow-up. Pacing Clin Electrophysiol 2003;26:743-746.

4. Natale A, Newby KH, Pisano E, Leonelli F, Fanelli R, Potenza D, Beheiry S, Tomassoni G. Prospective randomized comparison of antiarrhythmic therapy versus first-line radiofrequency ablation in patients with atrial flutter. J Am Coll Cardiol 2000;35:1898-1904.

5. Schmieder S, Ndrepepa G, Dong J, Zrenner B, Schreieck J, Schneider MA, Karch MR, Schmitt C. Acute and long-term results of radiofrequency ablation of common atrial flutter and the influence of the right atrial isthmus ablation on the occurrence of atrial fibrillation. Eur Heart J 2003;24:956-962.

6. Bertaglia E, Zoppo F, Bonso A, Proclemer A, Verlato R, Coro L, Mantovan R, D'Este D, Zerbo F, Pascotto P. Long term follow up of radiofrequency catheter ablation of atrial flutter: clinical course and predictors of atrial fibrillation occurrence. Heart 2004;90:59-63.

7. Bertaglia E, Bonso A, Zoppo F, Proclemer A, Verlato R, Coro L, Mantovan R, Themistoclakis S, Raviele A, Pascotto P. Different clinical courses and predictors of atrial fibrillation occurrence after transisthmic ablation in patients with preablation lone atrial flutter, coexistent atrial fibrillation, and drug induced atrial flutter. Pacing Clin Electrophysiol 2004;27:1507-1512.

8. Bottoni N, Donateo P, Quartieri F, Tomasi C, Oddone D, Lolli G, Menozzi C, Brignole M. Outcome after cavo-tricuspid isthmus ablation in patients with recurrent atrial fibrillation and drug-related typical atrial flutter. Am J Cardiol 2004;94:504-508.

9. Da CA, Romeyer C, Mourot S, Messier M, Cerisier A, Faure E, Isaaz K. Factors associated with early atrial fibrillation after ablation of common atrial flutter. A single centre prospective study. Eur Heart J 2002;23:498-506.

10. Da CA, Romeyer-Bouchard C, Zarqane-Sliman N, Messier M, Samuel B, Kihel A, Faure E, Isaaz K. Impact of first line radiofrequency ablation in patients with lone atrial flutter on the long term risk of subsequent atrial fibrillation. Heart 2005;91:97-98.

11. Delise P, Sitta N, Coro L, Marras E, Sciarra L, Bocchino M, Berton G. Common atrial flutter and atrial fibrillation are not always two stages of the same disease. A long-term follow-up study in patients with atrial flutter treated with cavo-tricuspid isthmus ablation. J Cardiovasc Med (Hagerstown ) 2006;7:800-805.

12. Hsieh MH, Tai CT, Chiang CE, Tsai CF, Yu WC, Chen YJ, Ding YA, Chen SA. Recurrent atrial flutter and atrial fibrillation after catheter ablation of the cavotricuspid isthmus: a very long-term follow-up of 333 patients. J Interv Card Electrophysiol 2002;7:225-231. 
13. Husser D, Bollmann A, Kang S, Girsky MJ, Lerman RD, Cannom DS, Bhandari AK. Effectiveness of catheter ablation for coexisting atrial fibrillation and atrial flutter. Am J Cardiol 2004;94:666-668.

14. Chinitz JS, Gerstenfeld EP, Marchlinski FE, Callans DJ. Atrial fibrillation is common after ablation of isolated atrial flutter during long-term follow-up. Heart Rhythm 2007;4:10291033.

15. Manusama R, Timmermans C, Limon F, Philippens S, Crijns HJ, Rodriguez LM. Catheterbased cryoablation permanently cures patients with common atrial flutter. Circulation 2004;109:1636-1639.

16. Manusama R, Timmermans C, Philippens S, Crijns HJ, Ayers GM, Rodriguez LM. Single cryothermia applications of less than five minutes produce permanent cavotricuspid isthmus block in humans. Heart Rhythm 2004;1:594-599.

17. Rodriguez LM, Geller JC, Tse HF, Timmermans C, Reek S, Lee KL, Ayers GM, Lau CP, Klein HU, Crijns HJ. Acute results of transvenous cryoablation of supraventricular tachycardia (atrial fibrillation, atrial flutter, Wolff-Parkinson-White syndrome, atrioventricular nodal reentry tachycardia). J Cardiovasc Electrophysiol 2002;13:1082-1089.

18. Rodriguez LM, Timmermans C. Transvenous cryoablation of cardiac arrhythmias. Technol Cancer Res Treat 2004;3:515-524.

19. Timmermans C, Ayers GM, Crijns HJ, Rodriguez LM. Randomized study comparing radiofrequency ablation with cryoablation for the treatment of atrial flutter with emphasis on pain perception. Circulation 2003;107:1250-1252.

20. Andrew P, Montenero AS. Atrial flutter: a focus on treatment options for a common supraventricular tachyarrhythmia. J Cardiovasc Med (Hagerstown ) 2007;8:558-567.

21. Camm AJ, Obel OA. Epidemiology and mechanism of atrial fibrillation and atrial flutter. Am J Cardiol 1996;78:3-11.

22. Nabar A, Rodriguez LM, Timmermans C, Smeets JL, Wellens HJ. Isoproterenol to evaluate resumption of conduction after right atrial isthmus ablation in type I atrial flutter. Circulation 1999;99:3286-3291.

23. Klemm HU, Ventura R, Rostock T, Brandstrup B, Risius T, Meinertz T, Willems S. Correlation of symptoms to ECG diagnosis following atrial fibrillation ablation. J Cardiovasc Electrophysiol 2006;17:146-150.

24. Hindricks G, Piorkowski C, Tanner H, Kobza R, Gerds-Li JH, Carbucicchio C, Kottkamp $\mathrm{H}$. Perception of atrial fibrillation before and after radiofrequency catheter ablation: relevance of asymptomatic arrhythmia recurrence. Circulation 2005;112:307-313.

25. Montenero AS, Bruno N, Antonelli A, Mangiameli D, Barbieri L, Andrew P, Murphy O, O'Connor S, Zumbo F. Long-term efficacy of cryo catheter ablation for the treatment of atrial flutter: results from a repeat electrophysiologic study. J Am Coll Cardiol 2005;45:573580 .

26. Collins NJ, Barlow M, Varghese P, Leitch J. Cryoablation versus Radiofrequency Ablation in the treatment of Atrial Flutter trial (CRAAFT). J Interv Card Electrophysiol 2006;16:1-5.

27. Nabar A, Rodriguez LM, Timmermans C, Smeets JL, Wellens HJ. Radiofrequency ablation of "class IC atrial flutter" in patients with resistant atrial fibrillation. Am J Cardiol 1999;83:785-7, A10.

28. Nabar A, Rodriguez LM, Timmermans C, van den DA, Smeets JL, Wellens HJ. Effect of right atrial isthmus ablation on the occurrence of atrial fibrillation: observations in four patient groups having type I atrial flutter with or without associated atrial fibrillation. Circulation 1999;99:1441-1445.

29. Calo L, Lamberti F, Loricchio ML, De RE, Bianconi L, Pandozi C, Santini M. Atrial flutter and atrial fibrillation: which relationship? New insights into the electrophysiological mechanisms and catheter ablation treatment. Ital Heart J 2005;6:368-373.

30. Chugh A, Latchamsetty R, Oral H, Elmouchi D, Tschopp D, Reich S, Igic P, Lemerand T, Good E, Bogun F, Pelosi F, Jr., Morady F. Characteristics of cavotricuspid isthmusdependent atrial flutter after left atrial ablation of atrial fibrillation. Circulation 2006;113:609-615. 
31. Fischer A, Mehta D. Atrial fibrillation after atrial flutter ablation. J Interv Card Electrophysiol 2002;6:181-182.

32. Horvath G, Goldberger JJ, Kadish AH. Simultaneous occurrence of atrial fibrillation and atrial flutter. J Cardiovasc Electrophysiol 2000;11:849-858.

33. Hsieh MH, Tai CT, Tsai CF, Yu WC, Lin WS, Huang JL, Ding YA, Chang MS, Chen SA. Mechanism of spontaneous transition from typical atrial flutter to atrial fibrillation: role of ectopic atrial fibrillation foci. Pacing Clin Electrophysiol 2001;24:46-52.

34. Hsieh MH, Tai CT, Chan P, Chen SA. Spontaneous transition from atrial fibrillation to typical atrial flutter during catheter ablation of the pulmonary vein. J Interv Card Electrophysiol 2004;10:289-291.

35. Kumagai K, Tojo H, Yasuda T, Noguchi H, Matsumoto N, Nakashima H, Gondo N, Saku $\mathrm{K}$. Treatment of mixed atrial fibrillation and typical atrial flutter by hybrid catheter ablation. Pacing Clin Electrophysiol 2000;23:1839-1842.

36. Lelorier P, Humphries KH, Krahn A, Connolly SJ, Talajic M, Green M, Sheldon R, Dorian P, Newman D, Kerr CR, Yee R, Klein GJ. Prognostic differences between atrial fibrillation and atrial flutter. Am J Cardiol 2004;93:647-649.

37. Morton JB, Byrne MJ, Power JM, Raman J, Kalman JM. Electrical remodeling of the atrium in an anatomic model of atrial flutter: relationship between substrate and triggers for conversion to atrial fibrillation. Circulation 2002;105:258-264.

38. Ramanna H, De Bakker JM, Hauer RN. Mechanism of propensity to atrial fibrillation in patients undergoing isthmus ablation for typical atrial flutter. J Cardiovasc Electrophysiol 2005;16:167-172.

39. Waldo AL. The interrelationship between atrial fibrillation and atrial flutter. Prog Cardiovasc Dis 2005;48:41-56.

40. Ellis K, Wazni O, Marrouche N, Martin D, Gillinov M, McCarthy P, Saad EB, Bhargava M, Schweikert R, Saliba W, Bash D, Rossillo A, Erciyes D, Tchou P, Natale A. (2007). Incidence of atrial fibrillation post-cavotricuspid isthmus ablation in patients with typical atrial flutter: left-atrial size as an independent predictor of atrial fibrillation recurrence. Journal of Cardiovascular Electrophysiology, 18:799-802. 


\section{CHAPTER III}

\section{Long-term Follow-up after Cryothermic Ostial Pulmonary Vein Isolation in Paroxysmal Atrial Fibrillation}

Wendel Moreira, MD*‡, Randy Manusama, MD*‡, Carl Timmermans, MD, PhD,* Benoit Ghaye MD†, Suzanne Philippens, RN*, Hein J. J. Wellens, MD, PhD, ** and Luz-Maria Rodriguez, MD, PhD*

From the *Department of Cardiology, Academic Hospital Maastricht, Maastricht, the Netherlands, †Department of Medical Imaging, University Hospital of Liége, Liége, Belgium and ${ }^{* *}$ Cardiovascular Research Institute Maastricht, Maastricht, the Netherlands

$\ddagger$ Both authors contributed equally to this work.

Abstract presented at the European Society of Cardiology Congress, Stockholm, Sweden, September 2005.

(Eur Heart J, 2005, 26(1): 63, P530).

Manuscript accepted for publication in the

Journal of the American College of Cardiology. 


\section{Abstract}

Objectives: Evaluate the long term effect of segmental PV cryoablation in patients with recent onset PAF.

Background: Patients with PAF have more triggers to initiate and less substrate to sustain AF. Elimination of the potential initiators alone may be sufficient to abolish the arrhythmia.

Methods: Patients with PAF were prospectively recruited from July 2001 to July 2005. If the triggers for AF were identified, PV cryoisolation of the arrhythmogenic vein(s) was performed. Otherwise, all PVs were isolated.

Results: Seventy patients with minimal or no heart disease (54 men; age $40 \pm 10$ years) were enrolled. The duration of AF was $4 \pm 1$ years. The LVEF and left atrial size were $59 \pm 8 \%$ and $41 \pm 5 \mathrm{~mm}$, respectively. An arrhythmogenic PV(s) was found in 10 patients (14\%). Complications occurred in $3(4 \%)$ patients. No PV stenosis or esophageal injury was detected during a mean follow up of $33 \pm 15$ months. Thirty four patients (49\%) achieved complete success (no AF and no AADs), 15 patients (22\%) had no recurrences on AADs and 8 patients $(11 \%)$, still with sporadic bursts of AF, improved $>50 \%$ on AADs. Overall, $82 \%$ of the patients benefited from the procedure. Patients in whom the arrhythmogenic $\mathrm{PV}(\mathrm{s})$ was identified and isolated had no recurrences.

Conclusions: PV cryoisolation is effective in $82 \%$ of patients with recent onset PAF during a mean follow-up of $33 \pm 15$ (15 to 60) months. If the arrhythmogenic PV is identified and isolated, the long-term outcome is excellent indicating no need to isolate all PVs. 


\section{Background}

Atrial fibrillation (AF) is a disease with different stages. In its early stages, paroxysmal and non sustained episodes are the rule., ${ }^{1,2}$ This is when the triggers, mostly located in the pulmonary veins (PVs), are the main culprit of AF. ${ }^{3}$ Over time, atrial remodeling starts to occur and more substrate becomes available to sustain longer episodes. ${ }^{4}$ Therefore self perpetuation of AF (AF begets AF) leads to the idea that a treatment strategy employed early in the disease would be more likely to succeed.

The actual ablative techniques are intended to eliminate the triggers (ostial PV isolation one by one or two by two) and/or to modify the substrate. A technique that modifies the substrate consists in the creation of multiple lines in both atria. ${ }^{5}$ Adding extensive left atrial linear ablation, although reported to improve overall success rates in a group of patients with more advanced stages of $\mathrm{AF}$, has increased morbidity and mortality (including iatrogenic left atrial flutter, phrenic nerve paralysis and left atrial-to-esophageal fistula which is almost universally fatal). ${ }^{6-8}$

Many patients with AF and structurally normal hearts are now frequently referred for ablation. In this group, empiric extensive left atrial ablation may not be the best approach because the long-term risk of such extensive lesions is unknown.

Cryothermy has been shown to have some inherent advantages over radiofrequency (RF) ablation. The absence of pulmonary vein stenosis is one of them. ${ }^{9}$ But despite its benefits, the great majority of $\mathrm{AF}$ ablation is done using RF. ${ }^{10}$

Our study - OPIPAF (Ostial Pulmonary vein Isolation in Paroxysmal Atrial Fibrillation) - was designed to evaluate the effect of a more localized ablation strategy using cryothermy in patients with PAF in the early stages of the disease.

\section{Methods}

Seventy patients with drug refractory, symptomatic PAF were enrolled prospectively from July 2001 to July 2006.

The screening protocol consisted of: review of Holter recordings, daily transtelephonic telemetry (TTM), the number of failed antiarrhythmic drugs (AADs), functional capacity, type of AF and imaging studies to exclude silent myocardial ischemia. Inclusion criteria required the following: 1) symptomatic $\mathrm{PAF}, 2)$ duration of PAF $\leq$ five years, 3) age $\leq 65$ years, 4) lone AF or minimal heart disease, 5) left atrial size $\leq 40 \mathrm{~mm}$ and no exposure to amiodarone.

All subjects were given a transtelephonic event recorder and instructed to 
use them daily (preferably at the same time) and when they had symptoms. This monitoring started 30 days before and continued up to day 180 after PVI. From then on, a Holter monitor was used during clinic visits (1, 3, 6, 9 and 12 months) or when patients had symptoms.

A baseline contrast-enhanced spiral CT scan of the thorax with threedimensional reconstruction of the heart was performed within 1 month before the ablation procedure and evaluated blindly by the same radiologist who did the follow-up study (B.G.).

All the patients in the study signed a written consent form that was approved by the local ethics committee.

Before PVI, all patients were orally anticoagulated to a therapeutic international normalized ratio of 2 to 3 for at least three weeks and up to three months after ablation.

All antiarrhythmic drugs were stopped 5 days prior to PVI and restarted immediately thereafter.

Transesophageal echocardiogram (TEE) was performed during the procedure to exclude left atrial thrombus and to aid in the transeptal puncture.

\section{Pulmonary Vein Cryoisolation}

All patients were studied in the fasting state without sedation except if external cardioversion was needed (when small doses of midazolam were used). Internal cardioversions were done without sedation. Those patients presenting in AF while in the catheterization room were converted to sinus rhythm by internal or external cardioversion.

During the procedure (but after the transseptal punctures) intravenous heparin was given as a $100-\mathrm{IU} / \mathrm{kg}$ bolus dose followed by boluses of $5000 \mathrm{IU}$ every 1.5 hour if needed to keep an ACT $\geq$ than 300 seconds. A decapolar catheter was positioned in the distal coronary sinus and a quadripolar catheter in the His bundle region via the femoral route. Double trans-septal catheterization was performed under fluoroscopic and transesophageal guidance.

Left atrial angiography was performed after adenosine administration (11) to visualize the ostia of the pulmonary veins. Together with the left atrial angiography, we used the NavX'TM system for virtual reconstruction of the ostia of the veins in the last 20 patients. A deflectable, circumferential decapolar mapping catheter (LASSO ${ }^{\text {TM }}$, Biosense-Webster Inc., Baldwin Park, California) was advanced into the left atrium and positioned at the ostium of each PV. A deflectable, 10.5F (6.5 mm tip) cryoablation catheter (CryoCor Inc., San Diego, California) was inserted into the left atrium through a $12 \mathrm{~F}, 65-\mathrm{cm}-$ long sheath (DAIG, St. Jude Medical Inc., St. Paul, Minnesota, or Cook Inc., Bloomington, Indiana).

Segmental isolation of PVs guided by the recording of their potentials with the LASSO ${ }^{\text {TM }}$ catheter, was performed using the CryoCor cryoablation system 
as described previously (12). Efforts were made to identify the arrhythmogenic PV (culprit PV) using adenosine (24 to $40 \mathrm{mg}$ ) - Figure 1 - or isoproterenol (1 to $5 \mathrm{mcg})$. If the culprit $\mathrm{PV}(\mathrm{s})$ were not identified, all veins with potentials recorded at their ostium were targeted for ablation.

Isolation of the PV was performed during sinus rhythm or coronary sinus pacing by delivering cryoablation at ostial sites that had the earliest bipolar potential.

Systematic pacing in the right superior PV region was performed prior to application to access phrenic nerve capture.

At each effective target site, defined by the abolishment of a PV potential or a change in the PV potential activation sequence during cryothermal application, 3 minutes of cryoablation was delivered. If no changes in the electrogram were observed after 20 seconds, despite a catheter tip temperature of $-90^{\circ} \mathrm{C}$, the application was stopped and the catheter repositioned. The early procedural end point was complete electrical isolation of PVs based on abolition of all ostial PV potentials or complete entrance conduction block into the PV.

\section{Post Ablation Management}

Every patient was monitored in hospital for 24 hours and oral anticoagulation was restarted the same day of the ablation. The same AADs were continued for at least 3 months after the procedure. After this period, the need for chronic anticoagulation was assessed by the amount of recurrences of AF and the presence of risk factors for thromboembolic events.

All patients had a Holter recording at discharge and during each clinic visit $(1,3,6,9,12$ months) or earlier if they had symptoms. They were instructed to keep a diary of events associated with their transtelephonic monitors. A visual analog scale ranging from zero (indicating no improvement at all) to 100 (asymptomatic and AF free after PVI) was used during the clinic visits.

Due to the logistics of the Maastricht area - and also the presence of a dedicated research nurse (S. P.) who was available to address patients' concerns and questions at any time - we were able to follow every patient on an individual basis and achieve a greater than 90\% compliance rate with daily TTMs at the end of 180 days.

To assess the presence of PV stenosis, serial CT scans of the heart were performed at 3, 6 (63 patients) and 12 months (12 patients). In 7 patients, a repeated CT scan was not performed on follow-up because of an allergic reaction to the contrast agent on their baseline scan $(n=3)$ and patient refusal $(n=$ 4). A TEE was performed in those individuals showing no increase in Doppler flow velocities suggestive of PVs stenosis.

The same radiologist (B.G.) reviewed all pre and post-cryoablation images in a blinded manner. The diameter of the ostia of the PVs was determined for each patient in a pairwise manner to maintain consistency in the measurements. 


\section{Definitions}

Arrhythmogenic veins were considered those that, during AF, had a tachycardia cycle length shorter than the one recorded in the coronary sinus catheter. Induction of AF was attempted first by manipulation of the LASSOTM catheter inside the vein (mechanical contact); if that did not result in arrhythmias, administrations of adenosine and isoproterenol infusion were used.

According to the $2007 \mathrm{HRS} / \mathrm{EHRA} / \mathrm{ECAS}$ expert consensus statement on catheter ablation of $\mathrm{AF}^{13}$, an episode of $\mathrm{AF}$ detected by monitoring was considered a recurrence if it had a duration of 30 seconds or more.

\section{Statistical analysis}

Continuous variables are presented as mean $\pm \mathrm{SD}$, where appropriate. In cases of a nongaussian distribution, medians and quartiles are given. Categorical variables are expressed as numbers and percentages of patients.

A Kaplan-Meier analysis was used to determine the percentage of patients either free from AF (with or without AADs) or with greater than $50 \%$ improvement after the index PVI.

\section{Results}

Our cohort consisted of 70 patients (54 men and 16 women) with PAF that fulfilled the described recruitment criteria of the OPIPAF study.

The mean age was $40 \pm 10$ years (range from 21 to 65 years). The mean duration of AF was $4 \pm 1$ years. Patients had failed 1 to 2 AAD before PVI and most of them had no ( $\mathrm{n}=54$ patients) or minimal heart disease ( $\mathrm{n}=16$ patients; 11 had arterial hypertension and 5 had a history of coronary artery disease). There was no history of amiodarone use.

The mean left atrial dimension was $38 \pm 2$ (33 to 40 ) $\mathrm{mm}$ with a mean left ventricular ejection fraction of $59 \pm 8 \%$.

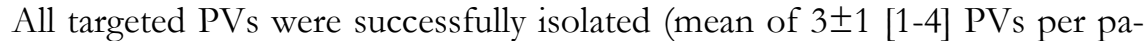
tient). The following veins had potentials and were isolated: left superior in 63 patients, left inferior in 52 patients, right superior in 57 patients and right inferior in 16 patients). The right inferior PV was mapped in 32 patients: half of them (16 patients) did not have any potentials in this vessel, whereas the other 16 patients had PV potentials that were ablated.

A total of 881 complete cryoapplications were given in 188 veins. A mean of 5 (from 1 to 13) applications were given per PV and 13 (from 3 to 23) applications per patient. No PV stenosis (accessed by serial spiral CT in 63 patients and TEE Doppler velocities in 7 patients) or esophageal injury was detected 
during a mean follow- up of $33 \pm 15$ (15 to 60$)$ months.

Total procedure time averaged 331 minutes and fluoroscopy time $88 \mathrm{~min}$ utes. Our long procedure times during PVI are in part due to extensive pacing/pharmacological maneuvers and other interventions we used trying to induce arrhythmias and access endpoints.

Thirty four patients (49\%) had no AF recurrences off AADs, 15 patients $(22 \%)$ had no AF recurrences on AADs and 8 patients $(11 \%)$ - with sporadic AF bursts - reported an improvement of $>50 \%$ on AADs after the ablation. Overall, $82 \%$ of patients benefited from the procedure after the index PVI (Figure 2). Of the 13 patients that did not improve, 10 had a second PVI 6 months after the first procedure. Of those, 6 had much improvement in their symptoms. Three remained having symptomatic AF and opted for rate control. In one patient a third procedure was needed to ablate a focal tachycardia coming from the left inferior PV. He became asymptomatic.

In only $10(14 \%)$ patients the arrhythmogenic PV(s) could be identified using the criteria of a higher AF rate in the PV than in the coronary sinus or adenosine administration (Figure 1). When compared to the rest of the cohort, no statistically significant differences were found in their clinical characteristics using t-tests and chi-square tests. They were distributed as follows: one patient had 3 different arrhythmogenic veins, seven patients had two arrhythmogenic veins and two patients had only one arrhythmogenic vein. In those patients no recurrences were observed during long term follow-up.

\section{Complications}

Complications were seen in $3(4 \%)$ patients. One of our first patients had a cerebral ischemic event with left-sided hemiplegia, occurring at the end of the procedure. It is important to notice that factors other than the energy source could have played a role in this event (such as problems with anticoagulation, several exchanges of the sheaths, long procedure time ...). Subsequently this patient recovered all his baseline function.

A second patient developed a pulmonary embolism two months after the ablation (when he was also found to be inadequately anticoagulated). Even though we can not directly associate this to the cryoablation we decided to count it as an adverse effect during our follow-up.

The third patient had transient phrenic nerve paralysis during the application in the RSPV. However, the diaphragmatic movement recovered immediately after stopping the cryoapplication. 


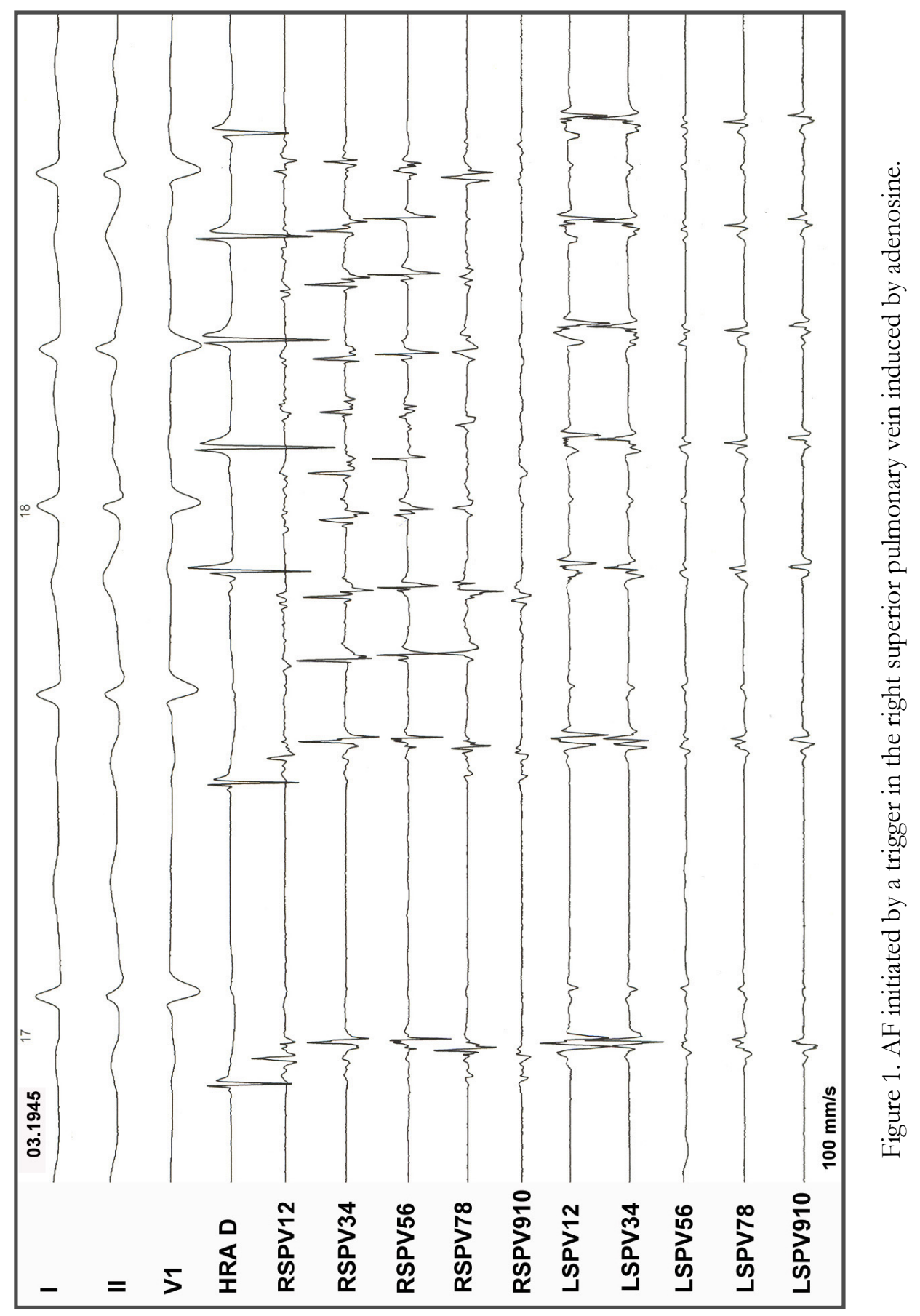




\section{Discussion}

\section{Main Findings}

Our study shows that a more localized ablation strategy using cryothermy is effective in $82 \%$ of patients with $\mathrm{PAF}-49 \%$ without $\mathrm{AF}$ recurrences off AADs, $22 \%$ without AF on AADs and $11 \%$ improved $>50 \%$ on AADs (sporadic bursts of AF) during a mean follow up of $33 \pm 15$ (15 to 60) months. The acute complications seen (stroke and transient phrenic nerve paralysis) were within the acceptable range for the procedure and did not result in long term limitations for the patients.

In those patients in whom the arrhythmogenic PV could be identified and isolated, no recurrences were observed.

\section{Cryothermy is effective as energy source in AF ablation}

Our study shows that $82 \%$ of patients with PAF benefited from pulmonary vein cryoisolation during long term follow up (Figure 2). Those results are similar to those obtained with RF.14-19 However, in comparison with RF, cryothermy may have some advantages.

Cryoenergy causes adherence of the catheter-tip to the underlying tissue during energy delivery assuring accurate lesion creation. ${ }^{20-22}$ This might be important in avoiding catheter dislocation to areas where complications could occur (like the posterior left atrium or inside the PVs).

It also has the ability to create reversible loss of function allowing the prediction of the effectiveness and safety of a lesion. ${ }^{23,24}$ It does not require conscious sedation or anesthesia as it is painless. ${ }^{25}$ This not only means more comfort for the patients but also decreases the low but real complications of anesthesia.

Cryothermal ablation preserves the extracellular matrix and endothelial integrity. As a result, it had not been associated with pulmonary vein stenosis, esophageal perforation or thromboembolic events during the treatment of AF.26,27 Even though the rate of thromboembolic complications during RF ablation of AF is small, its consequences could be dreadful in a relatively young and healthy population.

\section{Focal approach versus large lesions in the treatment of $A F$}

All patients in whom we were able to identify which PVs was the trigger were cured. Our relatively healthy population (no or minimal structural heart disease, normal left atrial dimension, paroxysmal atrial fibrillation ...) could represent 
the early stages of AF. At this time, ablation of potential triggers instead of isolation of all PVs should be preferred.

A study by Nanthakumar et al showed that adolescents (without structural heart disease) referred for ablative therapy due to lone AF have an excellent outcome with the focal ablation of distinct foci (most located in the PVs). ${ }^{28}$ Due to their age, this population could really represent the first stages of AF and the success in their treatment corroborates our findings of a more localized approach in a healthier population.

Gerstenfeld et al have showed a good long term (18 months) outcome in patients younger than 50 years with PAF, undergoing targeted ablation of $\leq 2$ PVs with triggered atrial premature beats or AF. ${ }^{29}$ Also a recent report by Oral et a ${ }^{30}$ using a tailored approach to catheter ablation of AF, have reported an $80 \%$ success rate despite having $40 \%$ of patients with evidence of structural heart disease. Even though one could say that their study population had already passed the first stages of AF, their results again ratify the success of limited electrophysiological guided lesions in the percutaneous treatment of arrhythmias.

\section{Study Limitations}

Our daily TTMs recorded only fractions of the day and do not represent cardiac rhythm during a 24 hour period. Continuous rhythm monitoring would be preferable but it would be hard to justify implanting a device in this healthy population. After 180 days we returned to a symptom guided recording method which, despite being widely used, has some disadvantages (poor correlation between symptoms and arrhythmias was shown consistently in two studies). ${ }^{31,32}$

Despite being around for a long time in the surgical field, catheter based cryoablation is still a relatively new technology compared to RF. Also, efficiency is highly dependent on the duration of application and pressure against the myocardial tissues. ${ }^{33,34}$ This could lead to the concept of longer procedure times when comparing cryo to RF. But if we consider total time in the electrophysiology laboratory (including time devoted to anesthesia) cryothermy and RF procedures are not that different.

Also the identification of an arrhythmogenic PV was not very frequent. In our population it was identified in only 10 patients (14\%). Unfortunately, this represents the reality of most patients with PAF submitted to PVI. 29,30 


\section{Conclusions}

In patients with recent onset PAF and no (or minimal) structural heart disease, PV cryoisolation is effective in $82 \%$ of patients - $49 \%$ with complete success (no AF and no AADs) and an additional 33\% with improvement (22\% AF free on AADs and $11 \%$, still with sporadic bursts of AF, reporting $>50 \%$ improvement compared to pre ablation) - during long term follow-up (mean of $33 \pm 15$ months). When the arrhythmogenic PV is identified and isolated, the long-term outcome is excellent $(100 \%$ freedom from AF) indicating no need to isolate all PVs. PVI alone should be performed in patients early in the process of the disease. 
Figure 2. Kaplan-Meyer curve showing the outcomes of PV cryoisolation.

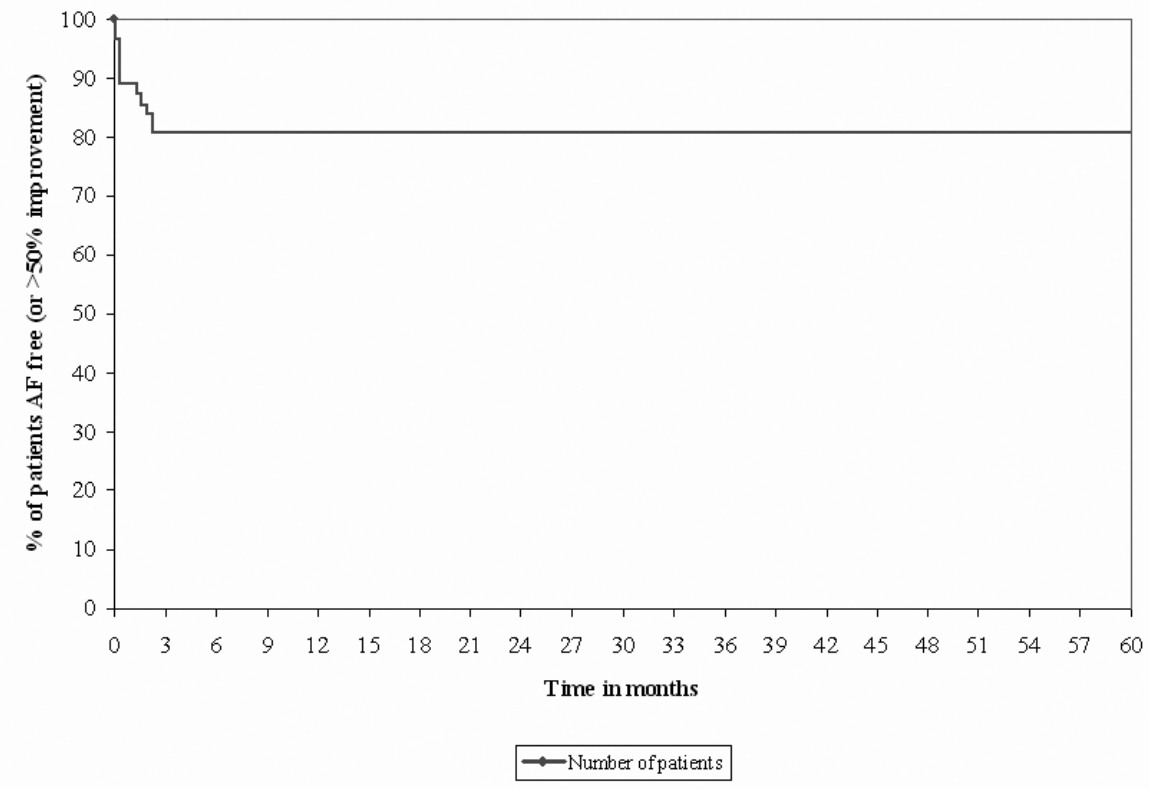

\begin{tabular}{|c|c|c|c|c|c|c|c|c|c|c|c|c|c|c|}
\hline $\begin{array}{l}\text { Follow-up } \\
\text { in months }\end{array}$ & 3 & 6 & 9 & $\begin{array}{l}12- \\
24\end{array}$ & 27 & $\begin{array}{l}30- \\
33\end{array}$ & 36 & 39 & 42 & $\begin{array}{c}45- \\
48\end{array}$ & 51 & 54 & 57 & 60 \\
\hline Events & 13 & 0 & 0 & 0 & 0 & 0 & 0 & 0 & 0 & 0 & 0 & 0 & 0 & 0 \\
\hline $\begin{array}{l}\text { Number of } \\
\text { patients at } \\
\text { risk }\end{array}$ & 70 & 57 & 57 & 57 & 45 & 33 & 21 & 15 & 14 & 10 & 9 & 8 & 7 & 7 \\
\hline
\end{tabular}

After a mean follow-up of $33 \pm 15$ months, PV cryoisolation was effective in $82 \%$ of patients. An event was considered a patient who, at any time, reported $<50 \%$ improvement.

The table shows the number of events compared to patients at risk over time. 


\section{References}

1. Blomstrom-Lundqvist C, Scheinman MM, Aliot EM, et al. ACC/AHA/ESC guidelines for the management of patients with supraventricular arrhythmias--executive summary: a report of the American College of Cardiology/American Heart Association Task Force on Practice Guidelines and the European Society of Cardiology Committee for Practice Guidelines (Writing Committee to Develop Guidelines for the Management of Patients With Supraventricular Arrhythmias). Circulation 2003; 108:1871-909.

2. Camm AJ, Obel OA. Epidemiology and mechanism of atrial fibrillation and atrial flutter. Am J Cardiol 1996; 78:3-11.

3. Haissaguerre M, Jais P, Shah DC, et al. Spontaneous initiation of atrial fibrillation by ectopic beats originating in the pulmonary veins. N Engl J Med 1998; 339:659-66.

4. Goette A, Honeycutt C, Langberg JJ. Electrical remodeling in atrial fibrillation. Time course and mechanisms. Circulation 1996; 94:2968-74.

5. Pappone C, Augello G, Santinelli V. Atrial fibrillation ablation. Ital Heart J 2005; 6:190-9.

6. Deisenhofer I, Estner H, Zrenner B, et al. Left atrial tachycardia after circumferential pulmonary vein ablation for atrial fibrillation: incidence, electrophysiological characteristics, and results of radiofrequency ablation. Europace 2006; 8:573-82.

7. Pappone C, Oral H, Santinelli V, et al. Atrio-Esophageal Fistula as a Complication of Percutaneous Transcatheter Ablation of Atrial Fibrillation. Circulation 2004; 109:2724-6.

8. Sacher F, Monahan KH, Thomas SP, et al. Phrenic Nerve Injury After Atrial Fibrillation Catheter Ablation: Characterization and Outcome in a Multicenter Study. J Am Coll Cardiol 2006; 47:2498-503.

9. Tse HF, Reek S, Timmermans C, et al. Pulmonary vein isolation using transvenous catheter cryoablation for treatment of atrial fibrillation without risk of pulmonary vein stenosis. J Am Coll Cardiol 2003; 42:752-8.

10. Cappato R, Calkins H, Chen SA, et al. Worldwide survey on the methods, efficacy, and safety of catheter ablation for human atrial fibrillation. Circulation 2005; 111:1100-5.

11. Tse HF, Lee KL, Lau CP. Adenosine triphosphate enhanced contrast pulmonary venogram to facilitate pulmonary vein ablation. J Cardiovasc Electrophysiol 2002; 13:300.

12. Rodriguez LM, Timmermans C. Transvenous cryoablation of cardiac arrhythmias. Technol Cancer Res Treat 2004; 3:515-24.

13. Calkins H, Brugada J, Packer DL, et al. HRS/EHRA/ECAS expert Consensus Statement on catheter and surgical ablation of atrial fibrillation: recommendations for personnel, policy, procedures and follow-up. A report of the Heart Rhythm Society (HRS) Task Force on catheter and surgical ablation of atrial fibrillation. Heart Rhythm 2007; 4:816-61.

14. Cheema A, Dong J, Dalal D, et al. Long-term safety and efficacy of circumferential ablation with pulmonary vein isolation. J Cardiovasc Electrophysiol 2006; 17:1080-5.

15. Domanski M, Waldo AL. Catheter ablation of atrial fibrillation: a treatment frontier. J Interv Card Electrophysiol 2006; 15:141-3.

16. Haissaguerre M, Hocini M, Sanders $\mathrm{P}$, et al. Catheter ablation of long-lasting persistent atrial fibrillation: clinical outcome and mechanisms of subsequent arrhythmias. J Cardiovasc Electrophysiol 2005; 16:1138-47.

17. Jais $\mathrm{P}$, Hocini M, Sanders $\mathrm{P}$, et al. Long-term evaluation of atrial fibrillation ablation guided by noninducibility. Heart Rhythm 2006; 3:140-5.

18. Pappone C, Santinelli V. Atrial fibrillation ablation: state of the art. Am J Cardiol 2005; 96:59L-64L.

19. Rostock T, Weiss C, Ventura R, Willems S. Pulmonary vein isolation during atrial fibrillation using a circumferential cryoablation catheter. Pacing Clin Electrophysiol 2004; 27:1024-5.

20. Siu CW, Tse HF, Lau CP. Avoidance of electromagnetic interference to implantable cardiovertor-defibrillator during atrioventricular node ablation for atrial fibrillation using transvenous cryoablation. Pacing Clin Electrophysiol 2006; 29:914-6. 
21. Skanes AC, Klein G, Krahn A, Yee R. Cryoablation: potentials and pitfalls. J Cardiovasc Electrophysiol 2004; 15:S28-S34.

22. Tuzcu V, Gonzalez MB, Schranz D. Cryoablation: better catheter stability compared to RF ablation. Anadolu Kardiyol Derg 2006; 6:182-4.

23. Skanes AC, Dubuc M, Klein GJ, et al. Cryothermal ablation of the slow pathway for the elimination of atrioventricular nodal reentrant tachycardia. Circulation 2000; 102:2856-60.

24. Skanes AC, Jones DL, Teefy P, et al. Safety and feasibility of cryothermal ablation within the mid- and distal coronary sinus. J Cardiovasc Electrophysiol 2004; 15:1319-23.

25. Timmermans C, Ayers GM, Crijns HJ, Rodriguez LM. Randomized study comparing radiofrequency ablation with cryoablation for the treatment of atrial flutter with emphasis on pain perception. Circulation 2003; 107:1250-2.

26. Khairy P, Chauvet $\mathrm{P}$, Lehmann J, et al. Lower incidence of thrombus formation with cryoenergy versus radiofrequency catheter ablation. Circulation 2003; 107:2045-50.

27. Tse HF, Kwong YL, Lau CP. Transvenous cryoablation reduces platelet activation during pulmonary vein ablation compared with radiofrequency energy in patients with atrial fibrillation. J Cardiovasc Electrophysiol 2005; 16:1064-70.

28. Nanthakumar K, Lau YR, Plumb VJ, Epstein AE, Kay GN. Electrophysiological Findings in Adolescents With Atrial Fibrillation Who Have Structurally Normal Hearts. Circulation 2004; 110:117-23.

29. Gerstenfeld EP, Sauer W, Callans DJ, et al. Predictors of success after selective pulmonary vein isolation of arrhythmogenic pulmonary veins for treatment of atrial fibrillation. Heart Rhythm 2006; 3:165-70.

30. Oral H, Chugh A, Good E, et al. A Tailored Approach to Catheter Ablation of Paroxysmal Atrial Fibrillation. Circulation 2006; 113:1824-31.

31. Hindricks G, Piorkowski C, Tanner H, et al. Perception of atrial fibrillation before and after radiofrequency catheter ablation: relevance of asymptomatic arrhythmia recurrence. Circulation 2005; 112:307-13.

32. Neumann T, Erdogan A, Dill T, et al. Asymptomatic recurrences of atrial fibrillation after pulmonary vein isolation. Europace 2006; 8:495-8.

33. Lustgarten DL, Keane D, Ruskin J. Cryothermal ablation: mechanism of tissue injury and current experience in the treatment of tachyarrhythmias. Prog Cardiovasc Dis 1999; 41:48198.

34. Tse HF, Lau CP. Impact of duration of cryothermal application on clinical efficacy of pulmonary vein isolation using transvenous cryoablation. Pacing Clin Electrophysiol 2005; 28:839-43. 


\section{CHAPTER IV}

\section{Recurrence Patterns of Atrial Fibrillation after Pulmonary Vein Cryoisolation}

Wendel Moreira, MD, Carl Timmermans, MD, PhD, Hein J. J. Wellens, MD, PhD*, David Perez, MD, Yuka Mizusawa, MD, Suzanne Philippens, RN and Luz-Maria Rodriguez, MD, PhD

From the Department of Cardiology, Academic Hospital Maastricht and *Cardiovascular Research Institute Maastricht (CARIM), Maastricht, the Netherlands

Abstract presented at the World Congress of Cardiology, Barcelona, Spain, September 2006.

(Eur Heart J 2006, 27(1): 39, 466).

Manuscript submitted for publication. 


\section{Abstract}

Background: Early recurrence of paroxysmal atrial fibrillation (PAF) post PVI is a recognized phenomenon. It can lead to concerns by patients regarding the success of their procedure and may also result in unnecessary interventions.

Objective: To evaluated the clinical characteristics and patterns of AF recurrence up to one year following PVI (pulmonary vein isolation).

Methods: Patients with PAF selected to undergo PV Cryoisolation were recruited from 2001 to 2005. Daily recordings with transtelephonic telemetry were obtained 30 days prior and up to 180 days after the procedure. After this period, Holter monitoring was used in each clinic visit or if symptoms developed.

Results: 60 patients ( 45 men; mean age 53 (21 to 68) years) were enrolled. We found 3 different patterns of recurrences after PVI: Group A - 26 patients with no further evidence of AF. Group B - 20 patients with a significant decrease of AF episodes. Group C - 14 patients with an increase in AF episodes compared to pre ablation telemetry. History of prior atrial flutter ablation was more common in Group $C$ patients ( $A=30 \%, B=20 \%, C=63 \%, p<0.05)$.

Conclusion: In the early months and up to one year following PV cryoisolation, three different patterns of $\mathrm{AF}$ recurrence can be found: A) no further episodes, B) decreased number of episodes (this decline starts 3 months after PVI and levels at 9 months) or C) immediate increase in the number of events (that declines throughout one year). History of prior atrial flutter ablation is more common in group C. 


\section{Introduction}

Immediate recurrence of atrial fibrillation (AF) after percutaneous ablative therapy has been described and its significance is a matter of debate., ${ }^{1,2}$ It commonly leads to concerns by patients regarding the success of their procedure and may also result in unnecessary interventions. Antiarrhythmic drugs (AAD) and anticoagulation are prescribed for those individuals found to have recurrences. ${ }^{2}$

But, since symptomatology is known to decrease regardless of the rhythm after ablation, looking for recurrences only based on patients' complaints can severely underestimate the real prevalence of this entity. ${ }^{3-8}$

In the literature currently available regarding the patterns of AF recurrence, we have studies using a symptom guided approach along with clinic visits (from every month to every three months). ${ }^{1,2,9}$ To really determine the prevalence of this condition an objective monitoring technique should be used., 4,5

The aim of this study was to evaluate the patterns of AF 30 days before and 180 days post pulmonary veins isolation (PVI) using daily transtelephonic telemetry (TTM). Thereafter, Holter monitoring during clinic visit (or when symptoms occurred) were used until one year (late follow up). We also evaluated the individual patient profiles according to the outcome.

\section{Methods}

Sixty patients with drug refractory, symptomatic paroxysmal atrial fibrillation (PAF) and deemed candidates for PVI (using cryothermy) were enrolled prospectively from January 2001 to January 2005. Their baseline clinical (including the low prevalence of structural heart disease (SHD), diabetes mellitus and arterial hypertension) and echocardiographic characteristics were similar and not statistically significant. A summary of those is shown in Table 1.

All subjects were given a transtelephonic event recorder and instructed to use them daily (preferably at the same time) and when they had symptoms. This monitoring started 30 days before and continued up to day 180 after PVI. From then on, a Holter monitor was used during clinic visits $(1,3,6,9$ and 12 months) or when patients had symptoms.

All the patients in the study signed a written consent form that was approved by the local ethics committee.

Before PVI, all individuals were orally anticoagulated to a therapeutic international normalized ratio of 2 to 3 for at least three weeks and up to three months after ablation.

Transesophageal echocardiogram (TEE) was performed during the procedure to exclude left atrial (LA) thrombus and to aid in the transseptal puncture. AAD were not discontinued before PVI. 
Table 1. Characteristics of the 60 patients divided into the 3 groups according to atrial fibrillation recurrences.

\begin{tabular}{lcccc}
\hline & $\begin{array}{c}\text { Group A } \\
(26 \text { patients })\end{array}$ & $\begin{array}{c}\text { Group B } \\
(20 \text { patients })\end{array}$ & $\begin{array}{c}\text { Group C } \\
(14 \text { patients })\end{array}$ & p value \\
\hline Age $(y)$ & 51 & 47 & 46 & 0.30 \\
LVSEDD & 0.84 & 0.88 & 0.88 & 0.46 \\
LVPWEDD & 0.85 & 0.89 & 0.87 & 0.59 \\
LA & 3.92 & 4.24 & 4.10 & 0.20 \\
EF $(\%)$ & 63.2 & 56.5 & 59.6 & 0.052 \\
Mean pvs treated $*$ & 2.8 & 2.4 & 2.8 & 0.50 \\
\hline
\end{tabular}

*Mean number of pulmonary veins treated in each patient

\section{Electrophysiologic Study and Ablation}

All patients were studied in the fasting state without sedation, except if external cardioversion was needed (when small doses of midazolam were used). Internal cardioversions were done without sedation. Those patients presenting in AF while in the catheterization room were converted to sinus rhythm by internal or external cardioversion.

During the procedure (but after the transseptal punctures) intravenous heparin was given as a $100-\mathrm{IU} / \mathrm{kg}$ bolus dose followed by boluses of $5000 \mathrm{IU}$ every 1.5 hour if needed to keep an ACT $\geq$ than 300 seconds.

Under local anesthesia, a decapolar catheter was positioned in the distal coronary sinus and a quadripolar catheter in the His bundle region, via the femoral route. Double transseptal catheterization was performed under fluoroscopic and TEE guidance.

LA angiography was performed after adenosine administration. ${ }^{10} \mathrm{~A}$ deflectable, circumferential decapolar mapping catheter LASSO $^{\text {TM }}$, Biosense-Webster Inc., Baldwin Park, California) was advanced into the LA and positioned at the ostium of each pulmonary vein (PV). A deflectable, 10F (6.5 mm tip) cryoablation catheter (CryoCor Inc., San Diego, California) was inserted into the LA through a 12F, 65-cm-long sheath (DAIG, St. Jude Medical Inc., St. Paul, Minnesota, or Cook Inc., Bloomington, Indiana).

The 12 lead ECG and intracardiac electrograms were recorded and stored by BARD Labsystem PRO.

Segmental isolation of PVs, as guided by the recording of their potentials with the LASSO ${ }^{\mathrm{TM}}$ catheter, was performed using the CryoCor ${ }^{\mathrm{TM}}$ cryoablation system as described previously. ${ }^{11,12}$ All PVs with potentials recorded at their ostium were targeted for isolation. PVI was performed during sinus rhythm or coronary sinus pacing by delivering cryoablation at ostial sites that had the earliest bipolar potential. 
At each effective target site, defined by the abolishment of a PV potential or a change in the PV potential activation sequence during cryothermal application, 3 min of cryoablation was delivered. If no changes in the electrogram were observed after $20 \mathrm{~s}$, despite a catheter tip temperature of $-90^{\circ} \mathrm{C}$, the application was stopped and the catheter was repositioned. The early procedural end point was complete electrical isolation of PVs based on abolition of all ostial PV potentials or complete entrance conduction block into the PV.

If a patient had prior cavotricuspid isthmus ablation of atrial flutter, a duodecapolar catheter was placed in the right atrium before the end of the study and the conduction through the before mentioned isthmus was evaluated.

\section{Post Ablation Management}

Everyone was monitored in hospital for $24 \mathrm{~h}$ and oral anticoagulation was started the same day of ablation. The same AAD were continued for at least 3 months after the procedure. After three months, anticoagulation was stopped (having in mind that the majority of patients did not meet criteria for chronic anticoagulation in $\mathrm{AF}$ ) and $\mathrm{AAD}$ were continued depending on the pattern and frequency of AF recurrences.

All patients had a Holter recording at discharge and during each clinic visit (1 month, 3, 6, 9, 12 months) or earlier if they had symptoms. They were also instructed to keep a diary of events associated with their transtelephonic monitors. A visual analog scale ranging from zero (indicating no improvement at all) to 100 (asymptomatic and AF free after PVI) was used during the clinic visits.

\section{Statistical analysis}

Continuous variables are presented as mean $\pm \mathrm{SD}$, where appropriate. In cases of a nongaussian distribution, medians and quartiles are given. Categorical variables are expressed as numbers and percentages of patients.

For comparison of the characteristics within the 3 different $\mathrm{AF}$ recurrence groups, continuous data such as age and AF burden registered on each TTM were tested for any statistically significant difference with a 2-way ANOVA for normally distributed data and the Kruskal-Wallis test for data in a nongaussian distribution. Differences in categorical data, such as sex, presence of structural heart disease, previous atrial flutter ablation, and use of antiarrhythmic drugs were tested for statistical significance among each of the 3 recurrences groups with the $\mathrm{x} 2$ test with Yates' correction (or Fisher's exact test).

Statistical significance was established at $\mathrm{p}<0.05$. 


\section{Results}

All patients were referred for PVI with a history of PAF refractory to medical therapy. The great majority of them $(90 \%)$ had no SHD. Mild arterial hypertension was present in 3 patients (one from each group), 2 had coronary artery disease (both in group B) and 1 tachycardia induced cardiomyopathy (group A). The mean age was 53 years (ranging from 21 to 68 years). There were 45 men and 15 women.

The behavior of AF after the procedure was analyzed for each patient. They were then divided in 3 groups according to AF recurrence post ablation (Figure 1):

Group A consisted of patients with no further evidence of AF after the procedure.

Group B consisted of patients that had a significant decrease in the number of AF episodes but still had them.

Group $C$ consisted of patients that had an increase in the number of AF episodes after PVI.

AF burden was considered as the percentage of patients with the arrhythmia on a given day. Group A had an average of $35.76 \%$ of its patients showing AF every day before ablation; post ablation no further arrhythmias were observed. Group B had more than half of its patients (53.08\%) with daily episodes of documented AF prior to ablation; after PVI 37.30\% of the patients had recurrences of AF. Group $\mathrm{C}$ had an increase in the number of patients found to be in AF comparing pre and post PVI (from $37.26 \%$ up to $58.62 \%$ ) (Table 2).

Table 2. AF burden: percentage of patients in AF on a given day.

\begin{tabular}{cccc}
\hline & Pre PVI & Post PVI (12 months) & P value \\
\hline Group A & $35.76 \%$ & 0 & $<0.05$ \\
Group B & $53.08 \%$ & $37.30 \%$ & $<0.05$ \\
Group C & $37.26 \%$ & $58.62 \%$ & $<0.05$ \\
\hline
\end{tabular}

All patients were on at least one AAD prior to ablation. The percentage of patients taking more than one AAD prior to PVI was as follows: Group $\mathrm{A}=$ 13\%; Group $B=40 \%$; Group $C=73 \%$. Amiodarone was given to 13 pts $(1$ in Group A, 4 in Group B and 8 in Group C). One year post ablation, $66 \%$ of patients (40 pts) were off any AAD (Group A - no patients taking any AAD; Group B - 12 patients off any AAD, 8 taking only one type of AAD; Group C had 2 patients off AAD, 8 taking one AAD and 4 still taking 2 AAD). Six patients were still on amiodarone, all in group C. All treated veins were successfully isolated. The ones not treated did not show potentials. No procedure related complications were noted.

We considered any episode greater than 30 seconds of AF seen in the tran- 
stelephonic telemetries as an AF day. ${ }^{13}$

Prior history of atrial flutter ablation was much more common in the patients who had an increase in AF burden post procedure (Group C) (Table 3). Those patients also had a worse outcome after one year with the lowest percentage of freedom from AF. Bidirectional cavotricuspid isthmus block was present in all subjects (with a history of prior atrial flutter ablation). This was confirmed at the end of the electrophysiological study when PVI was performed.

Table 3. Prior history of atrial flutter ablation (all successfully treated before the study by cavotricuspid isthmus ablation).

\begin{tabular}{ccccc}
\hline & $\begin{array}{c}\text { Group A } \\
(26 \mathrm{pts})\end{array}$ & $\begin{array}{c}\text { Group B } \\
(20 \mathrm{pts})\end{array}$ & $\begin{array}{c}\text { Group C } \\
(14 \mathrm{pts})\end{array}$ & P value \\
\hline $\begin{array}{c}\text { Prior History of } \\
\text { AFL }\end{array}$ & $30 \%$ & $20 \%$ & $63 \%$ & $<0.05$ \\
\hline
\end{tabular}

Group A had no further arrhythmias after ablation. Group B had a slight increase after ablation that after 30 days showed a steady decline. After 9 months the prevalence of $\mathrm{AF}$ was stable with a final rate of freedom from arrhythmia of $92 \%$. Group $\mathrm{C}$ had a significant increase in AF burden compared to before ablation. It returned to baseline level at 6 months and decreased until 270 days when the final success rate of $86 \%$ was maintained.

\section{Discussion}

\section{Main Finding}

To our knowledge, this is the first study showing three distinctive patterns of AF recurrences after PVI: a group of patients with no AF starting immediately after the procedure; a group with a decreasing number in AF episodes and a third group showing an increase in frequency of AF after PVI.

This behavior of those 3 groups was seen in the first year after the procedure. Furthermore, we found that a prior history of atrial flutter ablation was associated not only with an augmentation of $\mathrm{AF}$ episodes immediately after PVI but also during subsequent follow-up. 


\section{Patterns of atrial fibrillation recurrences}

Recurrence of atrial fibrillation after PVI have been described earlier but the specifics of this condition remain unanswered. ${ }^{14}$ It can be severely underestimated if subjective criteria for detection of arrhythmias (like patient's self reported symptoms) are the only factors triggering further evaluation by the clinician. In a prospective study with 114 patients with $\mathrm{AF}$ undergone left atrial modification using CARTO ${ }^{\mathrm{TM}}$, Hindricks and colleagues - using a continuous 7 day ECG pre and post ablation, and repeated at 3,6 and 12 months follow up showed that despite having an actual increase in the burden of AF (asymptomatic episodes of AF increased from $5 \%$ to $54 \%$ ), patients had less symptoms. ${ }^{8}$ They also concluded that a symptom-only-based follow-up could substantially overestimate the success rate of ablative procedures for $\mathrm{AF}$ and suggested that objective measures should be used to identify asymptomatic AF recurrences after ablation.

This fact was underlined by Strickberger when evaluating the incidence of supraventricular arrhythmias in patients with a history of AF and who had a pacemaker implanted. ${ }^{15}$ They concluded that $90 \%$ of atrial tachyarrhythmias were clinically silent.

Therefore, when trying to describe the arrhythmogenic behavior after percutaneous AF treatments, objective assessment should be used whenever possible in order to better estimate the true incidence of recurrences. Using daily TTMs, we were able to document only a fraction of the day. At the present time no other description of AF recurrences using methods with continuous rhythm recording is available.

Atrial fibrillation has triggers and requires a substrate. Electrical remodeling appears to occur before mechanical remodeling. ${ }^{16-18}$ Even though the great majority $(90 \%)$ of our population had no AHD (and the other 10\% had only minimal heart disease), some individuals might already have sufficient electrical changes to maintain the arrhythmia. This could be a sign that, in group $\mathrm{C}$ patients (which also more frequently had a history of common type atrial flutter) the electrical remodeling necessary for maintenance of $\mathrm{AF}$ was already present.

The interrelation of AF and AFL is known and differences of conduction velocities in the region of the crista terminalis (altered electrical conduction) are necessary for AFL to sustain. ${ }^{19}$ Waldo also suggests that, in the majority of times, the occurrence of common type AFL is related to AF creating a functional line of block necessary for the macroreentry to sustain. ${ }^{19}$ This close association usually is more evident in the latter stages of AF where the importance of substrate overcomes the triggers for the perpetuation of AF. Therefore one could speculate that cryolesions around the PVs could actually increase the excitability of an electrically inhomogeneous tissue in patients with AFL/AF. Both Group B and C had an immediate increase in AF burden after the proce- 
dure. Furthermore, the state of balance between the triggers and substrate in those patients will dictate how long it will take so for the benefits from the PVI (which provides only trigger elimination and not substrate modification) be apparent.

Recurrences of AF in group B patients returned to baseline on an average of 30 days and in the group C patients 180 days post PVI with the downward trend in recurrences reaching a plateau at 9 months. The longer time it took for our group $\mathrm{C}$ patients to reach a steady level could be a reflection of the greater role their altered substrate was playing in the etiology of their lone AF. Therefore, after eliminating the triggers, more time was needed to reverse the previously advanced electrical remodeling. Maybe in these patients the search and modification of a substrate would be the most appropriate approach.

These findings could help the electrophysiologist to plan the post operative care of patients with lone AF submitted to PVI, potentially avoiding premature unnecessary interventions. It also can contribute in the elucidation of questions regarding anticoagulation management in those individuals.

\section{Antiarrbythmic drugs post ablation}

Antiarrhythmic drugs (AADs) were continued during the first 3 months in all subjects. Thereafter, they were continued according to symptoms in patients from group B and C. At the end of our follow up (one year) the percentage of individuals free of any AAD were as follows: nobody in group A were on antiarrhythmic medication; $60 \%$ in group B (the majority of the $40 \%$ remained taking only one $\mathrm{AAD}$ ) and $15 \%$ in group $\mathrm{C}$. In the latter group, of those requiring pharmacological therapy, $67 \%$ were taking only one AAD while $33 \%$ needed two different antiarrhythmics. Based on those findings we can give our patients an estimate on the chances of being free of any medication according to their recurrence behavior.

\section{Study Limitations}

Due to the logistics of the Maastricht area we were able to follow every patient on an individual basis and achieve a greater than $90 \%$ compliance rate with daily TTMs at the end of 180 days. But our daily TTMs recorded only a fraction of the day and do not represent the rhythm during a 24 hour period. Continuous rhythm monitoring would be preferable but it would be hard to justify implanting a device to do so in this healthy population. Furthermore, after 180 days we returned to a symptom guided recording method which, despite being widely used, has the disadvantages previously mentioned.

Also we do not have direct evidence of the remodeling process we proposed in the discussion since no follow-up electrophysiological or morphological (e.g: 
MRI) studies were done. But our findings are encouraging for future research planned to better elucidate this issue.

\section{Conclusion}

Our findings suggest that when evaluating the pattern of AF recurrences in the early months up to one year following PV cryoisolation for patients with lone AF, three different groups of patients can be identified: A) Those without recurrences, B) those with a decreased number of episodes (this decline starts 30 days after PVI and levels at 9 months) or C) those with an immediate increase in AF burden that returns to baseline at 6 months and plateaus at 9 months.

A history of atrial flutter was more common in the lone AF group having an increased AF burden after PVI, suggesting the presence of an electrical substrate for atrial arrhythmias despite their normal LA morphology. 


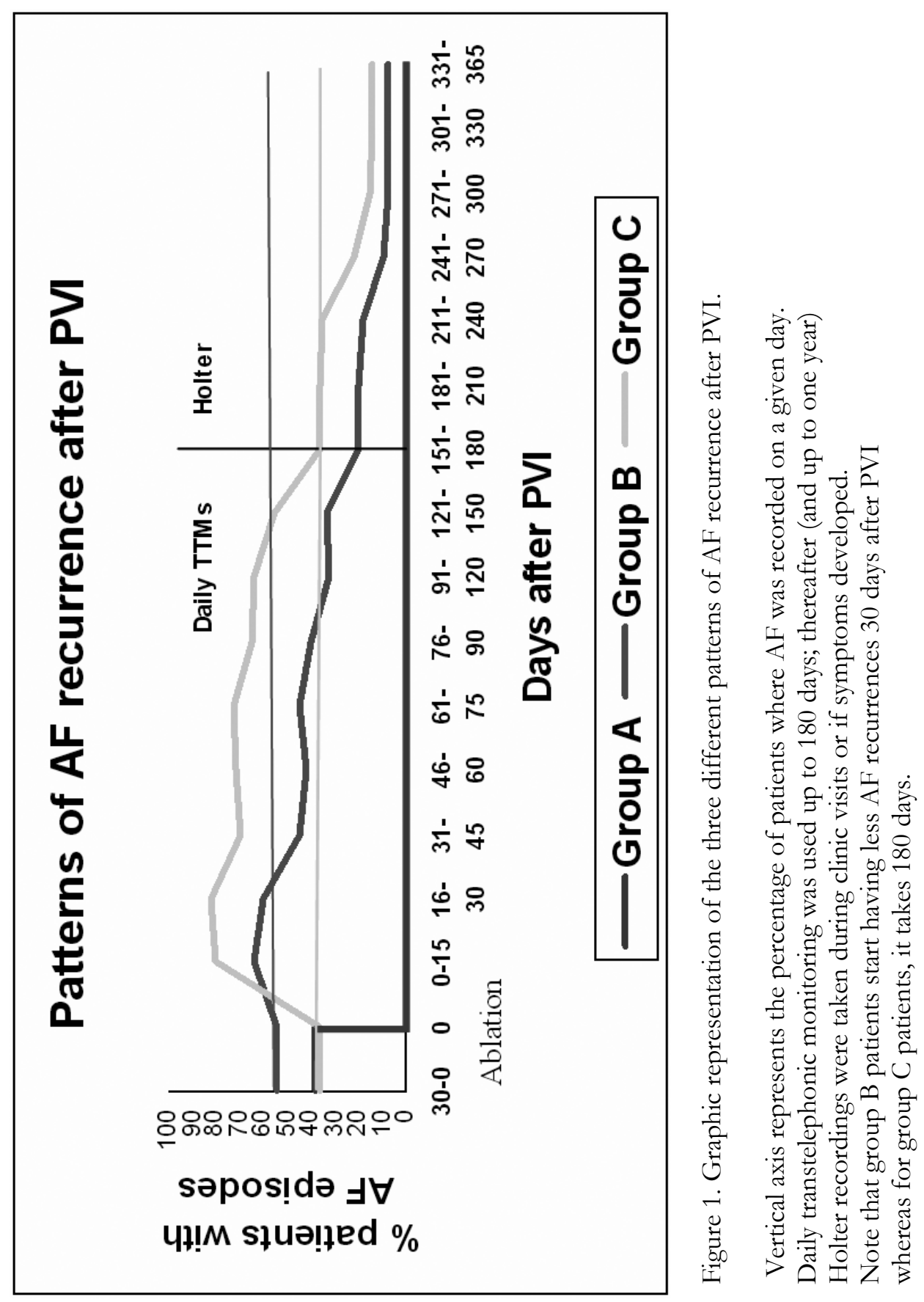




\section{References}

1. Kobza R, Hindricks G, Tanner H, Schirdewahn P, Dorszewski A, Piorkowski C, Gerds-Li $\mathrm{JH}$, Kottkamp H. Late recurrent arrhythmias after ablation of atrial fibrillation: incidence, mechanisms, and treatment. Heart Rhythm 2004;1:676-683.

2. Oral H, Knight BP, Ozaydin M, Tada H, Chugh A, Hassan S, Scharf C, Lai SW, Greenstein R, Pelosi F, Jr., Strickberger SA, Morady F. Clinical significance of early recurrences of atrial fibrillation after pulmonary vein isolation. J Am Coll Cardiol 2002;40:100-104.

3. Klemm HU, Ventura R, Rostock T, Brandstrup B, Risius T, Meinertz T, Willems S. Correlation of symptoms to ECG diagnosis following atrial fibrillation ablation. J Cardiovasc Electrophysiol 2006;17:146-150.

4. Lloyd MS, Langberg JJ. Recurrences of atrial fibrillation after ablation: when will this hydra meet its Hercules? J Cardiovasc Electrophysiol 2006;17:236-237.

5. Neumann T, Erdogan A, Dill T, Greiss H, Berkowitsch A, Sperzel J, Kuniss M, Kurzidim K, Hamm CW, Pitschner HF. Asymptomatic recurrences of atrial fibrillation after pulmonary vein isolation. Europace 2006;8:495-498.

6. Vasamreddy CR, Dalal D, Dong J, Cheng A, Spragg D, Lamiy SZ, Meininger G, Henrikson CA, Marine JE, Berger R, Calkins H. Symptomatic and asymptomatic atrial fibrillation in patients undergoing radiofrequency catheter ablation. J Cardiovasc Electrophysiol 2006;17:134-139.

7. Senatore G, Stabile G, Bertaglia E, Donnici G, De SA, Zoppo F, Turco P, Pascotto P, Fazzari M. Role of transtelephonic electrocardiographic monitoring in detecting short-term arrhythmia recurrences after radiofrequency ablation in patients with atrial fibrillation. J Am Coll Cardiol 2005;45:873-876.

8. Hindricks G, Piorkowski C, Tanner H, Kobza R, Gerds-Li JH, Carbucicchio C, Kottkamp $\mathrm{H}$. Perception of atrial fibrillation before and after radiofrequency catheter ablation: relevance of asymptomatic arrhythmia recurrence. Circulation 2005;112:307-313.

9. Husser D, Bollmann A, Kang S, Stridh M, Sornmo L, Olsson SB, Bhandari AK, Cannom DS. Determinants and prognostic significance of immediate atrial fibrillation recurrence following cardioversion in patients undergoing pulmonary vein isolation. Pacing Clin Electrophysiol 2005;28:119-125.

10. Tse HF, Lee KL, Lau CP. Adenosine triphosphate enhanced contrast pulmonary venogram to facilitate pulmonary vein ablation. J Cardiovasc Electrophysiol 2002;13:300.

11. Rodriguez LM, Geller JC, Tse HF, Timmermans C, Reek S, Lee KL, Ayers GM, Lau CP, Klein HU, Crijns HJ. Acute results of transvenous cryoablation of supraventricular tachycardia (atrial fibrillation, atrial flutter, Wolff-Parkinson-White syndrome, atrioventricular nodal reentry tachycardia). J Cardiovasc Electrophysiol 2002;13:1082-1089.

12. Rodriguez LM, Timmermans C. Transvenous cryoablation of cardiac arrhythmias. Technol Cancer Res Treat 2004;3:515-524.

13. Verma A, Minor S, Kilicaslan F, Patel D, Hao S, Beheiry S, Lakkireddy D, Elayi SC, Cummings J, Martin DO, Burkhardt JD, Schweikert RA, Saliba W, Tchou PJ, Natale A. Incidence of atrial arrhythmias detected by permanent pacemakers (PPM) post-pulmonary vein antrum isolation (PVAI) for atrial fibrillation (AF): correlation with symptomatic recurrence. J Cardiovasc Electrophysiol 2007;18:601-606.

14. Lee SH, Tai CT, Hsieh MH, Tsai CF, Lin YK, Tsao HM, Yu WC, Huang JL, Ueng KC, Cheng JJ, Ding YA, Chen SA. Predictors of early and late recurrence of atrial fibrillation after catheter ablation of paroxysmal atrial fibrillation. J Interv Card Electrophysiol 2004;10:221-226.

15. Strickberger SA, Ip J, Saksena S, Curry K, Bahnson TD, Ziegler PD. Relationship between atrial tachyarrhythmias and symptoms. Heart Rhythm 2005;2:125-131.

16. Goette A, Honeycutt C, Langberg JJ. Electrical remodeling in atrial fibrillation. Time course and mechanisms. Circulation 1996;94:2968-2974. 
17. Kinebuchi $\mathrm{O}$, Mitamura H, Shiroshita-Takeshita A, Kurita $\mathrm{Y}$, Ieda M, Ohashi N, Fukuda $\mathrm{Y}$, Sato T, Miyoshi S, Hara M, Takatsuki S, Nagumo M, Ogawa S. Oral verapamil attenuates the progression of pacing-induced electrical and mechanical remodeling of the atrium. Circ J 2004;68:494-500.

18. Kinebuchi O, Mitamura H, Shiroshita-Takeshita A, Kurita Y, Ohashi N, Tanimoto K, Fukuda Y, Ieda M, Sato T, Hara M, Takatsuki S, Ogawa S. Temporal patterns of progression and regression of electrical and mechanical remodeling of the atrium. Int J Cardiol 2005;98:91-98.

19. Waldo AL. The interrelationship between atrial fibrillation and atrial flutter. Prog Cardiovasc Dis 2005;48:41-56. 



\section{CHAPTER V}

Can Common Type Atrial Flutter be a Sign of an Arrhythmogenic Substrate in Paroxysmal Atrial Fibrillation?

Clinical and Ablative Consequences in Patients with Coexistent PAF/AFL

Wendel Moreira, MD, Carl Timmermans, MD, PhD,

Hein J. J. Wellens, MD, PhD*,

David Perez, MD, Yuka Mizusawa, MD,

Suzanne Philippens, RN and Luz-Maria Rodriguez, MD, PhD

From the Department of Cardiology, Academic Hospital Maastricht and *Cardiovascular Research Institute Maastricht (CARIM),

Maastricht, the Netherlands

Manuscript accepted for publication in

Circulation 


\section{Abstract}

Background: The coexistence of atrial fibrillation (AF) and atrial flutter (AFL) is well recognized. AF precedes the onset of AFL in almost all instances. We evaluated the effect of two ablation strategies in patients with paroxysmal AF (PAF) and AFL.

Methods and Results: Ninety eight patients with PAF/AFL were prospectively recruited to undergo pulmonary vein cryoisolation (PVI). Those with at least one episode of sustained common type AFL were assigned to cavotricuspid isthmus (CTI) cryoablation followed by a 6 weeks monitoring period and a subsequent PVI (CTI/PVI, n=36) - Group I. Patients with PAF only underwent PVI (PVI, $\mathrm{n}=62)$ - Group II. There were 76 men, mean age of $50 \pm 10$ years. Most patients $76(78 \%)$ had no structural heart disease. When comparing the two groups, residual AF after a blanking period of 3 months post PVI occurred in $24(67 \%)$ patients in group I vs $7(11 \%)$ patients in Group II (p $<0.05)$.

Conclusions: In patients with PAF and no documented common type AFL, PVI alone prevents the occurrence of $\mathrm{AF}$ in $82 \%$ whereas in patients with AFL/PAF, CTI cryoablation and PVI successfully treated sustained common type AFL but seemed insufficient to prevent recurrences of AF. In this population, AFL can be a sign that non PV triggers are the culprit of AF and/or enough electrical remodeling already has occurred in both atria and thus a strategy which includes substrate modification may be required. 


\section{Background}

It is known that, for the macroreentry circuit of the common type atrial flutter (AFL) to occur, a line of block between the venae cavae needs to be present along with other fixed anatomic lateral boundaries - the crista terminalis and the tricuspid annulus. ${ }^{1-3}$

The former is almost always functional, and usually develops during an initial period of transient atrial fibrillation (AF $)^{4}$ (Figure 1). Actually, Waldo suggests that, in most instances, without preceding AF, there will be no classic AFL. ${ }^{5}$

Percutaneous ablative techniques for the treatment of AF can be performed with high success rates. ${ }^{6-10}$ Because of the likely role of AF as initiator of AFL, we were interested in the best ablation approach for patients with paroxysmal atrial fibrillation (PAF) and AFL. Two cryoablation protocols in patients with $\mathrm{PAF} / \mathrm{AFL}$, in regard to the outcome of those arrhythmias, were prospectively evaluated.

\section{Methods}

Ninety eight patients with drug refractory, symptomatic PAF (and deemed candidates for pulmonary vein cryoisolation (PVI)) were enrolled prospectively from July 2001 to July 2006.

All subjects were given a transtelephonic monitoring (TTM) device and instructed to use it daily (preferably at the same time) and when they had symptoms. This monitoring started 30 days before and continued up to day 180 after PVI. From then on, a Holter monitor was used during clinic visits $(1,3,6,9$ and 12 months) or when patients had symptoms.

Based on the data provided by the clinical history, cardiac status, Holter and TTM's, patients were assigned to two ablation strategies. If at least one episode of sustained common type AFL was documented, patients underwent cavotricuspid isthmus (CTI) cryoablation, followed by PVI after a 6 weeks monitoring period (Group I - PAF/AFL). This group consisted of 36 patients. In patients in whom just PAF was documented (no history of sustained common type AFL), only PVI was performed (Group II). This group included 62 patients.

A consent form, approved by the local ethics committee was signed by all participants of the study.

Before PVI, all individuals were orally anticoagulated to a therapeutic international normalized ratio of 2 to 3 for at least three weeks and up to three months after ablation. A transesophageal echocardiogram was performed during the procedure to exclude left atrial thrombus and to aid in the transeptal puncture. Antiarrhythmic drugs (AAD) were not discontinued before PVI. 


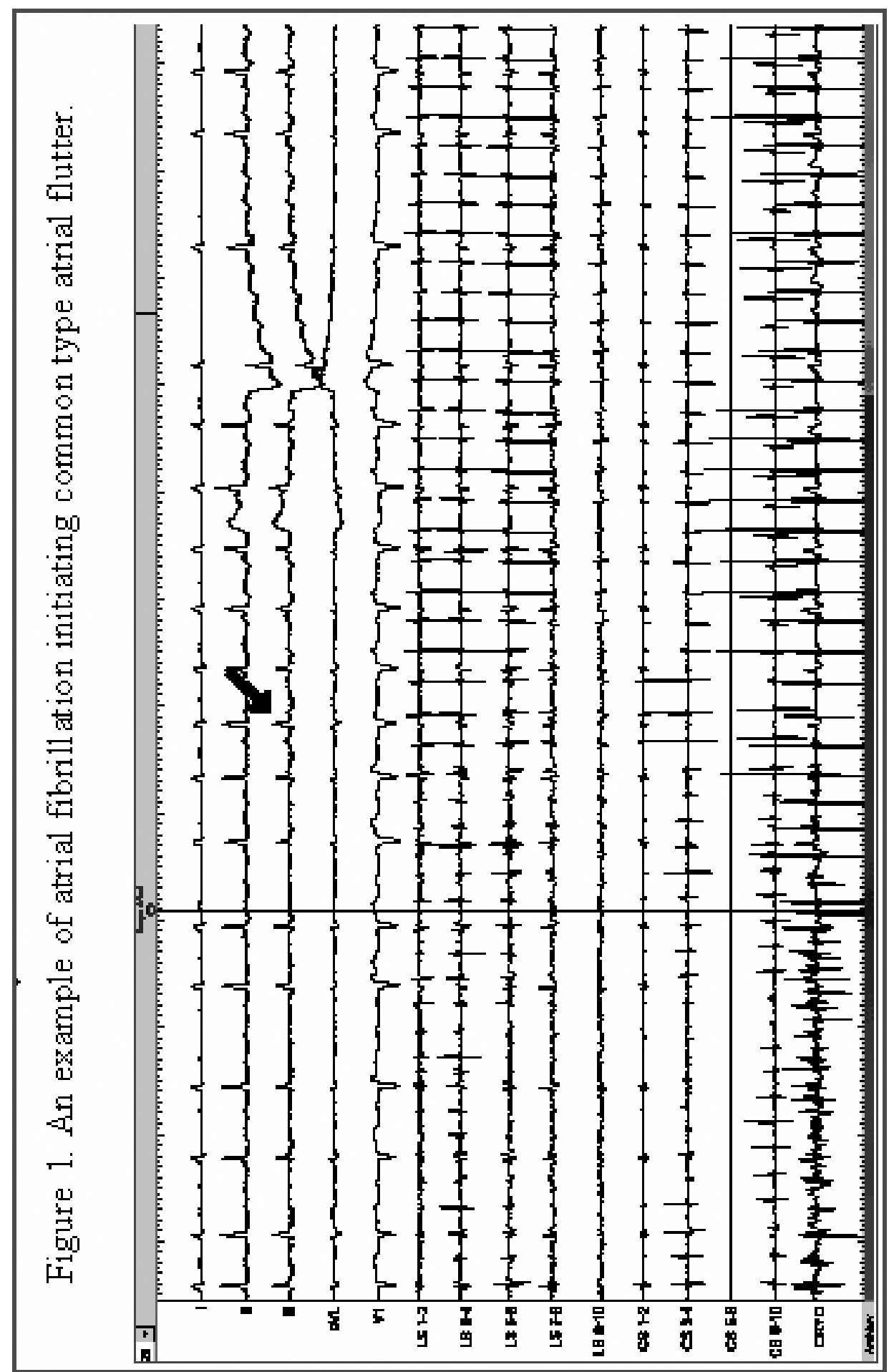




\section{Electrophysiologic Study and Ablation}

All patients were studied in the fasting state without sedation. Those presenting in AF while in the catheterization room were converted to sinus rhythm by internal or external cardioversion.

Group I underwent CTI cryoablation first. The following protocol was used: intravenous heparin was given as a $100-\mathrm{IU} / \mathrm{kg}$ bolus dose after the venous sheaths were inserted; via the femoral route a decapolar catheter was positioned in the distal coronary sinus (for evaluation of left atrial activation), a duodecapolar catheter (2-mm interelectrode spacing, Halo catheter, Biosense Webster) for mapping the right atrial lateral wall and a quadripolar catheter in the His bundle region. An additional deflectable, $10.5 \mathrm{~F}$ (with a $6.5 \mathrm{~mm}$ tip electrode) cryoablation catheter (CryoCor Inc., San Diego, California) was inserted into the right atrium through a 12 F, 65-cm-long sheath (DAIG, St. Jude Medical Inc., St. Paul, Minnesota, or Cook Inc., Bloomington, Indiana) and a linear lesion was created by use of a point-by-point technique with gradual pullback of the cryocatheter in a ventricular atrial fashion. The first application was delivered at the ventricular insertion of the CTI. Each cryoapplication lasted 3 minutes with a constant target temperature of $-90{ }^{\circ} \mathrm{C}$. After bidirectional isthmus conduction block was achieved, acute success was defined if it persisted for 30 minutes after the last application without and with isoproterenol infusion (1 to $3 \mathrm{mcg} / \mathrm{min}$ ). ${ }^{11}$ Patients were kept on oral anticoagulation and returned 6 weeks later for their PVI. During this period, daily TTMs were provided to access arrhythmia burden in comparison with the TTM data pre ablation.

The PVI cryoablation protocol has been previously described. ${ }^{12}$ Briefly, during the procedure (but after the transseptal punctures) intravenous heparin was given as a 100-IU/ $\mathrm{kg}$ bolus dose followed by boluses of $5000 \mathrm{IU}$ every 1.5 hour if needed to keep an ACT $\geq$ than 300 seconds. A decapolar catheter was positioned in the distal coronary sinus and a quadripolar catheter in the His bundle region via the femoral route. Double trans-septal catheterization was performed under fluoroscopic and transesophageal guidance.

Left atrial angiography (to visualize the PVs ostia) was performed after adenosine administration..$^{13}$ A deflectable, circumferential decapolar mapping catheter (LASSO ${ }^{\mathrm{TM}}$, Biosense-Webster Inc., Baldwin Park, California) was advanced into the left atrium and positioned at the ostium of each PV. A deflectable, $10.5 \mathrm{~F}$ (with a $6.5 \mathrm{~mm}$ tip electrode) cryoablation catheter (CryoCor Inc., San Diego, California) was inserted into the left atrium through a $12 \mathrm{~F}, 65-\mathrm{cm}-$ long sheath (DAIG, St. Jude Medical Inc., St. Paul, Minnesota, or Cook Inc., Bloomington, Indiana).

Segmental isolation of PVs guided by the recording of their potentials with the LASSO ${ }^{\mathrm{TM}}$ catheter, was performed using the CryoCor cryoablation system 
as described previously. ${ }^{14}$ Efforts were made to identify the arrhythmogenic PV (culprit PV) using adenosine (24 to $40 \mathrm{mg}$ ) or isoproterenol (1 to $5 \mathrm{mcg}$ ). If the culprit PV(s) were not identified, all veins with potentials recorded at their ostium were targeted for ablation.

Isolation of the PV was performed during sinus rhythm or coronary sinus pacing by delivering cryoablation at ostial sites that had the earliest bipolar potential.

At each effective target site, defined by the abolishment of a PV potential or a change in the PV potential activation sequence during cryothermal application, 3 minutes of cryoablation was delivered. If no changes in the electrogram were observed after 20 seconds, despite a catheter tip temperature of $-90{ }^{\circ} \mathrm{C}$, the application was stopped and the catheter was repositioned. The early procedural end point was complete electrical isolation of PVs based on abolition of all ostial PV potentials or complete entrance conduction block into the PV.

\section{Post Ablation Management}

Every patient was monitored in hospital for $24 \mathrm{~h}$ and oral anticoagulation was started the same day of the ablation. The same AAD were continued for at least 3 months after the procedure. After 3 months, the need for chronic anticoagulation was assessed by the amount of recurrences of AFL/PAF and the presence of risk factors for thromboembolic events.

All patients had a Holter recording at discharge and during each clinic visit $(1,3,6,9,12$ months) or earlier if they had symptoms. They were also instructed to keep a diary of events associated with their transtelephonic monitors.

A blanking period of 3 months (starting after the PVI procedure) was used before assessing recurrences.

We adopted the following definitions according to the latest ACC/AHA/ESC Guidelines for the Management of Patients with Atrial Fibrillation ${ }^{15}$ and/or the Guidelines for Supraventricular Arrhythmias ${ }^{16}$ :

1) PAF - self terminating episodes of AF lasting longer than 30 seconds and up to 7 days (usually less than 24 hours);

2) Common type AFL - organized atrial rhythm with a rate typically between 250 and 350 beats per minute in which the macroreentry circuit is dependent on the CTI in either a counterclockwise or clockwise fashion.

\section{Statistical analysis}

Continuous variables are presented as mean $\pm S D$, where appropriate. In cases of a nongaussian distribution, medians and quartiles are given. Categorical variables are expressed as numbers and percentages of patients.

Statistical analysis was performed using the Student t-test for unpaired data. 
The chi-square test was used to compare categorical variables. The McNemar's test was applied to evaluate the differences in medication use from pre-ablation to post PVI.

A Kaplan-Meier analysis was used to estimate the probability of freedom from recurrent PAF. These curves were constructed for both groups with and without PAF recurrences and compared between them with the Wilcoxon and Log-Rank tests. All values were considered significant at $\mathrm{p}<0.05$.

The authors had full access to the data and take responsibility for its integrity. All authors have read and agreed to the manuscript as written.

\section{Results}

Our cohort consisted of 98 patients considered for segmental PVI after being appropriately screened by both the referring cardiologist and our group. Review of Holter recordings, TTM, failure of AAD, functional capacity, type of AF and imaging studies were the main criteria used to recruit our patients. In patients with a prior history of coronary artery disease, myocardial perfusion studies were performed to exclude active ischemia.

The characteristics of the patients are shown in Table 1.

As previously mentioned, patients in Group I underwent first CTI cryoablation and 6 weeks later PVI. During this period, daily TTMs were compared to the ones prior to CTI cryoablation and the average number of AF episodes per patient $(1 \pm 1$ registered daily AF episode) did not change. The long term outcome of this group is as follows: regarding AFL recurrences, most of them occurred in the first 6 months (confirming our prior data) ${ }^{17}, 5$ patients underwent a second successful CTI cryoablation. Two of those AFL patients remained having symptomatic AF episodes; therefore, a second PVI was performed. On the other hand, 24 patients had recurrences of PAF. In the majority of them (17 patients) the arrhythmia is well controlled on AAD. Six patients underwent a second successful PVI and the remaining patient opted to undergo surgical Maze operation (Figure 2).

Concerning the long term outcome of group II, 7 patients had PAF recurrences. All of them underwent a second PVI. Five patients are asymptomatic after this second procedure and without AAD. The remaining 2 patients are on AAD. Interestingly, 5 out of the 62 patients developed new onset common type AFL (along with sporadic PAF episodes) as the predominant arrhythmia. All of them underwent a successful CTI ablation. Despite the CTI ablation procedure, all 5 patients remained on having PAF. Their PAF was controlled with a repeat PVI (2 patients), AAD (1 patient) and 2 patients had asymptomatic PAF and are without AAD (Figure 3). There were no differences in procedural characteristics regarding PVI between Group I (procedure time $=337$ minutes and fluoroscopy time 90 minutes) and Group II (procedure time $=331$ minutes and fluoroscopy time 88 minutes), $\mathrm{p}=$ ns. 
Table 1. Characteristics of the patients with PAF referred for PVI.

\begin{tabular}{|c|c|c|c|}
\hline & $\begin{array}{c}\text { Group I } \\
36 \text { pts }(37 \%) \text { with } \\
\text { CTI ablation and } \\
\text { PVI }\end{array}$ & $\begin{array}{c}\text { Group II } \\
62 \text { pts }(63 \%) \text { with } \\
\text { PVI alone }\end{array}$ & $\mathrm{p}$ value \\
\hline Age $(y)$ & $48 \pm 10$ & $51 \pm 10$ & ns \\
\hline Women & $6(17 \%)$ & $16(26 \%)$ & ns \\
\hline AHT & $4(11 \%)$ & $12(19 \%)$ & \\
\hline \multirow{3}{*}{$\begin{array}{l}\text { SHD } \\
\text { CAD }\end{array}$} & & & ns \\
\hline & & & \\
\hline & $2(6 \%)$ & $4(7 \%)$ & \\
\hline $\mathrm{LAd} \mathrm{cm}$ & 3.96 & 4.02 & ns \\
\hline LVEF (\%) & 59.4 & 60.8 & ns \\
\hline $\begin{array}{l}\text { Mean number of } \\
\text { PVs isolated }\end{array}$ & 3.06 & 2.89 & ns \\
\hline Residual AF & $24(67 \%)$ & $7(11 \%)$ & $<0.05$ \\
\hline Recurrent AFL & 5 & - & na \\
\hline New AFL & _ & 5 & na \\
\hline $\begin{array}{l}\text { Mean follow-up } \\
\text { (months) }\end{array}$ & $23 \pm 20$ & $27 \pm 16$ & ns \\
\hline
\end{tabular}

No significant differences were found when comparing the characteristics of the two groups (Table 1). The only 2 factors reaching statistical significance were: residual PAF after PVI - 24 (67\%) vs 7 (11\%) patients from Groups I and II respectively $(\mathrm{p}<0.05)$ - and the number of patients who needed AAD after the 3 months blanking period post PVI - 17 patients (47\%) from Group I and 5 $(8 \%)$ patients from Group II, $\mathrm{p}<0.05)$ - (Table 2).

The results of patients submitted to PVI taken as a whole are as follows: free of arrhythmia - 67 patients (68\%) after the index procedure; 13 patients (13\%) free of arrhythmia after a second PVI giving an overall freedom from PAF (and not taking any AAD) of $82 \%$. Seventeen patients (17\%) had significant improvement on AAD and refused a second procedure.

The percentage of freedom from PAF in both groups is shown in Figure 4.

After a mean follow-up of $26 \pm 17$ months, there were no complications related to the procedure or any evidence of atypical (including left sided) AFL. 
Table 2. Use of antiarrhythmic drugs before and after the 3 months blanking period post PVI.

\begin{tabular}{|c|c|c|c|c|}
\hline & \multicolumn{2}{|c|}{$\begin{array}{c}\text { Group I } \\
36(\mathrm{pts})(37 \%) \\
\text { with CTI cryoablation and } \\
\text { PVI }\end{array}$} & \multicolumn{2}{|c|}{$\begin{array}{c}\text { Group II } \\
62 \text { (pts) }(63 \%) \\
\text { with PVI alone }\end{array}$} \\
\hline & $\begin{array}{c}\text { Pre } \\
\text { ablation }\end{array}$ & Post PVI* & $\begin{array}{c}\text { Pre } \\
\text { ablation }\end{array}$ & Post PVI* \\
\hline Total & $36(100 \%)$ & $17(47 \%)+$ & $62(100 \%)$ & $5(8 \%) \dagger$ \\
\hline Class I C & $20(56 \%)$ & $9(53 \%)$ & $32(52 \%)$ & $3(60 \%)$ \\
\hline Amiodarone & $4(11 \%)$ & $1(6 \%)$ & $8(13 \%)$ & - \\
\hline Sotalol & $12(33 \%)$ & $7(41 \%)$ & $22(35 \%)$ & $2(40 \%)$ \\
\hline
\end{tabular}

† Post PVI $=$ counting after a 3 months blanking period post the index PVI.

$* \mathrm{p}<0.05$.

\section{Discussion}

\section{Main Findings}

To our knowledge this is the first study analyzing a population with coexistent PAF/AFL - treated with two different strategies - showing that a previous history of AFL is a bad sign regarding AF recurrences after catheter ablation.

Additionally this study demonstrated that a prophylactic ablation of the CTI should not be included in the treatment of patients with PAF and no documented common type AFL. Therefore a careful screening of the index arrhythmia(s) (e.g. PAF only or PAF/AFL) will allow to perform the correct ablation strategy and to obtain an optimal long term outcome. The success rate in Group II (PAF only) was 89\% whereas this was only 33\% group I (PAF/AFL). 
Figure 2. Long term outcome ( $23 \pm 20$ months) of PAF patients with a known history of AFL, treated with CTI ablation followed by PVI.

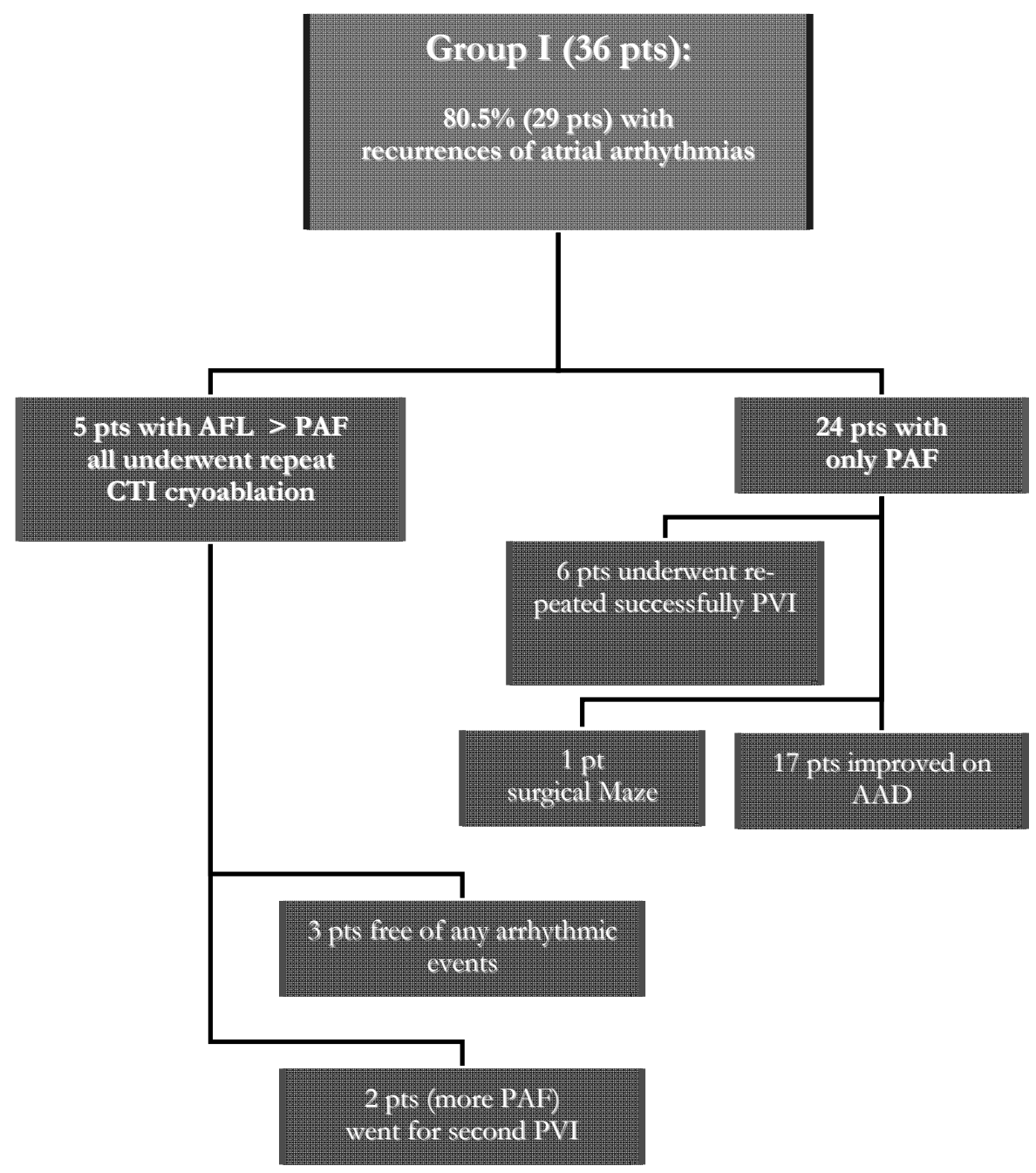

Abbreviations:

$\mathrm{AAD}=$ antiarrhythmic drugs;

$\mathrm{AFL}=$ common type atrial flutter;

CTI = cavotricuspid isthmus;

$\mathrm{PAF}=$ paroxysmal atrial fibrillation;

PTS $=$ patients. 
Figure 3. Long term (27 \pm 16 months) outcome of PAF patients without a prior history of AFL that underwent PVI.

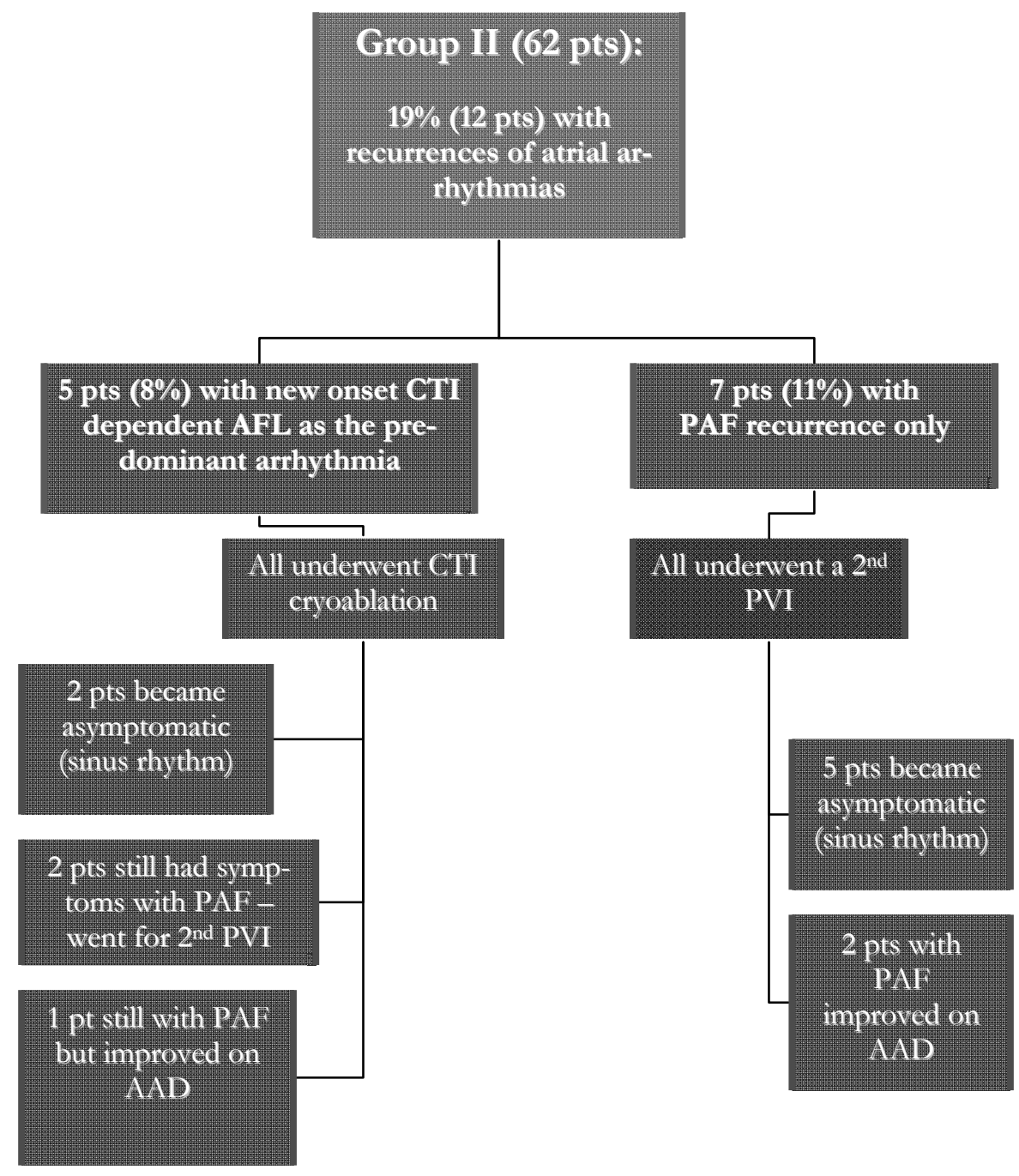

Footnote: abbreviations as in Figure 2. 
Those numbers were acquired with a follow-up where daily TTMs and the common methods to access recurrences (patient's symptoms with Holter and 12 lead ECGs being used only during clinic visits) were used. Even though those TTMs represent only a fraction of the day, they still can estimate asymptomatic episodes, but we know that patients' symptoms after AF ablation do not correspond to their real arrhythmia burden (as demonstrated by Hindricks and colleagues $)^{18}$ and continuous rhythm registration should be the ideal method when estimating the success of the ablative procedure.

\section{Is common type atrial flutter a sign of an arrbythmogenic substrate in $P A F$ ?}

The current advances in the percutaneous ablative therapy for the treatment of AF have helped us understand more extensively the importance of triggers and substrate in the pathophysiology of this arrhythmia. Segmental PV isolation done in a selected group of patients, has better success rates when compared to AADs. ${ }^{19,20}$

The association of AF and AFL is known and for the macroreentry circuit of CTI dependent AFL to occur, an intercaval line of block (in addition to the other anatomic barriers - the crista terminalis and the tricuspid annulus) is required. . $^{-4}$

Waldo et al advocate that a functional line of block between the venae cavae during $\mathrm{AF}$ is critical for the pathogenesis of classic AFL. If this functional component of the AFL circuit does not develop, AF will either persist or spontaneously convert back to sinus rhythm. ${ }^{5}$ In those patients in whom AF does not appear to precede the onset of AFL, a very high degree or even complete block between the venae cavae may already be present. ${ }^{21,22}$ If we extrapolate those findings to our population, one could say that our patients from Group I had a more critical substrate - intracaval functional line of block - for the development of sustained common type AFL than our patients from Group II.

Another important observation is that although ablation of the CTI permanently interrupted AFL in $86 \%$ of patients, residual AF was still present in $67 \%$ of them. That could be the result of non-PV sites acting as triggers (most of them found in the right atrium) ${ }^{23,24}$ and/or conditions (e.g., right atrial dilatation, electrical remodeling and fibrosis, etc.) which may act as substrate, together being responsible for the initiation and maintenance of AF in our Group I.

The ability to develop the intercaval functional line of block (essential in common type AFL) could represent a stage where electrical remodeling of atrial tissue (both right and left) is already important. In such a situation, elimination of the triggers in the PVs alone would not be enough to prevent AF. Any other premature beat could be sufficient to initiate AF which thereafter perpetuates in the remodeled substrate. Electrical remodeling is known to occur before mechanical remodeling in AF. ${ }^{25}$ The latter could be present in those patients from 
our relatively healthy population (minimal or no structural heart disease, normal left atrial size, PAF) who had worst outcomes.

Therefore AFL would then be a sign of right sided triggers and/or advanced electrical remodeling (of both atria) in patients with PAF who also have a history of common type sustained AFL. In this population, it is tempting to speculate that in addition to PVI a careful and systematic analysis of the right atrium (measurements of dimensions, search for triggers, electrogram analysis...) is warranted. If no RA (or other non PV foci in the LA) arrhythmogenic sources are identified, a percutaneous LA ablative approach aiming for substrate modification could potentially lead to better results.

The fact that our patients from Group II had only episodes of PAF indicates that no functional line of block was present (or if present, one with a much shorter length). This could represent absence of a substrate responsible for common type AFL. Isolation of the PVs (triggers) provided freedom from $\mathrm{AF}$ in $89 \%$ of those patients during follow-up. Those results might indicate that in those patients, prophylactic CTI is not necessary and therefore should not be included as an additional ablative step.

\section{Can the successful elimination of AF prevent the development of AFL?}

Wazni et al evaluated the effect of PVI/LAJ (left atrial junction) RF ablation in patients with AF/AFL. ${ }^{26}$ They showed that after a blanking period of 8 weeks, PVI/LAJ ablation alone (without concomitant CTI ablation) decreased the occurrence of not only AF but also AFL. Even though our study was not designed to evaluate this specific issue, some of our findings are consistent with their results. During an observational period of more than 2 years, only 5 out of 62 of our patients (all of them with associated AF) developed new onset common type AFL. This reinforces the theory that AF is needed for the initiation of AFL and that elimination of the initiating arrhythmia (AF) prevents the appearance of common type AFL. Further investigation of this concept is needed.

\section{Class IC drugs versus ablation for $A F / A F L$}

Before the introduction of PV isolation as a treatment strategy for AF, Class IC drugs were reported to be effective in converting AF to AFL which could then be treated by CTI ablation. ${ }^{27-31}$ The proposed mechanism was the ratedependent prolongation of the atrial refractory period by class IC agents with an increase in the wavelength, thus facilitating the conversion of AF (multiple smaller reentry circuits) to AFL (a single macro reentrant loop). One should note that those AAD could also have electrophysiologic effects in the intercaval region, creating the needed line of block for the common type AFL. Also, in those studies, a great number of patients had only improvement in their symp- 
toms (still having bouts of $\mathrm{AF}$ ) with a rate of conversion to sinus rhythm much lower than the ones achieved nowadays by percutaneous ablation. The inefficacy of AAD in AF was also confirmed in the AFFIRM trial with some suggestions of increased mortality. ${ }^{32}$ Therefore, ablation of AF seems to be a better solution than the use of AAD to convert AF into AFL.

\section{Study limitations}

Our daily TTMs recorded only a fraction of the day and do not represent the 24 hour period. Episodes of asymptomatic arrhythmias could have been missed. Also the classification of AFL vs. AF during follow-up event recordings and $24 \mathrm{hr}$ Holter recordings was not done blindly which could potentially be a source of bias. Even though the diagnosis of CTI dependent flutter can not be made with certainty from the event recorder or Holter tracings we confirmed the diagnosis in all the 10 patients with AFL post PVI by endocardial recordings during the subsequent electrophysiological study where CTI ablation was performed.

Assessment of atrial anatomy was done using transthoracic echocardiography which has known limitations in accurately evaluating the right sided structures. MRI could give a more precise estimation of the right atrial morphology.

Furthermore, some patients were taking $\mathrm{AAD}(\mathrm{s})$ to control $\mathrm{AF}$ during the post ablation period. We can not rule out that $A A D(s)$ were the cause for the transformation of AF into AFL. However, the type of $\mathrm{AAD}(\mathrm{s})$ and the percentage of patients taking those in the pre-ablation period were comparable in both groups. Table 2. Thus, this possibility would be pertinent only to the AFLs observed in the post ablation period (10 patients). Additionally, the nonrandomized nature of the study may account for a confounding factor.

\section{Conclusions}

We demonstrated that in patients with PAF and no documented common type AFL, PVI alone prevents the recurrence of AF in $82 \%$. Therefore preventive CTI ablation should not be included in the strategy for the treatment of PAF.

Furthermore, in patients with coexisting PAF/AFL, CTI ablation and PVI successfully treated sustained common type AFL but seemed insufficient to prevent recurrences of AF. In this population, AFL can be a sign that non PV triggers (including in the right atrium) are the culprit of AF and/or enough electrical remodeling has occurred in both atria and an ablative strategy which includes substrate modification is already required.

Future work is needed to tell us whether the combination of PAF/AFL could be a marker of early progression to persistent or permanent AF. 
Figure 4. Kaplan-Meier curve showing freedom from paroxysmal atrial fibrillation after the index pulmonary vein cryoisolation.

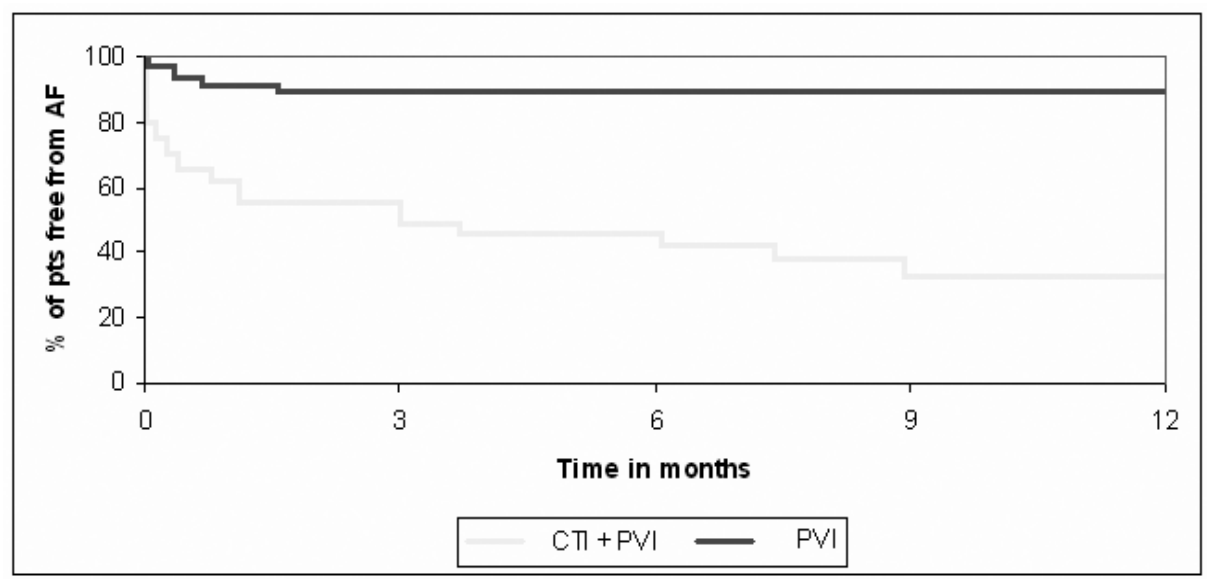

\begin{tabular}{|c|c|c|c|c|c|}
\hline \multicolumn{6}{|l|}{ Follow-up } \\
\hline Months & & 3 & 6 & 9 & 12 \\
\hline \multirow[t]{2}{*}{$\mathrm{CTI}+\mathrm{PVI}$} & Events & 20 & 2 & 2 & 0 \\
\hline & $\begin{array}{c}\text { Number of Patients } \\
\text { at Risk }\end{array}$ & 36 & 16 & 14 & 12 \\
\hline \multirow[t]{2}{*}{ PVI } & Events & 7 & 0 & 0 & 0 \\
\hline & $\begin{array}{c}\text { Number of Patients } \\
\text { at Risk }\end{array}$ & 62 & 55 & 55 & 55 \\
\hline
\end{tabular}

Footnote: AF recurrences were counted after a blanking period of 3 months post PVI. This corresponds in the Kaplan-Meier curve with a time of zero months.

Abbreviations:

PVI: Number of patients with paroxysmal atrial fibrillation submitted to pulmonary veins isolation with cryotermy;

PVI + CTI: Patients with paroxysmal atrial fibrillation and atrial flutter submitted to cavotricuspid isthmus cryoablation and subsequent pulmonary veins isolation with cryotermy; 


\section{References}

1. Waldo AL. Pathogenesis of atrial flutter. J Cardiovasc Electrophysiol 1998;9:S18-S25.

2. Waldo AL. Treatment of atrial flutter. Heart 2000;84:227-232.

3. Wellens HJ. Contemporary management of atrial flutter. Circulation 2002;106:649-652.

4. Waldo AL. Mechanisms of atrial flutter and atrial fibrillation: distinct entities or two sides of a coin? Cardiovasc Res 2002;54:217-229.

5. Waldo AL. The interrelationship between atrial fibrillation and atrial flutter. Prog Cardiovasc Dis 2005;48:41-56.

6. Pappone C, Santinelli V. Atrial fibrillation ablation: state of the art. Am J Cardiol 2005;96:59L-64L.

7. Jais P, Haissaguerre M, Hocini M, Clementy J. [Catheter ablation for atrial fibrillation]. Bull Acad Natl Med 2005;189:17-29.

8. Hummel JD. Cryoablation of atrial fibrillation: getting warmer? J Cardiovasc Electrophysiol 2005;16:1309-1310.

9. Hoyt RH, Wood M, Daoud E, Feld G, Sehra R, Pelkey W, Kay GN, Calkins H. Transvenous catheter cryoablation for treatment of atrial fibrillation: results of a feasibility study. Pacing Clin Electrophysiol 2005;28 Suppl 1:S78-S82.

10. Haissaguerre M, Hocini M, Sanders P, Sacher F, Rotter M, Takahashi Y, Rostock T, Hsu LF, Bordachar P, Reuter S, Roudaut R, Clementy J, Jais P. Catheter ablation of long-lasting persistent atrial fibrillation: clinical outcome and mechanisms of subsequent arrhythmias. J Cardiovasc Electrophysiol 2005;16:1138-1147.

11. Nabar A, Rodriguez LM, Timmermans C, Smeets JL, Wellens HJ. Isoproterenol to evaluate resumption of conduction after right atrial isthmus ablation in type I atrial flutter. Circulation 1999;99:3286-3291.

12. Rodriguez LM, Geller JC, Tse HF, Timmermans C, Reek S, Lee KL, Ayers GM, Lau CP, Klein HU, Crijns HJ. Acute results of transvenous cryoablation of supraventricular tachycardia (atrial fibrillation, atrial flutter, Wolff-Parkinson-White syndrome, atrioventricular nodal reentry tachycardia). J Cardiovasc Electrophysiol 2002;13:1082-1089.

13. Tse HF, Lee KL, Lau CP. Adenosine triphosphate enhanced contrast pulmonary venogram to facilitate pulmonary vein ablation. J Cardiovasc Electrophysiol 2002;13:300.

14. Rodriguez LM, Timmermans C. Transvenous cryoablation of cardiac arrhythmias. Technol Cancer Res Treat 2004;3:515-524.

15. Fuster V, Ryden LE, Cannom DS, Crijns HJ, Curtis AB, Ellenbogen KA, Halperin JL, Le Heuzey JY, Kay GN, Lowe JE, Olsson SB, Prystowsky EN, Tamargo JL, Wann S, Smith SC, Jr., Jacobs AK, Adams CD, Anderson JL, Antman EM, Halperin JL, Hunt SA, Nishimura R, Ornato JP, Page RL, Riegel B, Priori SG, Blanc JJ, Budaj A, Camm AJ, Dean V, Deckers JW, Despres C, Dickstein K, Lekakis J, McGregor K, Metra M, Morais J, Osterspey A, Tamargo JL, Zamorano JL. ACC/AHA/ESC 2006 Guidelines for the Management of Patients with Atrial Fibrillation: a report of the American College of Cardiology/American Heart Association Task Force on Practice Guidelines and the European Society of Cardiology Committee for Practice Guidelines (Writing Committee to Revise the 2001 Guidelines for the Management of Patients With Atrial Fibrillation): developed in collaboration with the European Heart Rhythm Association and the Heart Rhythm Society. Circulation 2006;114:e257-e354. 
16. Blomstrom-Lundqvist C, Scheinman MM, Aliot EM, Alpert JS, Calkins H, Camm AJ, Campbell WB, Haines DE, Kuck KH, Lerman BB, Miller DD, Shaeffer CW, Jr., Stevenson WG, Tomaselli GF, Antman EM, Smith SC, Jr., Alpert JS, Faxon DP, Fuster V, Gibbons RJ, Gregoratos G, Hiratzka LF, Hunt SA, Jacobs AK, Russell RO, Jr., Priori SG, Blanc JJ, Budaj A, Burgos EF, Cowie M, Deckers JW, Garcia MA, Klein WW, Lekakis J, Lindahl B, Mazzotta G, Morais JC, Oto A, Smiseth O, Trappe HJ. ACC/AHA/ESC guidelines for the management of patients with supraventricular arrhythmias--executive summary: a report of the American College of Cardiology/American Heart Association Task Force on Practice Guidelines and the European Society of Cardiology Committee for Practice Guidelines (Writing Committee to Develop Guidelines for the Management of Patients With Supraventricular Arrhythmias). Circulation 2003;108:1871-1909.

17. Manusama R, Timmermans C, Limon F, Philippens S, Crijns HJ, Rodriguez LM. Catheterbased cryoablation permanently cures patients with common atrial flutter. Circulation 2004;109:1636-1639.

18. Hindricks G, Piorkowski C, Tanner H, Kobza R, Gerds-Li JH, Carbucicchio C, Kottkamp H. Perception of atrial fibrillation before and after radiofrequency catheter ablation: relevance of asymptomatic arrhythmia recurrence. Circulation 2005;112:307-313.

19. Khaykin Y. Cost-effectiveness of catheter ablation for atrial fibrillation. Curr Opin Cardiol 2007;22:11-17.

20. Pappone C, Augello G, Sala S, Gugliotta F, Vicedomini G, Gulletta S, Paglino G, Mazzone P, Sora N, Greiss I, Santagostino A, LiVolsi L, Pappone N, Radinovic A, Manguso F, Santinelli V. A randomized trial of circumferential pulmonary vein ablation versus antiarrhythmic drug therapy in paroxysmal atrial fibrillation: the APAF Study. J Am Coll Cardiol 2006;48:2340-2347.

21. Olgin JE, Kalman JM, Fitzpatrick AP, Lesh MD. Role of right atrial endocardial structures as barriers to conduction during human type I atrial flutter. Activation and entrainment mapping guided by intracardiac echocardiography. Circulation 1995;92:1839-1848.

22. Olgin JE, Kalman JM, Lesh MD. Conduction barriers in human atrial flutter: correlation of electrophysiology and anatomy. J Cardiovasc Electrophysiol 1996;7:1112-1126.

23. Hsieh MH, Tai CT, Tsai CF, Yu WC, Lin WS, Huang JL, Ding YA, Chang MS, Chen SA. Mechanism of spontaneous transition from typical atrial flutter to atrial fibrillation: role of ectopic atrial fibrillation foci. Pacing Clin Electrophysiol 2001;24:46-52.

24. Lin WS, Tai CT, Hsieh MH, Tsai CF, Lin YK, Tsao HM, Huang JL, Yu WC, Yang SP, Ding YA, Chang MS, Chen SA. Catheter ablation of paroxysmal atrial fibrillation initiated by nonpulmonary vein ectopy. Circulation 2003;107:3176-3183.

25. Goette A, Honeycutt C, Langberg JJ. Electrical remodeling in atrial fibrillation. Time course and mechanisms. Circulation 1996;94:2968-2974.

26. Wazni O, Marrouche NF, Martin DO, Gillinov AM, Saliba W, Saad E, Klein A, Bhargava M, Bash D, Schweikert R, Erciyes D, bdul-Karim A, Brachman J, Gunther J, Pisano E, Potenza D, Fanelli R, Natale A. Randomized study comparing combined pulmonary vein-left atrial junction disconnection and cavotricuspid isthmus ablation versus pulmonary vein-left atrial junction disconnection alone in patients presenting with typical atrial flutter and atrial fibrillation. Circulation 2003;108:2479-2483.

27. Anne W, Willems R, Adriaenssens B, Adams J, Ector H, Heidbuchel H. Long-term symptomatic benefit after radiofrequency catheter ablation for atrial flutter despite a high incidence of post-procedural atrial fibrillation. Acta Cardiol 2006;61:75-82.

28. Bandini A, Golia P, Pantoli D, Galvani M, Rusticali F. Atrial fibrillation recurrence after drug-induced typical atrial flutter ablation. Ital Heart J 2005;6:584-590.

29. Nabar A, Rodriguez LM, Timmermans C, van den Dool A, Smeets JL, Wellens HJ. Effect of right atrial isthmus ablation on the occurrence of atrial fibrillation: observations in four patient groups having type I atrial flutter with or without associated atrial fibrillation. Circulation 1999;99:1441-1445. 
30. Nabar A, Rodriguez LM, Timmermans C, Smeets JL, Wellens HJ. Radiofrequency ablation of "class IC atrial flutter" in patients with resistant atrial fibrillation. Am J Cardiol 1999;83:785-7, A10.

31. Schumacher B, Jung W, Lewalter T, Vahlhaus C, Wolpert C, Luderitz B. Radiofrequency ablation of atrial flutter due to administration of class IC antiarrhythmic drugs for atrial fibrillation. Am J Cardiol 1999;83:710-713.

32. Wyse DG, Waldo AL, DiMarco JP, Domanski MJ, Rosenberg Y, Schron EB, Kellen JC, Greene HL, Mickel MC, Dalquist JE, Corley SD. A comparison of rate control and rhythm control in patients with atrial fibrillation. N Engl J Med 2002;347:1825-1833. 


\section{CHAPTER VI}

\section{The Importance of a Refractory Period Gradient $\geq 100 \mathrm{msec}$ Between Pulmonary Veins and Adjacent Left Atrium in Identifying the Culprit Pulmonary Vein}

Wendel Moreira, MD, Carl Timmermans, MD, PhD,

Hein J. J. Wellens, MD, PhD*,

David Perez, MD, Yuka Mizusawa, MD,

Suzanne Philippens, RN and Luz-Maria Rodriguez, MD, PhD

From the Department of Cardiology, Academic Hospital Maastricht and *Cardiovascular Research Institute Maastricht (CARIM),

Maastricht, the Netherlands

Abstract presented at the $3^{\text {rd }}$ Annual Congress of the European

Cardiac Arrhythmia Society (ECAS),

Marseille, France, June 2007.

(J Interv Card Electrophysiol (2007) 18: 57).

Manuscript submitted for publication. 


\section{Abstract}

Objectives: Compare arrhythmogenic versus non-arrhythmogenic Pulmonary Vein(s) (PV) in patients with paroxysmal atrial fibrillation (PAF) and no history of amiodarone use.

Background: The data regarding the electrophysiological (EP) properties of PVs in patients submitted to AF ablation is limited by the frequent use of amiodarone (known to alter the EP parameters of the PV myocytes) and the presence of structural heart disease.

Methods: All patients were submitted to segmental PV cryoisolation. An extra catheter was used for pacing inside and immediately outside the veins. Arrhythmogenic veins were those in which $\mathrm{AF}$ was induced when pacing from inside the specific vein. They were compared to the non arrhythmogenic veins in the same patient.

Results: Ten patients ( 8 men; mean age 54 y (42 to 60$)$ ) were enrolled. Of the 40 PVs studied, 38 had potentials. All veins showed decremental properties. No arrhythmias could be induced in 18 (47\%): non-arrhythmogenic group. The mean ERP of the arrhythmogenic veins was 118 versus $244 \mathrm{msec}$ in the non arrhythmogenic ones $(p<0.05)$. Mean atrial ERP was similar between the two groups (238 and $236 \mathrm{msec}$ respectively). The difference in the ERP between the LA and adjacent PV represent the gradient between those two regions. The mean gradient was significantly higher $(>100 \mathrm{msec})$ for the arrhythmogenic PVs compared to the non arrhythmogenic ones ( $<40 \mathrm{msec}), \mathrm{p}<0.05$.

Conclusions: In patients with PAF not exposed to amiodarone, a refractory period gradient of $\geq 100 \mathrm{msec}$ between the PV and adjacent LA is indicative of an arrhythmogenic area with an ideal milieu for reentry. 


\section{Background}

Muscular sleeves located in the pulmonary veins (PV) often harbor the trigger able to induce paroxysmal atrial fibrillation (PAF). That finding contributed to the development of percutaneous ablative techniques to treat this arrhythmia. Due to those findings, several ablative strategies have been developed. Isolation of all PVs in which electrical activity is observed constitute one of them. ${ }^{1}$ Still, in the majority of protocols used for the percutaneous treatment of $\mathrm{AF}$, the electrophysiological (EP) evaluation of PVs is not included. ${ }^{2-4}$

Our study evaluates the EP properties of different PVs (within the same patient) and their adjacent tissue in a population with PAF, not exposed to any antiarrhythmic drug including amiodarone, referred for PV isolation (PVI) with cryothermy.

\section{Methods}

Ten patients with drug refractory, symptomatic lone PAF were selected from September 2005 to January 2006.

All patients in the study signed a written consent form that was approved by the local ethics committee.

Before PVI, all patients were orally anticoagulated to a therapeutic international normalized ratio of 2 to 3 for at least three weeks and up to three months after ablation. All antiarrhythmic drugs (AAD) were stopped 5 days prior to the procedure. No patient has been ever exposed to amiodarone.

Transesophageal echocardiogram (TEE) was performed during the procedure to exclude left atrial (LA) thrombus and to aid in the transeptal puncture.

\section{Electrophysiologic Study}

The 12 lead ECG and the intracardiac electrograms were recorded and stored by the Bard Labsystem PRO. A navigation system $\left(\mathrm{NavX}^{\mathrm{TM}}\right)$ was used to aid in the localization of the deflectable, circumferential decapolar mapping catheter (LASSO $^{\text {TM }}$, Biosense-Webster Inc., Baldwin Park, California) in relation with the PVs ostia and also to serve as a guiding point during cryoapplication.

All patients were studied in the fasting state without sedation. They were all in sinus rhythm when brought to the catheterization room. During the procedure (but after the transseptal punctures) intravenous heparin was given as a $100-\mathrm{IU} / \mathrm{kg}$ bolus dose followed by boluses of $5000 \mathrm{IU}$ every 1.5 hour if needed to keep an ACT $\geq$ than 300 seconds.

Under local anesthesia, a decapolar catheter was positioned in the distal 
coronary sinus and a quadripolar catheter in the His bundle region via the femoral route. Double trans-septal catheterization was performed under fluoroscopic and TEE guidance.

LA angiography was performed after adenosine administration. ${ }^{5} \mathrm{AF}$ was not induced in any patients during the injection. The LASSO ${ }^{\mathrm{TM}}$ catheter was advanced into the LA and positioned at the ostium of each PV. After fluoroscopic confirmation, a virtual reconstruction of the PVs by the $\mathrm{Nav} \mathrm{X}^{\mathrm{TM}}$ system was performed.

Thereafter, an extra quadripolar catheter was inserted into the LA through a 12F, 65-cm-long sheath (DAIG, St. Jude Medical Inc., St. Paul, Minnesota, or Cook Inc., Bloomington, Indiana). The same sheath was used later to introduce the 10.5F, $6.5 \mathrm{~mm}$ tip cryoablation catheter (CryoCor Inc., San Diego, California). Once the LASSO ${ }^{\mathrm{TM}}$ catheter was reconfirmed to be in the ostium of each PV (guided by fluoroscopy, $\mathrm{Nav}^{\mathrm{TM}}$ and potentials), the stimulation protocol to evaluate the electrophysiological properties of the PVs and surrounding atrial tissue was started.

Figure 1. Schematic representation of the pacing sites.

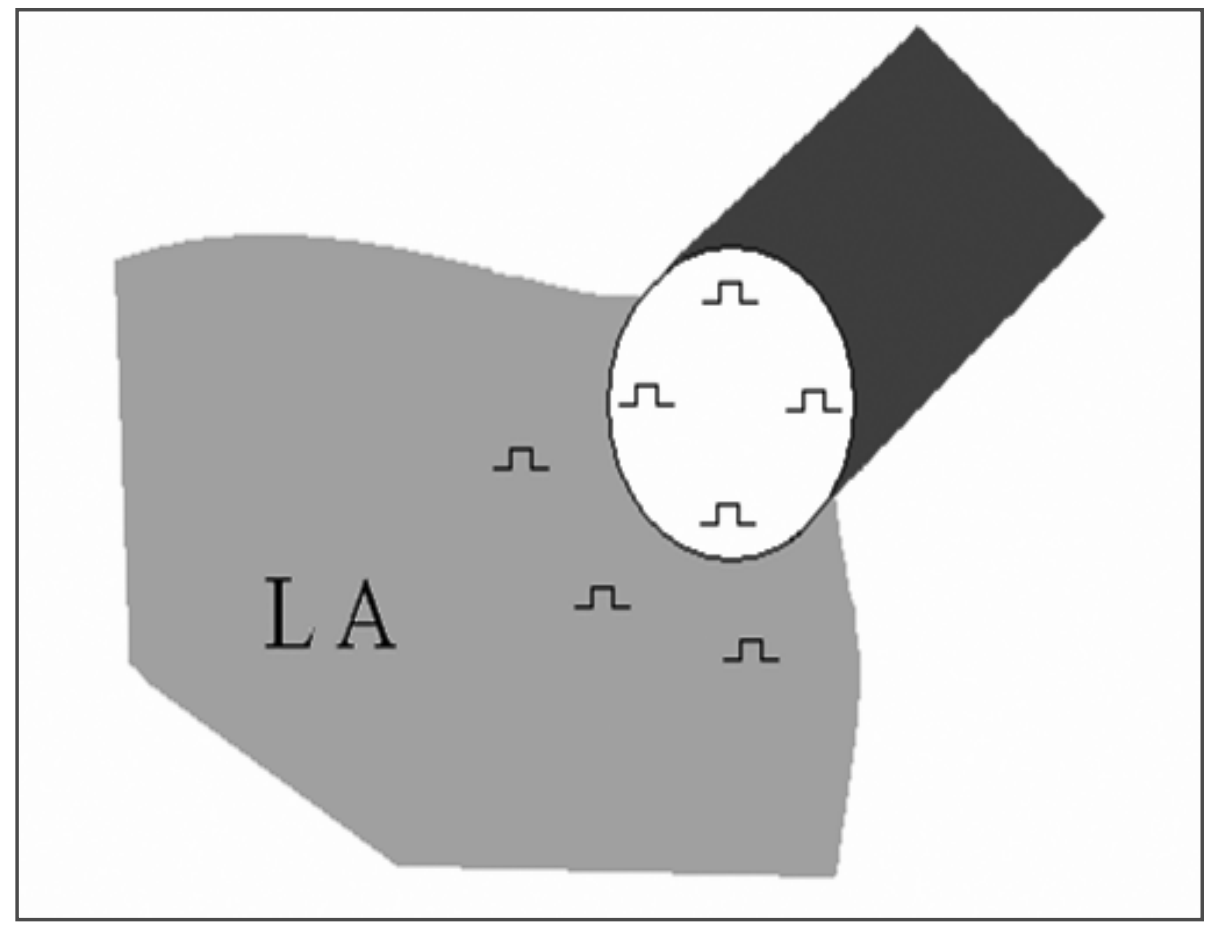

Caption: The Ohm sign indicates the distinct pacing points where capture was obtained inside the PV and adjacent LA. The anatomic locations were confirmed by fluoroscopy, NavX $\mathrm{X}^{\mathrm{TM}}$ and electrograms. 


\section{Stimulation protocol}

Stimulation was done at twice diastolic threshold using two different basic cycle lengths (500 and $430 \mathrm{msec}$ ). After eight basic stimuli, single extra stimulation (starting at $400 \mathrm{msec}$ ) was performed shortening the premature beat interval by 10 msec until the PV/LA tissue reached refractoriness. This protocol was performed in 4 different places in the PVs and in 3 places in the adjacent LA tissue (Figure 1). At the bottom of each vein this method was repeated twice. Pacing was done with a quadripolar catheter (6 F, 2-5-2 mm spacing), positioned outside the PV in the LA adjacent to the PV ostia (before the LASSO ${ }^{\mathrm{TM}}$ catheter) and inside the PV (behind the LASSO ${ }^{\mathrm{TM}}$ catheter). This technique was employed in each PV before and after ablation (when isoproterenol infusion is routinely started according to our protocol).

Three steps of subsequently stimulation trains were continued after the refractory period was reached to potentially unmask a gap phenomenon (not seen).

Since the primary aim of our study was to evaluate the refractory periods of the PVs and surrounding tissue we did not perform burst pacing trying to induce AF.

\section{Definitions}

1) The effective refractory period (ERP) of PVs was defined as the longest coupling interval at which a premature impulse (S2) failed to capture local PV musculature.

2) The ERP of the adjacent LA was defined as the longest coupling interval at which a premature impulse (S2) failed to capture the local atrial muscle immediately outside the LASSO ${ }^{\mathrm{TM}}$ catheter.

3) Arrhythmogenic veins were considered those in which, by using decremental pacing from inside the specific vein, AF could be induced. All episodes with short and irregular cycle lengths (regardless if sustained or not) were considered as AF. The electrophysiologic properties of those veins and surrounding tissue were then compared to the non arrhythmogenic veins in the same patient. Reproducibility was assessed in all patients at the site of good contact (usually the bottom of the PV).

\section{Statistical analysis}

Continuous variables are presented as mean \pm SD. Categorical variables are expressed as numbers of the ERPs.

Statistical analysis was performed using the Student t-test for paired data. All values were considered significant at $\mathrm{p}<0.05$. 


\section{Results}

There were 8 men with a mean age of $54 \pm 10$ (range 42 to 60) years. No patient had history of structural heart disease (SHD). All AAD were stopped at least 5 days prior to ablation. There was no history of amiodarone use. Their mean LA dimension was $38 \pm 2$ (33 to 44 ) $\mathrm{mm}$ with a mean left ventricular ejection fraction of $64 \pm 4 \%$. Mean duration of $\mathrm{AF}$ was $27 \pm 8$ months.

A total of 40 PVs were studied. Of those, 38 had documented potentials. In two patients no electrical activity was found in the right inferior PV.

Decremental properties were seen in all those veins when pacing from inside each PV.

AF could be induced using the previously described pacing protocol in 20 PVs (53\% of the veins with potentials) - those form our arrhythmogenic PV group (Table 1). Interestingly AF was never induced when pacing outside the veins.

In the other 18 PVs (non arrhythmogenic PV group) the ERP was reached (and confirmed twice) with no arrhythmia being induced. There was a mean of 2 arrhythmogenic and 2 non arrhythmogenic PVs per patient.

The mean ERP of the arrhythmogenic veins was $118 \mathrm{msec}$ versus $244 \mathrm{msec}$ in the non arrhythmogenic group $(\mathrm{p}<0.05)$ (Tables 1 and 2$)$. All PVs were compared within the same patient. When pacing the LA tissue adjacent to every PV, three different positions outside the LASSOTM catheter were selected (Figure1). The mean atrial ERP was not different between the two groups (238 msec in the arrhythmogenic and $236 \mathrm{msec}$ in the non arrhythmogenic group).

The difference in the ERP between the LA and adjacent PV represent the gradient between those two regions (Table 1). The mean gradient was significantly higher $(>100 \mathrm{msec})$ for the arrhythmogenic PVs compared to the non arrhythmogenic ones ( $<40 \mathrm{msec}$ ), $\mathrm{p}<0.05$ (Figure 2). Post ablation, the pacing maneuvers were repeated to access the success of isolation (Table 2). The majority of veins had no capture when pacing from inside (with the same previous protocol). That could represent the elimination of the muscular sleeves necessary to conduct electrical stimuli. The remaining PVs showed exit block - suggesting complete isolation of the vein and LA tissue (bidirectional block) (Figure 3).

Furthermore, the duration of AF was inversely related to the coupling interval of the atrial premature beat (Figure 4). In other words, long coupling intervals induced short runs of AF; short coupling intervals produced longer lasting AF. We also noted a significant fragmentation of the PV electrograms in the majority of cases when AF was induced. 


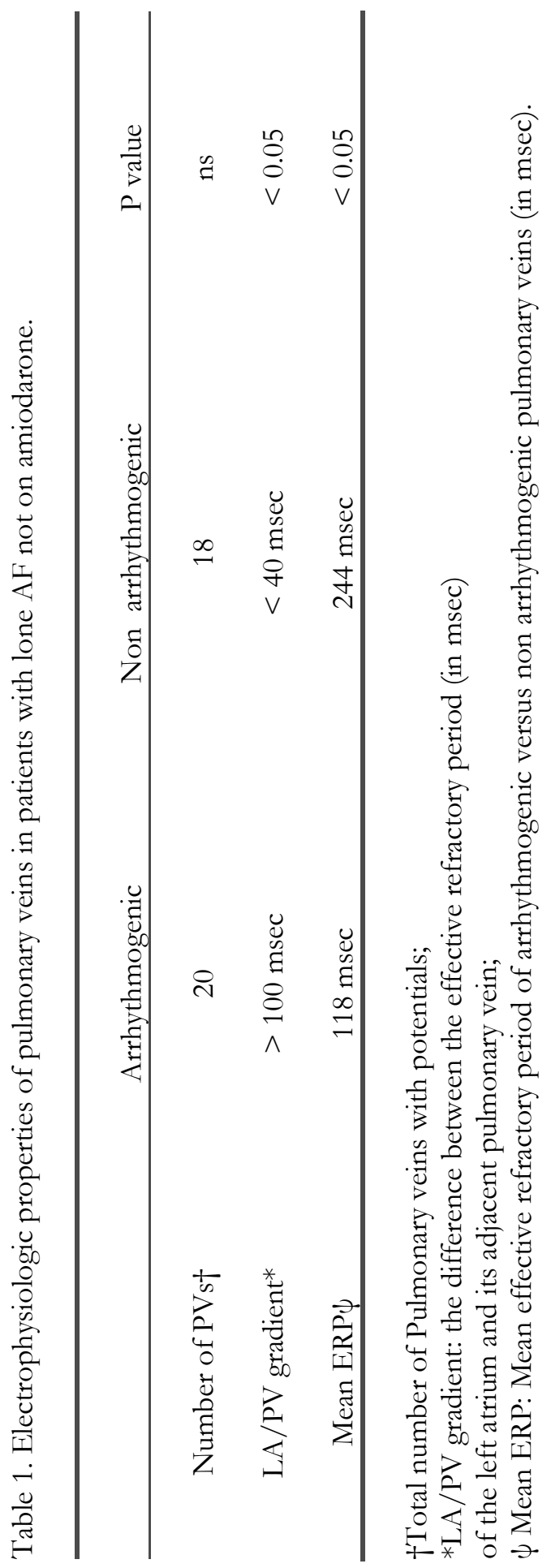


Table 2. Electrophysiological characteristics of arrhythmogenic veins in each individual patient.

\begin{tabular}{cccccc}
\hline Patient & \multicolumn{2}{c}{ Before PVI } & \multicolumn{2}{c}{ After PVI } & AF induced \\
\hline & LA ERP 500 & PV ERP 500 & LA ERP 500 & PV ERP 500 & Yes or No \\
1 & 230 & 110 & 220 & No capture* & Y \\
2 & 250 & 90 & 240 & No capture* & Y \\
3 & 220 & 110 & 230 & Exit blockt & Y \\
4 & 240 & 130 & 250 & Exit block† & Y \\
5 & 280 & 150 & 260 & No capture* & Y \\
6 & 250 & 140 & 240 & No capture* & Y \\
7 & 230 & 120 & 220 & No capture* & Y \\
8 & 250 & 130 & 250 & No capture* & Y \\
9 & 280 & 170 & 290 & No capture* & Y \\
10 & 240 & 140 & 250 & No capture* & Y \\
\hline
\end{tabular}

Table 2. Electrophysiological characteristics of arrhythmogenic veins in each individual patient.

\begin{tabular}{cccccc}
\hline Patient & \multicolumn{2}{c}{ Before PVI } & \multicolumn{2}{c}{ After PVI } & AF induced \\
\hline & LA ERP 430 & PV ERP 430 & LA ERP 430 & PV ERP 430 & Yes or No \\
1 & 220 & 100 & 210 & No capture* & Y \\
2 & 230 & 60 & 220 & No capture* & Y \\
3 & 190 & 90 & 190 & Exit block† & Y \\
4 & 250 & 110 & 230 & Exit block† & Y \\
5 & 270 & 130 & 260 & No capture* & Y \\
6 & 260 & 110 & 250 & No capture* & Y \\
7 & 250 & 120 & 250 & No capture* & Y \\
8 & 260 & 140 & 270 & No capture* & Y \\
9 & 280 & 180 & 290 & No capture* & Y \\
10 & 230 & 130 & 250 & No capture* & Y \\
\hline
\end{tabular}

Caption: note the significant difference in the refractory periods between the left atrium (LA) and pulmonary vein (PV) pre ablation. Post ablation, no capture was achieved in the majority of veins. The remaining showed exit block. There were no statistical significant differences between the ERPs found at the two different driving cycle lengths (500 and $430 \mathrm{msec}$ ).

* No capture: inability to capture inside the PV in at least three different places;

† Exit block: dissociation of the PV potentials (seen when pacing from inside the vein) and LA potentials.

Abbreviations: PVI: Pulmonary vein isolation; LA ERP 500/ LA ERP 430: effective refractory period in milliseconds (msec) of the LA tissue outside the PV measured using a baseline cycle length of 500 and $430 \mathrm{msec}$ respectively; PV ERP 500/ PV ERP 430: effective refractory period in milliseconds achieved when pacing inside the PV measured using a baseline cycle length of 500 and $430 \mathrm{msec}$ respectively 


\section{Discussion}

\section{Main Findings}

To our knowledge, this is the first study to evaluate the electrophysiological properties of arrhythmogenic versus non arrhythmogenic PVs in patients with PAF, no SHD and no history of exposure to any antiarrhythmic drug including amiodarone.

Our data support the fact that, by using pacing maneuvers inside and outside the PVs, arrhythmogenic and non arrhythmogenic veins could be identified. When comparing to non arrhythmogenic PVs (in the same patient) we were able to show the presence of a significant gradient $(>100 \mathrm{msec})$ between the ERP of the arrhythmogenic PVs and the ERP in their adjacent LA. The former, along with decremental conduction could create an ideal milieu for reentry and thus initiation of arrhythmias.

Previous studies have also shown "short" ERPs in the PVs. However, the population represented in those two studies had some factors that could interfere with the absolute measurements of ERP in the PVs.

The work from Kumagai et al ${ }^{6}$ evaluated 81 PVs of PAF patients with programmed stimulation being performed in the distal PV and PV-LA junction. They found that the ERP of the distal PV was significantly shorter than that of the PV-LA junction (177 \pm 43 vs. $222 \pm 30 \mathrm{~ms}$ ). In summary, their study has shown the presence of ERP heterogeneity and anisotropic conduction properties within the PV and at the PV-LA junction. But it is important to notice that almost one third of their patients had SHD. This could have played a role in the different ERPs found between our studies.

Another study ${ }^{7}$ assessed two groups of patients: 28 with PAF and 20 controls (without AF). Effective and functional refractory period and conduction time from PV to LA were compared using a single extrastimulus in the PVs and LA. In the AF group, the venous ERPs were shorter than that of the LA (185 \pm 71 versus $253 \pm 21 \mathrm{~ms})$ whereas in the control group, they were longer (282 \pm 45 versus $253 \pm 41 \mathrm{~ms}$ ). Decremental conduction in PVs was more frequent (93\% versus 56\%) in the AF group. The reported higher ERP(s) compared to our data could have been due to the fact that almost one third of their cohort had not only SHD but also a history of exposure to amiodarone. The former has been shown recently to significantly alter the electrophysiological properties of the PVs. ${ }^{8}$ We also evaluated the veins within each patient and not amongst different groups.

Therefore our findings can not be compared to the previously reported studies. Our population had no SHD and was without AADs. This may be the ideal situation to study the EP properties of the PVs and adjacent tissues.

So it seems that, in patients with PAF and minimal or no SHD a gradient 
between PVs and adjacent LA tissue of $>100 \mathrm{msec}$ can be used to identify which veins are arrhythmogenic.

\section{Large lesions versus electrophysiologic guided segmental ablations}

The landmark finding by Haissaguerre et al about the importance of the PVs as triggers for AF started a new era in electrophysiology. Initially, with the main focus staying on the discovery of the potentials present in the PVs of AF patients, ablative procedures aiming to isolate all veins with electrical activity (without performing any type of stimulation to evaluate the arrhythmogenicity of those vessels) became the standard. ${ }^{9}$ However the high rate of electrical reconnection (up to $80 \%)^{10}$ in patients undergoing a second procedure along with the appearance of PV stenosis led to the development of an anatomic (and not electrical) strategy for isolation of all PVs. ${ }^{11}$

This pure anatomical approach has been the cornerstone in the incorporation of more and more ablation lines to the percutaneous treatment of AF which now is aiming for substrate modification. ${ }^{4}$

But adding extensive LA linear ablation, although reported to improve overall success rates in a group of patients with more advanced stages of AF, has increased morbidity and mortality (including iatrogenic left atrial flutter, phrenic nerve paralysis and left atrial-to-esophageal fistula which is almost universally fatal). ${ }^{12-14}$ Many patients with AF and structurally normal hearts are now frequently referred for ablation. In this group, empiric extensive LA ablation may not be the best approach because the long-term risk of such extensive lesions is unknown.

A recent study with adolescents (without SHD) referred for interventional therapy due to lone AF has shown an excellent outcome with the focal ablation of distinct foci (most located in the PVs). ${ }^{15}$ Our current findings support the focal nature of triggers in patients with PAF and no evidence of SHD.

Prior data suggest that the PVs may be a privileged site for reentry. The PV cardiomyocytes have been shown to have shorter action potentials ${ }^{16}$ and smaller phase 0 upstroke velocities ${ }^{17}$ when compared to the left atrium. Those cellular properties could translate into abbreviated refractoriness and reduced source current for electrical conduction. That, in conjunction with source-sink mismatches (due to abrupt changes in fiber orientation near their ostia) ${ }^{18}$, can result in marked conduction delays. Both abbreviated refractoriness and slowed conduction favor reentry. Our results reinforce those findings by demonstrating the significant gradient $(>100 \mathrm{msec})$ in the PV/LA region. 
Since the aim of our study focused on the ERPs of the PV/LA junction we only performed decremental pacing techniques - which favor reentry as an arrhythmogenic mechanism. Therefore, by not performing burst pacing, we could not evaluate arrhythmogenicity due to triggered activity or automaticity.

The significant prolongation of the procedure time - because of the various pacing maneuvers used to identify and confirm the arrhythmogenic veins made us study a small number of patients. Also this population was selected, having PAF and no evidence of SHD or current exposure to AADs (stopped 5 days prior to ablation). It would be of interest to study a larger population with more advanced stages of $\mathrm{AF}$ to evaluate the importance of our findings in those patients.

\section{Conclusions}

In patients with PAF, no SHD and not exposed to antiarrhythmic drugs including amiodarone, a refractory period gradient of $\geq 100 \mathrm{msec}$ between the PV and adjacent LA is indicative of an arrhythmogenic area. This region represents an ideal environment for reentry and could be used as an endpoint to assess which PV should be targeted for ablation. Isolation of only those arrhythmogenic veins might be enough to achieve a successful outcome in the ablative therapy for AF. 


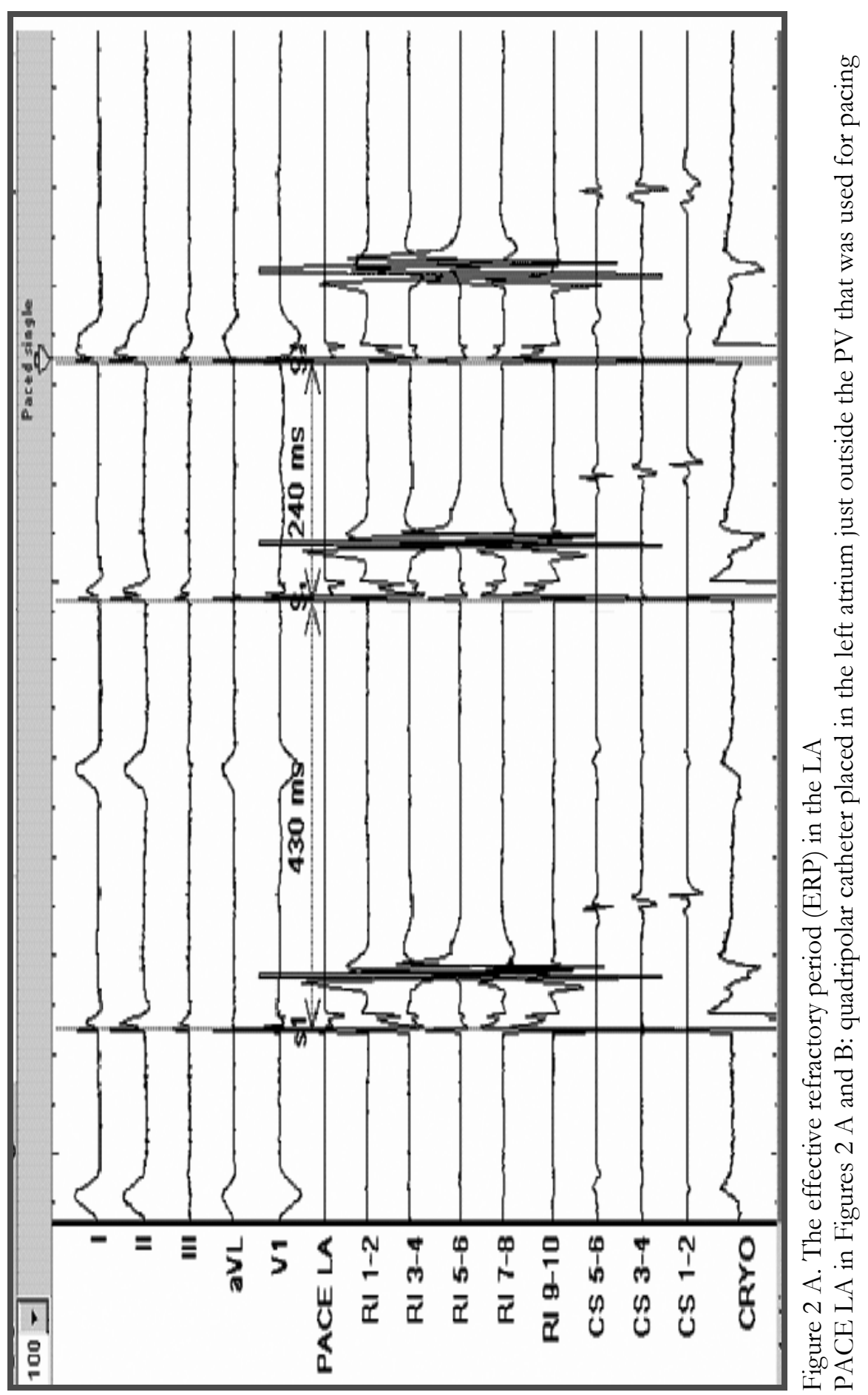




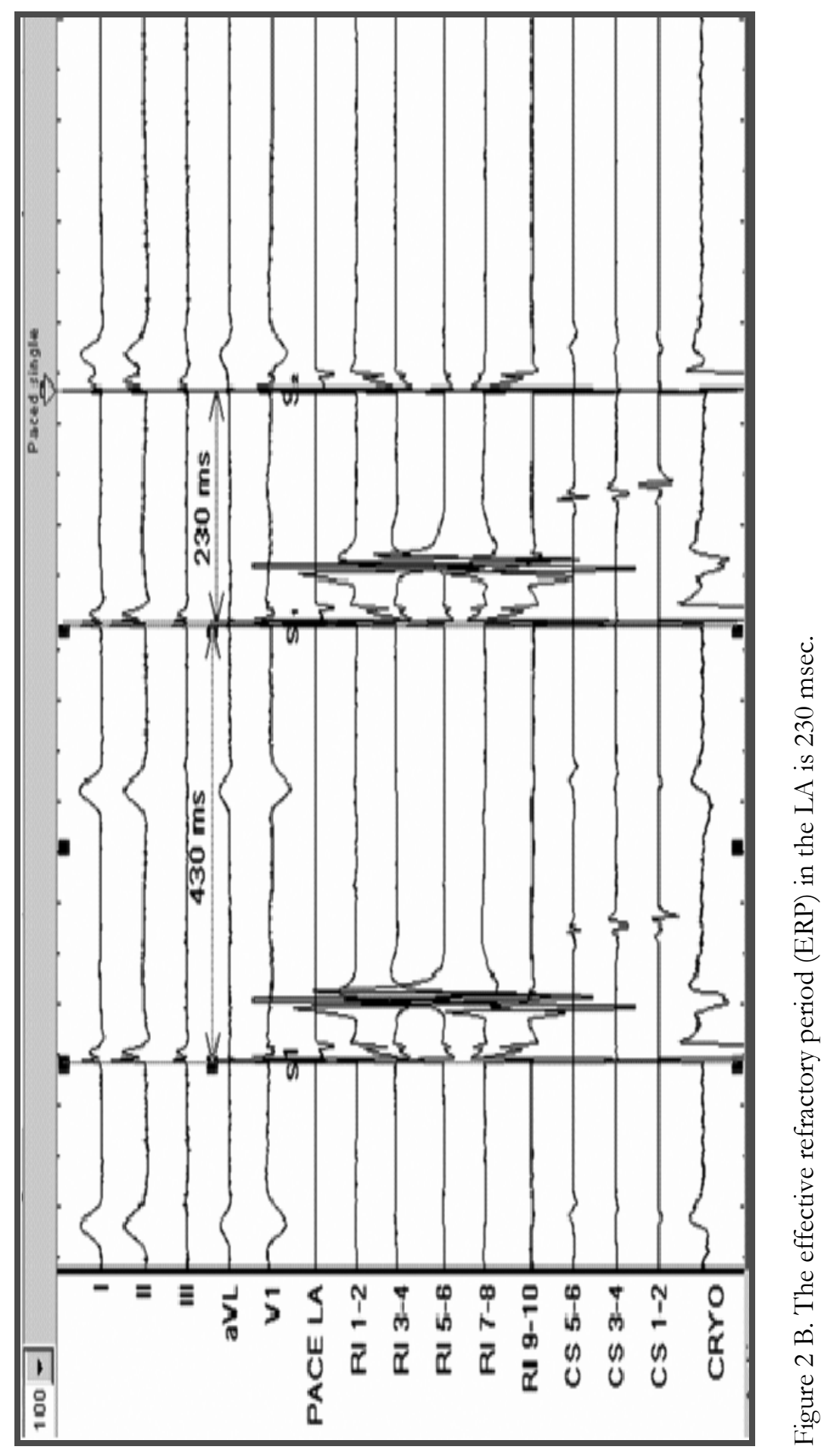




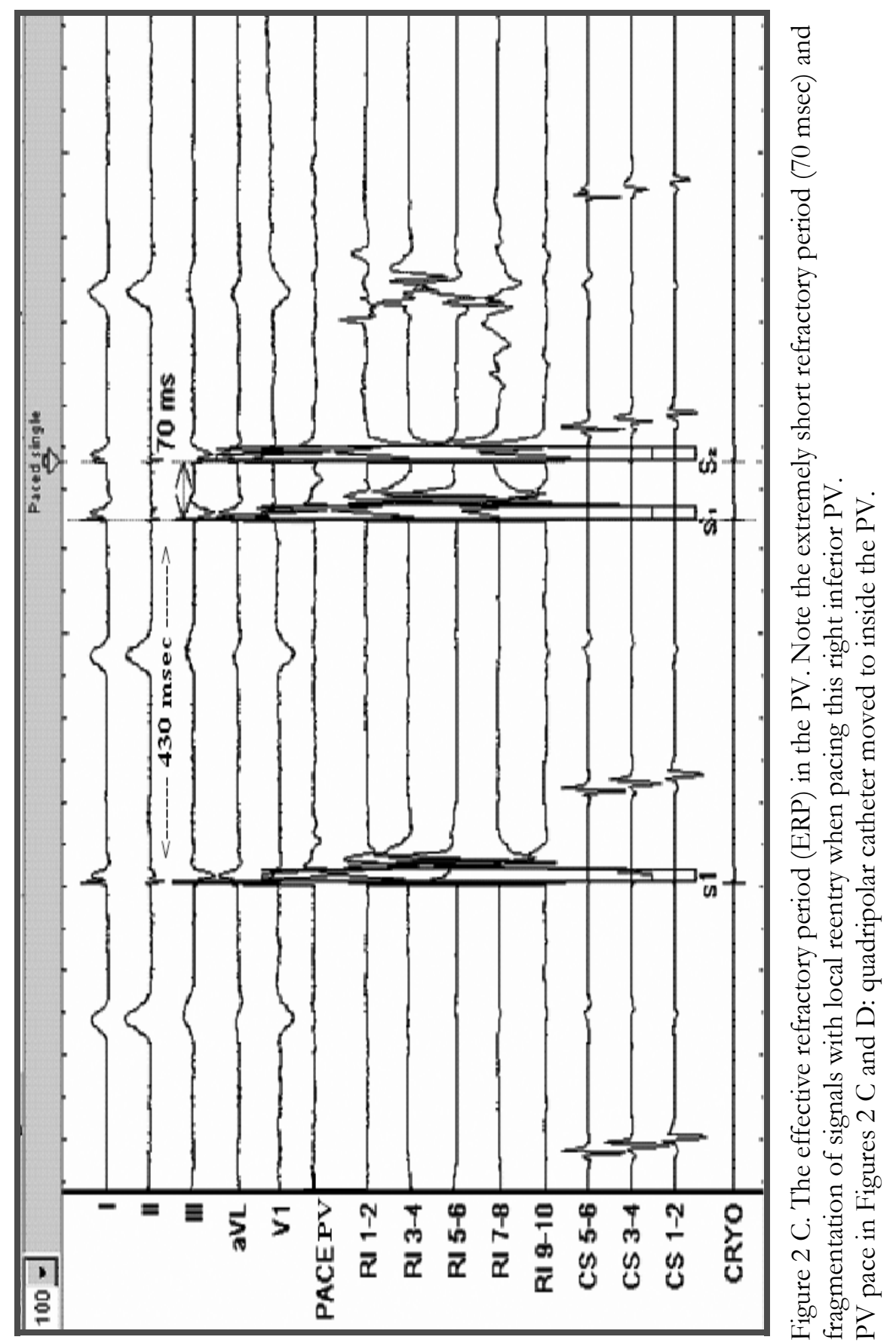




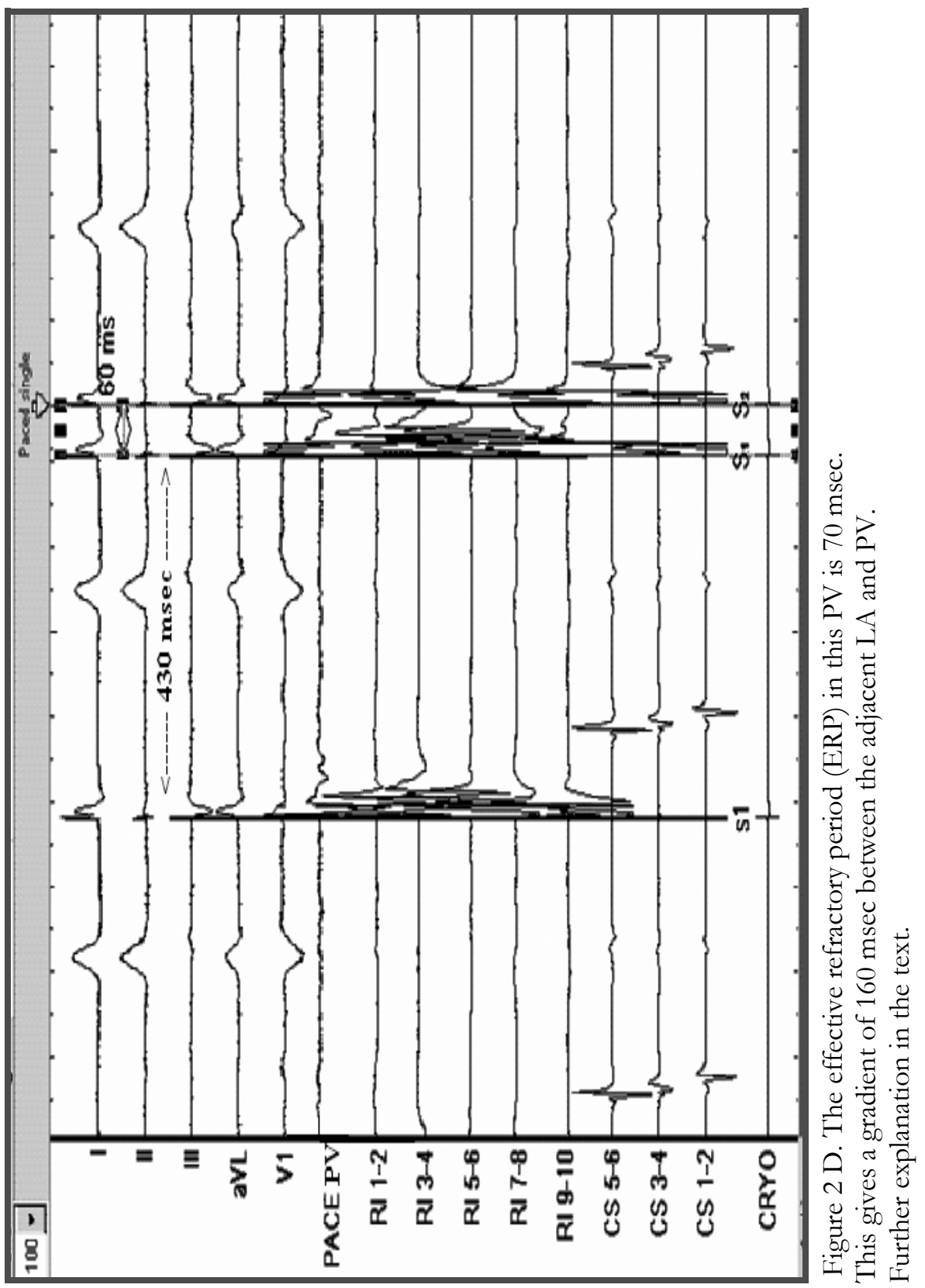




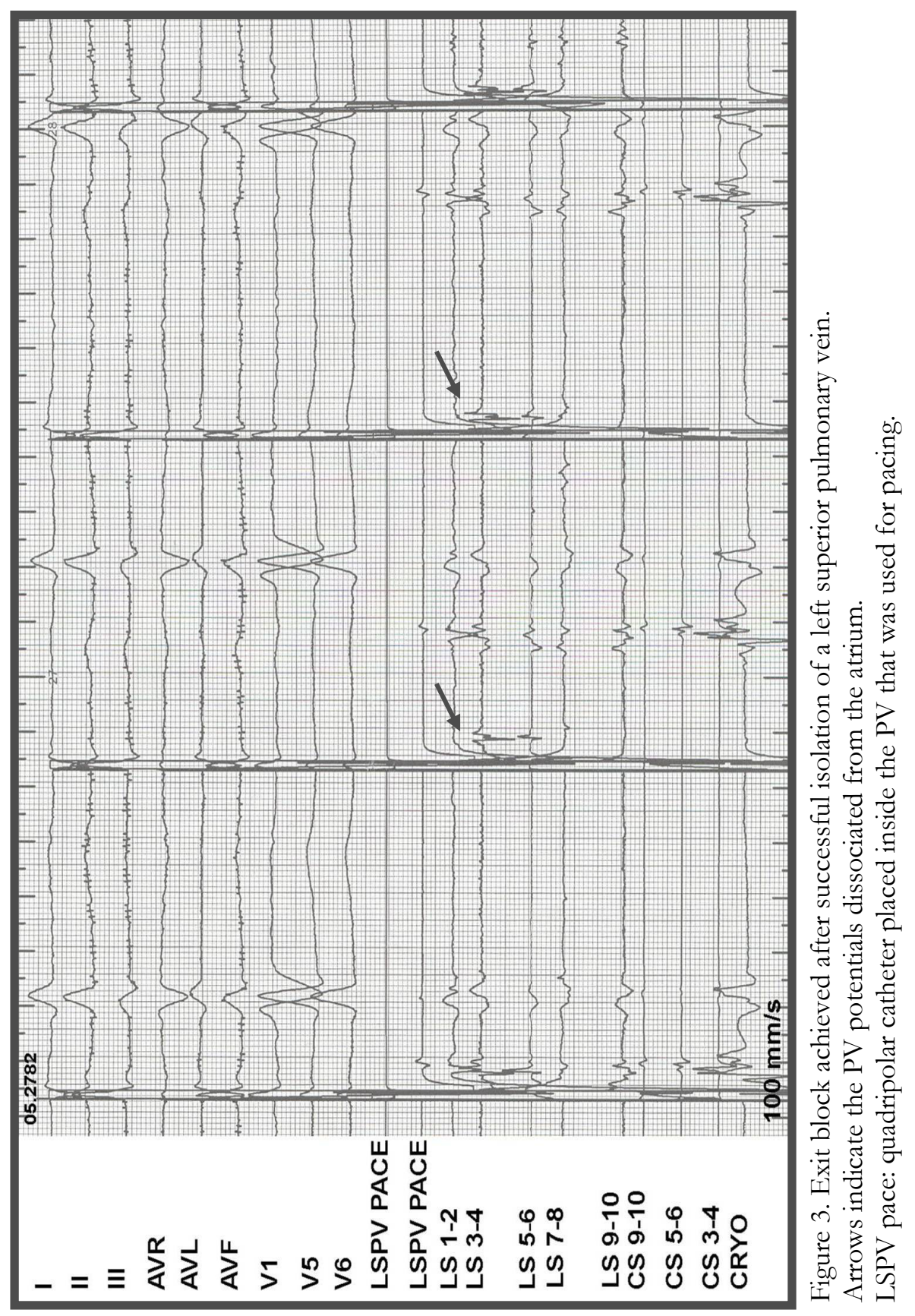




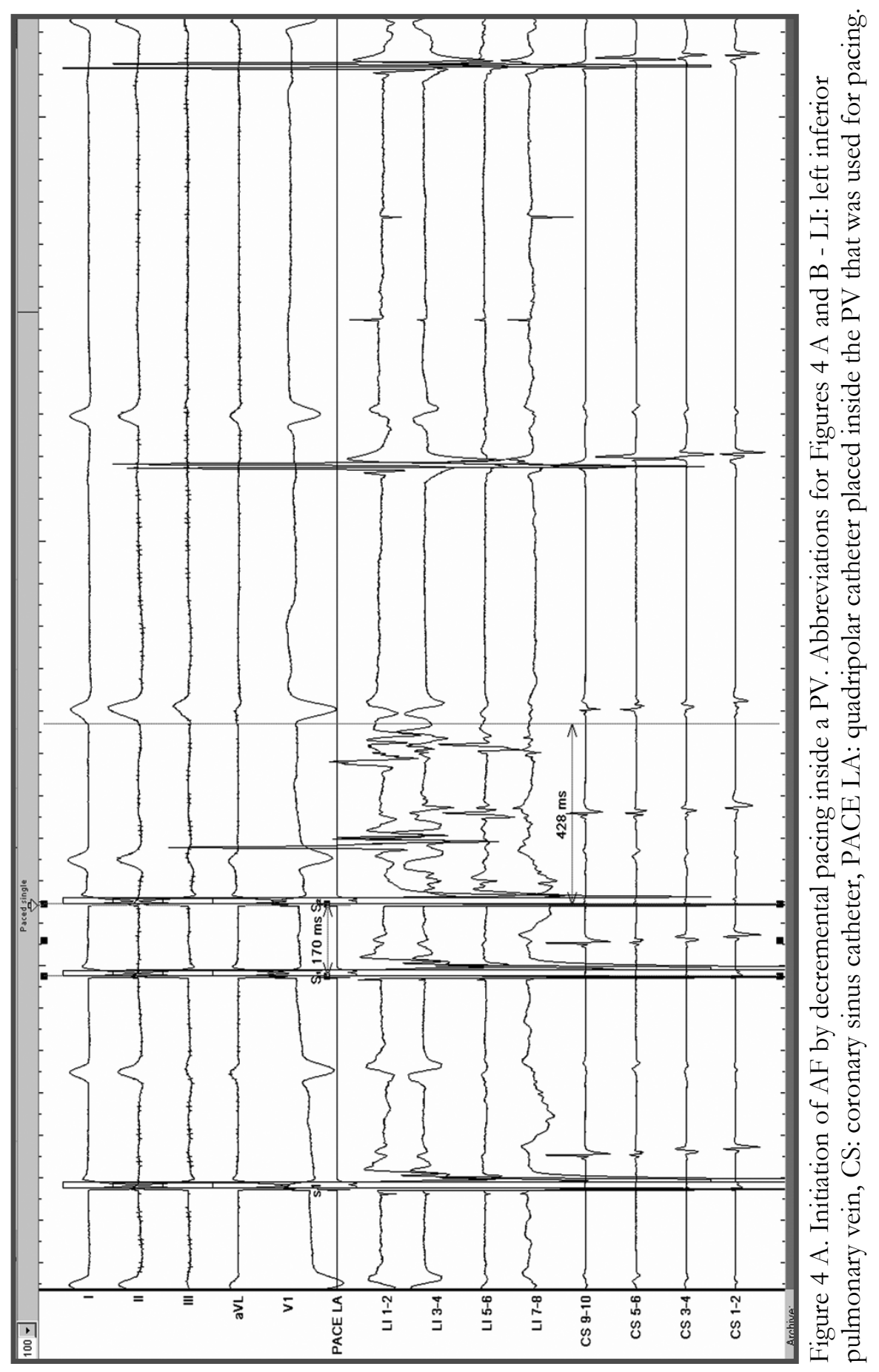




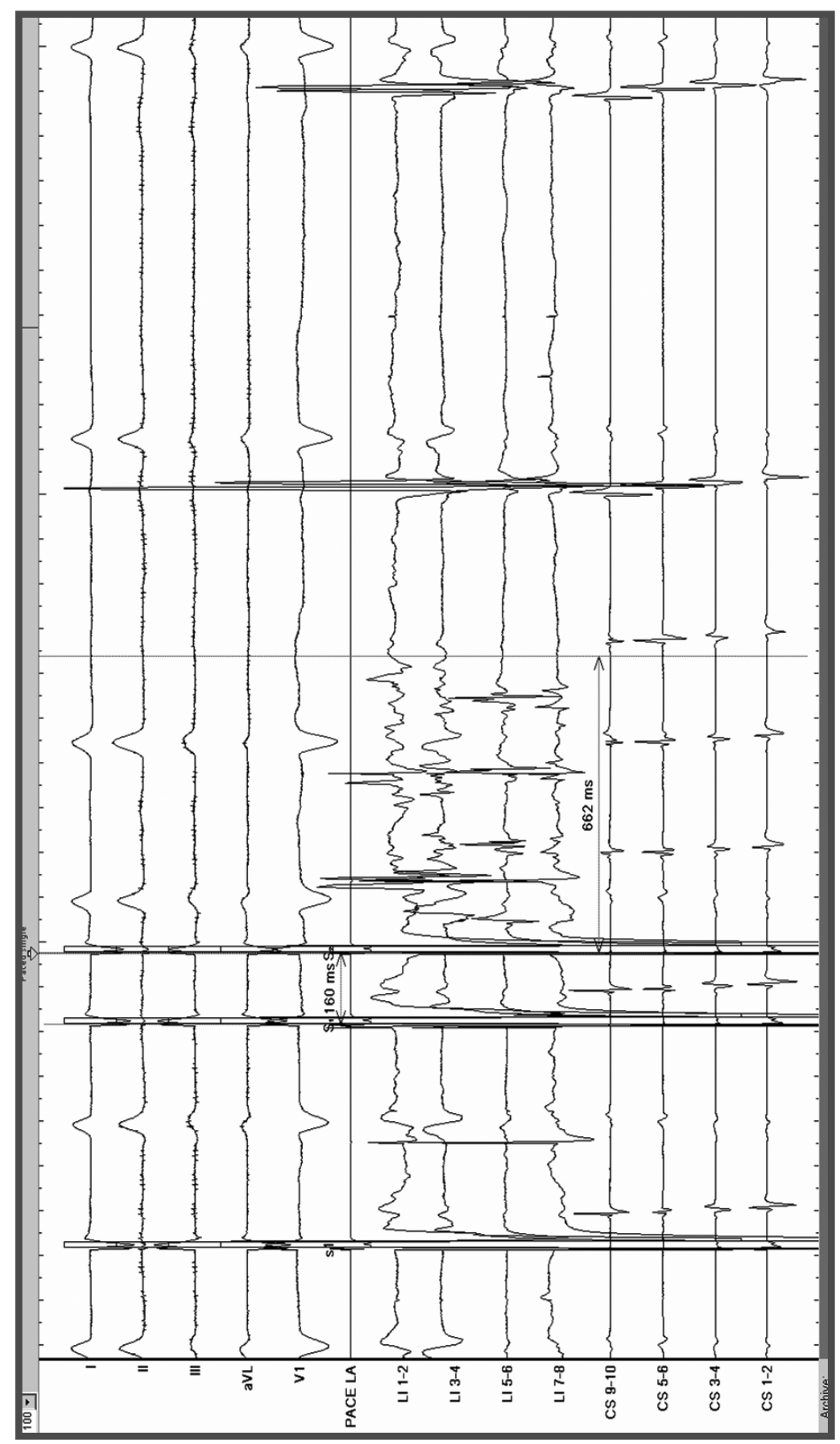

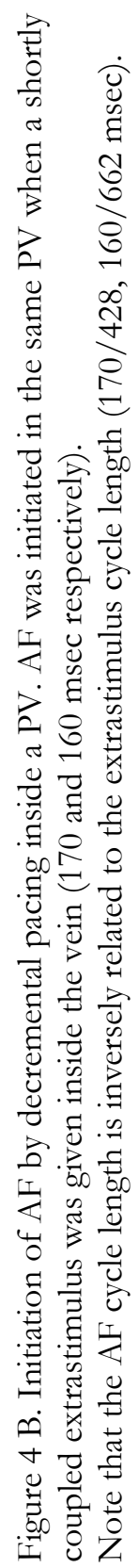




\section{References}

1. Haissaguerre M, Jais P, Shah DC, Takahashi A, Hocini M, Quiniou G, Garrigue S, Le MA, Le MP, Clementy J. Spontaneous initiation of atrial fibrillation by ectopic beats originating in the pulmonary veins. N Engl J Med 1998;339:659-666.

2. Cappato R, Calkins H, Chen SA, Davies W, Iesaka Y, Kalman J, Kim YH, Klein G, Packer D, Skanes A. Worldwide survey on the methods, efficacy, and safety of catheter ablation for human atrial fibrillation. Circulation 2005;111:1100-1105.

3. Oral H, Knight BP, Ozaydin M, Chugh A, Lai SWK, Scharf C, Hassan S, Greenstein R, Han JD, Pelosi F, Jr., Strickberger SA, Morady F. Segmental Ostial Ablation to Isolate the Pulmonary Veins During Atrial Fibrillation: Feasibility and Mechanistic Insights. Circulation 2002;106:1256-1262.

4. Pappone C, Santinelli V. Atrial fibrillation ablation: state of the art. Am J Cardiol 2005;96:59L-64L.

5. Tse HF, Lee KL, Lau CP. Adenosine triphosphate enhanced contrast pulmonary venogram to facilitate pulmonary vein ablation. J Cardiovasc Electrophysiol 2002;13:300.

6. Kumagai K, Ogawa M, Noguchi H, Yasuda T, Nakashima H, Saku K. Electrophysiologic properties of pulmonary veins assessed using a multielectrode basket catheter. J Am Coll Cardiol 2004;43:2281-2289.

7. Jais P, Hocini M, MacLe L, Choi KJ, Deisenhofer I, Weerasooriya R, Shah DC, Garrigue S, Raybaud F, Scavee C, Le MP, Clementy J, Haissaguerre M. Distinctive electrophysiological properties of pulmonary veins in patients with atrial fibrillation. Circulation 2002;106:24792485.

8. Rostock T, Servatius H, Risius T, Ventura R, Weiss C, Meinertz T, Willems S. Impact of Amiodarone on Electrophysiologic Properties of Pulmonary Veins in Patients with Paroxysmal Atrial Fibrillation. Journal of Cardiovascular Electrophysiology 2005;16:39-44.

9. Haissaguerre M, Jais P, Shah DC, Garrigue S, Takahashi A, Lavergne T, Hocini M, Peng JT, Roudaut R, Clementy J. Electrophysiological End Point for Catheter Ablation of Atrial Fibrillation Initiated From Multiple Pulmonary Venous Foci. Circulation 2000;101:1409-1417.

10. Cappato R, Negroni S, Pecora D, Bentivegna S, Lupo PP, Carolei A, Esposito C, Furlanello F, De AL. Prospective assessment of late conduction recurrence across radiofrequency lesions producing electrical disconnection at the pulmonary vein ostium in patients with atrial fibrillation. Circulation 2003;108:1599-1604.

11. Pappone C, Rosanio S, Oreto G, Tocchi M, Gugliotta F, Vicedomini G, Salvati A, Dicandia C, Mazzone P, Santinelli V, Gulletta S, Chierchia S. Circumferential Radiofrequency Ablation of Pulmonary Vein Ostia : A New Anatomic Approach for Curing Atrial Fibrillation. Circulation 2000;102:2619-2628.

12. Deisenhofer I, Estner H, Zrenner B, Schreieck J, Weyerbrock S, Hessling G, Scharf K, Karch MR, Schmitt C. Left atrial tachycardia after circumferential pulmonary vein ablation for atrial fibrillation: incidence, electrophysiological characteristics, and results of radiofrequency ablation. Europace 2006;8:573-582.

13. Pappone C, Oral H, Santinelli V, Vicedomini G, Lang CC, Manguso F, Torracca L, Benussi S, Alfieri O, Hong R, Lau W, Hirata K, Shikuma N, Hall B, Morady F. Atrio-Esophageal Fistula as a Complication of Percutaneous Transcatheter Ablation of Atrial Fibrillation. Circulation 2004;109:2724-2726.

14. Sacher F, Monahan KH, Thomas SP, Davidson N, Adragao P, Sanders P, Hocini M, Takahashi Y, Rotter M, Rostock T, Hsu LF, Clementy J, Haissaguerre M, Ross DL, Packer DL, Jais P. Phrenic Nerve Injury After Atrial Fibrillation Catheter Ablation: Characterization and Outcome in a Multicenter Study. J Am Coll Cardiol 2006;47:2498-2503. 
15. Nanthakumar K, Lau YR, Plumb VJ, Epstein AE, Kay GN. Electrophysiological Findings in Adolescents With Atrial Fibrillation Who Have Structurally Normal Hearts. Circulation 2004;110:117-123.

16. Ehrlich JR, Cha TJ, Zhang L, Chartier D, Melnyk P, Hohnloser SH, Nattel S. Cellular electrophysiology of canine pulmonary vein cardiomyocytes: action potential and ionic current properties. J Physiol 2003;551:801-813.

17. Arora R, Verheule S, Scott L, Navarrete A, Katari V, Wilson E, Vaz D, Olgin JE. Arrhythmogenic substrate of the pulmonary veins assessed by high-resolution optical mapping. Circulation 2003;107:1816-1821.

18. Hocini M, Ho SY, Kawara T, Linnenbank AC, Potse M, Shah D, Jais P, Janse MJ, Haissaguerre M, de Bakker JM. Electrical conduction in canine pulmonary veins: electrophysiological and anatomic correlation. Circulation 2002;105:2442-2448. 


\section{CHAPTER VII}

\section{Atrial tachycardia originating from the pulmonary vein: importance of the stimulation sites.}

Wendel Moreira, MD, Carl Timmermans, MD, PhD, Hein J. J. Wellens, MD, PhD*, and Luz-Maria Rodriguez, MD, PhD

From the Department of Cardiology, Academic Hospital Maastricht and *Cardiovascular Research Institute Maastricht (CARIM), Maastricht, the Netherlands

Manuscript accepted for publication in the

Texas Heart Institute Journal 


\begin{abstract}
We describe a case where using different stimulation points we were able to demonstrate the electrophysiologic properties of an arrhythmogenic pulmonary vein (PV) compared to the others and successfully treat a focal atrial tachycardia. From this case we demonstrate that the known importance of the stimulation site in inducing arrhythmias also applies to the left atrium (LA)/PVs area and by using different pacing maneuvers, unique arrhythmogenic parameters in that region can be revealed and also be used to guide a successful ablation.
\end{abstract}




\section{Introduction}

The introduction of percutaneous ablative techniques for atrial fibrillation (AF) brought along new information regarding a previously "overseen" region by the electrophysiologist - the left atrium (LA)/ pulmonary veins (PV)s region. The AF procedures started with ablation of specific points in the PVs, followed by isolation of all of them (still in use) and from then on, variations which include multiple lines guided by electro anatomic (and not electrophysiological) mapping PVs are being employed, all of those with encouraging results. Nevertheless, pacing maneuvers are rarely used to evaluate the electrophysiological properties around the target areas. Having in mind the known concept of the importance of stimulation sites in inducing many other kinds of arrhythmias (e.g: AVNRT, AT, VT,...) we evaluated if the former would also apply to the LA/PV region.

\section{Case Report}

A 53 years old man with no significant past medical history (who had a negative cardiac work-up in another institution) presented to us due to recurrent episodes of palpitation and syncope. An implantable loop recorder (Reveal TM Medtronic Inc) revealed symptoms related episodes of typical atrial flutter (AFL) and atrial tachycardia (AT).

We decided to treat the AFL first with cavotricuspid isthmus ablation using cryothermy. The procedure was successfully performed. However, 4 weeks later, his symptomatology recurred and correlated with bouts of AT. Twelve lead ECG suggested a left atrial tachycardia (Figure 1). The patient opted to have a second electrophysiological study for evaluation of his AT over the continuous use of antiarrhythmic drugs.

During the subsequent electrophysiological study a decapolar catheter was positioned in the CS (coronary sinus) and a quadripolar in the His bundle region. Transseptal approach guided by transesophageal echocardiogram was used. Two LASSO ${ }^{\text {TM }}$ catheters along with a cryocatheter were positioned in the LA. The LASSO ${ }^{\mathrm{TM}}$ catheters were then placed in the ostial region of each left sided PV.

To induce the arrhythmia we used the following protocol: basic drive cycle lengths (8 stimuli) of 500 and $430 \mathrm{msec}$ with a single coupled premature extrastimulus (starting at $400 \mathrm{msec}$ ). Decremental stimulation was performed with shortened coupling interval in 10-msec steps until refractoriness was reached.

Pacing at a 2 msec pulse width and twice the diastolic threshold was per- 
formed from CS, in the LA (before the LASSO ${ }^{\mathrm{TM}}$ catheter) and inside each PV pre and post ablation. Three steps of subsequently stimulation trains were continued after the refractory period was achieved to potentially unmask a gap phenomenon.

Figure 1. 12 lead ECG of the tachycardia.

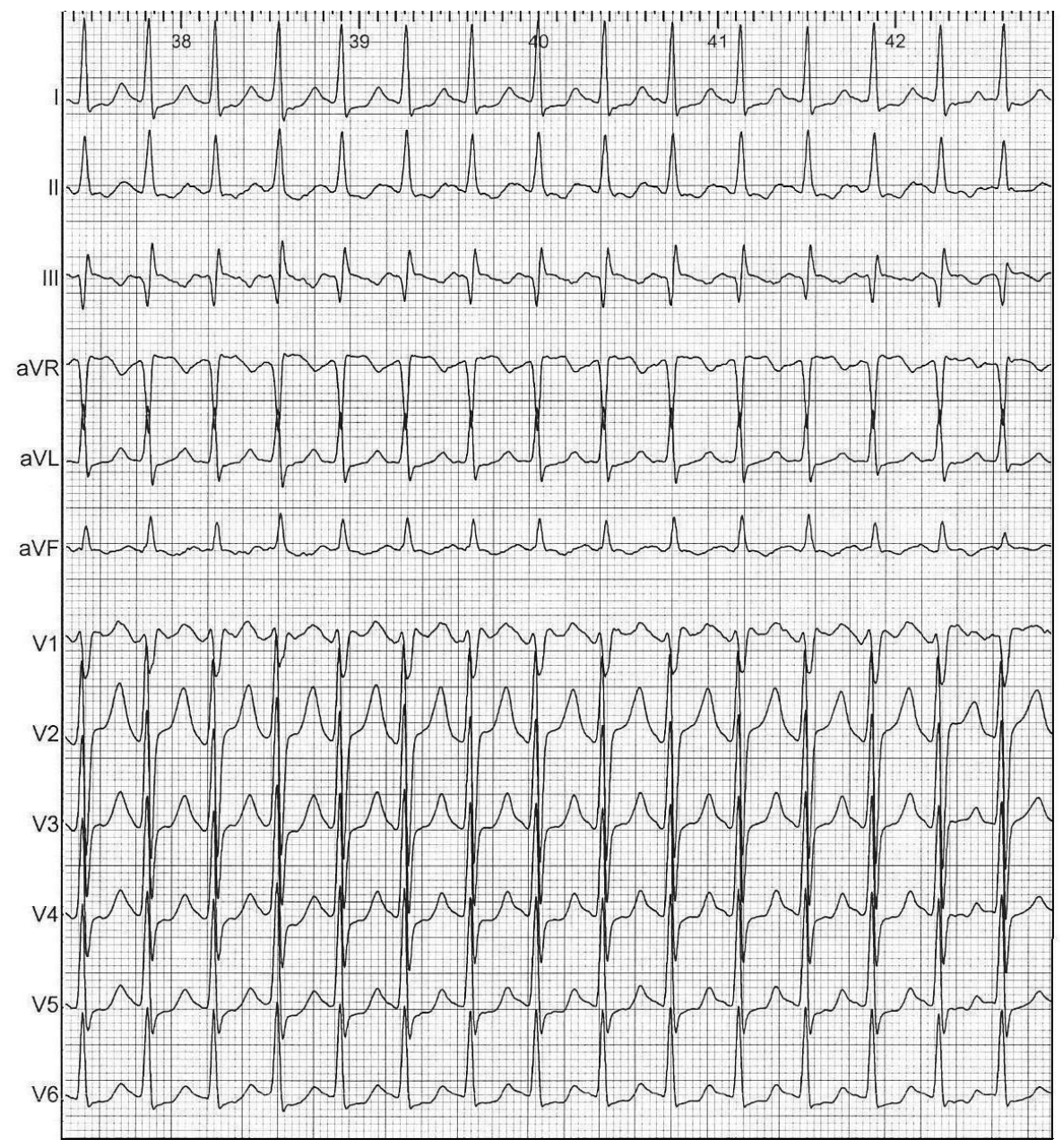

Legend: 12 Lead ECG of the clinical atrial tachycardia. Note that the polarity of the $\mathrm{p}$ wave is flat in lead I, negative in AVL and positive in inferior leads. This suggests a left atrial origin of the tachycardia. 
The following table shows the refractory periods of at different stimulation sites before and after ablation (Table).

Atrial tachycardia was only induced when pacing from inside the LIPV (left inferior pulmonary vein) (Figure 2). CS pacing and pacing from outside the vein (LA) did not induce AT. Cryoisolation of the LIPV was performed. After that, despite using aggressive pacing protocols, no further arrhythmias could be induced. There were no acute or chronic complications related to the procedure. After one year follow-up the patient is arrhythmia free.

Table: Refractory Periods in msec pre and post ablation.

\begin{tabular}{|c|c|c|c|c|}
\hline \multicolumn{5}{|l|}{ Pre-Ablation } \\
\hline $\begin{array}{c}\text { Site of stimulati- } \\
\text { on }\end{array}$ & $\begin{array}{c}\text { S1-S1 } 500 \\
\text { Outside PV } \\
\text { (AERP) }\end{array}$ & $\begin{array}{l}\text { S1-S1 } 500 \\
\text { Inside PV } \\
\text { (PVERP) }\end{array}$ & $\begin{array}{c}\text { S1-S1 } 430 \\
\text { Outside PV } \\
\text { (AERP) }\end{array}$ & $\begin{array}{l}\text { S1-S1 } 430 \\
\text { Inside PV } \\
\text { (PVERP) }\end{array}$ \\
\hline LSPV & 190 & 220 & 190 & 210 \\
\hline LIPV & 190 & $<100$ & 190 & $<100$ \\
\hline RSPV & 220 & 230 & 210 & 200 \\
\hline RIPV & 200 & 230 & 200 & 210 \\
\hline \multicolumn{5}{|l|}{ Post-Ablation } \\
\hline $\begin{array}{c}\text { Site of stimulati- } \\
\text { on }\end{array}$ & $\begin{array}{c}\text { S1-S1 } 500 \\
\text { Outside PV } \\
\text { (AERP) }\end{array}$ & $\begin{array}{l}\text { S1-S1 } 500 \\
\text { Inside PV } \\
\text { (PVERP) }\end{array}$ & $\begin{array}{c}\text { S1-S1 430 } \\
\text { Outside PV } \\
\text { (AERP) }\end{array}$ & $\begin{array}{l}\text { S1-S1 430 } \\
\text { Inside PV } \\
\text { (PVERP) }\end{array}$ \\
\hline LSPV & 220 & 210 & 200 & 200 \\
\hline LIPV & 180 & No capture & 170 & No capture \\
\hline RSPV & 230 & 220 & 210 & 210 \\
\hline RIPV & 210 & 220 & 200 & 200 \\
\hline
\end{tabular}

Legend: Note the difference in refractory periods between the left atrium (LA pacing outside the vein) and the arrhythmogenic PV (LIPV) pre ablation. This gradient of almost $100 \%$ is eliminated post ablation when no further tachycardia could be induced.

Abbreviations: LSPV: left superior pulmonary vein; LIPV: left inferior pulmonary vein; RSPV: right superior pulmonary vein; RIPV: right inferior pulmonary vein. AERP: atrial effective refractory period; PVERP: pulmonary vein effective refractory period. 


\section{Discussion}

The current advances in the percutaneous ablative therapy for the treatment of AF have helped us understand more extensively the pathophysiology of this arrhythmia. Segmental PVI 1,2 and circumferential ${ }^{3,4}$ PVs ablation along with empiric lines in the LA ${ }^{5,6}$ using electroanatomic mapping are the most common methods utilized at present time. One interesting point of this procedure is that only a few stimulation protocols (if any) are routinely used. The majority of them are directed towards differentiating PVs from LA potentials.

In order to better delineate LA/PV potentials, pacing from the CS lead has been advocated by some authors. ${ }^{8,9}$ Constant pacing at a cycle length of $600 \mathrm{~ms}$ from the CS has been shown to decrease the overlap of the atrial and PV electrograms in $50 \%$ of the veins. ${ }^{8}$ Others ${ }^{9}$ have proposed that premature stimulation from the CS could also delineate PV/LA potentials. One pertinent finding in Tada's paper' ${ }^{9}$ is that AF was never induced using this pacing protocol. In our patient we also could not induce AF when pacing from the CS but when pacing from inside the vein, arrhythmias were easily induced. We propose the following explanations for this fact:

1) Unidirectional block related to the orientation and geometrical expansion of fibers in the PV. Kleber and Rudy ${ }^{7}$ report that, at a critical strand width immediately beyond an abrupt tissue expansion (in our case from LA to LIPV), propagation of a wavefront is blocked while conduction is maintained in the opposite direction (unidirectional block);

2) Increase in safety factor for impulse conduction in oblique (PV) compared to parallel (LA) tissues ${ }^{7}$;

3) The distance from the stimulation site to the tissue to be evaluated should be considered as well since it is known that the inducibility of reentry is inversely related to the space between the electrode and the arrhythmogenic site. A recent report of heterogeneous depolarization amongst myocardial cells present inside the pulmonary veins ${ }^{12}$ ratifies the importance of the stimulation point.

Another consideration is the effective refractory period (ERP) we found using the described stimulation technique. Not only the arrhythmogenic PV had an extremely short ERP $(<100 \mathrm{~ms})$ but the gradient between inside an outside the vein was almost $100 \%$. All the other PVs did not show any gradient.

This anisotropic region is ideal for reentry, which can be easily postulated as a mechanism for our patient's arrhythmia. After we ablated those myocardial sleeves (no further capture post cryoablation) the gradient that drove the substrate for the arrhythmia was eliminated along with the atrial tachycardia.

It is also important to notice that similar ERP findings were described in a study by Jais ${ }^{10}$ but since more than one third of his patients were on amiodar- 
one and the former, in a recent study by Rostock ${ }^{11}$, was found to significantly alter the electrophysiological properties of the PVs. These finding indicates that in order to obtain the real ERP of the PVs, patients must be off amiodarone (the case of our patient). Furthermore, this method of pacing might help evaluate the acute procedural success in patients who are submitted to PVI for the treatment of AF. 


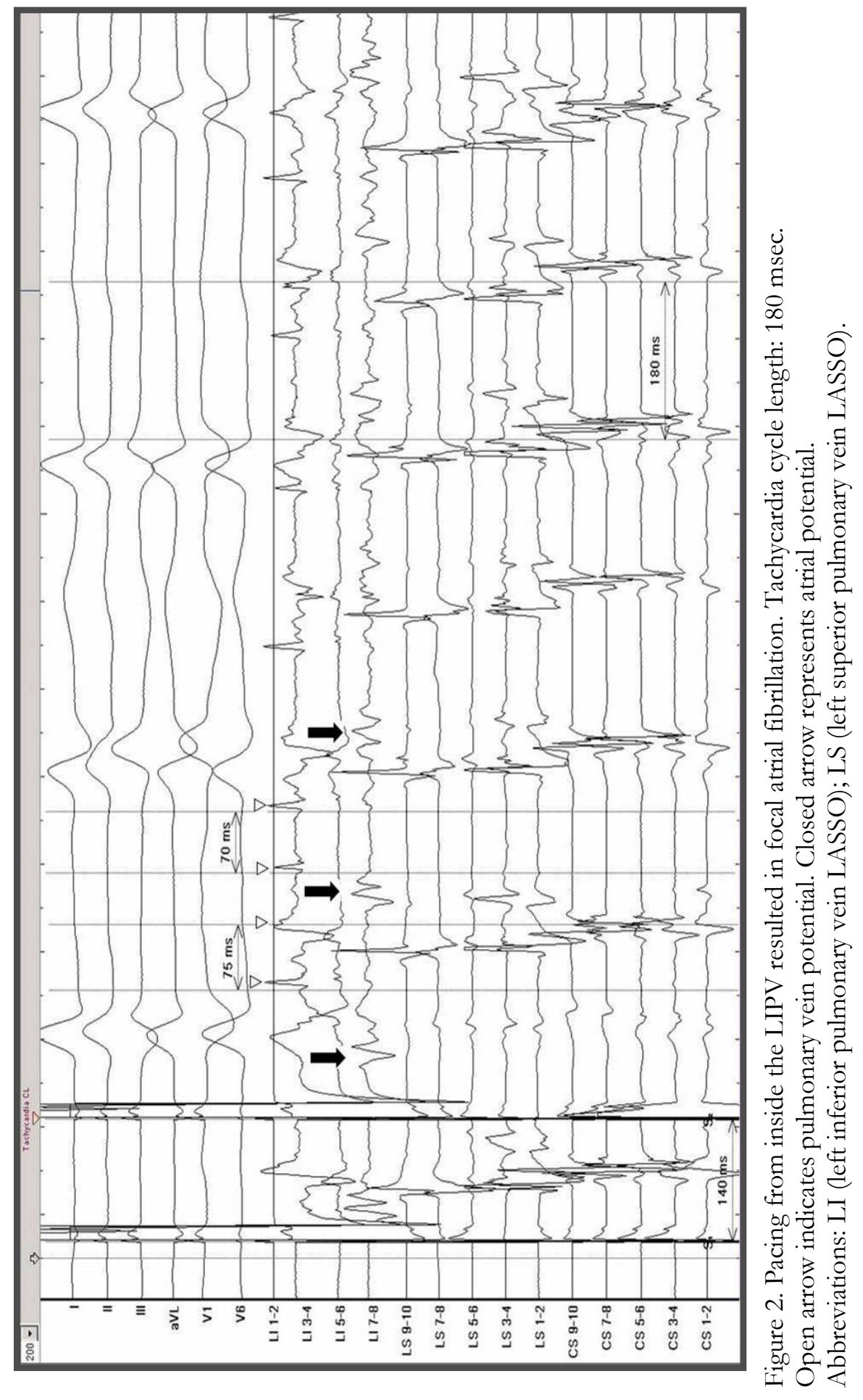




\section{References}

1. Oral H, Knight BP, Tada H, Ozaydin M, Chugh A, Hassan S, Scharf C et al.: Pulmonary vein isolation for paroxysmal and persistent atrial fibrillation. Circulation 2002;105:10771081.

2. Hocini M, Sanders P, Jais P, Hsu LF, Takahashi Y, Rotter M, Clementy J et al.: Techniques for curative treatment of atrial fibrillation. J Cardiovasc Electrophysiol 2004;15:1467-1471.

3. Pappone C, Rosanio S, Oreto G, Tocchi M, Gugliotta F, Vicedomini G, Salvati A et al.: Circumferential radiofrequency ablation of pulmonary vein ostia:A new anatomic approach for curing atrial fibrillation. Circulation 2000;102:2619-2628.

4. Pappone C, Santinelli V: The who, what, why, and how-to guide for circumferential pulmonary vein ablation. J Cardiovasc Electrophysiol 2004;15:1226-1230.

5. Oral H, Scharf C, Chugh A, Hall B, Cheung P, Good E, Veerareddy S et al.: Catheter ablation for paroxysmal atrial fibrillation: Segmental pulmonary vein ostial ablation versus left atrial ablation. Circulation 2003;108:2355-2360.

6. Pappone C, Manguso F, Vicedomini G, Gugliotta F, Santinelli O, Ferro A, Gulletta S et al.: Prevention of iatrogenic atrial tachycardia after ablation of atrial fibrillation: A prospective randomized study comparing circumferential pulmonary vein ablation with a modified approach. Circulation 2004;110:3036-3042.

7. Kleber, A and Rudy, Y: Basic mechanisms of cardiac impulse propagation and associated arrhythmias. Physiol Rev 2004; 84: 431-488,

8. Tada H, Oral H, Greenstein R, Pelosi F Jr, Knight BP, Strickberger SA, Morady F. Differentiation of atrial and pulmonary vein potentials recorded circumferentially within pulmonary veins. J Cardiovasc Electrophysiol 2002;13:118-123.

9. Tada H, Oral H, Ozaydin M, Greenstein R, Pelosi F Jr, Knight BP, Strickberger SA et al. Response of pulmonary vein potentials to premature stimulation. J Cardiovasc Electrophysiol 2002;13:33-37.

10. Jaïs P, Hocini M, Macle L, Choi KJ, Deisenhofer I, Weerasooriya R, et al. Distinctive electrophysiological properties of pulmonary veins in patients with atrial fibrillation. Circulation 2002; 106: 2479-2485.

11. Rostock, T, Servatius, H , Risius, T, et al. Impact of Amiodarone on Electrophysiologic Properties of Pulmonary Veins in Patients with Paroxysmal Atrial Fibrillation. Journal of Cardiovascular Electrophysiology 16 (1), 39-44. 2005.

12. Miyauchi Y, Hayashi H, Miyauchi M, Okuyama Y, Mandel WJ, Chen PS, Karagueuzian HS. Heterogeneous pulmonary vein myocardial cell repolarization implications for reentry and triggered activity. Heart Rhythm. 2005 Dec;2(12):1339-45. 



\section{CHAPTER VIII}

\section{Feasibility of Cryoablation for Atrial Fibrillation Using a Non-contact Mapping System}

Wendel Moreira, MD, Carl Timmermans, MD, PhD, Hein J. J. Wellens, MD, PhD*, David Perez, MD, Yuka Mizusawa, MD, Suzanne Philippens, RN and Luz-Maria Rodriguez, MD, PhD

From the Department of Cardiology, Academic Hospital Maastricht and *Cardiovascular Research Institute Maastricht (CARIM), Maastricht, the Netherlands

Abstract presented at the First BenSca ESI user Group Meeting, Stockholm, Sweden, April 2006.

Manuscript submitted for publication. 


\section{Abstract}

Objectives: The majority of AF procedures use a navigation system that is limited to catheters using radiofrequency (RF). This factor prevents the use of other catheters having other energy sources. We report the feasibility of using $\mathrm{Na}$ $v X{ }^{\circledR}$ as a navigation system when a different energy source (in our case cryothermy) is used for the percutaneous treatment of atrial fibrillation (AF).

Methods: Forty consecutive patients (30 men, age: $40 \pm 10$ yrs) with paroxysmal AF were included. The first 20 patients were ablated using fluoroscopy guidance and in the following 20 patients the $\mathrm{NavX}{ }^{\circledR}$ system was used. Segmental PV cryoisolation, using the Lasso ${ }^{\mathrm{TM}}$ catheter, was performed.

Results: All targeted PVs were isolated. NavX ${ }^{\circledR}$ guided procedures significantly reduced the fluoroscopy time $(71 \pm 20 \mathrm{~min}$ vs $91 \pm 18 \mathrm{~min} ; \mathrm{P}<0.003)$. The procedure time was also reduced with $\mathrm{NavX}{ }^{\circledR}$ compared to fluoroscopy guided procedures, but this did not reach the significance level (295 $\pm 48 \mathrm{~min}$ vs $318 \pm 44$ $\min ; \mathrm{P}=0.10$ ).

Conclusions: The high resolution 3-dimensional reconstruction of the Lasso ${ }^{\mathrm{TM}}$ and CryoBlater ${ }^{\mathrm{TM}}$ catheters using $\mathrm{NavX}{ }^{\circledR}$ allows a precise identification of the sites targeted for PV isolation. Those results support the feasibility of using a navigation system with different energy sources (in our case cryothermy) for the ablation of AF. 


\section{Introduction}

Percutaneous ablative therapy for atrial fibrillation (AF) has become a standard procedure. Many current techniques used nowadays rely on the aid of non fluoroscopic navigation systems.

In a worldwide survey done by Cappato and colleagues ${ }^{1}$ the navigation system chosen by the great majority of centers was CARTOTM which limits the ablative procedure to radiofrequency (RF) energy. The same study also showed a big discrepancy regarding the source of power used. Of the data available for 4918 patients: 4127 received radiofrequency current ablation; 220 cryotherapy; 115 ultrasound; 94 laser and 93, other forms of energy.

Radiofrequency ablation has been found to have some disadvantages over other sources of energy, particularly in left sided procedures..$^{2-5}$ Therefore the ability to expand the ablative options and at the same time still take advantage of a navigation system would be welcome.

The aim of our study was to access the feasibility of using a different source of energy - in our case cryothermy - with a non contact navigation system $\left(\mathrm{Nav} \mathrm{X}^{\circledR}\right)$ in $\mathrm{AF}$ ablation.

\section{Methods}

Forty patients with drug refractory, symptomatic lone AF (and deemed candidates for PVI) were enrolled from June 2004 to November 2005.

In the first 20 patients the $\mathrm{NavX}{ }^{\circledR}$ system was used to aid the cryoablation procedure (NavX ${ }^{\circledR}+$ Fluoro group) whereas in the following 20 patients, only fluoroscopic guidance was used (fluoro group).

All the patients in the study signed a written consent form that was approved by the local ethics committee.

Before PVI, all individuals were orally anticoagulated to a therapeutic international normalized ratio of 2 to 3 for at least three weeks and up to one month after ablation.

Transesophageal echocardiogram was performed during the procedure to exclude left atrial thrombus and to aid in the transeptal puncture. 


\section{Electropysiologic Study and Ablation}

All patients were studied in the fasting state without sedation. Those presenting in $\mathrm{AF}$ while in the catheterization room were converted to sinus rhythm by internal or external cardioversion.

Procedure time was counted from the first needlestick until the sheaths were pulled. Fluoro time was the total time using fluoroscopy.

During the procedure (but after the transseptal punctures) intravenous heparin was given as a 100-IU $/ \mathrm{kg}$ bolus dose followed by boluses of $5000 \mathrm{IU}$ every 1.5 hour if needed to keep an ACT greater than 300 seconds. Protamine was administered routinely as a reversal agent before pulling the sheaths.

Under local anesthesia, a decapolar catheter was positioned in the distal coronary sinus and a quadripolar in the His bundle region via the femoral route. Double trans-septal catheterization was performed under fluoroscopic and transesophageal guidance.

The 12 lead ECG and the intracardiac electrograms were recorded and stored by BARD Labsystem PRO.

\section{The Non-fluoroscopic navigation system}

The EnSite NavX ${ }^{\circledR}$ system utilizes three pairs of nominally orthogonal patches that are driven in time multiplex, with currents of $350 \mathrm{~mA}$ at a frequency of 5.7 $\mathrm{kHz}$. The magnitude of the resulting electrical potential shows a linear decrease along its axis and allows exact electrode localization in relation to a reference, in this study, the proximal coronary sinus catheter electrode. The system allows the realtime visualization of the positions of up to 12 catheters. (Figure 1).

Venograms of all targeted PVs were obtained. A deflectable, circumferential decapolar mapping catheter (LASSO ${ }^{\mathrm{TM}}$, Biosense-Webster Inc., Baldwin Park, California) was advanced into the left atrium and positioned at the ostium of each PV. A deflectable, $10.5 \mathrm{~F}$ cryoablation catheter (CryoCor Inc.) was inserted into the left atrium through a $11 \mathrm{~F}$ to $12 \mathrm{~F}, 65-\mathrm{cm}$-long sheath (DAIG, St. Jude Medical Inc., St. Paul, Minnesota, or Cook Inc., Bloomington, Indiana) and used to perform the ablation. Using the coronary sinus catheter as reference, the LASSO ${ }^{\mathrm{TM}}$ and the cryoablation catheters were displayed in the $\mathrm{NavX}^{\circledR}$ interface. (Figure 1).

Segmental isolation of PVs, as guided by the recording of PV potentials with the LASSO ${ }^{\mathrm{TM}}$ catheter, was performed using the CryoCor cryoablation system as described previously. ${ }^{6}, 7$ Visual confirmation of the application site corresponding to the LASSO ${ }^{\mathrm{TM}}$ / cryoablation catheter position seen in the NavX ${ }^{\circledR}$ system was also used to ratify the desired location for application. Whenever feasible, all PVs with potentials recorded at their ostium were targeted for isolation. Isolation of the PV was performed during sinus rhythm or coronary sinus pacing by delivering cryoablation at ostial sites that had the earliest bipolar po- 
tential. (Figure 2).

At each effective target site, defined by the abolishment of a PV potential or a change in the PV potential activation sequence during cryothermal application, 3 min of cryoablation was delivered. If no changes in the electrogram were observed after $15 \mathrm{~s}$, despite a catheter tip temperature of $<-90^{\circ} \mathrm{C}$, the application was stopped and the catheter was repositioned. The early procedural end point was complete electrical isolation of PVs based on abolition of all ostial PV potentials or complete entrance conduction block into the PV.

\section{Post Ablation Management}

All patients were monitored for $24 \mathrm{~h}$ and received anticoagulant therapy (warfarin) and the same anti-arrhythmic drugs (AADs) as before the ablation for at least 3 months after the procedure. After three months, the continuation of anti-arrhythmic drugs and anticoagulation was re-evaluated. If the patient had no recurrences, AADs were stopped. If other risk factors for thromboembolic events were present, oral anticoagulation was continued.

A transtelephonic monitoring (TTM) device was given to every patient with instructions to use it daily (preferably at the same time) and when they had symptoms. This monitoring started 30 days before and continued up to day 180 after PVI. From then on, a Holter monitor was used during clinic visits (1, 3, 6, 9 and 12 months) or when patients had symptoms.

\section{Statistical analysis}

All variables are expressed as mean $\pm \mathrm{SD}$. Mean values were compared by 1 -way ANOVA, and the $\mathrm{x} 2$ test (or Fisher's exact test) was used for testing homogeneity in contingency tables. Statistical significance was established at $\mathrm{P}<0.05$.

The authors had full access to the data and take responsibility for its integrity. All authors have read and agree to the manuscript as written. 
Figure 1. Catheters are shown with the LASSO just outside the ostium of LSPV prior to the first application.

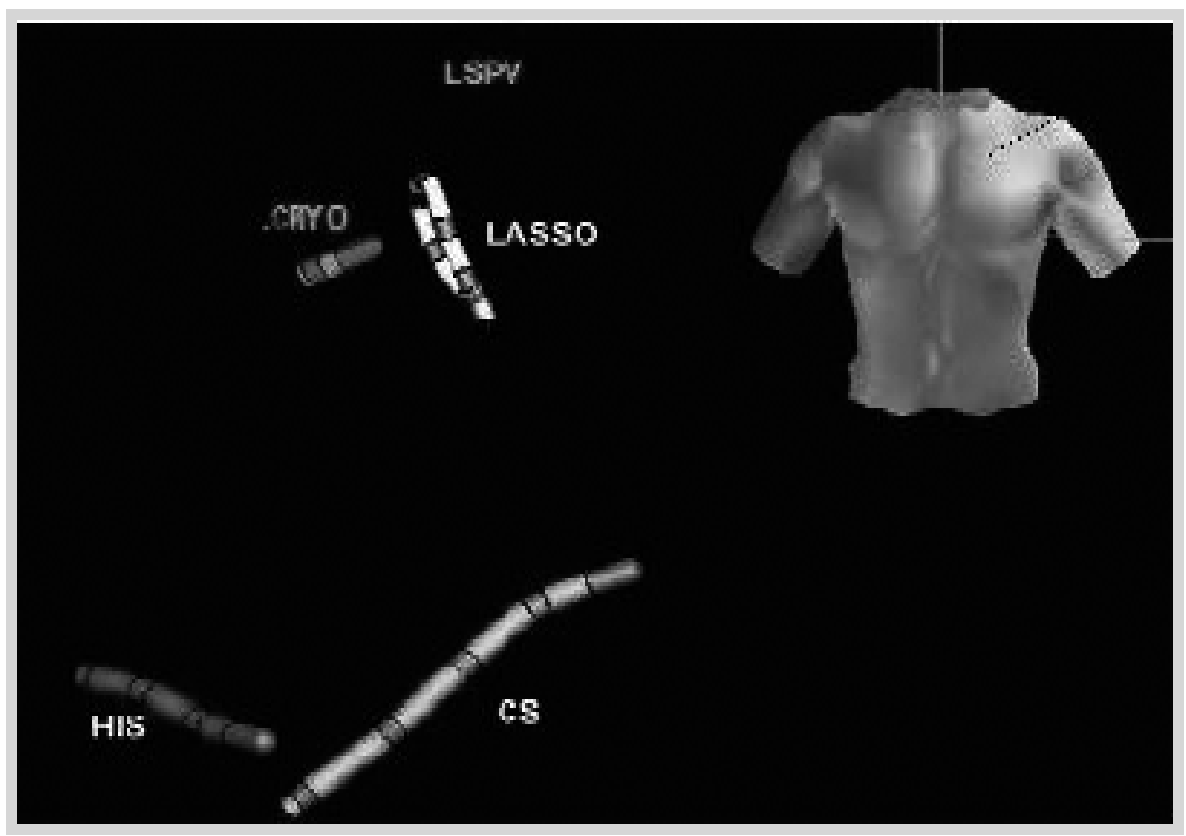

\section{Results}

All patients were referred for PV cryoisolation due to history of paroxysmal AF refractory to medical therapy. There were 30 men and 10 women with a mean age of $40 \pm 10$ years.

The majority of patients had minimal or no structural heart disease (arterial hypertension in 7 patients in the fluoro group and 3 patients in the $\mathrm{NavX} \AA+$ fluoro group, $\mathrm{p}=\mathrm{ns})$. All patients had a normal left atrial diameter: mean of 4.1 $\mathrm{cm}$ in the fluoro group and 3.9 in the $\mathrm{NavX}{ }^{\circledR}+$ fluoro group $(\mathrm{p}=\mathrm{ns})$. Left ventricular ejection fraction (calculated by the Simpsons echocardiographic formula) and mean number of PVs treated did not differ amongst the two groups. (Table). 


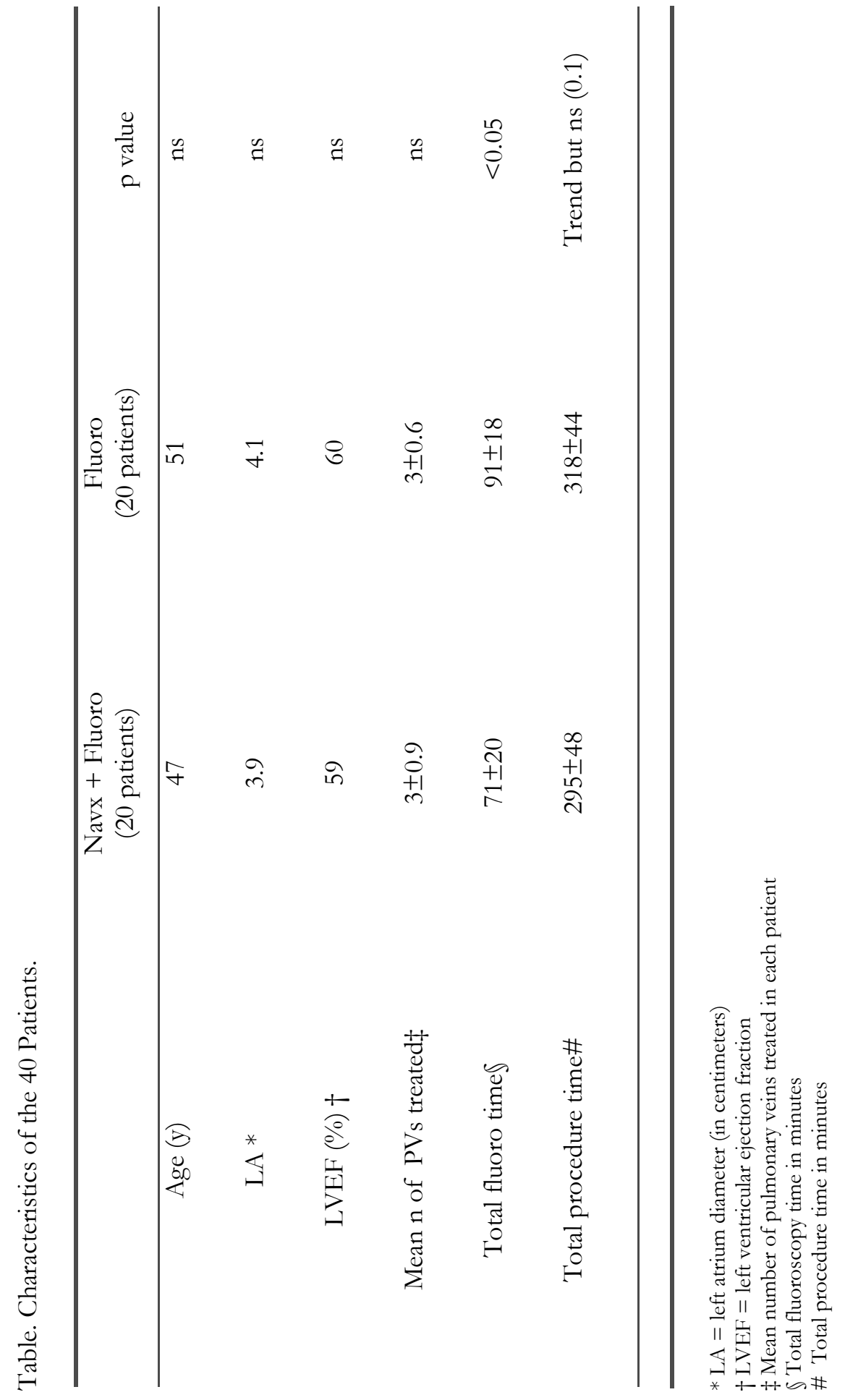


Fluoroscopy time was significant lower in the NavX® group $(71 \pm 20 \mathrm{~min})$ compared to Fluoro only group $(91 \pm 18 \mathrm{~min}) \mathrm{p}<0.05$. The NavX® group had a trend towards a shorter total procedure time $(295 \pm 48 \mathrm{~min})$ when compared to fluoro only $(318 \pm 44 \mathrm{~min})$. It is important to note that the relative long times found in our study are partially due to other research protocols and the time spent assessing end points of the procedure (pacing maneuvers, adenosine and isoproterenol administration).

All the veins with potentials were successfully isolated. (Figure 2). The total number of complete cryoapplications per patient did not differ amongst the 2 groups $\left(\mathrm{NavX}{ }^{\circledR}=16\right.$ and Fluoro $\left.=18, \mathrm{p}=\mathrm{ns}\right)$. No complications occurred during or following the procedure.

After 6 months, a freedom from AF (or significant symptomatic improvement) was observed in 15 patients $(75 \%)$ in both groups, giving an overall success rate of $75 \%$ after the index PVI. Three patients in the NavX ${ }^{\circledR}$ group had a second successful PVI. The remaining two patients had their arrhythmia improved on AADs. Four patients in the Fluoro group underwent a second PVI (3 with total freedom from AF thereafter and one improving on AAD). The one patient who opted not to have a second procedure is doing well.

\section{Discussion}

\section{Main findings}

The use of non fluoroscopic navigation systems in the electrophysiology laboratory grew exponentially with the advance in percutaneous techniques for the treatment of AF. Its advantages in reducing fluoroscopic and procedure times have been previously reported. . $^{812}$ The two most common systems used (CAR$\mathrm{TO}^{\mathrm{TM}}$ and $\mathrm{NavX}{ }^{\circledR}$ ) seem to have similar outcomes in achieving their role as navigation tools which decrease the use of fluoroscopy.10,13

However CARTO ${ }^{\mathrm{TM}}$ limits the ability of the operator to choose the type of energy to be used for the ablation (RF only). Also a reconstruction of atrial anatomy is needed in all CARTO ${ }^{\mathrm{TM}}$ procedures whereas a recent report by Estner et al showed the feasibility of using just the anatomic localization of the Lasso and RF catheters (without the need of morphological reconstruction) in successfully performing segmental PVI - with a significant reduction in fluoro and procedure times. ${ }^{8}$ Based on those findings, we focused our study in evaluating the possibility of combining a different source of energy (in our case cryothermy) with the benefits of a navigation system in the treatment of AF. Even though not much effort was given to prove a reduction in times (since we allowed our patients to be included in other research protocols and also routinely used pacing maneuvers to evaluate end points) we still had a statistically significant decrease in fluoro and a trend towards a decrease in total procedure times. 
We were able to achieve our goal of demonstrating for the first time the feasibility of using a navigation system with an energy source other than radiofrequency (in our case cryothermy) for the treatment of AF.

\section{Differences between Cryothermy and Radiofrequency energy}

Ablative therapy is quickly becoming the treatment of choice for selected patients with lone AF. The great majority of those procedures is being performed using radiofrequency energy. Complications such as pulmonary vein stenosis, esophageal perforations, stroke, etc. , $, 2,14$ are thought to be infrequent but at the same time devastating in this group of relatively young and healthy patients. Many of those adverse events are inherent to radiofrequency, and other forms of energy (such as cryothermy) have been proven superior in this aspect., $4,7,15-17$

Cryothermy does not require conscious sedation or anesthesia as it is painless.(18) Not only this represents more comfort for the patients but also decreases the very low but real complications of anesthesia. It also has the ability to create reversible loss of function allowing the prediction of the effectiveness and safety of a lesion. ${ }^{19,20}$

Cryoenergy causes adherence of the catheter-tip to the underlying tissue during energy delivery assuring accurate lesion creation. ${ }^{21-23}$ This might be important in avoiding catheter dislocation to areas where complications could occur (like the posterior left atrium or inside the PVs).

Cryothermal ablation preserves the extracellular matrix and endothelial integrity. As a result, it has not been associated with pulmonary vein stenosis, esophageal perforation or thromboembolic events during the treatment of atrial fibrillation. ${ }^{24,25}$ Even though the rate of thromboembolic complications during $\mathrm{RF}$ ablation is minimal, its consequences could be aggravated by the presence of right to left shunts (e.g.: patent foramen ovale).

Also in comparison to RF, the lesions from cryoablation are large, transmural and homogeneous with a well-demarcated border zone. ${ }^{26,27}$

While being around for a long time in the surgical field, cryo is still a relatively new catheter based form of energy compared to RF. Efficiency is highly dependent on duration of the freeze (longer times needed to produce a similar lesion as RF) and pressure against the myocardial tissue. ${ }^{28,29}$

\section{Study Limitations}

The fact that other research protocols were being conducted in the same patients might have contaminated our fluoro and procedure times. But since several authors already demonstrated the efficacy of NavX in reducing those, $8,10,12,30$ we focused our findings on the association of a different energy source with a navigation system. 


\section{Conclusions}

The high resolution 3-dimensional reconstruction of the Lasso ${ }^{\mathrm{TM}}$ and CryoBlater ${ }^{\mathrm{TM}}$ catheters allows a precise identification of the sites targeted for isolation of the pulmonary veins. This system provides the feasibility of a navigation system to be used with different energy sources (in our case cryothermy) for the ablation of AF. 
Figure 2.

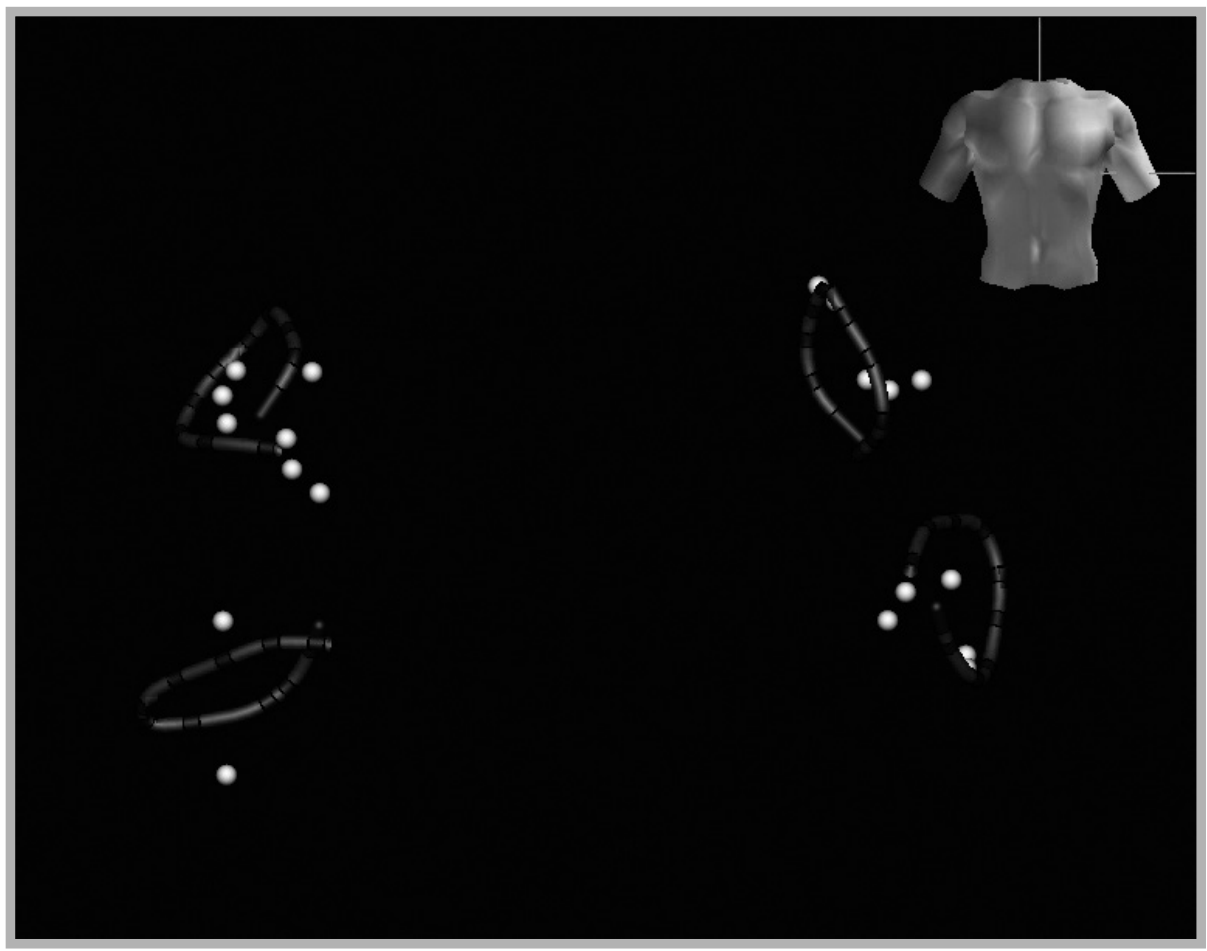

Legend: Points of cryoapplications with LASSO ${ }^{\mathrm{TM}}$ shadows at the ostia of all PVs at the end of the procedure.

Abbreviations: LASSO: LASSO ${ }^{\mathrm{TM}}$ (Biosense-Webster Inc., Baldwin Park, California) circumferential decapolar mapping catheter;

White dots: points where 3 minutes of cryothermy where successful in eliminating PV potentials 


\section{References}

1. Cappato R, Calkins H, Chen SA, et al. Worldwide survey on the methods, efficacy, and safety of catheter ablation for human atrial fibrillation. Circulation 2005; 111:1100-5.

2. Saad EB, Rossillo A, Saad CP, et al. Pulmonary vein stenosis after radiofrequency ablation of atrial fibrillation: functional characterization, evolution, and influence of the ablation strategy. Circulation 2003; 108:3102-7.

3. Saad EB, Marrouche NF, Saad CP, et al. Pulmonary vein stenosis after catheter ablation of atrial fibrillation: emergence of a new clinical syndrome. Ann Intern Med 2003; 138:634-8.

4. Cummings JE, Pacifico A, Drago JL, Kilicaslan F, Natale A. Alternative energy sources for the ablation of arrhythmias. Pacing Clin Electrophysiol 2005; 28:434-43.

5. Wazni OM, Rossillo A, Marrouche NF, et al. Embolic events and char formation during pulmonary vein isolation in patients with atrial fibrillation: impact of different anticoagulation regimens and importance of intracardiac echo imaging. J Cardiovasc Electrophysiol 2005; 16:576-81.

6. Rodriguez LM, Geller JC, Tse HF, et al. Acute results of transvenous cryoablation of supraventricular tachycardia (atrial fibrillation, atrial flutter, Wolff-Parkinson-White syndrome, atrioventricular nodal reentry tachycardia). J Cardiovasc Electrophysiol 2002; 13:1082-9.

7. Rodriguez LM, Timmermans C. Transvenous cryoablation of cardiac arrhythmias. Technol Cancer Res Treat 2004; 3:515-24.

8. Estner HL, Deisenhofer I, Luik A, et al. Electrical isolation of pulmonary veins in patients with atrial fibrillation: reduction of fluoroscopy exposure and procedure duration by the use of a non-fluoroscopic navigation system (NavX). Europace 2006; 8:583-7.

9. Ma CS, Liu X, Dong JZ, et al. [Pulmonary vein antrum isolation guided by 3-D mapping system in 100 patients with chronic atrial fibrillation]. Zhonghua Yi Xue Za Zhi 2006; 86:1111-4.

10. Liu X, Wang XH, Gu JN, Zhou L, Qiu JH. [Electroanatomical systems guided circumferential pulmonary veins ablation for atrial fibrillation: initial experience from comparison between the EnSite-NavX and CARTO system]. Zhonghua Xin Xue Guan Bing Za Zhi 2005; 33:975-8.

11. Pappone C, Augello G, Santinelli V. Atrial fibrillation ablation. Ital Heart J 2005; 6:190-9.

12. Rotter M, Takahashi Y, Sanders P, et al. Reduction of fluoroscopy exposure and procedure duration during ablation of atrial fibrillation using a novel anatomical navigation system. Eur Heart J 2005; 26:1415-21.

13. Earley MJ, Showkathali R, Alzetani M, et al. Radiofrequency ablation of arrhythmias guided by non-fluoroscopic catheter location: a prospective randomized trial. Eur Heart J 2006; 27:1223-9.

14. Cummings JE, Schweikert RA, Saliba WI, et al. Assessment of temperature, proximity, and course of the esophagus during radiofrequency ablation within the left atrium. Circulation 2005; 112:459-64.

15. Tse HF, Kwong YL, Lau CP. Transvenous cryoablation reduces platelet activation during pulmonary vein ablation compared with radiofrequency energy in patients with atrial fibrillation. J Cardiovasc Electrophysiol 2005; 16:1064-70.

16. Tse HF, Reek S, Timmermans C, et al. Pulmonary vein isolation using transvenous catheter cryoablation for treatment of atrial fibrillation without risk of pulmonary vein stenosis. J Am Coll Cardiol 2003; 42:752-8.

17. Rodriguez LM, Leunissen J, Hoekstra A, et al. Transvenous cold mapping and cryoablation of the AV node in dogs: observations of chronic lesions and comparison to those obtained using radiofrequency ablation. J Cardiovasc Electrophysiol 1998; 9:1055-61. 
18. Timmermans C, Ayers GM, Crijns HJ, Rodriguez LM. Randomized study comparing radiofrequency ablation with cryoablation for the treatment of atrial flutter with emphasis on pain perception. Circulation 2003; 107:1250-2.19. Skanes AC, Dubuc M, Klein GJ, et al. Cryothermal ablation of the slow pathway for the elimination of atrioventricular nodal reentrant tachycardia. Circulation 2000; 102:2856-60.

20. Skanes AC, Jones DL, Teefy P, et al. Safety and feasibility of cryothermal ablation within the mid- and distal coronary sinus. J Cardiovasc Electrophysiol 2004; 15:1319-23.

21. Siu CW, Tse HF, Lau CP. Avoidance of electromagnetic interference to implantable cardiovertor-defibrillator during atrioventricular node ablation for atrial fibrillation using transvenous cryoablation. Pacing Clin Electrophysiol 2006; 29:914-6.

22. Skanes AC, Klein G, Krahn A, Yee R. Cryoablation: potentials and pitfalls. J Cardiovasc Electrophysiol 2004; 15:S28-S34.

23. Tuzcu V, Gonzalez MB, Schranz D. Cryoablation: better catheter stability compared to RF ablation. Anadolu Kardiyol Derg 2006; 6:182-4.

24. Khairy P, Chauvet P, Lehmann J, et al. Lower incidence of thrombus formation with cryoenergy versus radiofrequency catheter ablation. Circulation 2003; 107:2045-50.

25. Tse HF, Kwong YL, Lau CP. Transvenous cryoablation reduces platelet activation during pulmonary vein ablation compared with radiofrequency energy in patients with atrial fibrillation. J Cardiovasc Electrophysiol 2005; 16:1064-70.

26. Messali A, Lavergne T, Sebag C, et al. [Long-term evaluation of endocavitary cryoablation of nodal reentry]. Arch Mal Coeur Vaiss 2005; 98:628-33.

27. Friedman PL. Catheter cryoablation of cardiac arrhythmias. Curr Opin Cardiol 2005; 20:4854.

28. Lustgarten DL, Keane D, Ruskin J. Cryothermal ablation: mechanism of tissue injury and current experience in the treatment of tachyarrhythmias. Prog Cardiovasc Dis 1999; 41:48198.

29. Tse HF, Lau CP. Impact of duration of cryothermal application on clinical efficacy of pulmonary vein isolation using transvenous cryoablation. Pacing Clin Electrophysiol 2005; 28:839-43.

30. Novak PG, Macle L, Thibault B, Guerra PG. Enhanced left atrial mapping using digitally synchronized NavX three-dimensional nonfluoroscopic mapping and high-resolution computed tomographic imaging for catheter ablation of atrial fibrillation. Heart Rhythm 2004; 1:521-2. 



\section{CHAPTER IX}

General Discussion and Future Perspectives 


\section{Conclusion of the thesis}

We showed that cavotricuspid isthmus (CTI) dependent atrial flutter (AFL) is intimately related to atrial fibrillation (AF). The long term follow-up of our patients submitted to CTI cryoablation indicated the effectiveness of this treatment in common type AFL, by interrupting the macroreentry circuit necessary for its existence. However despite the disappearance of AFL, $69 \%$ of the patients suffered from AF on the long run. This suggests that the culprit arrhythmia was AF and not AFL. This was validated by showing that in patients with paroxysmal AF and no documented common type AFL, segmental pulmonary vein isolation (PVI) alone not only prevented the occurrence of AF in $82 \%$ but also lowered the incidence of sustained common type AFL. The idea that AF is the initiator of AFL (by causing the intercaval line of block necessary for the macroreentry circuit to occur) is illustrated in figure 1 and further explained in figure 2 .

Another important observation we made is that there are three patterns of recurrence of paroxysmal AF after PVI:

1 - Patients in whom the initiating focus is discovered and ablated have no recurrence, indicating the importance to look for triggers. If a source is not found, we suggest a complete electrophysiological evaluation of the PVs in order to identify arrhythmogenic area(s). The presence of a gradient greater than $100 \mathrm{msec}$ in the effective refractory period between the PV and the surrounding LA region is a sign of arrhythmogenicity indicating the necessity for ablation and the ablation site.

2 - Patients with a decrease in number of AF episodes after PVI (starting at 3 months and stabilizing at 9 months) and

3 - Patients having an immediate increase in the number of AF recurrences, which declines throughout one year. Those individuals had more frequently a history of prior AFL.

The latter finding supports that AFL may create a right atrial arrhythmogenic substrate favoring AF recurrences. Figure 2. The interplay between paroxysmal AF and common type AFL suggests that in AFL patients an electrophysiological evaluation of right atrial properties could be of value, looking for ectopic impulse formation and sites of abnormal electrograms. In those patients right atrial substrate modification could be an additional step for effective AF ablation. 


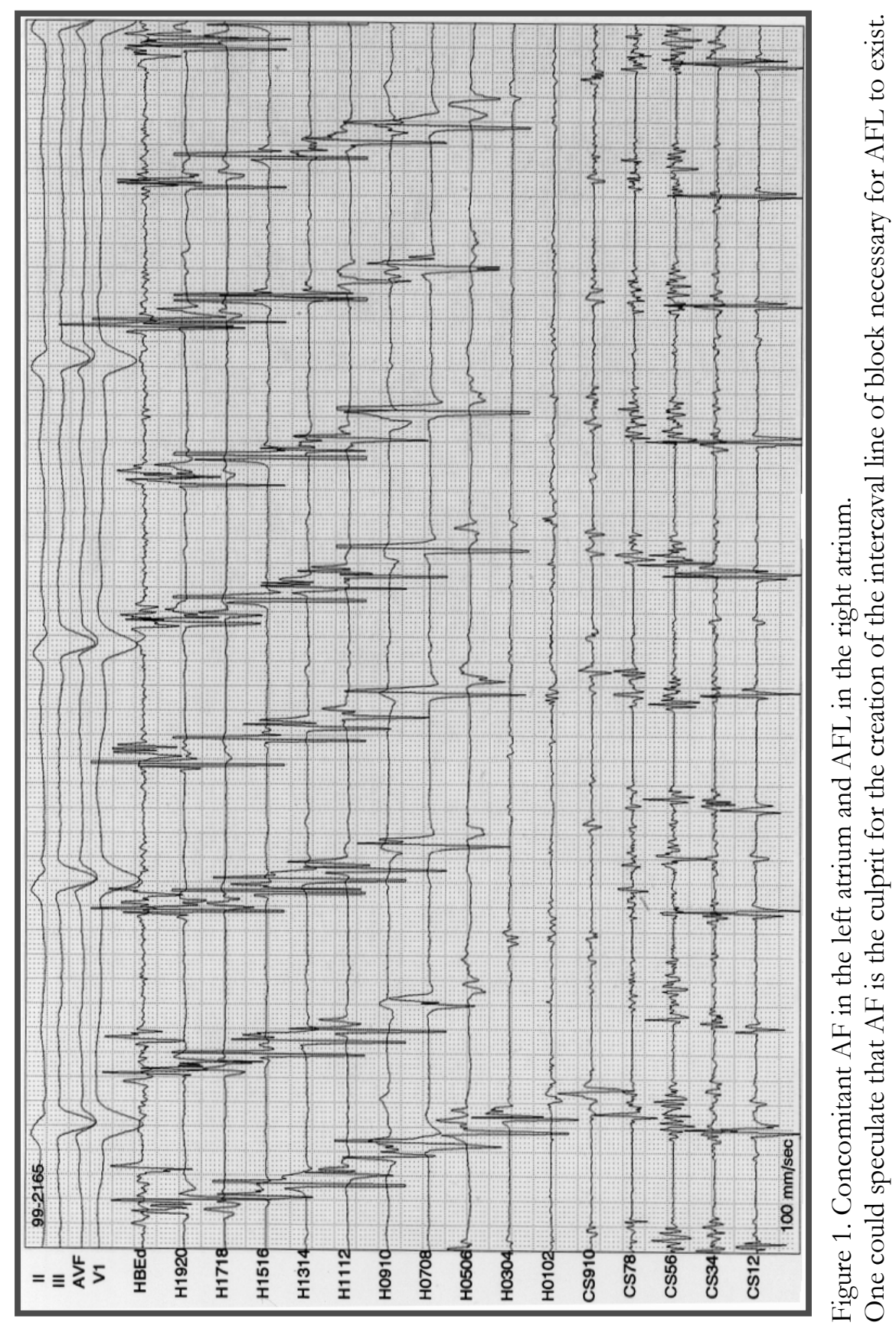


Figure 2. Flow diagram showing how AF in different stages can contribute to the development of common type AFL. Also common type AFL can add to the substrate (needed for AF perpetuation) due to the rapid rates in the RA (tachycardiomyopathy) - dashed arrow.

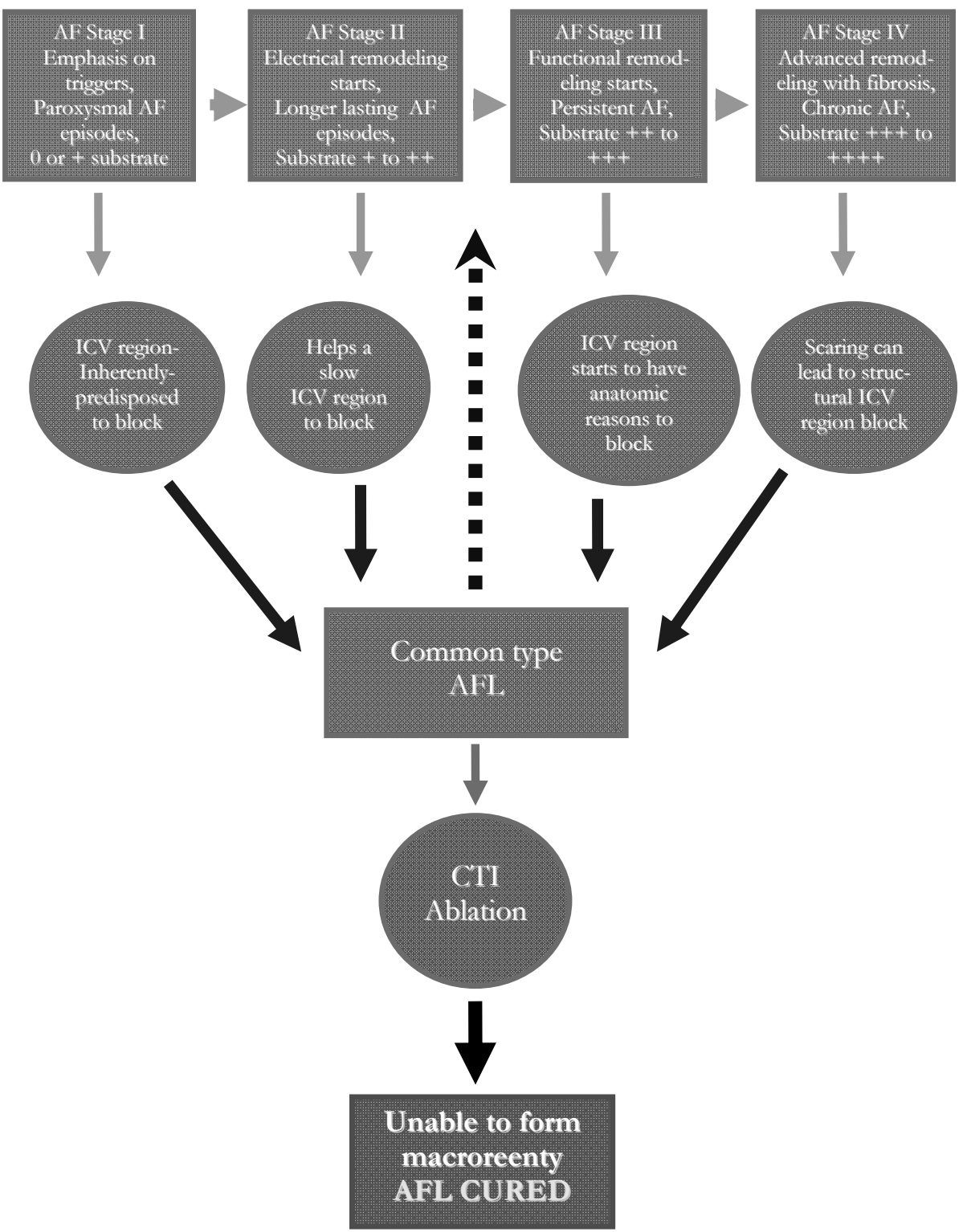




\section{Insights in AF/AFL mechanisms}

For a tachyarrhythmia to occur, both an initiating event and a substrate for its perpetuation must exist. For example, in case of a common slow/fast AVNRT the premature beat is the initiator and the slow/fast AV nodal pathways constitute the anatomical/electrophysiological substrate. That basic theory also applies to AF but due to its different forms (from focal, self sustained episodes to a chronic, refractory arrhythmia) unraveling the AF mechanism can be very difficult.

In order to better understand the different mechanisms of AF (with potential therapeutic implications) we will adopt the following staging system. Table.

\begin{tabular}{|c|c|c|c|c|}
\hline & Stage I & Stage II & Stage III & Stage IV \\
\hline Duration & Paroxysmal & $\begin{array}{c}\text { Longer Las- } \\
\text { ting }\end{array}$ & Persistent & Chronic \\
\hline $\begin{array}{c}\text { Importance of } \\
\text { Triggers }\end{array}$ & ++++ & +++ & ++ & + \\
\hline Remodeling & $\begin{array}{l}\text { None to } \\
\text { Electrical }\end{array}$ & $\begin{array}{c}\text { Electrical to } \\
\text { Functional }\end{array}$ & $\begin{array}{c}\text { Functional to } \\
\text { Fibrosis }\end{array}$ & Fibrosis \\
\hline Substrate & $0 /+$ & $+/++$ & $++/+++$ & $\begin{array}{l}+++/ \\
++++\end{array}$ \\
\hline $\begin{array}{l}\text { Possible AF } \\
\text { Mechanism }\end{array}$ & $\begin{array}{l}\text { Focal au- } \\
\text { tomaticity } \\
\text { and/or reen- } \\
\text { try }\end{array}$ & $\begin{array}{l}\text { Single Ro- } \\
\text { tors and/or } \\
\text { motherwave } \\
\text { "drivers" }\end{array}$ & $\begin{array}{l}\text { Multiple ro- } \\
\text { tors and/or } \\
\text { motherwave } \\
\text { "perpetuators" }\end{array}$ & $\begin{array}{l}\text { All the pre- } \\
\text { vious plus } \\
\text { multiple } \\
\text { wavelets }\end{array}$ \\
\hline
\end{tabular}

Legend: proposed staging system for atrial fibrillation. 


\section{Triggers}

The concept of a focal origin of atrial fibrillation is not new ${ }^{1}$ but only after the work by Haissaguerre and colleagues showing the possibility of a cure by ablating specific points in the pulmonary veins ${ }^{2}$ that triggers became important. Focal automaticity along with microreentry are mechanisms in which the pulmonary veins are thought to be the drivers of $\mathrm{AF} .^{3-8}$ However, PVs can play a different role depending on which stage of AF the patient present. ${ }^{9}$ (Table). A recent study with adolescents, without structural heart disease, referred for ablative therapy due to lone AF showed an excellent outcome with focal ablation of distinct foci (most of them located in the PVs). ${ }^{10}$ However, isolation of the pulmonary veins only may not be enough in patients with persistent AF. Ablative techniques with more extensive lines performed in the left atrium (along with PVI) seem to have a better outcome in this subgroup. ${ }^{11-13}$

Some studies report that up to $28 \%$ of the patients with paroxysmal AF have triggers in areas other than the pulmonary veins. ${ }^{14,15}$ But despite of the location, the arrhythmogenic mechanisms appear to be similar as those of the pulmonary veins and focal ablation of those regions have a very high success rate in the treatment of atrial fibrillation. ${ }^{14,15}$ The question in which category of patients with paroxysmal atrial fibrillation one should look for extra foci outside the PV has been partially answered in our thesis (Chapters III, IV and V): patients with concomitant AFL.

\section{Substrate}

Moe and colleagues introduced almost half a century ago the concept that multiple randomly propagating wavelets of activation were necessary to create the chaotic rhythm of chronic AF. ${ }^{16}$ Allessie et al corroborated this multiple-circuit reentry theory by showing that the wavelength of each circuit was dependent on the product of refractory period and conduction velocity. ${ }^{17-21}$ They also stated that no anatomic obstacle needed to be involved. ${ }^{19}$ The critical mass concept was born and became the cornerstone for the introduction of the first curative therapy for this arrhythmia (the surgical Cox maze procedure).22-24

It was not until recently that this theory was challenged by the work of Jalife and colleagues. ${ }^{25-28}$ They postulated that stable, self-sustained rotors can exist in the atria and that the high frequency activation by such rotors resulted in the complex patterns of activation responsible for the perpetuation of AF.

But the famous adage "atrial fibrillation begets atrial fibrillation" comes from the findings by Wijffels and colleagues. ${ }^{29}$ Using a goat model they were able to show that an increase in AF duration was related to a progressive shortening of the atrial effective refractory period; the latter being responsible for the higher susceptibility to AF. The concept of electrical remodeling provided the clinical implication that the duration of AF could be important when treat- 
ing AF patients. ${ }^{30-32}$

Fast heart rates have been shown to alter cellular properties leading to structural changes (tachycardiomyopathy). ${ }^{33}$ Those morphological changes in the atrium are known to be responsible for the transition from paroxysmal to chronic atrial fibrillation. Therefore, the finding that electrical remodeling occurs before mechanical remodeling ${ }^{34}$, acting earlier in the disease could prevent the appearance of self perpetuating mechanisms responsible for atrial fibrillation. In Chapters III and VII we were able to show an excellent outcome when segmental ablation of the arrhythmogenic area was performed in the early stage of AF.

The relation between complex fractionated atrial electrograms (CFAE) and AF was described in 1994 by Konings and colleagues. ${ }^{35}$ AF was induced during intraoperative mapping of patients with Wolff-Parkinson-White syndrome (undergoing surgery for interruption of their accessory pathways) and a subgroup of patients showed highly fragmented potentials across the right atrium. Those were thought to be due to different numbers and dimensions of intra-atrial reentrant circuits, areas of slow conduction forming the critical turning point of the self perpetuating wavelets.

Nademanee et al used this concept to evaluate the effects of complex fractionated atrial electrogram ablation on different types of atrial fibrillation. They defined complex fractionated potentials as fragmented atrial electrograms composed of two (or more deflections) and/or atrial electrograms with very short cycle lengths $(<120 \mathrm{msec})$. Those are usually low voltage multiple potential signals between $0.06-0.25 \mathrm{mV}$ and "surprisingly stationary, exhibiting relative spatial and temporal stability". ${ }^{36,37}$ Further description of those electrograms, including the comparison of unipolar versus bipolar, are not the aim of this chapter but can be found in the work of De Groot and colleages. ${ }^{38-40}$ Guided by CARTO mapping, Nademanee's group targeted areas with low voltage and CFAE and proposed the following classification: Type I AF (majority of patients with PAF) - CFAE localized in only one area (predominantly the pulmonary veins); Type II AF (mixed PAF and chronic AF) - CEFA localized in two areas (mostly the pulmonary veins and in the septum) and Type III AF (majority of patients with chronic AF) - CEFA in three or more areas (interatrial septum in $83 \%$; PVs in 67\%). Those findings correlate with our proposed mechanistic approach to AF. (Table). By ablating those regions Nademanee obtained a $76 \%$ freedom from arrhythmias at one year follow-up. Haissaguerre et al using a different technique to localize the fragmented potentials showed a success rate of $82 \%$ in patients who had failed PVI. ${ }^{41}$ This electrophysiological guided ablation is promising for the treatment of AF in more advanced stages. Our findings described in Chapters III to VII support this approach.

On the other hand, in order to modify the substrate responsible for the maintenance of atrial fibrillation, some technique of percutaneous AF ablation advocate extensive and anatomically (not electrophysiologically) guided lesions in both atria. ${ }^{13,42,43}$ Those procedures are made possible by the use of navigation 
systems nowadays commonly present in electrophysiological laboratories. (Chapter VIII). Even though some short term outcome data are encouraging, one should remember that the long term effect of those lesions in patients with an already diseased left atrium is unknown. Also, in patients in the earlier stages of AF, applying discrete lesions (e.g: segmental PVI) should be enough to prevent not only atrial fibrillation but also the potential dreadful complications of those extensive ablations (including iatrogenic left atrial flutter, phrenic nerve paralysis and left atrial-to-esophageal fistula which is almost universally fatal). ${ }^{44-}$ 46

\section{Other influencing factors (stretch, autonomic nervous system, toxins, inflammation)}

The majority of conditions that produce an increase in atrial pressure can be related to atrial fibrillation, being arterial hypertension and congestive heart failure the most common diseases associated with both AF and increase in left atrial pressure. ${ }^{47} \mathrm{~A}$ common mechanism they have is that both cause distention of atrial and pulmonary veins tissue. Stretch has been show not only to increase the automaticity of pulmonary veins (and others) foci but also to promote the ideal electrophysiological/mechanical milieu for reentry. ${ }^{48-52}$ Therefore, if an adequate control of factors that increase atrial pressure is not achieved, percutaneous ablative techniques to treat atrial fibrillation (regardless of what type) will most likely be unable to prevent the progression of the disease.

The important role of the autonomic nervous system in the genesis of atrial fibrillation has been recognized for many years but with the current advances in the percutaneous therapies for AF new emphasis was placed on this subject. Parasympathetic stimulation shortens the atrial effective refractory period, increases its dispersion, and decreases the wavelength of reentrant circuits facilitating initiation and perpetuation of AF. ${ }^{33} \mathrm{On}$ the other hand, sympathetic stimulation increases automaticity and triggered activity. ${ }^{54,55}$ Vagal predominance is observed in structurally normal hearts, being the part of the autonomic nervous system that plays a major role in patients with paroxysmal AF. Some authors advocate a better outcome in AF ablation when "vagal responses" are abolished. ${ }^{56}$ Patients with structural heart disease have an enhanced sympathetic tone; the former is the main trigger of an eventual concomitantly present atrial fibrillation. ${ }^{57}$ This part of the autonomic nervous system, associated with the chronic stretch caused by the increase in atrial pressure in the presence of more advanced structural heart disease, is responsible for the perpetuation of atrial fibrillation in this group of patients.

Thyrotoxicosis, ethanol abuse and inflammatory disorders are other causes of atrial fibrillation that share common causal mechanisms: enhanced automaticity/ triggered activity (by up-regulation of adrenergic receptors or intracellular imbalance of electrolytes) and reentry due to direct electrophysiological changes, interstitial edema or cell death. ${ }^{58-64}$ Amongst the inflammatory disor- 
ders, those can be systemic (e.g.: rheumatological disorders, rheumatic fever, sarcoidosis, sepsis, infections . . . ) or localized (e.g.: post pericardiectomy, rheumatic fever, pericarditis of any type, myocarditis, myocardial infarction, myocardial ischemia ... ). Another important point is, when considering congestive heart failure as an inflammatory state ${ }^{65-67}$, we can speculate that some of the beneficial effects of drugs without any antiarrhythmic activity (such as ACE inhibitors, angiotensin receptor blockers, statins ... ) in the treatment of atrial fibrillation lies on their antiinflammatory (and subsequently anti fibrotic) properties. ${ }^{61,68-72}$

And finally, it is important to mention that these described factors are not mutually exclusive and may at various times coexist in the same patient. Figure 3 summarizes the elements necessary for atrial fibrillation to occur.

\section{The relation between atrial fibrillation and common type atrial flutter}

The clinical interrelationship between AFL and AF has long been recognized. 1,73-75 Patients who primarily manifest AFL commonly also experience AF and vice versa. ${ }^{73,75-77}$ The idea of a macroreentrant rhythm (AFL) degenerating into microreentrant wavelets (AF) is well accepted. In addition to this established mechanism, the difference in prevalence of the two arrhythmias makes it easier for one to see the conversion of AFL into AF than the opposite. Figure 4.

How about the concept that AF can be the culprit of AFL initiation? Waldo advocates that in most instances, without preceding AF, there will be no classic AFL. ${ }^{78}$ Figure 1.

In order for the macroreentry circuit of the cavotricuspid isthmus dependent AFL to occur, a functional intercaval line of block (on top of the other anatomic barrier - the tricuspid annulus) needs to be present. ${ }^{79}$ Most of the times, this line of block is functional and very often caused by the electrophysiologic changes produced in the right atrium during AF. ${ }^{73,78}$ Figure 1. We were able to support such a concept by showing that successful elimination of AF prevents AFL (Chapter V). Figure 2.

In patients presenting with "lone" atrial fibrillation the presence of atrial flutter can be an indicator of the presence of sufficient electrical remodeling (in both atria) to sustain longer episodes of AF. In those individuals, percutaneous therapy for AF should include not only PVI but also a more extensive electrophysiological evaluation (in both atria) to identify other potential triggers. If different pacing maneuvers along with pharmacological interventions are not able to identify the culprit PVs, a different AF ablation technique directed towards substrate modification should be able to provide a better outcome. (Chapters III to VIII). 


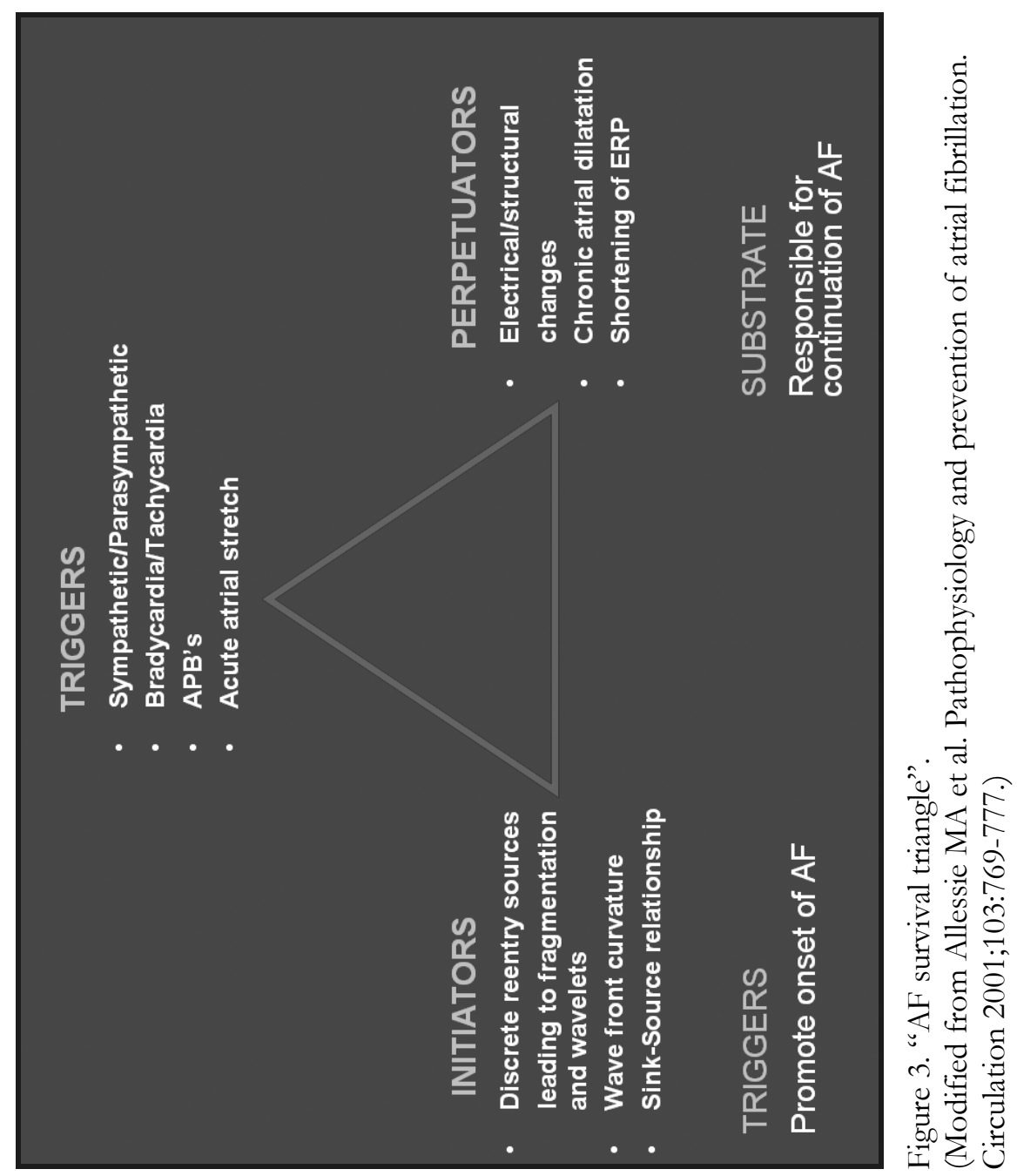




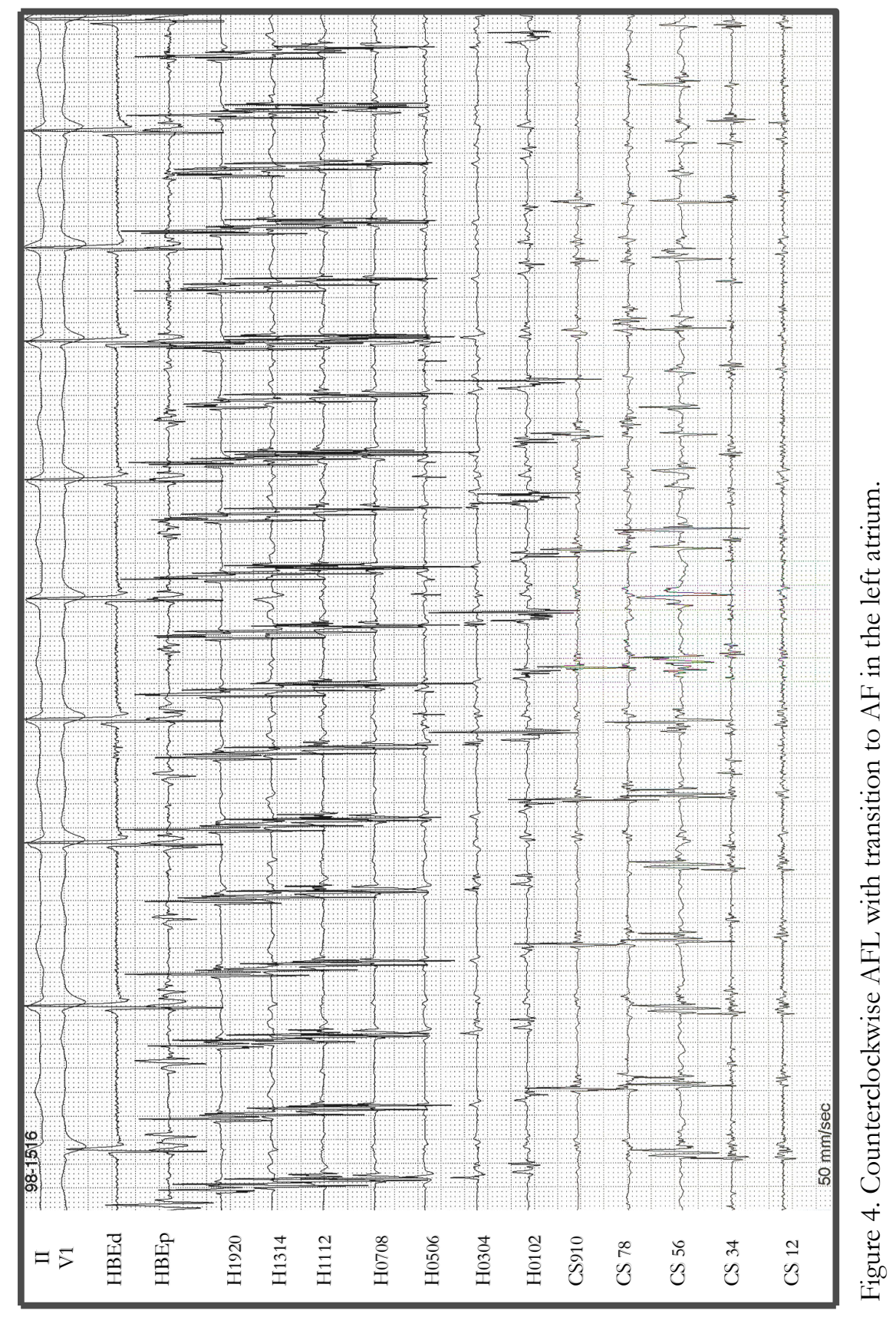




\section{Procedural endpoints in AF ablation}

Prognostic markers of success are a very important factor in the development of a new technology. As time passes with an evolving technique, one learns to relate long term outcome with specific procedural endpoints. This also holds for AF ablation. The recent introduction and/or major differences in ablation techniques play a role in the current lack of definite procedural endpoints.

It would make sense that, in the case of AF ablation, non inducibility of this arrhythmia at the end of the procedure would be related to optimal outcome. Some studies support this finding. ${ }^{80-83}$ Others state the opposite. ${ }^{84,85}$ Some of this confusion comes from the fact that, in these studies, different ablation strategies were used and the applied definitions of inducibility as well as the used stimulation protocols differ widely. Another possibility is that those differences are due to the inherent deficiency of invasive electrophysiology to provide long term prognosis, as in the case of ventricular tachyarrhythmias. ${ }^{86-88}$

Other factors were also observed to associate with procedural endpoints. Gerstenfeld and colleagues have published the utility of exit block in assessing reconduction in the PVs. ${ }^{89}$ Figure 5. Another group suggested that entrance block could also be added in the evaluation of reconduction. ${ }^{90,91}$ Figure 6. Therefore the demonstration of a bidirectional LA/PV conduction block seems to be an important finding in defining success. One should also remember that the timing of those measurements after ablation can influence the assessment of PV reconnection. As shown by Sauer et al and Chema et al, there is increasing reconduction when measurements are made 30 to 60 minutes after the ablation. ${ }^{92,93}$ Some pharmacological agents are thought to be helpful for this purpose. The administration of adenosine/isoproterenol has been shown to unmask PV reconnection after PVI (using RF) up to $43 \%{ }^{94-96}$ 
Figure 5. Exit block achieved after successful isolation of a left superior pulmonary vein.

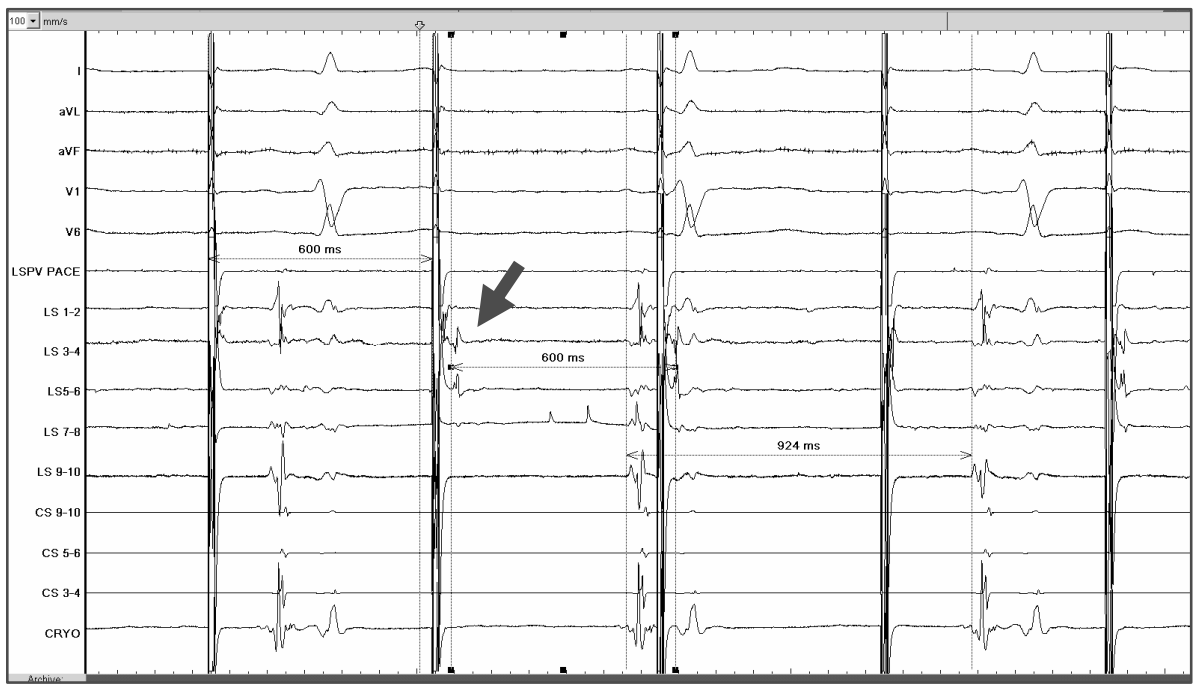

Legend: Note that when pacing the LSPV at a baseline cycle length of $600 \mathrm{msec}$, the pulmonary vein is constantly captured at $600 \mathrm{msec}$ (arrows show PV potentials) while the left atrium is independently activated at the sinus cycle length of 924 msec.

Abbreviations:

LS: left superior pulmonary vein;

CS: coronary sinus catheter;

LSPV pace: quadripolar catheter placed inside the PV that was used for pacing;

Cryo: cryoablation catheter. 
Figure 6. An example of entrance block.

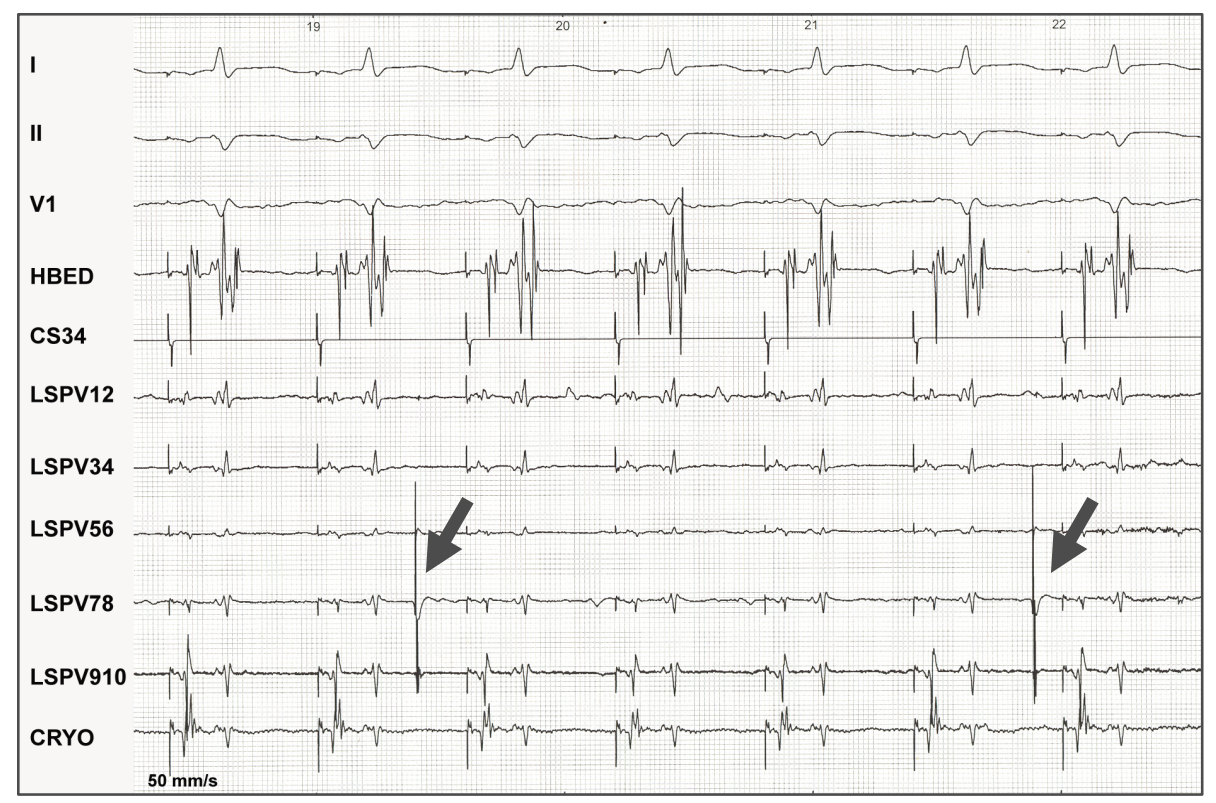

Legend: When pacing from the distal CS, dissociation between the left atrium and the PV potentials (arrows) is present.

Abbreviations:

LSPV: left superior pulmonary vein;

CS: coronary sinus catheter;

Cryo: cryoablation catheter. 
Another key observation is that the pacing site is very important while accessing an arrhythmogenic area. (Chapter VII) The most common pacing protocols used nowadays aim to differentiate PV and LA potentials and are usually done outside the PVs. ${ }^{97}$ Jais was able to induce AF when pacing inside the PVs in $25 \%$ of times. That was significantly different from pacing in the LA (1\%) where AF could almost never be induced. ${ }^{98}$

When performing selective electrophysiological stimulation for a guided AF ablation, pacing should take place inside each pulmonary vein and in the adjacent LA. Using this protocol we were able to show (Chapters VI and VII) that the finding of gradient of $>100 \mathrm{msec}$ between the left atrium just outside the PV and the PV itself was indicative of an arrhythmogenic region. We propose that such a finding indicates the need for isolation of that vein. Future studies using this strategy are needed.

As a result of the above mentioned factors, no definite guidelines are currently present to help the electrophysiologist to determine the optimal endpoints for a successful atrial fibrillation ablation. A recent report of the Heart Rhythm Society (HRS) Task Force on Catheter and Surgical Ablation of Atrial Fibrillation entitled: HRS/EHRA/ECAS Expert Consensus Statement on Catheter and Surgical Ablation of Atrial Fibrillation: Recommendations for Personnel, Policy, Procedures and Follow- $U_{p}{ }^{99}$ discusses these issues suggesting that guidelines will come, when more data on long term outcome of this procedure become available.

\section{Why other energy sources?}

The increase in indications for AF ablation calls for the development of new tools to increase the success, safety and easiness of the electrophysiological procedures. Navigation systems are being used routinely nowadays.100-105 (Chapter VIII). New catheters and different energy sources (each one with its own pitfalls and advantages) are already available in the clinical arena. ${ }^{106,107}$ Figure 7.

Of those energy sources, cryothermy has a very attractive profile.

Cryothermy has been previously validated against radiofrequency in the treatment of diverse types of arrhythmias showing similar results with some particular advantages. ${ }^{108-112}$

Cryoenergy causes adherence of the catheter-tip to the underlying tissue during energy delivery assuring accurate lesion creation. ${ }^{113,114}$ This might be important in patients with abnormal cardiac anatomy with distortion of the usual CTI. 


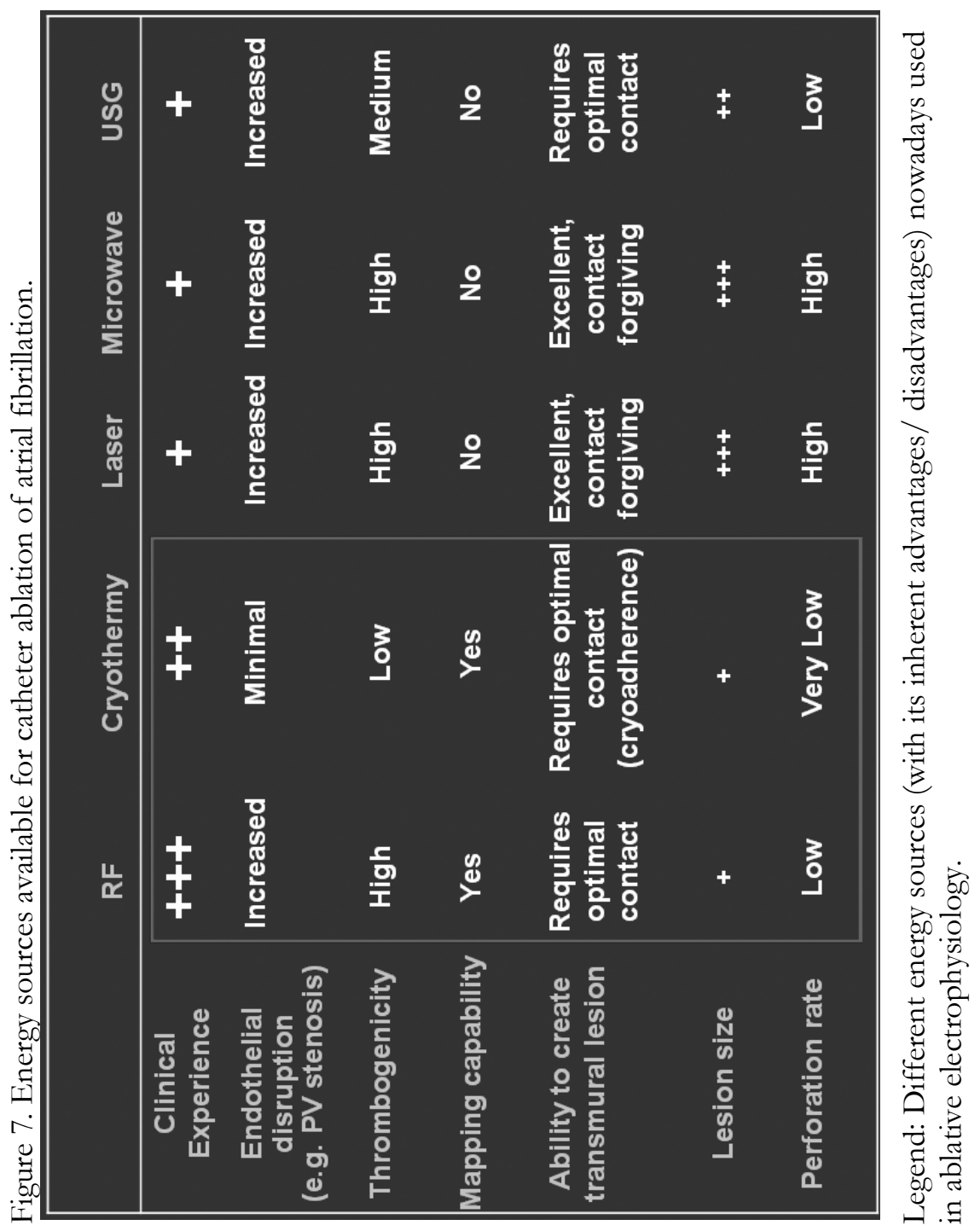


Cryothermy does not require conscious sedation or anesthesia as it is painless. ${ }^{115}$ This not only means more comfort for the patient but also decreases the low but real complications of anesthesia. It also has the ability to create reversible loss of function allowing the prediction of the effectiveness and safety of a lesion. ${ }^{110,116}$

Cryothermal ablation preserves the extracellular matrix and endothelial integrity. As a result, it has not been associated with pulmonary vein stenosis, esophageal perforation or thromboembolic events during the treatment of atrial fibrillation. ${ }^{117,118}$ Even though the rate of thromboembolic complications during RF ablation is minimal, its consequences can be aggravated by the presence of right to left shunts (e.g.: patent foramen ovale).

Furthermore, cryo creates transmural and larger lesions. They are homogeneous with a well-demarcated border zone. ${ }^{114,119-121}$

Despite being around for a long time in the surgical field, catheter based cryoablation is still a relatively new technology compared to RF. Also, its efficiency is highly dependent on its duration and pressure against the myocardial tissues. ${ }^{122}$ However, the duration of a freeze has evolved over time and now permanent lesions can be obtained with similar application duration as RF. When we consider the total procedure time in the electrophysiology laboratory (including time devoted to anesthesia) cryo and RF end up not being that different.

\section{Future Perspectives}

Primary prevention with optimal treatment of the very prevalent AF promoting diseases (such as arterial hypertension and congestive heart failure) could have a huge impact in atrial fibrillation. ${ }^{123-136}$ Those diseases favor the development of atrial fibrosis, a process which is age related, thus the importance of earlier interventions.

When we take the case of systemic arterial hypertension, the Seventh Report of the Joint National Committee on Prevention, Detection, Evaluation, and Treatment of High Blood Pressure ${ }^{137}$, estimates the worldwide prevalence to be as much as 1 billion people. An individual normotensive at 55 years of age will have a $90 \%$ lifetime risk of developing arterial hypertension. Furthermore, approximately $30 \%$ of adults are unaware of their high blood pressure, more than $40 \%$ of individuals with arterial hypertension are not on treatment and two thirds of hypertensive patients are not being controlled to blood pressure levels less than 140/90 mm Hg. Optimal pharmacological treatments are available for this condition; therefore due to the strong association between systemic arterial hypertension and $\mathrm{AF}$, better control of the first could have a great impact in the prevalence of atrial fibrillation.

For the group of individuals where $\mathrm{AF}$ is thought to be the primary disor- 
der, early detection could lead to more successful outcomes of treatment. ${ }^{138-140}$ Genetic studies are promising (familial forms of AF have already been identified ${ }^{141-147}$ and once more genes related to AF are described they could play a role in the screening process of patients at risk. Possibly, genetic therapeutic options may become available in the long future. ${ }^{148-154}$

For those patients already presenting with AF, non invasive methods of screening (like atrial imaging of scar/substrate ${ }^{155-158}$, serological markers ${ }^{159-166}$, small external and patient friendly rhythm monitoring devices ${ }^{167,168} \ldots$. . ) could help in the evaluation of the specific type of AF. Treatment could then be more individualized: patients in the early stages where triggers play a major role could have an excellent outcome with more localized ablative procedures; patients with more advanced AF where the fibrotic substrate starts being the main culprit could have the option of other successful ablation strategies.

Much is lacking regarding contemporary pharmacologic therapy. The available antiarrhythmic medications to convert and keep the patients in sinus rhythm are barely effective and some may have dreadful side effects. Drugs that target traditional and newly discovered cardiac ion channels, as well as new molecular and signaling pathways that modulate arrhythmic substrates are promising in the future, specially when they are atrium specific. ${ }^{169,170}$ Nevertheless, the low efficacy of the current antiarrhythmic drugs has contributed importantly to the development of percutaneous ablative techniques.

Ideally, rate control should not be an option. By default, humans are "designed" to be in sinus rhythm. The results of trials suggesting that rate control is superior to "rhythm" control only express the failure of the existing antiarrhythmic drugs. ${ }^{171-176}$ Because of that, most AF patients are exposed to all the inconveniences and risks of the much needed anticoagulation medications currently available. Research is active in this field but it will take a while until a replacement for the old vitamin $\mathrm{K}$ antagonists is found. ${ }^{177}$ Anticoagulation only would no longer be an issue in atrial fibrillation when we have the tools that will allow us to cure this arrhythmia.

Atrial fibrillation ablation is currently becoming an attractive option for a greater number of patients, especially those with paroxysmal atrial fibrillation. The technical aspects of this intervention are developing quickly and the subsequent benefits to both the electrophysiologist and the patients are already apparent. Both complications and procedure times are constantly decreasing. Sophisticated imaging systems such as intracardiac echo, CT and MRI alone or in combination and navigation systems guided by magnetic resonance (where, from a remote station, the physician can produce very well defined lesions) are already being used. ${ }^{178,179}$ New and safer energy sources are being validated (Chapters II to VIII). The concept of performing atrial fibrillation ablation as an outpatient procedure is not far from becoming a reality, like it already is for percutaneous coronary interventions.

We have to realize though that atrial fibrosis formation with aging plays an 
important role in the genesis and maintenance of $\mathrm{AF}$ in the elderly patient. Long term follow-up studies after AF catheter ablation are therefore needed to know whether we are delaying progression of $\mathrm{AF}$ or able to offer a curative treatment for the AF patient.

In summary, the great recent developments in the treatment of the most common arrhythmia grant us the ability to hope for an era where atrial fibrillation would be part of the past. Only time will tell. 


\section{References}

1. Scherf D, Terranova R. Mechanism of auricular flutter and fibrillation. Am J Physiol 1949;159:137-142.

2. Haissaguerre M, Jais P, Shah DC, Takahashi A, Hocini M, Quiniou G, Garrigue S, Le MA, Le MP, Clementy J. Spontaneous initiation of atrial fibrillation by ectopic beats originating in the pulmonary veins. N Engl J Med 1998;339:659-666.

3. Nattel S. New ideas about atrial fibrillation 50 years on. Nature 2002;415:219-226.

4. Nattel S. Atrial electrophysiology and mechanisms of atrial fibrillation. J Cardiovasc Pharmacol Ther 2003;8 Suppl 1:S5-11.

5. Nattel S, Shiroshita-Takeshita A, Cardin S, Pelletier P. Mechanisms of atrial remodeling and clinical relevance. Curr Opin Cardiol 2005;20:21-25.

6. Nattel S. Pulmonary vein cellular electrophysiology and atrial fibrillation: does basic research help us understand clinical pulmonary-vein arrhythmogenesis? Heart Rhythm 2005;2:1346.

7. Miyauchi Y, Hayashi H, Miyauchi M, Okuyama Y, Mandel WJ, Chen PS, Karagueuzian HS. Heterogeneous pulmonary vein myocardial cell repolarization implications for reentry and triggered activity. Heart Rhythm 2005;2:1339-1345.

8. Tan AY, Li H, Wachsmann-Hogiu S, Chen LS, Chen PS, Fishbein MC. Autonomic innervation and segmental muscular disconnections at the human pulmonary vein-atrial junction: implications for catheter ablation of atrial-pulmonary vein junction. J Am Coll Cardiol 2006;48:132-143.

9. Nattel S. Basic electrophysiology of the pulmonary veins and their role in atrial fibrillation: precipitators, perpetuators, and perplexers. J Cardiovasc Electrophysiol 2003;14:1372-1375.

10. Nanthakumar K, Lau YR, Plumb VJ, Epstein AE, Kay GN. Electrophysiological findings in adolescents with atrial fibrillation who have structurally normal hearts. Circulation 2004;110:117-123.

11. Cheema A, Vasamreddy CR, Dalal D, Marine JE, Dong J, Henrikson CA, Spragg D, Cheng A, Nazarian S, Sinha S, Halperin H, Berger R, Calkins H. Long-term single procedure efficacy of catheter ablation of atrial fibrillation. J Interv Card Electrophysiol 2006;15:145-155.

12. Gaita F, Riccardi R, Caponi D, Shah D, Garberoglio L, Vivalda L, Dulio A, Chiecchio A, Manasse E, Gallotti R. Linear cryoablation of the left atrium versus pulmonary vein cryoisolation in patients with permanent atrial fibrillation and valvular heart disease: correlation of electroanatomic mapping and long-term clinical results. Circulation 2005;111:136-142.

13. Haissaguerre M, Hocini M, Sanders P, Sacher F, Rotter M, Takahashi Y, Rostock T, Hsu LF, Bordachar P, Reuter S, Roudaut R, Clementy J, Jais P. Catheter ablation of long-lasting persistent atrial fibrillation: clinical outcome and mechanisms of subsequent arrhythmias. J Cardiovasc Electrophysiol 2005;16:1138-1147.

14. Lee SH, Tai CT, Hsieh MH, Tsao HM, Lin YJ, Chang SL, Huang JL, Lee KT, Chen YJ, Cheng JJ, Chen SA. Predictors of Non-Pulmonary Vein Ectopic Beats Initiating Paroxysmal Atrial Fibrillation: Implication for Catheter Ablation. J Am Coll Cardiol 2005;46:1054-1059.

15. Lin WS, Tai CT, Hsieh MH, Tsai CF, Lin YK, Tsao HM, Huang JL, Yu WC, Yang SP, Ding YA, Chang MS, Chen SA. Catheter ablation of paroxysmal atrial fibrillation initiated by nonpulmonary vein ectopy. Circulation 2003;107:3176-3183.

16. Moe GK, Abildskov JA. Atrial fibrillation as a self-sustaining arrhythmia independent of focal discharge. Am Heart J 1959;58:59-70.

17. Allessie MA, Bonke FI, Schopman FJ. The mechanism of supraventricular tachycardia induced by a single premature beat in the isolated left atrium of the rabbit. I. Circus movement as a consequence of unidirectional block of the premature impulse. Recent Adv Stud Cardiac Struct Metab 1975;5:303-308. 
18. Allessie MA, Bonke FI, Schopman FJ. Circus movement in rabbit atrial muscle as a mechanism of tachycardia. II. The role of nonuniform recovery of excitability in the occurrence of unidirectional block, as studied with multiple microelectrodes. Circ Res 1976;39:168-177.

19. Allessie MA, Bonke FI, Schopman FJ. Circus movement in rabbit atrial muscle as a mechanism of tachycardia. III. The "leading circle" concept: a new model of circus movement in cardiac tissue without the involvement of an anatomical obstacle. Circ Res 1977;41:9-18.

20. Allessie MA, Bonke FI. Direct demonstration of sinus node reentry in the rabbit heart. Circ Res 1979;44:557-568.

21. Allessie MA, Boyden PA, Camm AJ, Kleber AG, Lab MJ, Legato MJ, Rosen MR, Schwartz PJ, Spooner PM, Van Wagoner DR, Waldo AL. Pathophysiology and prevention of atrial fibrillation. Circulation 2001;103:769-777.

22. Cox JL, Schuessler RB, Cain ME, Corr PB, Stone CM, D'Agostino HJ, Jr., Harada A, Chang BC, Smith PK, Boineau JP. Surgery for atrial fibrillation. Semin Thorac Cardiovasc Surg 1989;1:67-73.

23. Cox JL, Schuessler RB, Boineau JP. The development of the Maze procedure for the treatment of atrial fibrillation. Semin Thorac Cardiovasc Surg 2000;12:2-14.

24. Sundt TM, III, Camillo CJ, Cox JL. The maze procedure for cure of atrial fibrillation. Cardiol Clin 1997;15:739-748.

25. Jalife J, Berenfeld O, Mansour M. Mother rotors and fibrillatory conduction: a mechanism of atrial fibrillation. Cardiovasc Res 2002;54:204-216.

26. Atienza F, Jalife J. Reentry and atrial fibrillation. Heart Rhythm 2007;4:S13-S16.

27. Jalife J, Pandit SV. Ionic mechanisms of wavebreak in fibrillation. Heart Rhythm 2005;2:660-663.

28. Jalife J. Experimental and clinical AF mechanisms: bridging the divide. J Interv Card Electrophysiol 2003;9:85-92.

29. Wijffels MC, Kirchhof CJ, Dorland R, Allessie MA. Atrial fibrillation begets atrial fibrillation. A study in awake chronically instrumented goats. Circulation 1995;92:1954-1968.

30. Allessie MA, Konings K, Kirchhof CJ, Wijffels M. Electrophysiologic mechanisms of perpetuation of atrial fibrillation. Am J Cardiol 1996;77:10A-23A.

31. Allessie MA. Atrial electrophysiologic remodeling: another vicious circle? J Cardiovasc Electrophysiol 1998;9:1378-1393.

32. Allessie MA. Atrial fibrillation-induced electrical remodeling in humans: what is the next step? Cardiovasc Res 1999;44:10-12.

33. Shiroshita-Takeshita A, Brundel BJ, Nattel S. Atrial fibrillation: basic mechanisms, remodeling and triggers. J Interv Card Electrophysiol 2005;13:181-193.

34. Goette A, Honeycutt C, Langberg JJ. Electrical remodeling in atrial fibrillation. Time course and mechanisms. Circulation 1996;94:2968-2974.

35. Konings KT, Kirchhof CJ, Smeets JR, Wellens HJ, Penn OC, Allessie MA. High-density mapping of electrically induced atrial fibrillation in humans. Circulation 1994;89:1665-1680.

36. Nademanee K, McKenzie J, Kosar E, Schwab M, Sunsaneewitayakul B, Vasavakul T, Khunnawat C, Ngarmukos T. A new approach for catheter ablation of atrial fibrillation: mapping of the electrophysiologic substrate. J Am Coll Cardiol 2004;43:2044-2053.

37. Nademanee K, Schwab M, Porath J, Abbo A. How to perform electrogram-guided atrial fibrillation ablation. Heart Rhythm 2006;3:981-984.

38. Houben RP, de Groot NM, Lindemans FW, Allessie MA. Automatic mapping of human atrial fibrillation by template matching. Heart Rhythm 2006;3:1221-1228.

39. de Groot NM, Schalij MJ. Fragmented, long-duration, low-amplitude electrograms characterize the origin of focal atrial tachycardia. J Cardiovasc Electrophysiol 2006;17:1086-1092.

40. de Groot NM, Allessie MA. Mapping of atrial fibrillation. Ann Ist Super Sanita 2001;37:383392.

41. Haissaguerre M, Hocini M, Sanders P, Takahashi Y, Rotter M, Sacher F, Rostock T, Hsu LF, Jonsson A, O'Neill MD, Bordachar P, Reuter S, Roudaut R, Clementy J, Jais P. Localized sources maintaining atrial fibrillation organized by prior ablation. Circulation 2006;113:616-625. 
42. Pappone C, Santinelli V. Atrial fibrillation ablation: state of the art. Am J Cardiol 2005;96:59L-64L.

43. Pappone C, Santinelli V. Substrate ablation in treatment of atrial fibrillation. J Cardiovasc Electrophysiol 2006;17 Suppl 3:S23-S27.

44. Deisenhofer I, Estner H, Zrenner B, Schreieck J, Weyerbrock S, Hessling G, Scharf K, Karch MR, Schmitt C. Left atrial tachycardia after circumferential pulmonary vein ablation for atrial fibrillation: incidence, electrophysiological characteristics, and results of radiofrequency ablation. Europace 2006;8:573-582.

45. Pappone C, Oral H, Santinelli V, Vicedomini G, Lang CC, Manguso F, Torracca L, Benussi S, Alfieri O, Hong R, Lau W, Hirata K, Shikuma N, Hall B, Morady F. Atrio-Esophageal Fistula as a Complication of Percutaneous Transcatheter Ablation of Atrial Fibrillation. Circulation 2004;109:2724-2726.

46. Sacher F, Monahan KH, Thomas SP, Davidson N, Adragao P, Sanders P, Hocini M, Takahashi Y, Rotter M, Rostock T, Hsu LF, Clementy J, Haissaguerre M, Ross DL, Packer DL, Jais P. Phrenic Nerve Injury After Atrial Fibrillation Catheter Ablation: Characterization and Outcome in a Multicenter Study. J Am Coll Cardiol 2006;47:2498-2503.

47. Fuster V, Ryden LE, Cannom DS, Crijns HJ, Curtis AB, Ellenbogen KA, Halperin JL, Le Heuzey JY, Kay GN, Lowe JE, Olsson SB, Prystowsky EN, Tamargo JL, Wann S, Smith SC, Jr., Jacobs AK, Adams CD, Anderson JL, Antman EM, Halperin JL, Hunt SA, Nishimura R, Ornato JP, Page RL, Riegel B, Priori SG, Blanc JJ, Budaj A, Camm AJ, Dean V, Deckers JW, Despres C, Dickstein K, Lekakis J, McGregor K, Metra M, Morais J, Osterspey A, Tamargo JL, Zamorano JL. ACC/AHA/ESC 2006 Guidelines for the Management of Patients with Atrial Fibrillation: a report of the American College of Cardiology/American Heart Association Task Force on Practice Guidelines and the European Society of Cardiology Committee for Practice Guidelines (Writing Committee to Revise the 2001 Guidelines for the Management of Patients With Atrial Fibrillation): developed in collaboration with the European Heart Rhythm Association and the Heart Rhythm Society. Circulation 2006;114:e257-e354.

48. Petersen P, Kastrup J, Brinch K, Godtfredsen J, Boysen G. Relation between left atrial dimension and duration of atrial fibrillation. Am J Cardiol 1987;60:382-384.

49. Yamane T, Shah DC, Jais P, Hocini M, Peng JT, Deisenhofer I, Clementy J, Haissaguerre M. Dilatation as a marker of pulmonary veins initiating atrial fibrillation. J Interv Card Electrophysiol 2002;6:245-249.

50. Sato R, Koumi S. Characterization of the stretch-activated chloride channel in isolated human atrial myocytes. J Membr Biol 1998;163:67-76.

51. Hagiwara N, Masuda $\mathrm{H}$, Shoda M, Irisawa $\mathrm{H}$. Stretch-activated anion currents of rabbit cardiac myocytes. J Physiol 1992;456:285-302.

52. Bode F, Katchman A, Woosley RL, Franz MR. Gadolinium decreases stretch-induced vulnerability to atrial fibrillation. Circulation 2000;101:2200-2205.

53. Liu L, Nattel S. Differing sympathetic and vagal effects on atrial fibrillation in dogs: role of refractoriness heterogeneity. Am J Physiol 1997;273:H805-H816.

54. Coumel P. Autonomic influences in atrial tachyarrhythmias. J Cardiovasc Electrophysiol 1996;7:999-1007.

55. Coumel P. Atrial fibrillation: one more sporting inconvenience? Eur Heart J 2002;23:431433.

56. Pappone C, Santinelli V, Manguso F, Vicedomini G, Gugliotta F, Augello G, Mazzone P, Tortoriello V, Landoni G, Zangrillo A, Lang C, Tomita T, Mesas C, Mastella E, Alfieri O. Pulmonary vein denervation enhances long-term benefit after circumferential ablation for paroxysmal atrial fibrillation. Circulation 2004;109:327-334.

57. Gould PA, Yii M, McLean C, Finch S, Marshall T, Lambert GW, Kaye DM. Evidence for increased atrial sympathetic innervation in persistent human atrial fibrillation. Pacing Clin Electrophysiol 2006;29:821-829.

58. Boos CJ, Lip GY. The role of inflammation in atrial fibrillation. Int J Clin Pract 2005;59:870-872. 
59. Engelmann MD, Svendsen JH. Inflammation in the genesis and perpetuation of atrial fibrillation. Eur Heart J 2005;26:2083-2092.

60. Klein I, Ojamaa K. Thyroid Hormone and the Cardiovascular System. N Engl J Med 2001;344:501-509.

61. Korantzopoulos P, Kolettis TM, Kountouris E. Inflammation and anti-inflammatory interventions in atrial fibrillation. Int J Cardiol 2005;104:361-362.

62. Maki T, Toivonen L, Koskinen P, Naveri H, Harkonen M, Leinonen H. Effect of ethanol drinking, hangover, and exercise on adrenergic activity and heart rate variability in patients with a history of alcohol-induced atrial fibrillation. Am J Cardiol 1998;82:317-322.

63. Pan M, Zhu JH, Jiang WP, Liu ZH, Li HM, Yu XH, Yang XJ. Inflammation: a possible pathogenic link to atrial fibrillation. Med Hypotheses 2006;67:1305-1307.

64. Tselentakis EV, Woodford E, Chandy J, Gaudette GR, Saltman AE. Inflammation effects on the electrical properties of atrial tissue and inducibility of postoperative atrial fibrillation. J Surg Res 2006;135:68-75.

65. Kotlyar E, Vita JA, Winter MR, Awtry EH, Siwik DA, Keaney J, Sawyer DB, Cupples LA, Colucci WS, Sam F. The Relationship Between Aldosterone, Oxidative Stress, and Inflammation in Chronic, Stable Human Heart Failure. Journal of Cardiac Failure 2006;12:122-127.

66. Torre-Amione G, Kapadia S, Benedict C, Oral H, Young JB, Mann DL. Proinflammatory Cytokine Levels in Patients With Depressed Left Ventricular Ejection Fraction: A Report From the Studies of Left Ventricular Dysfunction (SOLVD). J Am Coll Cardiol 1996;27:1201-1206.

67. White M, Ducharme A, Ibrahim R, Whittom L, Lavoie J, Guertin MC, Racine N, He Y, Yao G, Rouleau JL, Schiffrin EL, Touyz RM. Increased systemic inflammation and oxidative stress in patients with worsening congestive heart failure: improvement after short-term inotropic support. Clin Sci (Lond) 2006;110:483-489.

68. Karthikeyan VJ, Lip GY. Review: Angiotensin converting enzyme inhibitors and angiotensin receptor blockers prevent atrial fibrillation. Evid Based Med 2006;11:15.

69. Patlolla V, sheikh-Ali AA, Al-Ahmad AM. The renin-angiotensin system: a therapeutic target in atrial fibrillation. Pacing Clin Electrophysiol 2006;29:1006-1012.

70. Liu T, Li G. Anti-inflammatory effects of angiotensin-converting enzyme inhibitors and angiotensin receptor blockers: Potential benefits for the prevention of atrial fibrillation. Eur Heart J 2006;27:2370-2371.

71. Everett TH, Olgin JE. Atrial fibrosis and the mechanisms of atrial fibrillation. Heart Rhythm 2007;4:S24-S27.

72. Ganotakis ES, Mikhailidis DP, Vardas PE. Atrial fibrillation, inflammation and statins. Hellenic J Cardiol 2006;47:51-53.

73. Waldo AL. Pathogenesis of atrial flutter. J Cardiovasc Electrophysiol 1998;9:S18-S25.

74. Camm AJ, Obel OA. Epidemiology and mechanism of atrial fibrillation and atrial flutter. Am J Cardiol 1996;78:3-11.

75. Horvath G, Goldberger JJ, Kadish AH. Simultaneous occurrence of atrial fibrillation and atrial flutter. J Cardiovasc Electrophysiol 2000;11:849-858.

76. Waldo AL. Treatment of atrial flutter. Heart 2000;84:227-232.

77. Waldo AL. Mechanisms of atrial flutter and atrial fibrillation: distinct entities or two sides of a coin? Cardiovasc Res 2002;54:217-229.

78. Waldo AL. The interrelationship between atrial fibrillation and atrial flutter. Prog Cardiovasc Dis 2005;48:41-56.

79. Wellens HJ. Contemporary management of atrial flutter. Circulation 2002;106:649-652.

80. Haissaguerre M, Sanders P, Hocini M, Hsu LF, Shah DC, Scavee C, Takahashi Y, Rotter M, Pasquie JL, Garrigue S, Clementy J, Jais P. Changes in atrial fibrillation cycle length and inducibility during catheter ablation and their relation to outcome. Circulation 2004;109:30073013. 
81. Oral H, Chugh A, Lemola K, Cheung P, Hall B, Good E, Han J, Tamirisa K, Bogun F, Pelosi F, Jr., Morady F. Noninducibility of atrial fibrillation as an end point of left atrial circumferential ablation for paroxysmal atrial fibrillation: a randomized study. Circulation 2004;110:2797-2801.

82. Jais P, Hocini M, Sanders P, Hsu LF, Takahashi Y, Rotter M, Rostock T, Sacher F, Clementy J, Haissaguerre M. Long-term evaluation of atrial fibrillation ablation guided by noninducibility. Heart Rhythm 2006;3:140-145.

83. Rotter M, Jais P, Garrigue S, Sanders P, Hocini M, Hsu LF, Takahashi Y, Rostock T, Sacher F, Clementy J, Haissaguerre M. Clinical predictors of noninducibility of sustained atrial fibrillation after pulmonary vein isolation. J Cardiovasc Electrophysiol 2005;16:1298-1303.

84. Lemola K, Oral H, Chugh A, Hall B, Cheung P, Han J, Tamirisa K, Good E, Bogun F, Pelosi F, Jr., Morady F. Pulmonary vein isolation as an end point for left atrial circumferential ablation of atrial fibrillation. J Am Coll Cardiol 2005;46:1060-1066.

85. Richter B, Gwechenberger M, Filzmoser P, Marx M, Lercher P, Gossinger HD. Is inducibility of atrial fibrillation after radio frequency ablation really a relevant prognostic factor? Eur Heart J 2006;27:2553-2559.

86. Wichterle D, Simek J, Camm J, Malik M. Predictive characteristics of holter-based postinfarction risk stratifiers appear superior to electrophysiological testing. Pacing Clin Electrophysiol 2005;28 Suppl 1:S182-S186.

87. Raczak G, Pinna GD, Maestri R, nilowicz-Szymanowicz L, Szwoch M, Lubinski A, Kempa M, La Rovere MT, Swiatecka G. Different predictive values of electrophysiological testing and autonomic assessment in patients surviving a sustained arrhythmic episode. Circ J 2004;68:634-638.

88. Bocker D, Breithardt G. Evaluating AVID, CASH, CIDS, CABG-patch and MADIT: are they concordant? J Interv Card Electrophysiol 2000;4 Suppl 1:103-108.

89. Gerstenfeld EP, Dixit S, Callans D, Rho R, Rajawat Y, Zado E, Marchlinski FE. Utility of exit block for identifying electrical isolation of the pulmonary veins. J Cardiovasc Electrophysiol 2002;13:971-979.

90. Kumagai K, Noguchi H, Ogawa M, Nakashima H, Zhang B, Miura S, Saku K. New approach to pulmonary vein isolation for atrial fibrillation using a multielectrode basket catheter. Circ J 2006;70:88-93.

91. Kumagai K, Ogawa M, Noguchi H, Nakashima H, Zhang B, Miura S, Saku K. Comparison of 2 mapping strategies for pulmonary vein isolation. Circ J 2005;69:1496-1502.

92. Cheema A, Dong J, Dalal D, Marine JE, Henrikson CA, Spragg D, Cheng A, Nazarian S, Bilchick K, Sinha S, Scherr D, Almasry I, Halperin H, Berger R, Calkins H. Incidence and time course of early recovery of pulmonary vein conduction after catheter ablation of atrial fibrillation. J Cardiovasc Electrophysiol 2007;18:387-391.

93. Sauer WH, McKernan ML, Lin D, Gerstenfeld EP, Callans DJ, Marchlinski FE. Clinical predictors and outcomes associated with acute return of pulmonary vein conduction during pulmonary vein isolation for treatment of atrial fibrillation. Heart Rhythm 2006;3:10241028.

94. Arentz T, MacLe L, Kalusche D, Hocini M, Jais P, Shah D, Haissaguerre M. "Dormant" pulmonary vein conduction revealed by adenosine after ostial radiofrequency catheter ablation. J Cardiovasc Electrophysiol 2004;15:1041-1047.

95. Hachiya H, Hirao K, Takahashi A, Nagata Y, Suzuki K, Maeda S, Sasaki T, Kawabata M, Isobe M, Iesaka Y. Clinical implications of reconnection between the left atrium and isolated pulmonary veins provoked by adenosine triphosphate after extensive encircling pulmonary vein isolation. J Cardiovasc Electrophysiol 2007;18:392-398.

96. Tritto M, De PR, Salerno-Uriarte JA, Spadacini G, Marazzi R, Moretti P, Lanzotti M. Adenosine restores atrio-venous conduction after apparently successful ostial isolation of the pulmonary veins. Eur Heart J 2004;25:2155-2163.

97. Tada H, Oral H, Greenstein R, Pelosi F, Jr., Knight BP, Strickberger SA, Morady F. Differentiation of atrial and pulmonary vein potentials recorded circumferentially within pulmonary veins. J Cardiovasc Electrophysiol 2002;13:118-123. 
98. Jais P, Hocini M, MacLe L, Choi KJ, Deisenhofer I, Weerasooriya R, Shah DC, Garrigue S, Raybaud F, Scavee C, Le MP, Clementy J, Haissaguerre M. Distinctive electrophysiological properties of pulmonary veins in patients with atrial fibrillation. Circulation 2002;106:24792485.

99. Calkins H, Brugada J, Packer DL, Cappato R, Chen SA, Crijns HJG, Damiano J, Davies DW, Haines DE, Haissaguerre M, Iesaka Y, Jackman W, Jais P, Kottkamp H, Kuck KH, Lindsay BD, Marchlinski FE, McCarthy PM, Mont JL, Morady F, Nademanee K, Natale A, Pappone C, Prystowsky E, Raviele A, Ruskin JN, Shemin RJ. HRS/EHRA/ECAS Expert Consensus Statement on Catheter and Surgical Ablation of Atrial Fibrillation: Recommendations for Personnel, Policy, Procedures and Follow-Up: A report of the Heart Rhythm Society (HRS) Task Force on Catheter and Surgical Ablation of Atrial Fibrillation. Developed in partnership with the European Heart Rhythm Association (EHRA) and the European Cardiac Arrhythmia Society (ECAS); in collaboration with the American College of Cardiology (ACC), American Heart Association (AHA), and the Society of Thoracic Surgeons (STS). Endorsed and Approved by the governing bodies of the American College of Cardiology, the American Heart Association, the European Cardiac Arrhythmia Society, the European Heart Rhythm Association, the Society of Thoracic Surgeons, and the Heart Rhythm Society. Heart Rhythm 2007;4:816-861.

100. Earley MJ, Showkathali R, Alzetani M, Kistler PM, Gupta D, Abrams DJ, Horrocks JA, Harris SJ, Sporton SC, Schilling RJ. Radiofrequency ablation of arrhythmias guided by nonfluoroscopic catheter location: a prospective randomized trial. Eur Heart J 2006;27:12231229.

101. Estner HL, Deisenhofer I, Luik A, Ndrepepa G, von BC, Zrenner B, Schmitt C. Electrical isolation of pulmonary veins in patients with atrial fibrillation: reduction of fluoroscopy exposure and procedure duration by the use of a non-fluoroscopic navigation system (NavX). Europace 2006;8:583-587.

102. Liu X, Wang XH, Gu JN, Zhou L, Qiu JH. [Electroanatomical systems guided circumferential pulmonary veins ablation for atrial fibrillation: initial experience from comparison between the EnSite-NavX and CARTO system]. Zhonghua Xin Xue Guan Bing Za Zhi 2005;33:975-978.

103. Ma CS, Liu X, Dong JZ, Yu RH, Wang XH, Liu XP, Shi HF, Long DY, Fang DP, Hu FL, Tang RB. [Pulmonary vein antrum isolation guided by 3-D mapping system in 100 patients with chronic atrial fibrillation]. Zhonghua Yi Xue Za Zhi 2006;86:1111-1114.

104. Novak PG, Macle L, Thibault B, Guerra PG. Enhanced left atrial mapping using digitally synchronized NavX three-dimensional nonfluoroscopic mapping and high-resolution computed tomographic imaging for catheter ablation of atrial fibrillation. Heart Rhythm 2004;1:521-522.

105. Rotter M, Takahashi Y, Sanders P, Haissaguerre M, Jais P, Hsu LF, Sacher F, Pasquie JL, Clementy J, Hocini M. Reduction of fluoroscopy exposure and procedure duration during ablation of atrial fibrillation using a novel anatomical navigation system. Eur Heart $\mathrm{J}$ 2005;26:1415-1421.

106. Cummings JE, Pacifico A, Drago JL, Kilicaslan F, Natale A. Alternative energy sources for the ablation of arrhythmias. Pacing Clin Electrophysiol 2005;28:434-443.

107. Hoyt RH, Wood M, Daoud E, Feld G, Sehra R, Pelkey W, Kay GN, Calkins H. Transvenous catheter cryoablation for treatment of atrial fibrillation: results of a feasibility study. Pacing Clin Electrophysiol 2005;28 Suppl 1:S78-S82.

108. Manusama R, Timmermans C, Philippens S, Crijns HJ, Ayers GM, Rodriguez LM. Single cryothermia applications of less than five minutes produce permanent cavotricuspid isthmus block in humans. Heart Rhythm 2004;1:594-599.

109. Skanes AC, Klein G, Krahn A, Yee R. Cryoablation: potentials and pitfalls. J Cardiovasc Electrophysiol 2004;15:S28-S34.

110. Skanes AC, Jones DL, Teefy P, Guiraudon C, Yee R, Krahn AD, Klein GJ. Safety and feasibility of cryothermal ablation within the mid- and distal coronary sinus. J Cardiovasc Electrophysiol 2004;15:1319-1323. 
111. Skanes AC, Jensen SM, Papp R, Li J, Yee R, Krahn AD, Klein GJ. Isolation of pulmonary veins using a transvenous curvilinear cryoablation catheter: feasibility, initial experience, and analysis of recurrences. J Cardiovasc Electrophysiol 2005;16:1304-1308.

112. Yiu KH, Lau CP, Lee KL, Tse HF. Emerging energy sources for catheter ablation of atrial fibrillation. J Cardiovasc Electrophysiol 2006;17 Suppl 3:S56-S61.

113. Siu CW, Tse HF, Lau CP. Avoidance of electromagnetic interference to implantable cardiovertor-defibrillator during atrioventricular node ablation for atrial fibrillation using transvenous cryoablation. Pacing Clin Electrophysiol 2006;29:914-916.

114. Tuzcu V, Gonzalez MB, Schranz D. Cryoablation: better catheter stability compared to RF ablation. Anadolu Kardiyol Derg 2006;6:182-184.

115. Timmermans C, Ayers GM, Crijns HJ, Rodriguez LM. Randomized study comparing radiofrequency ablation with cryoablation for the treatment of atrial flutter with emphasis on pain perception. Circulation 2003;107:1250-1252.

116. Skanes AC, Dubuc M, Klein GJ, Thibault B, Krahn AD, Yee R, Roy D, Guerra P, Talajic M. Cryothermal ablation of the slow pathway for the elimination of atrioventricular nodal reentrant tachycardia. Circulation 2000;102:2856-2860.

117. Khairy P, Chauvet P, Lehmann J, Lambert J, MacLe L, Tanguay JF, Sirois MG, Santoianni $\mathrm{D}$, Dubuc M. Lower incidence of thrombus formation with cryoenergy versus radiofrequency catheter ablation. Circulation 2003;107:2045-2050.

118. Tse HF, Kwong YL, Lau CP. Transvenous cryoablation reduces platelet activation during pulmonary vein ablation compared with radiofrequency energy in patients with atrial fibrillation. J Cardiovasc Electrophysiol 2005;16:1064-1070.

119. Friedman PL. Catheter cryoablation of cardiac arrhythmias. Curr Opin Cardiol 2005;20:4854.

120. Lustgarten DL, Keane D, Ruskin J. Cryothermal ablation: mechanism of tissue injury and current experience in the treatment of tachyarrhythmias. Prog Cardiovasc Dis 1999;41:481498.

121. Rodriguez LM, Timmermans C. Transvenous cryoablation of cardiac arrhythmias. Technol Cancer Res Treat 2004;3:515-524.

122. Tse HF, Lau CP. Impact of duration of cryothermal application on clinical efficacy of pulmonary vein isolation using transvenous cryoablation. Pacing Clin Electrophysiol 2005;28:839-843.

123. Fatini C, Sticchi E, Abbate R, Gensini GF. Genetic susceptibility to atrial fibrillation (AF) in patients with congestive heart failure. Heart Rhythm 2006;3:1395.

124. Fukuda T, Yamashita T, Sagara K, Kato T, Sawada H, Aizawa T. Development of congestive heart failure in Japanese patients with atrial fibrillation. Circ J 2007;71:308-312.

125. Gould PA, Yii M, Esler MD, Power JM, Kaye DM. Atrial fibrillation impairs cardiac sympathetic response to baroreceptor unloading in congestive heart failure. Eur Heart J 2005;26:2562-2567.

126. Heist EK, Ruskin JN. Atrial fibrillation and congestive heart failure: risk factors, mechanisms, and treatment. Prog Cardiovasc Dis 2006;48:256-269.

127. Nattel S. Driver regions in atrial fibrillation associated with congestive heart failure: where are they, and what are they telling us? J Cardiovasc Electrophysiol 2005;16:1359-1361.

128. Sturmer ML, Talajic M, Thibault B, Guerra PG, Dubuc M, Novak P, Roy D. Management of atrial fibrillation in patients with congestive heart failure. Am J Geriatr Cardiol 2005;14:91-94.

129. Healey JS, Connolly SJ. Atrial fibrillation: hypertension as a causative agent, risk factor for complications, and potential therapeutic target. Am J Cardiol 2003;91:9G-14G.

130. Katritsis DG, Toumpoulis IK, Giazitzoglou E, Korovesis S, Karabinos I, Paxinos G, Zambartas C, Anagnostopoulos CE. Latent arterial hypertension in apparently lone atrial fibrillation. J Interv Card Electrophysiol 2005;13:203-207.

131. Kirchhof P, Schotten U. Hypertension begets hypertrophy begets atrial fibrillation? Insights from yet another sheep model. Eur Heart J 2006;27:2919-2920. 
132. Korantzopoulos P, Kolettis T, Goudevenos J. Atrial fibrillation in hypertension: an established association with several unresolved issues. Cardiology 2003;100:105-106.

133. Lip GY. Atrial fibrillation in hypertension: under recognised or over diagnosed? J Hum Hypertens 1997;11:691-693.

134. Ostgren CJ, Merlo J, Rastam L, Lindblad U. Atrial fibrillation and its association with type 2 diabetes and hypertension in a Swedish community. Diabetes Obes Metab 2004;6:367-374.

135. Verdecchia P, Reboldi G, Gattobigio R, Bentivoglio M, Borgioni C, Angeli F, Carluccio E, Sardone MG, Porcellati C. Atrial fibrillation in hypertension: predictors and outcome. Hypertension 2003;41:218-223.

136. Wachtell K, Hornestam B, Lehto M, Slotwiner DJ, Gerdts E, Olsen MH, Aurup P, Dahlof B, Ibsen H, Julius S, Kjeldsen SE, Lindholm LH, Nieminen MS, Rokkedal J, Devereux RB. Cardiovascular morbidity and mortality in hypertensive patients with a history of atrial fibrillation: The Losartan Intervention For End Point Reduction in Hypertension (LIFE) study. J Am Coll Cardiol 2005;45:705-711.

137. Chobanian AV, Bakris GL, Black HR, Cushman WC, Green LA, Izzo JL, Jr., Jones DW, Materson BJ, Oparil S, Wright JT, Jr., Roccella EJ, the National High Blood Pressure Education Program Coordinating Committee. Seventh Report of the Joint National Committee on Prevention, Detection, Evaluation, and Treatment of High Blood Pressure. Hypertension 2003;42:1206-1252.

138. Haines DE. With pharmacologic conversion of atrial fibrillation, is timing everything? Heart Rhythm 2005;2:231-233.

139. Komatsu T, Nakamura S, Suzuki O, Horiuchi D, Owada S, Kameda K, Tomita H, Oikawa $\mathrm{K}$, Abe N, Okumura K. [Long-term efficacy of combination therapy using antiarrhythmic agents and angiotensin converting enzyme inhibitor in patients with paroxysmal and persistent atrial fibrillation: importance of the timing of administration]. J Cardiol 2003;41:73-80.

140. Shah DC. The effectiveness and timing of elective pharmacological cardioversion for paroxysmal atrial fibrillation. Eur Heart J 1999;20:1768-1769.

141. Volders PG, Zhu Q, Timmermans C, Eurlings PM, Su X, Arens YH, Li L, Jongbloed RJ, Xia M, Rodriguez LM, Chen YH. Mapping a novel locus for familial atrial fibrillation on chromosome 10p11-q21. Heart Rhythm 2007;4:469-475.

142. Xia M, Jin Q, Bendahhou S, He Y, Larroque MM, Chen Y, Zhou Q, Yang Y, Liu Y, Liu B, Zhu Q, Zhou Y, Lin J, Liang B, Li L, Dong X, Pan Z, Wang R, Wan H, Qiu W, Xu W, Eurlings P, Barhanin J, Chen Y. A Kir2.1 gain-of-function mutation underlies familial atrial fibrillation. Biochem Biophys Res Commun 2005;332:1012-1019.

143. Darbar D, Herron KJ, Ballew JD, Jahangir A, Gersh BJ, Shen WK, Hammill SC, Packer DL, Olson TM. Familial atrial fibrillation is a genetically heterogeneous disorder. J Am Coll Cardiol 2003;41:2185-2192.

144. Chen YH, Xu SJ, Bendahhou S, Wang XL, Wang Y, Xu WY, Jin HW, Sun H, Su XY, Zhuang QN, Yang YQ, Li YB, Liu Y, Xu HJ, Li XF, Ma N, Mou CP, Chen Z, Barhanin J, Huang W. KCNQ1 gain-of-function mutation in familial atrial fibrillation. Science 2003;299:251-254.

145. Tikanoja T, Kirkinen P, Nikolajev K, Eresmaa L, Haring P. Familial atrial fibrillation with fetal onset. Heart 1998;79:195-197.

146. MacRae CA. Familial atrial fibrillation. N Engl J Med 1997;337:350.

147. Brugada R, Tapscott T, Czernuszewicz GZ, Marian AJ, Iglesias A, Mont L, Brugada J, Girona J, Domingo A, Bachinski LL, Roberts R. Identification of a genetic locus for familial atrial fibrillation. N Engl J Med 1997;336:905-911.

148. Roberts R. Mechanisms of disease: Genetic mechanisms of atrial fibrillation. Nat Clin Pract Cardiovasc Med 2006;3:276-282.

149. Beery TT. The genetics of cardiac arrhythmias. Biol Res Nurs 2005;6:249-261.

150. Lai LP, Lin JL, Huang SK. Molecular genetic studies in atrial fibrillation. Cardiology 2003;100:109-113.

151. Roberts R, Brugada R. Genetics and arrhythmias. Annu Rev Med 2003;54:257-267. 
152. Shah G, Brugada R, Gonzalez O, Czernuszewicz G, Gibbs RA, Bachinski L, Roberts R. The cloning, genomic organization and tissue expression profile of the human DLG5 gene. BMC Genomics 2002;3:6.

153. Hatcher CJ, Kim MS, Basson CT. Atrial form and function: lessons from human molecular genetics. Trends Cardiovasc Med 2000;10:93-101.

154. James TN. Congenital disorders of cardiac rhythm and conduction. J Cardiovasc Electrophysiol 1993;4:702-718.

155. Song ZZ, Ma J. Tissue Doppler imaging analysis at precardioversion time may be a useful marker to identify a subgroup of patients with increased risk for atrial fibrillation recurrence. J Cardiovasc Electrophysiol 2007;18:E15.

156. Bollmann A, Husser D, Stridh M, Sornmo L. Transthoracic tissue Doppler imaging of the atria to determine atrial fibrillation cycle length. J Cardiovasc Electrophysiol 2007;18:E13E14.

157. Donal E, Sallach JA, Daniel MR, Drinko JK, Jasper SE, Thomas JD, Klein AL. Contrastenhanced tissue Doppler imaging of the left atrial appendage is a new quantitative measure of spontaneous echocardiographic contrast in atrial fibrillation. Eur J Echocardiogr 2006.

158. Wazni OM, Tsao HM, Chen SA, Chuang HH, Saliba W, Natale A, Klein AL. Cardiovascular imaging in the management of atrial fibrillation. J Am Coll Cardiol 2006;48:2077-2084.

159. Gedikli O, Dogan A, Altuntas I, Altinbas A, Ozaydin M, Akturk O, Acar G. Inflammatory markers according to types of atrial fibrillation. Int J Cardiol 2007.

160. Marcucci R, Betti I, Cecchi E, Poli D, Giusti B, Fedi S, Lapini I, Abbate R, Gensini GF, Prisco D. Hyperhomocysteinemia and vitamin B6 deficiency: new risk markers for nonvalvular atrial fibrillation? Am Heart J 2004;148:456-461.

161. Rosa A, Diurni V, Placido A, Bertazzoni G. Markers of inflammation in atrial fibrillation. Acta Cardiol 2003;58:43-44.

162. Al-Saady NM, Sopher M. Prothrombotic markers in atrial fibrillation: what is new? Eur Heart J 2001;22:1635-1639.

163. Mabuchi N, Tsutamoto T, Maeda K, Kinoshita M. Plasma cardiac natriuretic peptides as biochemical markers of recurrence of atrial fibrillation in patients with mild congestive heart failure. Jpn Circ J 2000;64:765-771.

164. Vikenes K, Omvik P, Farstad M, Nordrehaug JE. Cardiac biochemical markers after cardioversion of atrial fibrillation or atrial flutter. Am Heart J 2000;140:690-696.

165. Feinberg WM, Pearce LA, Hart RG, Cushman M, Cornell ES, Lip GY, Bovill EG. Markers of thrombin and platelet activity in patients with atrial fibrillation: correlation with stroke among 1531 participants in the stroke prevention in atrial fibrillation III study. Stroke 1999;30:2547-2553.

166. Ad N, Snir E, Vidne BA, Golomb E. Potential preoperative markers for the risk of developing atrial fibrillation after cardiac surgery. Semin Thorac Cardiovasc Surg 1999;11:308-313.

167. Patten M, Maas R, Karim A, Muller HW, Simonovsky R, Meinertz T. Event-recorder monitoring in the diagnosis of atrial fibrillation in symptomatic patients: subanalysis of the SOPAT trial. J Cardiovasc Electrophysiol 2006;17:1216-1220.

168. Ricci RP, Russo M, Santini M. Management of atrial fibrillation - what are the possibilities of early detection with Home Monitoring? Clin Res Cardiol 2006;95 Suppl 3:III10-III16.

169. Darbar D, Roden DM. Future of antiarrhythmic drugs. Curr Opin Cardiol 2006;21:361-367.

170. Goldstein RN, Stambler BS. New antiarrhythmic drugs for prevention of atrial fibrillation. Prog Cardiovasc Dis 2005;48:193-208.

171. Bush D, Martin LW, Leman R, Chandler M, Haywood LJ. Atrial fibrillation among African Americans, Hispanics and Caucasians: clinical features and outcomes from the AFFIRM trial. J Natl Med Assoc 2006;98:330-339.

172. Shelton RJ. The AFFIRM study: approaches to control rate in atrial fibrillation. J Am Coll Cardiol 2004;44:2418-2419.

173. Boriani G, Biffi M, Martignani C, Branzi A. Rate control in AFFIRM: considerations about the clinical implications. Am J Cardiol 2004;94:1104-1105. 
174. Blackshear JL, Safford RE. AFFIRM and RACE trials: implications for the management of atrial fibrillation. Card Electrophysiol Rev 2003;7:366-369.

175. Olshansky B, Rosenfeld LE, Warner AL, Solomon AJ, O'Neill G, Sharma A, Platia E, Feld GK, Akiyama T, Brodsky MA, Greene HL. The Atrial Fibrillation Follow-up Investigation of Rhythm Management (AFFIRM) study: approaches to control rate in atrial fibrillation. J Am Coll Cardiol 2004;43:1201-1208.

176. Salam AM. Rate control versus rhythm control for the management of atrial fibrillation: the verdict of the AFFIRM trial. Expert Opin Investig Drugs 2003;12:1231-1237.

177. Fuller R, Dudley NJ. Atrial fibrillation: will new drugs and patient choice improve anticoagulation outcomes? Heart 2005;91:423-424.

178. Pappone C, Vicedomini G, Manguso F, Gugliotta F, Mazzone P, Gulletta S, Sora N, Sala S, Marzi A, Augello G, LiVolsi L, Santagostino A, Santinelli V. Robotic magnetic navigation for atrial fibrillation ablation. J Am Coll Cardiol 2006;47:1390-1400.

179. Pappone C, Santinelli V. Remote navigation and ablation of atrial fibrillation. J Cardiovasc Electrophysiol 2007;18 Suppl 1:S18-S20. 



\section{CHAPTER X}

Summary 
Ablation of the cavotricuspid isthmus (CTI) is the treatment of choice in patients with common type atrial flutter (AFL). However, most data regarding long term outcome not only have a relatively short follow-up but are also restricted to radiofrequency ablation.

In Chapter II we present the long term follow-up of 180 patients with common type AFL submitted to CTI cryoablation. Our population had the following characteristics: mean age 58 y (from 18 to 86 ), 39 women (22\%), no structural heart disease in 86 patients (48\%), mean LA diameter $44 \pm 7 \mathrm{~mm}$ and mean LVEF $57 \pm 7 \%$. We achieved acute success in 171 (95\%) of the patients. There were no complications.

Follow-up ranged from 12 to 60 months (mean of $27 \pm 17$ months). The chronic success rate was $91 \%$. A prior history of atrial fibrillation (AF) was present in 123 patients (68\%). Of these, 85 patients (69\%) remained having episodes of AF on long term follow-up. Sixty nine patients (81\%) were treated with antiarrhythmic drugs, pulmonary vein isolation was performed in 14 patients $(16 \%)$, and AV nodal ablation with pacemaker implantation in 2 patients $(3 \%)$. Among the 57 patients without a history of AF prior to CTI ablation, new AF developed in 20 (35\%) patients (all asymptomatic on AAD).

Our data show that cryoablation of the CTI in patients with common type AFL has a $91 \%$ chronic (range 12 to 60 months) success rate. Also we corroborated the frequent association of AF (69\%) with AFL, the former being the main cause of burden in this group of patients.

In Chapter III we evaluated the long term data of patients with $4 \pm 1$ years of Paroxysmal AF submitted to segmental pulmonary vein (PV) cryoisolation. Patients with PAF were prospectively recruited from July 2001 to July 2005. Thirty days before ablation, a 12 lead ECG, Holter and daily transtelephonic telemetry (TTM) were obtained. The TTMs were continued for 180 days after the procedure. Thereafter, Holter monitoring was used at each outpatient clinic visit or if symptoms developed. A spiral CT scan to evaluate PVs morphology was performed in all patients before the procedure and in the majority of them during 3, 6 and 12 months of follow-up. If the triggers for AF were identified, PV cryoisolation of the arrhythmogenic vein(s) was performed. Otherwise, all PVs were isolated. Single cryothermy applications $\left(\mathrm{CryoCor}^{\mathrm{TM}}\right.$ ) were given lasting 3 minutes.

A total of 70 patients (54 men; age $40 \pm 10$ years) were enrolled. The duration of PAF was $4 \pm 1$ years. Patients had failed 1 to 2 AAD before ablation and most of them had minimal or no heart disease. The LVEF and left atrial size were $59 \pm 8 \%$ and $41 \pm 5 \mathrm{~mm}$, respectively. All targeted PVs were successfully isolated (mean of $3 \pm 1$ PVs per patient).

Arrhythmogenic veins were considered those that, during AF, had a tachycardia cycle length shorter that the one recorded in the coronary sinus catheter. Induction of AF was attempted first by manipulation of the LASSO ${ }^{\mathrm{TM}}$ catheter inside the vein (mechanical contact); if that did not result in arrhythmias, administrations of adenosine and isoproterenol infusion were used. An arrhyth- 
mogenic PV(s) was found in 10 patients (14\%). Complications occurred in 3 $(4 \%)$ patients (one stroke, one pulmonary embolus and one transient diaphragmatic paralysis). No PV stenosis or esophageal injury was detected during a mean follow up was $33 \pm 15$ (15 to 60) months. Thirty four patients $(49 \%)$ had no recurrences and 23 patients $(33 \%$ ) improved $>50 \%$ (overall success rate of $=82 \%$ ).

Patients in whom the arrhythmogenic PV(s) were identified and isolated had no recurrences. From this study we conclude that PV cryoisolation is effective in $82 \%$ of patients with PAF during a mean follow-up of $33 \pm 15$ months (15 to 60). Most importantly, if the arrhythmogenic PV is identified and isolated, the long-term outcome is excellent indicating no need to isolate all PVs.

But what about the patients who have recurrences after PVI? Is immediate return of AF a bad prognostic sign showing that this patient has failed ablation? Those answers came from the study described in Chapter IV. No systematic study has been performed as to incidence and type of recurrences following percutaneous ablation of AF. Some types of early recurrences can lead to concern regarding the success of the procedure and may also result in unnecessary re-interventions. Recent literature suggests a poor correlation of patients' symptoms with their rhythm after AF ablation.

Our study prospectively evaluated 60 patients with paroxysmal AF submitted to PV cryoisolation (45 men; mean age 53 (21 to 68) years) using daily recordings with transtelephonic telemetry (from 30 days prior and up to 180 days after the procedure).

We were able to demonstrate three different types of behavior of AF recurrence after PVI: 1) Group A - 26 patients with no further episodes of AF immediately after the procedure, 2) Group B - 20 patients with a significant decrease of AF episodes after PVI (starting at 3 months and stabilizing at 9 months) or 3) Group C - 14 patients with immediate increase in the number of events (that declines throughout one year). A history of prior atrial flutter ablation was found to be a sign of bad prognosis as to AF recurrences.

This finding led us to the following question: can common type AFL be a sign of an arrhythmogenic substrate in paroxysmal atrial fibrillation? In Chapter $\mathbf{V}$ we evaluated the clinical and ablative consequences in patients with coexistent $\mathrm{AF} / \mathrm{AFL}$.

Ninety eight patients with paroxysmal AF/AFL were prospectively recruited from July 2001 to July 2006 to undergo PV cryoisolation. Based on telemetry, 12 lead ECG and Holter, our cohort was assigned to two different ablation strategies: Group I included 36 patients who had cavotricuspid isthmus ablation (if at least one episode of sustained common type AFL was documented) followed by pulmonary vein isolation. The other 62 patients with PAF formed our Group II where only PVI was performed.

Our results show that in patients with paroxysmal AF and no documented common type AFL, PVI alone prevents the occurrence of AF in $82 \%$ and lowers the incidence of the sustained common type AFL. Furthermore, in patients 
with AFL/AF, CTI ablation and PVI cured AFL but did not prevent AF recurrences. The latter finding suggests that AFL may be a sign that non PV triggers (including in the right atrium) are the culprit of $\mathrm{AF}$ and/or enough electrical remodeling has occurred in both atria and an ablative strategy which includes substrate modification is already required.

The knowledge that pulmonary veins (PV) are the trigger in a large percentage of patients with paroxysmal atrial fibrillation (PAF) has contributed importantly to the development of percutaneous ablative techniques in the treatment of atrial fibrillation (AF). With the main emphasis on electrical potentials in the pulmonary veins of patients with $\mathrm{AF}$, the approach was to isolate all veins with electrical activity. However, in the majority of protocols used for the percutaneous treatment of AF, electrophysiological evaluation of PVs is not included.

Distinct electrophysiological properties of PVs such as shorter refractory periods and decremental properties were previously described in patients with AF. But these data were frequently affected by exposure to amiodarone (in one third of the patients). This drug has been shown to significantly alter the refractory periods of the PVs. In Chapter VI we therefore evaluated the electrophysiologic properties of different PVs and their adjacent tissue (in the same patient) in a population with PAF not exposed to amiodarone referred for PV cryoisolation.

A total of 10 patients with lone AF ( 8 men; mean age 54 y (42 to 60)) were enrolled. Mean left atrium (LA) diameter was $38 \mathrm{~mm}$ (33 to 44) with a mean LVEF of $64 \%$. Of the 40 PVs studied, potentials with decremental properties were found in 38 PVs. No arrhythmias could be induced in $18(47 \%)$ of those $>$ non-arrhythmogenic group (mean of 2 veins per patient).

Our findings suggest that in patients with paroxysmal AF not exposed to amiodarone, arrhythmogenic PVs have extremely low refractory periods with a significant refractory period gradient compared to the adjacent LA. Such a situation may promote reentry, especially since decremental properties are present in the pulmonary veins.

In accordance with that finding we show in Chapter VII an example of the importance of the pacing site in order to evaluate the arrhythmogenic location in patients with paroxysmal AF submitted to ablation.

Non fluoroscopic navigation systems play a beneficial role in AF ablation. But the most common system used (CARTO ${ }^{\mathrm{TM}}$ ) limits the operator to radiofrequency energy. In Chapter VIII we demonstrate the feasibility of another navigation system $\left(\mathrm{Nav} \mathrm{X}^{\mathrm{TM}}\right)$ in $\mathrm{AF}$ ablation using cryothermy.

The clinical implications of all our findings are given in the General Discussion session. 


\section{CHAPTER XI}

Samenvatting 
Bij patiënten met een typische atriale flutter (AFL), is ablatie van de cavotricuspid isthmus (CTI) de meest gekozen vorm van behandeling. De meeste studies over de lange termijn resultaten van deze behandeling hebben echter een relatief korte follow-up en maken gebruik van radiofrequente energie.

In |Hoofdstuk II worden de lange termijn resultaten beschreven van 180 patiënten met een typische AFL die behandeld werden met cryoablatie. Deze patiënten populatie had de volgende karakteristieken: een gemiddelde leeftijd van 58 jaar (18-86), er waren 39 vrouwen (22\%), afwezigheid van structureel hartlijden in 86 patiënten (48\%), een gemiddelde linker atrium (LA) diameter van $44 \pm 7 \mathrm{~mm}$ en een gemiddelde linker ventrikel ejectiefractie (LVEF) van 57 $\pm 7 \%$. De procedure was succesvol in 171 (95\%) van de patiënten. Er traden geen complicaties op.

Er was een gemiddelde follow-up van $27 \pm 17$ (van 12 tot 60 ) maanden. Het lange termijn succes bedroeg 91\%. Bij 123 patiënten $(68 \%)$ werd voor de cryoablatie atriumfibrilleren (AF) vastgesteld. Bij 85 van hen $(69 \%)$ waren er nog steeds AF episoden tijdens de lange termijn follow-up na de ablatie. Negenenzestig patiënten (81\%) werden behandeld met antiaritmica. Bij 14 patiënten $(16 \%)$ werd een isolatie van de longvenen uitgevoerd en 2 patiënten $(3 \%)$ ondergingen een ablatie van de AV knoop gevolgd door pacemaker implantatie. Van de 57 patiënten die voor de CTI ablatie geen AF hadden, trad AF voor het eerst bij $20(35 \%)$ van hen na de ablatie op (alle patiënten werden asymptomatisch met antiaritmica).

Onze gegevens tonen aan dat cryoablatie van de CTI bij patiënten met een typische atriale flutter een chronisch succespercentage van 91\% (tussen 12 tot 60 maanden) heeft. Het onderzoek bevestigt het frequent voorkomen van AF (69\%) met AFL. AF was de voornaamste burden bij deze patiënten.

In Hoofdstuk III worden de lange termijn resultaten beschreven van patienten met $4 \pm 1$ jaar paroxysmaal AF (PAF) die een segmentale longvenen cryoisolatie ondergingen. Patiënten met PAF werden tussen juli 2001 en juli 2005 prospectief geincludeerd. Dertig dagen voor de ablatie werd er een 12-lead ECG, een 24-uur holter registratie en dagelijkse transtelefonische telemetrie (TTM) verricht. TTM werd tot 180 dagen na de ablatie uitgevoerd. Daarna werd tijdens elke poliklinische controle en indien de patiënt klachten had een 24-uur holter registratie afgesproken. Om de morfologie van de longvenen te beoordelen werd er bij iedere patiënt, voor de procedure, een spiraal CT-scan van het hart uitgevoerd. Deze CT scan werd bij de meeste patiënten herhaald na 3, 6 en 12 maanden follow-up. Cryoisolatie van de aritmogene longvene(n) werd uitgevoerd indien de triggers voor AF werden geïdentificeerd. Indien dit niet mogelijk was, werden alle longvenen geïsoleerd. Er werden cryo-applicaties (CryoCor ${ }^{\mathrm{TM}}$ ) van 3 minuten gegeven.

In totaal werden er 70 patiënten (54 mannen met een gemiddelde leeftijd van $40 \pm 10$ jaar) geincludeerd. De gemiddelde duur van PAF was $4 \pm 1$ jaar. De patiënten werden voor de ablatie met 1 tot 2 verschillende antiaritmica zonder succes behandeld. Het grootste deel van de patiënten had geen tot minimaal 
structureel hartlijden. De LVEF was $59 \pm 8 \%$ en LA diameter $41 \pm 5 \mathrm{~mm}$. Alle behandelde longvenen werden succesvol geïsoleerd (gemiddeld $3 \pm 1$ longvenen per patiënt).

Een longvene werd als aritmogeen beschouwd indien in deze longvene, tijdens AF, een kortere cyclus lengte werd gemeten dan in de sinus coronarius. Allereerst werd er geprobeerd AF op te starten tijdens het plaatsen van de LASSO ${ }^{\text {TM }}$ katheter in de longvenen (mechanisch contact). Indien er op deze manier geen aritmiëen optraden, werd adenosine of isoproterenol intraveneus toegediend. Bij 10 patiënten (14\%) werd(en) er een aritmogene longvene(n) geïdentificeerd. Bij 3 patiënten (4\%) traden er complicaties op (een patiënt met een CVA, een patiënt met een longembool en een patiënt met een tijdelijke diafragma paralyse). Er werd geen longvene stenose of slokdarm letsel vastgesteld tijdens een gemiddelde follow-up van $33 \pm 15$ (15 - 60) maanden. Vierendertig patiënten $(49 \%)$ hadden geen recidief van AF en bij 23 patiënten $(33 \%)$ was er een duidelijke verbetering van meer dan 50\%. Het globaal succespercentage bedroeg 82\%. Patiënten waarbij de aritmogene longvene(n) werd(en) geïdentificeerd en geïsoleerd hadden geen recidief van AF.

Deze studie toonde aan dat cryoisolatie van de longvenen in $82 \%$ van de patiënten met PAF effectief was na een gemiddelde follow-up van $33 \pm 15$ (16 60) maanden. Indien de aritmogene longvene(n) wordt geïdentificeerd en geïsoleerd, is het lange termijn resultaat uitstekend; dit toont aan dat het niet nodig is om alle longvenen te isoleren.

Wat dient men te doen bij patiënten die een recidief AF hebben na een longvenen isolatie? Is het vroegtijdig heroptreden van AF een slecht prognostisch teken dat de ablatie niet geslaagd is? De antwoorden op deze vragen kwamen van een studie die beschreven staat in Hoofdstuk IV. Tot nu toe werd er geen enkele studie uitgevoerd die de incidentie en het type recidief na percutane ablatie van AF naging. Een vroegtijdig recidief kan het resultaat van de procedure in vraag stellen en kan aanleiding geven tot onnodige re-interventies. Recente publicaties laten een slechte correlatie zien tussen de symptomen van de patiënten en hun ritme na AF ablatie.

In onze studie werden er 60 patiënten met PAF (45 mannen met een gemiddelde leeftijd van 53 (21 - 68) jaar), die een longvene cryoisolatie ondergingen, geëvalueerd. Tijdens de studie werd dagelijks gebruik gemaakt van transtelefonische monitoring (van 30 dagen voor tot 180 dagen na de ablatie).

Wij stelden vast dat er 3 vormen van AF recidief na longvenen isolatie zijn: 1) Groep $A-26$ patiënten met geen $A F$ episodes meer onmiddellijk na de procedure, 2) Groep B - 20 patiënten met een significante afname van AF episodes na longvenen isolatie (optredend na 3 maanden en gestabiliseerd na 9 maanden) of 3) Groep C - 14 patiënten met een onmiddellijke toename van het aantal episodes (die nadien afnamen over een tijdspanne van 1 jaar). Patiënten die voorheen een atriale flutter ablatie ondergingen hebben een slechte prognose voor het heroptreden van AF.

Deze bevinding bracht ons tot de volgende vraag: is een typische atriale 
flutter een teken van een aritmogeen substraat bij patiënten met PAF? In Hoofdstuk V hebben we de ablatie en klinische resultaten geëvalueerd bij patienten met zowel AF als AFL.

Tussen juli 2001 en juli 2006 werden er 89 patiënten met PAF/AFL prospectief geincludeerd voor cryoisolatie van de longvenen. Op basis van telemetrie, 12-lead ECG en holter registratie, werden de patiënten behandeld volgens 1 van de 2 ablatie strategieën. In Groep I werden 36 patiënten geincludeerd die eerst een CTI ablatie ondergingen (indien er tenminste 1 episode van sustained typische AFL was gedocumenteerd) gevolgd door een longvenen isolatie. Bij de andere 62 patiënten met PAF (Groep II) werd enkel een longvenen isolatie uitgevoerd.

Onze resultaten tonen aan dat bij patiënten met PAF en geen documentatie van een typische AFL, alleen het isoleren van de longvenen AF voorkomt in 82 $\%$ en de kans op sustained typische AFL verlaagt. Bij patiënten met AFL/AF, voorkwam CTI ablatie en longvenen isolatie het optreden van AFL maar niet van AF. Deze laatste bevinding suggereert dat AFL mogelijk een teken is 1) dat triggers die niet afkomstig zijn van de longvenen (inclusief het rechter atrium) de oorzaak zijn van AF en/of 2) dat er reeds voldoende elektrische remodeling in beide atria aanwezig is zodat er voor een ablatie strategie met substraat modificatie moet worden gekozen.

Het feit dat de longvenen de triggers zijn in een groot aantal patiënten met PAF, heeft een belangrijke rol gespeeld in de ontwikkeling van percutane ablatie technieken. Gezien elektrische potentialen in de longvenen bij patiënten met PAF een belangrijke rol spelen, is het doel van een ablatie procedure de elektrische isolatie van alle longvenen. In de meeste protocollen die gebruikt worden bij de percutane behandeling van AF wordt er geen elektrofysiologische evaluatie van de longvenen uitgevoerd.

Verschillende elektrofysiologische eigenschappen van de longvenen, zoals een korte refractaire periode en 'decremental properties', werden reeds beschreven bij patiënten met AF. De gegevens werden echter vaak beïnvloed door het gebruik van amiodarone (bij eenderde van de patiënten). Dit medicament beïnvloedt de refractaire periode van de longvenen. In Hoofdstuk VI hebben we daarom de elektrofysiologische eigenschappen van de verschillende longvenen en het omliggende atriaal weefsel geëvalueerd bij patiënten met PAF, die geen amiodarone innamen en die verwezen werden voor longvenen isolatie.

In totaal werden er 10 patiënten met lone AF (8 mannen met een gemiddelde leeftijd van 54 (42 - 60) jaar) geincludeerd. De gemiddelde LA diameter bedroeg $38 \mathrm{~mm}$ (33 - 40) en de gemiddelde LVEF was 64\%. Bij 38 van de 40 longvenen waren er potentialen aanwezig met 'decremental properties'. In 18 (47\%) longvenen werden er geen aritmiëen geïnduceerd (de niet-aritmogene groep; gemiddelde 2 venen per patiënt).

Onze bevindingen suggereren dat bij patiënten met PAF, die geen amiodarone gebruiken, de aritmogene longvenen een zeer korte refractaire periode en een significante refractaire periode gradiënt, in vergelijking met het aangrenzend 
LA, hebben. Deze situatie kan reentry bevorderen, zeker indien de longvenen 'decremental properties' hebben.

In Hoofdstuk VII wordt, met behulp van een voorbeeld, het belang van de pacing plaats voor lokalisatie van de aritmogene longvene bij patiënten met PAF die een ablatie ondergaan beschreven.

Navigatiesystemen die geen gebruik maken van röntgenstraling spelen een belangrijke rol bij AF ablatie. Bij het meest gebruikte systeem (CARTOTM) kan enkel radiofrequente energie toegediend worden. In Hoofdstuk VIII beschrijven we het gebruik van een ander navigatiesysteem $\left(\mathrm{NavX}^{\mathrm{TM}}\right)$ waar ook cryothermie kan gebruikt worden.

De klinische implicaties van onze bevindingen worden beschreven in de algemene discussie. 



\title{
CHAPTER XII
}

\author{
Resumen
}


La ablación del istmo cavotricuspideo (ICT) es el tratamiento de elección en pacientes con aleteo atrial del tipo común (AA). Sin embargo, la mayoría de los datos con respecto a pronóstico a largo plazo han sido tomados de seguimientos a corto plazo y también han sido limitados a la ablación por radiofrecuencia.

En el capítulo II presentamos el seguimiento a largo plazo de 180 pacientes con AA del tipo común con ablación del ICT con crioablación. La muestra tuvo las siguientes características: 39 mujeres (22\%), edad media de 58 años (de 18 a 86 años), sin alteración cardiaca estructural en 86 pacientes (48\%), diámetro medio del atrio izquierdo (AI) $44 \pm 7 \mathrm{~mm}$, y fracción de expulsión del ventrículo izquierdo (FEVI) media de $57 \pm 7 \%$. Se alcanzó éxito agudo en $95 \%$ (171) de los pacientes. No hubo complicaciones.

El seguimiento fue de 12 a 60 meses (medio de $27 \pm 17$ meses). La tasa de éxito crónico fue de $91 \%$. Historia de fibrilación atrial (FA) estuvo presente en 123 pacientes $(68 \%)$. De estos, 85 pacientes $(69 \%)$ continuaron presentando episodios de FA durante el seguimiento, por lo que 69 pacientes (81\%) fueron tratados con antiarrítmicos, se realizó ablación de venas pulmonares en 14 pacientes $(16 \%)$ y ablación del nodo AV con implante de marcapaso en 2 pacientes $(3 \%)$. De los 57 pacientes sin historia de FA previa a la ablación del ICT, nuevos episodios de FA se presentaron en 20 (35\%) de los pacientes (todos asintomáticos con antiarrímicos.

Mostramos que la crioablación del ICT en pacientes con AA del tipo común tiene una tasa de éxito crónico de 91\% (12 a 60 meses). También corroboramos la asociación frecuente de FA $(69 \%)$ con AA, la primera siendo la principal causa de agravamiento en este grupo de pacientes.

En el estudio Aislamiento Ostial de las venas Pulmonares en Fibrilación Atrial Paroxística (OPIPAF por su siglas en inglés) (Capítulo III) evaluamos el seguimiento a largo plazo de pacientes con FA en estadios tempranos a quienes se les realizó aislamiento segmentario de venas pulmonares con criotermia. Pacientes con FA paroxística (FAP) fueron prospectivamente reclutados de Julio del 2001 a Julio del 2005. Treinta días previos a la ablación, electrocardiograma (ECG) de 12 derivaciones, Holter y telemetría transtelefónica (TTT) diaria fueron obtenidos. Las TTTT fueron continuadas durante 180 días después del procedimiento. También el monitoreo Holter fue usado en cada visita del paciente a la consulta externa o si el paciente presentaba síntomas. Una tomografía helicoidal (TH) se realizó para evaluar la morfología de las venas pulmonares (VP) en todos los pacientes previo al procedimiento y en la mayoría de ellos a los 3,6 y 12 meses de seguimiento. Si los triggers para FA eran identificados, crioablación de las venas pulmonares arritmogénicas se realizó. Si no se identificaban, se realizó aislamiento de todas las venas pulmonares. Las aplicaciones de criotermia (CryoCorTM) fueron realizadas durante 3 minutos.

Un total de 70 pacientes (54 hombres; edad $40 \pm 10$ años) fueron incluidos en el estudio. La duración de la FA fue de $4 \pm 1$ años. Los pacientes habían recibido sin éxito de 1 a 2 fármacos antiarrítmicos antes del procedimiento y la mayoría de ellos no tenían enfermedad cardiaca o tenían enfermedad no signifi- 
cativa. La FEVI fue $59 \pm 8 \%$ y el tamaño de AI fue $41 \pm 5 \mathrm{~mm}$. En todos los pacientes se aislaron exitosamente las VP (media de $3 \pm 1$ por paciente).

Venas pulmonares arritmogénicas fueron encontradas en 10 pacientes (14\%). Complicaciones ocurrieron en $3(4 \%)$ de los pacientes (1 evento vascular cerebral, 1 embolismo pulmonar y 1 parálisis diafragmática transitoria). No se detectó estenosis de VP o daño esofágico durante el seguimiento medio de 33 \pm 15 (15 a 60) meses. Treinta y cuatro pacientes (49\%) no tuvieron recurrencias y 23 pacientes (33\%) mejoraron en más del 50\% (tasa total de éxito del 81\%).

Los pacientes en quienes una VP arritmogénica fue identificada y aislada no tuvieron recurrencias. Podemos concluir que la crioablación de VP es efectiva en $81 \%$ de los pacientes con FAP de reciente inicio durante el seguimiento medio de $33 \pm 15$ meses (15 a 60).

De importancia, si la VP arritmogénica es identificada y aislada, el pronóstico a largo plazo es excelente, lo que indica que no es necesario aislar el resto de las VP.

Pero ¿Cómo es que los pacientes con aislamiento de VP tienen recurrencias? ¿es la recurrencia inmediata de FA un signo de mal pronóstico que indica una ablación fallida? Esas respuestas se desprenden de nuestro estudio en el capítulo IV. Hasta ahora ningún estudio sistemático se ha realizado acerca de la incidencia y tipos de recurrencias después de la ablación percutánea de FA. Algunos tipos de recurrencia temprana pueden llevar a preocupar respecto al éxito del procedimiento y puede resultar en intervenciones inecesarias. Así mismo, la literatura reciente muestra una pobre relación entre los síntomas del paciente y su ritmo después de la ablación.

Nuestro estudio prospectivamente evaluó 60 pacientes con FAP a quienes se les realizó crioaislamiento de VP (45 hombres; edad media 53 (21 a 68) años con T'T'T diaria ( desde 30 días previos al procedimiento y hasta 180 días después).

Encontramos 3 patrones diferentes de recurrencias después del procedimiento: Grupo A- 26 pacientes sin evidencia de FA. Grupo B - 20 pacientes con un decremento significativo en los episodios de FA. Grupo C - 14 pacientes con incremento en los episodios de FA después del procedimiento. Historia de ablación de ICT por AA fue más común en el Grupo C.

Con estos datos fuimos capaces de demostrar tres escenarios diferentes en la recurrencia de FA: 1) Sin episodios de FA inmediatamente después del procedimiento, 2) decremento en el número de episodios de FA después del procedimiento (iniciando a los 3 meses y estabilizándose a los 9 meses) o 3) inmediato incremento en el número de eventos (que disminuye durante el primer año). Historia de ablación de ICT por AA fue un antecedente de mal pronóstico.

Este hallazgo nos llevó a la siguiente pregunta ¿es el AA del tipo común un indicador de un sustrato no unicamente del atrio izquierdo (AI), pero tambien del atrio derecho para el desarrollo de FA?. En el capítulo V evaluamos las consecuencias clínicas y de la ablación en pacientes con AA y FA coexistentes. 
Noventa y ocho pacientes con AA/FAP fueron prospectivamente incluidos de Julio del 2001 a Julio del 2006 para crioaislamiento de VP. Basados en la TTT, ECG y Holter, nuestra población fue llevada a dos estrategias diferentes de ablación: Grupo 1 incluyó 36 pacientes con ablación del ICT (si al menos un episodio de AA sostenido fue documentado) seguido (seis semanas después) de aislamiento de VP. Los otros 62 pacientes con AF formaron el Grupo II donde sólo se realizó aislamiento de VPs.

Los resultados mostraron que en pacientes con FAP y sin documentar AA tipo común, el aislamiento de VP solo, previene la ocurrencia de FA en 82\% y disminuye la incidencia de AA tipo común sostenido. Más aún, en pacientes con AA/FA, la ablación de ICT y aislamiento de VP cura el AA pero no previene las recurrencias de FA. Este último hallazgo sugiere que el AA puede crear un sustrato arritmogénico principalmente en el $\mathrm{AD}$ favoreciendo las recurrencias de FA. En estos pacientes la evaluación de las propiedades electrofisiológicas del AD (formación de impulso ectópico, análisis de electrogramas, etc) puede ser un paso adicional para una ablación efectiva de la FA.

El conocimiento que las VP son los triggers en un gran porcentaje de los episodios de FAP ha contribuido en forma importante al desarrollo de técnicas para ablación percutánea de la FA. Con el énfasis otorgado al hallazgo de potenciales eléctricos en las VP de pacientes con FA, el abordaje adoptado fue aislar todas las venas con actividad eléctrica. Aún hasta nuestros días, en la mayoría de los protocolos usados para el tratamiento percutáneo de la FA, la evaluación electrofisiológica de las VP no está incluida.

Distintas propiedades electrofisiológicas de las VP como periodos refractarios más cortos y propiedades decrementales fueron descritas previamente en pacientes con FA. Pero estos datos fueron contaminados por la exposición a amiodarona (un tercio de los pacientes). Este fármaco ha mostrado alterar en forma significativa los periodos refractarios de las VP. En el capítulo VI evaluamos las propiedades electrofisiológicas de diferentes venas pulmonares (en el mismo paciente) y el tejido adyacente (tejido entre las VP y el AI ) en una población con FAP (y no expuesta a amiodarona) referida para crioablación.

Un total de 10 pacientes con FA solitaria y sin exposición a amiodarona (8 hombres; edad media 54 (42 a 60) años) fueron incluidos prospectivamente. El diámetro medio del AI fue $38 \mathrm{~mm}$ (33 a 44) con FEVI media de 64\%. De las 40 VP estudiadas, 38 tenían potenciales y propiedades decrementales. No se pudo inducir arritmias en 18 (47\%) de aquellos del grupo no arritmogénico (media de 2 VP por paciente).

Nuestro hallazgos sugieren que en pacientes con FAP no expuestos a amiodarona, las VP arritmogénicas tienen periodos refractarios extremadamente bajos con un gradiente significativo cuando se compara al tejido adyacente (tejido entre VP y AI). Esto puede propiciar un sustrato ideal para la reentrada. Sin embargo, las propiedades decrementales están presentes tanto en las VP arritmogénicas como en las no arritmogénicas.

Siguiendo este pensamiento, en el capítulo VII mostramos que tan impor- 
tante es el sitio de estimulación con el fin de evaluar realmente la localización arritmogénica en pacientes con FAP llevado a ablación.

Los sistemas de navegación no fluroscópica acompañan de cerca la ablación de la FA. Sus beneficios en los procedimienos electrofisiológicos han sido bien establecidos, pero el sistema más comúnmente usado (CARTO TM) limita al operador a la utilización de un solo tipo de energía (radiofrecuencia). En el capítulo VIII mostramos la posibilidad de usar un sistema de navegación (NavXTM) en la ablación de FA usando un tipo diferente de energía (crioter$\mathrm{mia})$. 



\section{CHAPTER XIII}

\section{Resumo}


Ablação por catéter do ístmo cavotricuspídeo (ICT) é o tratamento de escolha para pacientes com flutter atrial comum. Entretanto, a maior parte dos dados relativos a resultados de longo prazo apenas tiveram um acompanhamento a curto termo, ademais de serem restritos ao procedimento de ablação por radiofreqüência.

No Capítulo II, apresentamos os dados relativos ao acompanhamento a longo prazo de 180 pacientes com flutter atrial comum (FLA) submetidos a crioablação do ICT. Nossa população estudada possuía as seguintes características: 39 mulheres (22\%), idade média de 58 anos (de 18 a 86), ausência de doença estrututal cardíaca em 86 pacientes (48\%), diâmetro médio do átrio esquerdo de $44 \pm 7 \mathrm{~mm}$ e fração de ejeção ventricular esquerda média de $57 \pm$ $7 \%$. Sucesso imediato foi obtido em 95\% (171) dos pacientes. Não houve complicações.

O acompanhamento variou de 12 a 60 meses (média de $27 \pm 17$ meses). A taxa de sucesso a longo prazo foi de $91 \%$. História prévia de fibrilação atrial (FA) estava presente em 123 pacientes (68\%). $85(69 \%)$ deles continuaram tendo episódios de FA no seguimento tardio - 69 pacientes (81\%) tratados com medicamentos antiarrítmicos, ablação da veia pulmonar em 14 pacientes (16\%) e ablação do nodo atrioventricular com implantação de marcapasso em 2 pacientes $(3 \%)$. Entre os 57 pacientes que não possuíam uma história prévia de FA antes de serem submetidos à ablação do ICT, 20 (35\%) desenvolveram esta arritmia (todos asimtomáticos com o uso de medicamentos antiarrítmicos). Fomos capazes de demonstrar que a crioablação do ICT para pacientes com flutter atrial comum tem uma eficácia a longo prazo (entre 12 e 60 meses) de $91 \%$. Corroboramos também a associação frequente entre FA $(69 \%)$ e flutter atrial, sendo o primeiro o responsável pelos sintomas nesse grupo de pacientes.

No estudo OPIPAF (ostial pulmonary vein isolation in paroxysmal atrial fibrillation) (Capítulo III) avaliamos os efeitos a longo prazo da crioablação segmental das veias pulmonares em pessoas nos estágios iniciais de fibrilação atrial. Pacientes com FA paroxística foram recrutados prospectivamente de Julho/2001 à Julho/2005. Um eletrocardiograma e monitoramento por Holter basais foram feitos trinta dias antes da ablação juntamente com registros electrocardiográficos diários feitos por telemetria transtelefônica. Estes ùltimos foram então continuados por 180 dias após a crioablação. Depois deste período, monitoramento por Holter foi usado em cada consulta clínica ou se aparecessem sintomas. Uma tomografia computadorizada espiral (com o objetivo de avaliar a morfologia das veias pulmonares) foi feita em todos os pacientes antes do procedimento e na maioria dos mesmos durante o acompanhamento de 3, 6 e 12 meses. Durante a ablação, se impulsos elétricos considerados como responsáveis pela iniciação da FA fossem encontrados em uma determinada veia pulmonar, fazia-se o crioisolamento desses focos arritmogênicos. Caso contrário, isolava-se todas as veias pulmonares. Aplicações ùnicas de criotermia (CryoCor ${ }^{\mathrm{TM}}$ ) foram dadas durante 3 minutos.

Um total de 70 pacientes foi recrutado (54 homens; idade $40 \pm 10$ anos). A 
duração média de FA era de $4 \pm 1$ anos. Um ou dois medicamentos antiarrítmicos foram usados sem sucesso pelos pacientes antes da ablação; a maioria desses indivíduos não possuia nenhuma outra enfermidade cardíaca. A fração de ejeção ventricular esquerda média e o diâmetro médio do átrio esquerdo eram $59 \pm 8 \%$ e $41 \pm 5 \mathrm{~mm}$, respectivamente. Todas as veias pulmonares submetidas à ablação foram isoladas com sucesso (média de $3 \pm 1$ veias pulmonares por paciente).

Dez pacientes $(14 \%)$ apresentaram veias pulmonares consideradas arritmogênica. Complicações ocorreram em $3(4 \%)$ pacientes (um acidente vascular cerebral, uma embolia pulmonar e uma paralisia transitória do diafragma). Não foram observados nenhum caso de estenose de veia pulmonar ou trauma esofágico durante um seguimento médio de $33 \pm 15$ (15 à 60) meses. Trinta e quatro pacientes $(49 \%)$ não tiveram nenhum tipo de recorrência e 23 pacientes (33\%) apresentaram uma melhora $>50 \%$ (taxa de sucesso global de $82 \%$ ).

Pacientes nos quais a veia pulmonar considerada arritmogênica foi encontrada e isolada ficaram completamente curados de qualquer arritmia. Deste estudo conclui-se que o crioisolamento de veias pulmonares é efetivo em $82 \%$ dos pacientes com FA recente e paroxística durante um seguimento a longo termo. Além do mais, se a veia pulmonar arritmogênica for encontrada e isolada, o indivíduo tem um prognóstico excelente, não havendo assim a necessidade do isolamento de todas as veias pulmonares.

Mas e quanto aos pacientes que apresentam recorrências de FA após o procedimento? O retorno imediato da arritmia pode ser considerado como um mau fator prognóstico representando que a ablação não foi bem sucedida nesse indivíduo? As respostas à essas questões vieram do nosso trabalho apresentado no Capítulo IV. Até agora nenhum estudo sistemático foi realizado para avaliar a incidência e os tipos de recorrência que se sucedem à ablação percutânea da fibrilação atrial. Alguns tipos de recorrência no pós operatório imediato podem levar não somente à dúvidas em relação ao sucesso do procedimento mas também resultar em re-intervenções desnecessárias. Ao mesmo tempo, estudos recentes demonstraram a pobre correlação existente entre os simtomas dos pacientes com os seus ritmos cardíaco reais seguindo à ablação de FA.

Nosso estudo avaliou em perspectiva 60 pacientes com FA paroxística submetidos ao crioisolamento das veias pulmonares ( 45 homens; idade média 53 (21 a 68) anos) usando gravações diárias por meio de telemetria transtelefônica (de 30 dias previamente até 180 dias após o procedimento). Nós encontramos 3 padrões diferentes de recorrência após o isolamento de veias pulmonares: Grupo A - 26 pacientes sem mais nenhuma evidência de FA. Grupo B - 20 pacientes com uma diminuição significativa dos episódios de FA. Grupo C - 14 pacientes com um aumento dos episódios de FA (comparados à telemetria pré ablação). Uma história prévia de flutter atrial estava presente mais freqüentemente no grupo C. Com estes dados nós pudemos demonstrar três comportamentos diferentes de recorrência de FA após o isolamento de veias pulmonares: 1) abolição total da FA imediatamente depois do procedimento, 2) diminuição 
do número de episódios de FA após a ablação (começando aos 3 meses e se estabilizando aos 9 meses) ou 3) o aumento imediato no número dos eventos (com declínio progressivo ao decorrer de um ano). Uma história prévia de flutter atrial foi considerada como um fator de mau prognóstico.

Este achado conduziu-nos à seguinte pergunta: seria o flutter atrial do tipo comum um indicador da presença de um substrato arritmogênico em pacientes com FA paroxística? No Capítulo $\mathbf{V}$ nós avaliamos as conseqüências clínicas e ablativas de indivíduos com concomitante FA/FLA. Noventa e oito pacientes com FA paroxística e FLA foram recrutados prospectivamente de Julho/2001 à Julho/2006 para submeterem-se ao crioisolamento das veias pulmonares. Baseado na telemetria transtelefônica, eletrocardiograma e Holter, nosso grupo de pacientes foi designado à duas estratégias diferentes de ablação: Grupo I contendo 36 pacientes submetidos à ablação to ICT (se ao menos um episódio de FLA sustentado foi documentado) seguido pelo isolamento das veias pulmonares e Grup II com outros 62 pacientes (nos quais FA era a arritmia predominante) onde somente o isolamento das veias pulmonares foi realizado. Nossos resultados mostraram que nos pacientes com FA paroxística e sem documentação de FLA do tipo comum, apenas o isolamento das veias pulmonares impede a ocorrência de FA em $82 \%$ e abaixa a incidência de FLA tipo comum. Além disso, nos pacientes com FA/FLA, a ablação do ICT juntamente com o isolamento das veias pulmonares curam FLA mas não impedem a recorrência de FA.

Este fato nos sugere que FLA ou pode ser um sinal de que triggers não relacionados às veias pulmonares são os responsáveis pela iniciação da FA (incluindo os localizados no àtrio direito) e/ou de que já existe um remodelamento elétrico biatrial suficiente para manter um substrato arritmogênico o qual favorece aos retornos da FA. Nesses pacientes, uma estratégia ablativa que inclua não só o isolamento das veias pulmonares mas também a modificação do substrato atrial deve ser empregada, a fim de se obter uma ablação eficaz da FA.

O conhecimento de que as veias pulmonares contituem os focos arritmogênicos de uma grande porcentagem dos pacientes com FA paroxística contribuiu substancialmente para o desenvolvimento das técnicas percutâneas ablativas usadas no tratamento da fibrilação atrial. Inicialmente, a ênfase principal do procedimento estava em encontrar e isolar todas as veias com potenciais elétricos nos pacientes com FA. Ainda hoje em dia, a maioria dos protocolos usados na ablação da FA não inclue uma avaliação eletrofisiológica das veias pulmonares. Propriedades eletrofisiológicas distintas destas veias foram descritas previamente nos pacientes com FA. Mas estes dados foram contaminados pela exposição à amiodarona (em um terço dos pacientes); e estudos recentes mostram que esta referida droga altera significativamente os períodos refratários das veias pulmonares.

No Capítulo VI nós avaliamos as propriedades eletrofisiológicas de diferentes veias pulmonares (nos mesmos pacientes) e do tecido atrial adjacente à elas em uma população com FA paroxística (e sem contato com amiodarona) sub- 
metida à crioablação das veias pulmonares. Um total de 10 pacientes com FA e sem nenhuma outra anomalia cardíaca (8 homens; idade média de 54 (42 a 60) anos) foi estudado. O diâmetro atrial esquerdo médio foi de 38 milímetros (33 a 44) e a fração de ejeção ventricular esquerda média foi de 64\%. Das 40 veias estudadas, 38 apresentavam potenciais elétricos e propriedades decrescentes. Nenhuma arritmia pôde ser induzida em 18 (47\%) veias - que formaram o nosso grupo não arritmogênico (média de 2 veias por o paciente).

Nossos achados sugerem que, nos pacientes com FA paroxística não expostos à amiodarona, as veias pulmonares arritmogênicas tem períodos refratários extremamente curtos com um gradiente significativo quando comparado ao tecido atrial esquerdo adjacente. Isto poderia propiciar um meio ideal para a ocorrência do fenômeno da reentrada - potencial causador da FA. Também, concluímos que as propriedades decrescentes estão presentes tanto nas veias pulmonares arritmogênicas quanto nas que não os são.

Seguindo esta linha de pensamento, no Capítulo VII nós mostramos um exemplo da importância da localização precisa das áreas a serem estimuladas a fim de elucidar as regiões arritmogênicas nas veias pulmonares.

Os sistemas não fluoroscópicos de navegação acompanharam muito pròximamente o desenvolvimento da ablação percutânea da FA. Seus benefícios no auxílio aos procedimentos eletrofisiológicos são bem estabelecidos. Porém o sistema mais comum usado atualmente $\left(\mathrm{CARTO}^{\mathrm{TM}}\right)$ limita o operador a usar somente um tipo de energia (radiofrequência). No Capítulo VIII nós demonstramos a praticabilidade de se empregar um sistema de navegação $\left(\mathrm{NavX}^{\mathrm{TM}}\right)$ na ablação da FA usando um tipo diferente de energia (criotermia).

As implicações clínicas dos nossos achados estão localizadas no capítulo de Discussões Gerais e Perspectivas Futuras. 



\title{
CURRICULUM VITAE
}

\author{
Wendel Santos Moreira \\ Born in Goiânia, Goiás, Brazil on March 28th 1975
}

\section{Academic Background}

February 1992 until December 1997 - Medical School at the Universidade Federal de Goiás, Goiânia, Brazil, in a six year program; MD degree granted by this institution in Jan 1998

January and February 1995 - Clerkship rotations in Internal Medicine, Cardiology, Hem/Onc and Rheumatology at the Atlantic City Medical Center, Atlantic City, New Jersey, USA

February to December 1997 - Clerkship rotations in Internal Medicine, Hem/Onc, Medical ER, Cardiology, Infectious Diseases, Pediatrics, Pediatrics ICU, Trauma ICU, General/Oncological Surgery and Ob/Gyn at the University of Miami School of Medicine, Miami, Florida, USA

June 1998 until June 2001 - Categorical Medical Resident in Internal Medicine at the Jackson Memorial Hospital/ University of Miami School of Medicine, Miami, Florida, USA

July 2001 until June 2002 - Chief Medical Resident/ Voluntary Clinical Instructor in Internal Medicine at the University of Miami School of Medicine, Miami, Florida, USA

July 2002 until June 2005 - Clinical Cardiology Fellow at the Texas Heart Institute/ Baylor College of Medicine, Houston, Texas, USA

June 2004 until December 2004 - Chief Cardiology Fellow at the Texas Heart Institute/ Baylor College of Medicine, Houston, Texas, USA

July 2005 until December 2007 - Clinical Electrophysiology Fellow and PhD scholar at the Academisch Ziekenhuis Maastricht, Maastricht, The Netherlands 


\section{Honors and Awards}

Cardiology Fellow of the Year presented by the Saint Luke's Episcopal Hospital CCU/ Texas Heart Institute, Houston, TX, June 2003,

Certificate of Appreciation from the Department of Veterans Affairs, Miami, FL, June 2002;

ACP/ASIM Chief Resident Award presented by the Florida Chapter American College of Physicians - American Society of Internal Medicine, 33rd Scientific Meeting, Florida Oct 6th, 2001.

Outstanding Intern Award given by the University of Miami School of Medicine - Jackson Memorial Hospital, Department of Medicine, Miami, FL, May 1999.

Winner of the regional American College of Physicians/ American Society of Internal Medicine Clinical Vignettes (Fever and Lymphadenopathy) - Jackson Memorial Hospital / University of Miami School of Medicine, Miami, Florida, December 1998.

Winner of the Associates Meeting - Florida Chapter of the American College of Physicians/ American Society of Internal Medicine Clinical Vignettes and Research Presentations (Fever and Lymphadenopathy) - Tampa, Florida, April 1999.

\section{Others}

Guest speaker at the Scientific Forum XIV, São Francisco de Assis Cardiovascular Foundation - ServCor with the topics: 1) Implantable Defibrillators: Types, Indications, Techniques and Results; 2) Electrical Remodeling, Belo Horizonte - Brazil, 3rd to 5th of December 2004

Guest speaker at the III International Clinicord Forum of Valvulopathies with the topic: Sudden Death in Valvular Heart Diseases. 30 min. Goiânia, Brazil, October 2000.

International Finances Secretary of the XIII World Congress of Cardiology, Rio de Janeiro, Brazil, April 1998.

Lecturer of the History of Medicine Course from UFG, Goiânia, Brazil. 
Teaching assistant at the Departments of Histology (1993) and Pharmacology (1994) at the Universidade Federal de Goiás, Goiânia, Brazil.

\section{Certifications}

USMLE (United States Medical License Examination) Step 1, October 1997;

USMLE Step 2, August 1997; USMLE Step 3, February 2001;

ECFMG (Educational Committee for Foreign Medical Graduates) certificate in 1998;

Diplomate of the American Board of Internal Medicine, 2001;

Diplomate of the American Board of Cardiovascular Diseases, 2005;

Diplomate of the American Board of Echocardiography, 2005.

American Society of Nuclear Cardiology, Basic Radioisotope Handling, 2003.

\section{Medical Licensure}

Florida, USA - ME 83042

Brazil - CRM/GO 7881

The Netherlands - BIG inschrijfnummer 19065859401 



\title{
PUBLICATIONS
}

\author{
Book Publication
}

Contributing Author in the Book: Doencas do Coracao (Heart Diseases), by Celmo Celeno Porto (editor), first ed. Guanabara-Coogan, 1998. Responsible, together with Prof. Dr. Hernando E. Nazzetta, for Chapter 139 - Coronary Restenosis.

\section{Articles}

Leon, Fernando MD; Salazar, Hector MD; Moreira, Wendel MD; Angelini, Paolo MD Are Muscular Bridges Capable of Causing Myocardial Infarction?. Texas Heart Institute Journal. 33(4):539-540, December 2006.

Leon F, Salazar H, Moreira W, Angelini P. Daughter, you broke my heart: accidental thrombosis at a muscular bridge. Tex Heart Inst J 2006;33:380-382.

Moreira W, Perez D, Timmermans C, Rodriguez LM. Images in cardiovascular medicine. From bad to worse: complete heart block leading to ventricular fibrillation. Circulation 2006;113:e707-e708.

Razavi M, Zhang S, Yang D, Sanders RA, Kar B, Delapasse S, Ai T, Moreira W, Olivier B, Khoury DS, Cheng J. Effects of pulmonary vein ablation on regional atrial vagal innervation and vulnerability to atrial fibrillation in dogs. J Cardiovasc Electrophysiol 2005;16:879-884.

Jefferies JL, Moreira W, Massumi A, Stainback RF. Images in cardiovascular medicine. Rapid progression of extreme septal hypertrophic cardiomyopathy. Circulation 2003;108:e136. 


\section{Abstracts}

W. Moreira, C. Timmermans, Y. Mizusawa, S. Philippens, L.M. Rodriguez. Two years follow-up after cavotricuspid isthmus cryoablation for the treatment of common atrial flutter. European Society of Cardiology (ESC), Vienna, Austria, September 2007.

Eur Heart J 2007.

W. Moreira, C. Timmermans, H. J J Wellens,Y. Mizusawa, D. Perez, S. Philippens, L.M. Rodriguez. The Importance of a Refractory Period Gradient $\geq$ $100 \mathrm{msec}$ Between Pulmonary Veins and Adjacent Left Atrium in Identifying the Culprit Pulmonary Vein. 3rd Annual Congress of the European Cardiac Arrhythmia Society (ECAS), Marseille, France, June 2007. J Interv Card Electrophysiol (2007) 18: 57.

W. Moreira, C. Timmermans, Y. Mizusawa, S. Philippens, D. Perez, H. Crijns, L.M. Rodriguez. Recurrence patterns of atrial fibrillation after pulmonary veins cryoisolation. World Congress of Cardiology, Barcelona, Spain. September 2006. Eur Heart J 2006, 27(1): 39, 466.

W. Moreira, C.C.M.M. Timmermans, R. Manusama, S. Philippens, D. Perez, Y. Mizusawa, G.M. Ayers, L.M. Rodriguez. Cryothermy can effectively be delivered with the same application duration as radiofrequency energy. World Congress of Cardiology, Barcelona, Spain. September 2006. Eur Heart J 2006, 27(1): 325, 2082.

W. Moreira, L.M. Rodriguez, C. Timmermans, R. Manusama, S. Philippens, D. Perez, Y. Mizusawa. Long term follow-up after cryo-isolation of the pulmonary veins in patients with recent onset atrial fibrillation. World Congress of Cardiology, Barcelona, Spain. September 2006. Eur Heart J 2006, 27(1): 727, 4429.

Y. Mizusawa, W. Moreira, D. Perez, C. Timmermans , H.J.G.M Crijns, L.M. Rodriguez. The Brugada syndrome and ECG changes during a long follow-up period. World Congress of Cardiology, Barcelona, Spain. September 2006. Eur Heart J 2006, 27(1): 723, 4412.

W. Moreira, C.C.M.M. Timmermans, R. Manusama, S. Philippens, D. Perez, Y. Mizusawa, G.M. Ayers, L.M. Rodriguez. Cryothermy can effectively be delivered with the same application duration as radiofrequency energy. World Congress of Cardiology, Barcelona, Spain. September 2006. Eur Heart J 2006, 27(1): 325, 2082. 
M. van de Shoot, , C. Timmermans, R. Manusama, S. Philippens, W. Moreira D. Perez, Y. Mizusawa, G.M. Ayers, L.M. Rodriguez. Cryothermy can effectively be delivered with the same application duration as radiofrequency energy. $15^{\text {th }}$ World Congress in Cardiac Electrophysiology and Cardiac Techniques (Cardiostim 2006), Nice, France. June 2006. Europace 2006, 8(s1): 1-178, 218P/10.

W. Moreira, C. Timmermans, D. Perez, Y. Mizusawa, S. Philippens, L.M. Rodriguez. Atrial fibrillation recurrence behavior in the first months after pulmonary vein cryoisolation. 15 $5^{\text {th }}$ World Congress in Cardiac Electrophysiology and Cardiac Techniques (Cardiostim 2006), Nice, France. June 2006. Europace 2006, 8(s1): 1-178, 218P/12.

Wendel Moreira, MD; Carl Timmermans, MD, PhD; Yuka Mizusawa, MD; David Perez, MD; Suzanne Philippens, RN; HJGM Crijns, MD, PhD; LuzMaria Rodriguez, MD, PhD. Comparison of pulmonary veins patterns amongst young adults and patients above 40 years old with Paroxysmal Atrial Fibrillation (PAF). Scientific Meeting Netherlands Society of Cardiology, Amsterdam, The Netherlands. April 2006

Maud van de Schoot, MD, Carl Timmermans, MD, PhD, Randy Manusama, MD, Suzanne Philippens, RN, Wendel Moreira, MD, David Perez, MD, Yuka Mizusawa, MD, Gregory M. Ayers, MD, PhD and Luz-Maria Rodriguez, MD, PhD. A Large Electrode Tip Is Superior For RF Ablation Of Atrial Flutter What About Cryoablation? Scientific Meeting Netherlands Society of Cardiology, Amsterdam, The Netherlands. April 2006

W. Moreira, C. Timmermans, H. J J Wellens,Y. Mizusawa, D. Perez, S. Philippens, L.M. Rodriguez. Feasibility of cryoablation for atrial fibrillation using a

non-contact mapping system. First BenSca ESI user Group Meeting, Stockholm, Sweden, April 2006.

W. Moreira , P. Jardim et al. Evaluation of Blood Pressure Measurement as a Routine in Brazilian Pediatric Medical Examination, published at the American Journal of Hypertension, April 1997, Vol 10, No. 4, 208; presented at the XII Scientific Meeting of the American Society of Hypertension, San Francisco, California, May 1997;

P. Jardim, W. Moreira et al. League of Childhood Hypertension from the Federal University of Goias/ School of Medicine - Initial Experience and First Results, presented at the II Inter American Congress of Hypertension/ VI Brazilian Congress of Hypertension, Sao Paulo, Brazil, July 1996; 
R. Blanco, W. Moreira et al. Prevalence of Childhood Hypertension as Casual Finding in the Physical Exam at Cardiopediatric Office, presented at the II Inter American Congress of Hypertension/ VI Brazilian Congress of Hypertension, Sao Paulo, Brazil, July 1996;

R. Blanco, W. Moreira et al. The use of Drawing and its Effects on the Physician-Patient Relationship in Cardiopediatrics, presented at the LII Brazilian Congress of Cardiology, Salvador, Brazil, September 1996;

W. Moreira, P. Jardim et al. Evaluation of Blood Pressure Measurement as a Routine in Brazilian Pediatric Medical Examination, presented at the LII Brazilian Congress of Cardiology, Salvador, Brazil, September 1996;

H. Rosa , W. Moreira et al. Behavioral Patterns of Rats During and After Induction of Cirrhosis by CCl4, presented at the XXVII Brazilian Congress of Gastroenterology, Goiania, Brazil, August 1996;

H. Rosa, W. Moreira et al. Serum Levels of Endogenous Diazepam in Cirrhotic Rats, presented at the XXVII Brazilian Congress of Gastroenterology, Goiania, Brazil, August 1996;

H. Nazzetta, W. Moreira et al. Balloon Valvoplasty for Rheumatic Mitral Stenosis - Experience of the Federal University of Goias/ School of Medicine, published at the Journal of the Middle-West Brazilian Society of Cardiology, Nov 1995, Vol 4, No. 2, 52; presented at the IV Scientific Meeting of the MiddleWest Brazilian Society of Cardiology, Brasilia, Brazil, Nov 1995.

\section{Others}

Wendel Moreira, MD. University of Miami School of Medicine

Medical Grand - Rounds: Cardiology Update 2002; April 3rd 2002, available for webcast at http://www.med.miami.edu/grandrounds/archive.asp; 